LUIS FERNANDO SILVA MOURA

\title{
ANÁLISE NUMÉRICA DA DILATAÇÃO LINEAR DE TUBULAÇÕES DURANTE O REGIME DE TRANSIENTE TÉRMICO
}

Dissertação apresentada à Escola Politécnica da Universidade de São Paulo para obtenção do título de Mestre em Engenharia

Área de concentração:

Engenharia Mecânica de Energia e Fluidos

Orientador: Prof. Dr. Jorge Luis Baliño 
Este exemplar foi revisado e corrigido em relação à versão original, sob responsabilidade única do autor e com a anuência de seu orientador.

São Paulo, de de

Assinatura do autor:

Assinatura do orientador:

Catalogação-na-publicação

Moura, Luis Fernando

Análise numérica da dilatação linear de tubulações durante o regime de transiente térmico / L. F. Moura -- versão corr. -- São Paulo, 2015. $107 \mathrm{p}$.

Dissertação (Mestrado) - Escola Politécnica da Universidade de São Paulo. Departamento de Engenharia Mecânica.

1.Transferência de calor 2.Tubulações 3.Dilatação 4.Carga I.Universidade de São Paulo. Escola Politécnica. Departamento de Engenharia Mecânica II.t. 
A meus pais, Antônio Luiz Moura e Maria Tereza Silva Moura, que sempre reconheceram o valor do conhecimento.

A meus irmãos, Antônio Luiz Moura Junior, Gabriela Silva Moura e Luiz Henrique Silva Moura, pelo apoio. 


\section{AgRADECIMENTOS}

Ao Professor Dr. Otavio de Mattos Silvares, in memoriam, pelas orientações, abertura e pelo esforço para, mesmo debilitado, fazer-se presente.

Ao Professor Dr. Jorge Luis Baliño pelo acolhimento em um momento de grande indefinição, pela disponibilidade e pelos conselhos e opiniões assertivos e corretos.

Aos engenheiros Marcel Merlone e Mario Yago Junior, que me ensinaram os primeiros passos na Engenharia de Tubulação e contribuíram direta ou indiretamente com essa dissertação.

À Maria Paz Silva Jiménez, que sempre esteve ao meu lado e me ajudou em um momento de grande hesitação.

Ao Conselho Nacional de Desenvolvimento Científico e Tecnológico ( $\mathrm{CNPq}$ ), pelo apoio financeiro para o desenvolvimento desse trabalho através da bolsa de Mestrado.

À Escola Politécnica da Universidade de São Paulo pelos recursos e a estrutura fundamental para o desenvolvimento desse trabalho. 


\section{RESUMO}

A dilatação térmica é um problema com o qual os engenheiros de tubulação frequentemente precisam lidar, já que parte do papel destes profissionais é controlar as dilatações lineares totais e minimizar tensões e forças associadas a este fenômeno físico. O projeto de sistemas de tubulação é guiado por normas, sendo a ASME B31.3 (2010) certamente a mais utilizada no Brasil e nos Estados Unidos. Para a referida norma o sistema de tubulação, do ponto de vista térmico, é avaliado com base em uma temperatura de projeto constante e uniforme definida pelos critérios desta norma, temperatura esta normalmente estabelecida com base na temperatura de regime permanente. Estes critérios são suficientes para garantir a integridade estrutural da tubulação em virtude da forma como as tensões admissíveis e atuantes estão estabelecidas, contudo, a norma é omissa em relação ao transiente térmico e a dilatação linear da tubulação durante esse período. Tal dilatação poderá estar associada a forças transmitidas pela tubulação a equipamentos e estruturas, forças essas negligenciadas pela ASME B.31.3 e a literatura em geral. Esse trabalho apresenta as equações envolvidas no problema do transiente térmico de tubulações e, baseando-se nos resultados de simulações numéricas e na mecânica classicamente adotada pela Engenharia de Tubulação para computar forças, faz uma discussão a respeito das forças associadas à dilatação no período do transiente térmico. Verificou-se que quanto maior a velocidade do escoamento, maior o número de Nusselt e maior a difusividade térmica do material do tubo, maior será a taxa de aquecimento da tubulação e que, quanto maior essa taxa de aquecimento e o coeficiente de dilatação, maior será a taxa de dilatação linear do tubo. Além disso, a força associada à dilatação linear passa a ser transmitida ao ponto fixo (ancoragem ou trava) de forma abrupta e aumenta de forma intermitente até o seu máximo valor, para então cair ao seu mínimo valor de forma extremamente abrupta, sendo este valor mínimo o obtido nas análises usuais de sistemas de tubulação.

Palavras-chave: Transiente térmico. Tubulação. Dilatação. Cargas. 


\begin{abstract}
Thermal expansion is a problem the pipe engineers often have to deal with, since it is important to control the total linear thermal expansion and minimize stresses and forces associated with this physical phenomenon. The design of pipe systems is guided by standards, being ASME B31.3 (2010) certainly the most used in Brazil and the United States. For this standard the pipe system, from the thermal standpoint, is evaluated based on a constant and uniform design temperature, being this normally referenced by the steady state value. These criteria are sufficient to ensure the pipe structural integrity due to the way the admissible and acting stresses are established; however, the standard is silent regarding the thermal transient and the pipe linear thermal expansion during this period. Such thermal expansion may be associated with forces transmitted by the pipe to equipment and structures, neglected by ASME B.31.3 and the literature. This work presents the equations involved in the pipe thermal transient problem. Based on the results of numerical simulations and the procedures normally used by Pipeline Engineering to compute forces, a discussion is made about the forces associated with the thermal expansion in the period of the thermal transient. It was found that the higher the flow velocity, the Nusselt number and the thermal diffusivity of the pipe material, the higher the pipe heating rate. Besides, it was found that the higher the heating rate and the thermal expansion coefficient, the higher the linear thermal expansion rate of the pipe. Moreover, the force associated with the linear thermal expansion starts to be transmitted to the pipe fixed point (anchor or stop) in an abrupt way and increases intermittently until its maximum value, then falls to its minimum value in an extremely abrupt way, being this minimum value the load obtained in the usual pipe load analysis.
\end{abstract}

Keywords: Thermal transient. Pipe. Thermal expansion. Loads. 


\title{
Lista DE Abreviaturas E Siglas
}

\author{
ASME American Society of Mechanical Engineer \\ CFD Computational Fluid Dynamics \\ EDA Equação Diferencial Algébrica \\ EDO Equação Diferencial Ordinária \\ EDP Equação Diferencial Parcial \\ Gr Número de Grashof \\ $\mathrm{Nu} \quad$ Número de Nusselt \\ Pe Número de Peclet \\ PR Pipe Rack \\ $\operatorname{Pr} \quad$ Número de Prandtl \\ Ra Número de Rayleigh \\ Re Número de Reynolds \\ USP Universidade de São Paulo
}




\section{LISTA DE SÍMBOLOS}

c calor específico

$c_{f} \quad$ calor específico do fluido

$c_{t} \quad$ calor específico do tubo

$d$ espessura da parede do tubo

$D_{e} \quad$ diâmetro externo

$D_{i} \quad$ diâmetro interno

$D_{n} \quad$ diâmetro nominal

e rugosidade média do tubo

E módulo de elasticidade

$f \quad$ fator de atrito

$F_{a}$ força de atrito

$F_{x}$ força horizontal

$F_{y}$ força vertical

$g$ gravidade

$h_{e} \quad$ coeficiente de convecção externa

$h_{i} \quad$ coeficiente de convecção interna

I momento de inércia

L comprimento do tubo

$k \quad$ condutividade térmica

$k_{a r} \quad$ condutividade térmica do ar

$k_{f} \quad$ condutividade térmica do fluido

$k_{t} \quad$ condutividade térmica do tubo

$\dot{m} \quad$ vazão mássica

$\hat{p} \quad$ pressão média temporal local

$r_{0} \quad$ raio interno do tubo

$R_{\text {tot }}^{\prime}$ resistência térmica total

$t$ tempo

$T$ temperatura

$T_{a b s}$ temperatura absoluta

$T_{\infty} \quad$ temperatura infinita 
$\bar{T}_{f} \quad$ temperatura média do fluido no regime transitório

$\hat{T}_{f} \quad$ temperatura média temporal local do fluido

$T_{m} \quad$ temperatura média do fluido no regime permanente

$T_{m e} \quad$ temperatura média de entrada do fluido

$T_{m s}$ temperatura média de saída do fluido

$T_{t} \quad$ temperatura do tubo

$\bar{T}_{t} \quad$ temperatura média do tubo

$U \quad$ velocidade média do escoamento

$\hat{u} \quad$ velocidade média temporal local do fluido na direção $x$

$\hat{u}_{r} \quad$ velocidade média temporal local do fluido na direção $r$

$\hat{u}_{\theta} \quad$ velocidade média temporal local do fluido na direção $\theta$

$x_{\max }$ posição onde a ancoragem está alocada
$\alpha \quad$ difusividade térmica
$\alpha_{f} \quad$ difusividade térmica do fluido
$\alpha_{t} \quad$ difusividade térmica do tubo
$\beta \quad$ coeficiente de expansão térmica volumétrica
$\delta \quad$ dilatação total ou flecha
$\varepsilon_{H} \quad$ difusividade turbulenta de calor
$\varepsilon_{M}$ difusividade turbulenta de momento
$\epsilon \quad$ erro calculado
$\varphi \quad$ coeficiente de dilatação
$\gamma \quad$ sub-relaxamento da solução da EDP
$\mu \quad$ coeficiente de atrito
$\rho$ densidade
$\rho_{f} \quad$ densidade do fluido
$\rho_{t} \quad$ densidade do tubo
$\nu \quad$ viscosidade cinemática
$\zeta \quad$ máximo erro admitido 


\section{SUMÁRIO}

Resumo

Abstract iii

Lista de Abreviaturas e Siglas $\quad$ v

Lista de Símbolos vii

1 Introdução 1

1.1 Importância acadêmica e tecnológica . . . . . . . . . . . . . . . . 2

1.2 Importância do transiente térmico em tubulações . . . . . . . . . . . . . . 2

1.3 Pipe racks ........................... 6

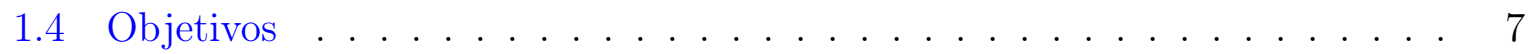

1.5 Revisão bibliográfica . . . . . . . . . . . . . . . . . . 7

1.5.1 Zargary e Brock (1973) . . . . . . . . . . . . . . 9

1.5.2 Kawamura (1976) . . . . . . . . . . . . . 9

1.5.3 Vich, Özişik e Ullich (1983) . . . . . . . . . . . . . . . . . 9

1.5.4 Lin e Kuo (1988) . . . . . . . . . . . . . . . . . . . . . 10

1.5.5 Yan, Tsay e Lin (1989) . . . . . . . . . . . . . . . . . 10

1.5.6 Negiz, Hastaoglu e Heidemann (1993) . . . . . . . . . . . . . . . . . 10

1.5.7 Hastaoglu, Negiz e Heidemann (1995) . . . . . . . . . . . . . . . . . 10

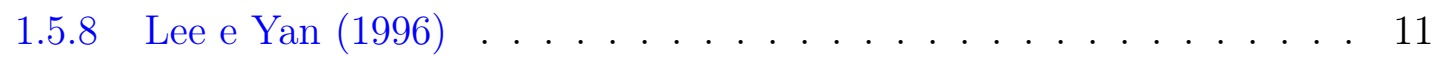

1.5.9 Jackson, Büyükalaca e He (1998) . . . . . . . . . . . . . . . . . . . 11

1.5.10 Espinosa Paredes et al. (2001) . . . . . . . . . . . . . . . 11

1.5.11 Bilir e Ateş (2003) . . . . . . . . . . . . . . . . . 11

1.5.12 Luna, Méndez e Mar (2003) . . . . . . . . . . . . . . . . . 12

1.5.13 Bhowmik e Tou (2004) . . . . . . . . . . . . . . . . 12

1.5.14 Boumaza e Omara (2013) . . . . . . . . . . . . . . 12

1.5 .15 Bokaian $(2004) \ldots \ldots \ldots \ldots \ldots$

2 Equações envolvidas na análise da dilatação térmica linear transiente 13

2.1 Modelo matemático . . . . . . . . . . . . . . . . . . . . 13 
2.1.1 Equação da continuidade . . . . . . . . . . . . . . . . . . . . . . . . 14

2.1.2 Equação da conservação de momento . . . . . . . . . . . . . . . . . 14

2.1 .3 Equação da energia . . . . . . . . . . . . . . . . . . . . . 15

2.1.3.1 Para o fluido . . . . . . . . . . . . . . 15

2.1.3.2 Para o tubo ................... . . . 16

2.2 Dilatação térmica transiente . . . . . . . . . . . . . . . . . . . . 17

2.2.1 Coeficiente de dilatação . . . . . . . . . . . . . . . . . 17

2.2.1.1 Dilatação do aço . . . . . . . . . . . . . . 17

2.2.1.2 Dilatação do cobre . . . . . . . . . . . . . . 17

3 Metodologia $\quad 19$

3.1 Caso de estudo . . . . . . . . . . . . . . . . . . . . . . . . . 22

3.2 Discussões acerca do modelo matemático e da metodologia . . . . . . . . . . . . . . . . . . 23

4 Resultados $\quad 29$

4.1 Análise da dilatação no transiente térmico . . . . . . . . . . . . . . . . . . 29

4.1.1 Análise da dilatação no transiente térmico para tubo de aço com $D_{n}=8$ " e $U=3 \mathrm{~m} / \mathrm{s} \ldots \ldots \ldots \ldots$

4.1.2 Efeito da velocidade média do escoamento interno $U$. . . . . . . 33

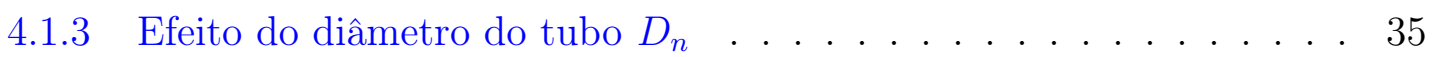

4.1.4 Efeito do material do tubo . . . . . . . . . . . . . . . . 37

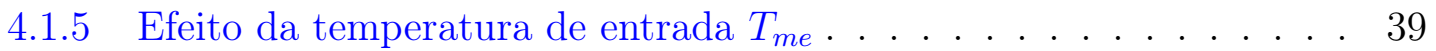

4.1.6 Forças relacionadas à dilatação transitória . . . . . . . . . . . . . . 41

4.1.6.1 Instante de máxima força . . . . . . . . . . . . . . . . 45

4.2 Resultados de simulações de transientes térmicos e de dilatações transientes para vários diâmetros e velocidades $U$. . . . . . . . . . . . . . . . . . 46

$\begin{array}{lll}5 & \text { Conclusões } & 47\end{array}$

A Solução analítica para o regime permanente térmico 49

B A influência da taxa de dilatação $\quad 51$

B.1 Força devido à flecha . . . . . . . . . . . . . . . . . . 51

B.2 Força devido a variação da quantidade de movimento . . . . . . . . . . . . . . . . . . . 52

C Perfis de velocidade do escoamento interno 54

C.1 Tubo com $D_{n}=4 " \ldots \ldots \ldots \ldots \ldots \ldots$. . . . . . . . . . . . . . . . . . .

C.2 Tubo com $D_{n}=6 " \ldots \ldots \ldots \ldots \ldots \ldots$. . . . . . . . . . . . . . . . .

C.3 Tubo com $D_{n}=8 " \ldots \ldots \ldots \ldots \ldots \ldots$ 
C.4 Tubo com $D_{n}=10 " \ldots \ldots \ldots \ldots \ldots$. . . . . . . . . . . . 59

D Gráficos da temperatura e da dilatação transitória para vários diâmetros e velocidades $U$

D.1 Tubo de aço com $D_{n}=4 " \ldots \ldots \ldots \ldots$. . . . . . . . . . . . 63

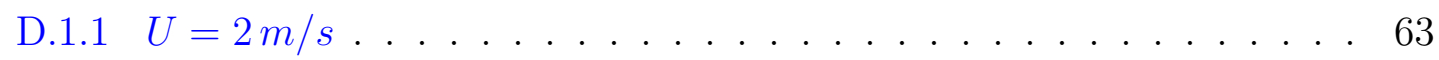

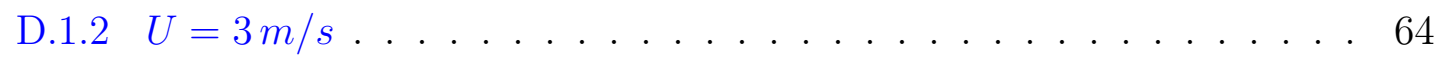

D.1.3 $U=4 \mathrm{~m} / \mathrm{s} \ldots \ldots \ldots \ldots$. . . . . . . . . . . . 66

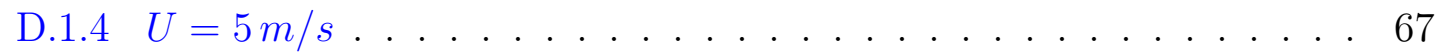

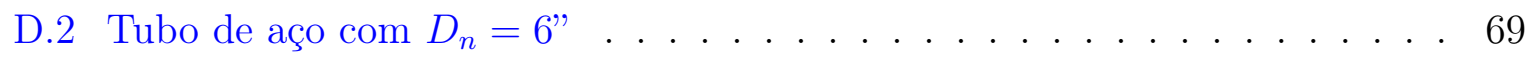

D.2.1 $U=2 \mathrm{~m} / \mathrm{s} \ldots \ldots \ldots \ldots \ldots \ldots \ldots \ldots$

D.2.2 $U=3 \mathrm{~m} / \mathrm{s} \ldots \ldots \ldots \ldots \ldots \ldots \ldots$. . . . . . . . . . . . . . . . .

D.2.3 $U=4 \mathrm{~m} / \mathrm{s} \ldots \ldots \ldots \ldots \ldots \ldots$. . . . . . . . . . . . . . . . .

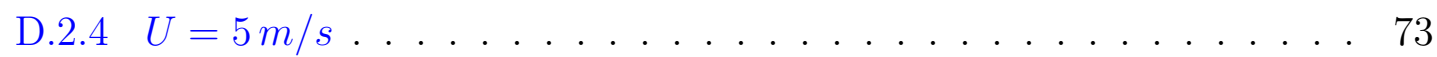

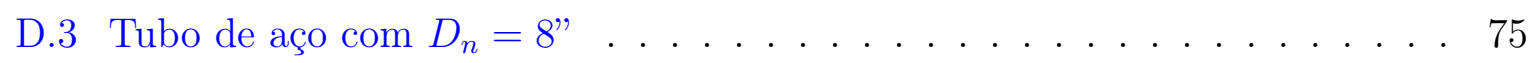

D.3.1 $U=2 \mathrm{~m} / \mathrm{s} \ldots \ldots \ldots \ldots \ldots \ldots \ldots$. . . . . . . . . . . . . . . . .

D.3.2 $U=3 \mathrm{~m} / \mathrm{s} \ldots \ldots \ldots \ldots \ldots \ldots$. . . . . . . . . . . . . . .

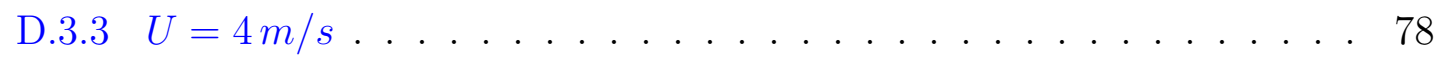

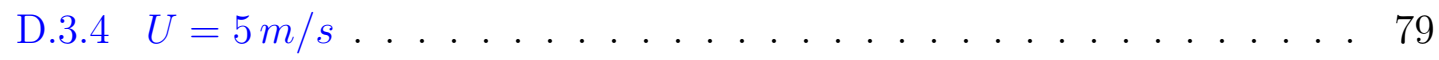

D.4 Tubo de aço com $D_{n}=10 " \ldots \ldots \ldots \ldots \ldots$. . . . . . . . . . . . .

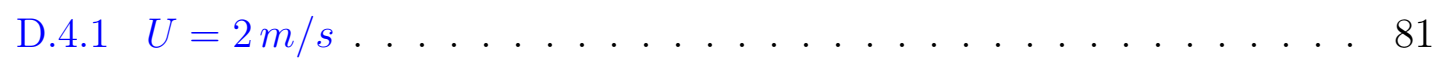

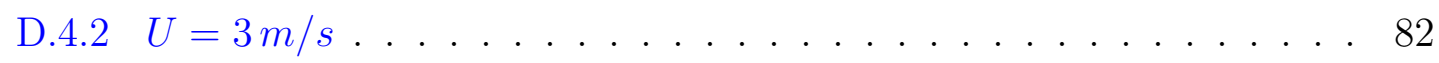

D.4.3 $U=4 \mathrm{~m} / \mathrm{s} \ldots \ldots \ldots \ldots \ldots \ldots$. . . . . . . . . . . 84

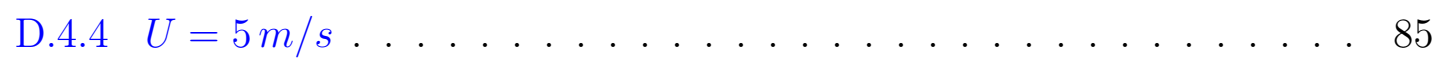




\section{Capítulo 1}

\section{Introdução}

Uma dada tubulação cujo serviço é transportar um fluido que se encontra à temperatura diferente da ambiente dilatará devido aos gradientes de temperatura em sua parede, gradiente este consequência da temperatura e das características do fluxo interno e das condições de contorno externas ao tubo. A dilatação térmica, que é um fenômeno explicado pela Termodinâmica e pela Física Molecular, está diretamente associada à temperatura do corpo.

No contexto da Engenharia de Tubulação, a dilatação térmica é um problema com o qual os engenheiros frequentemente precisam lidar, já que parte do papel destes profissionais é controlar as dilatações lineares totais e minimizar tensões e cargas associadas a este fenômeno físico. Entretanto, tais profissionais, devido a uma lacuna na literatura e nas normas que regem o projeto de sistemas de tubulação, já que tradicionalmente o problema é abordado apenas no regime permanente térmico, muitas vezes têm dúvidas de como a tubulação se comporta durante o transiente térmico, o que os leva a associar, por exemplo, as cargas relacionadas à dilatação térmica a altos fatores de projeto ou até mesmo ignorá-las.

Esse trabalho estudará o problema da transferência de calor transiente em tubulações devido ao escoamento interno e condições de contorno externas convectivas. São apresentadas as equações da continuidade, conservação de momento e da energia apropriadas e o método utilizado para resolvê-las numericamente. Com o conhecimento de como a temperatura do tubo varia como função da posição e do tempo, será possível associar o transiente térmico à dilatação térmica linear da tubulação, e, desta forma, melhorar o entendimento desse processo para então discutir, com base na mecânica classicamente utilizada pela Engenharia de Tubulação para computar cargas, o comportamento das forças de origem térmica.

Como resultado final, espera-se que esse trabalho contribua para o aprimoramento das práticas da Engenharia de Tubulação. 


\subsection{Importância acadêmica e tecnológica}

Após trabalhar como engenheiro de tubulação para empresas que prestam serviço de engenharia básica e executiva, foi verificado por este autor que são insuficientes os critérios de avaliação em relação ao comportamento térmico das tubulações industriais quando estas entram em operação, até o momento em que é atingido o regime permanente térmico. O correto entendimento do processo de expansão térmica linear é fundamental para que, por exemplo, as forças transmitidas pela tubulação às estruturas que a suportam sejam adequadamente mensuradas.

Tal insuficiência de critérios provavelmente se deve ao fato de que as literaturas específicas da Engenharia de Tubulação não abordam o tema, importando-se apenas com as dilatações totais após estabelecido o regime permanente térmico.

Em geral, para se aprofundar no tema, é preciso consultar literaturas relacionadas à Mecânica dos Fluidos e à Transferência de Calor. No caso do transiente térmico devido ao escoamento interno em tubos e dutos, mesmo as literaturas específicas deixam uma lacuna, já que estas tradicionalmente tratam apenas da transferência de calor em regime permanente neste tipo de escoamento.

Todos esses fatores, não somente esses, levam a difusão de práticas e procedimentos de engenharia que na imensa maioria dos casos superestimam as cargas e tensões relacionadas à expansão térmica linear da tubulação.

\subsection{Importância do transiente térmico em tubulações}

O projeto de sistemas de tubulação é guiado por normas estabelecidas por associações oficialmente ligadas a um dado país, podendo estas terem ainda um alcance global, e por critérios de projeto desenvolvidos pelos escritórios de engenharia.

A norma ASME B31.3 (2010) é certamente a mais utilizada no Brasil e nos Estados Unidos, sendo este último o país do qual esta norma é originária. Ela visa estabelecer boas práticas aprimoradas ao longo de décadas - a primeira publicação da série ASME B31 é de 1935 -, minimizando então os riscos associados ao projeto e a operação de sistemas de tubulação.

No caso do projeto estrutural do sistema de tubulação, a ASME B31.3 se preocupa fundamentalmente em proteger a tubulação estabelecendo as tensões admissíveis e a maneira como as tensões atuantes no sistema de tubulação devem ser calculadas, não se importando com as forças que o sistema de tubulação aplicará a equipamentos e estruturas devido à dilatação térmica, ainda que as restrições impostas por estes influenciem nos cálculos.

Do ponto de vista da norma ASME B31.3, o projeto do sistema de tubulação pode perfeitamente estar aprovado, ainda que as forças que a tubulação exercerá em equipa- 
mentos e estruturas sejam inaceitáveis. O sistema, do ponto de vista térmico, é avaliado conforme uma temperatura de projeto uniforme definida pelos critérios da ASME, temperatura esta normalmente baseada na temperatura de regime permanente. Este critério é suficiente para garantir a integridade estrutural da tubulação em virtude da forma como as tensões admissíveis e atuantes estão estabelecidas pela referida norma.

A seguir será demonstrado, através de simulações ilustrativas feitas no programa Caesar II (INTERGRAPH $\left.{ }^{\circledR}, 2015\right)$, como o transiente térmico influencia nas forças aplicadas pela tubulação à estrutura. O programa Caesar II é baseado na norma ASME B31.3, entre outras, e é um dos mais utilizados em todo o mundo em projetos de tubulação.

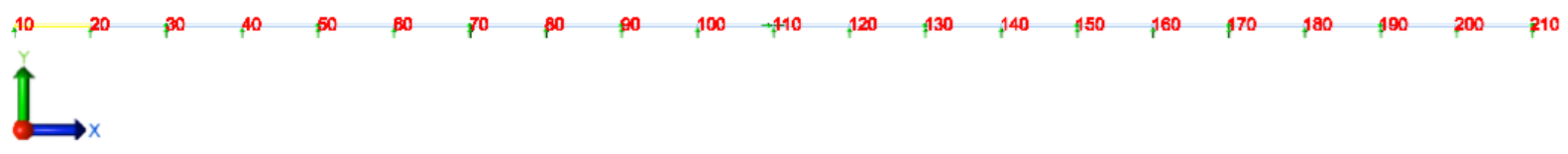

Figura 1.1: Tubulação modelada no Caesar II.

O modelo da Fig. 1.1 é a representação de um tubo reto de 200 metros com uma trava bem no meio deste, representada no nó 110. Os demais nós possuem apoios simples. A trava, que é um suporte de tubulação, fisicamente é montada conforme a Fig. 1.2, onde se vê a tubulação seccionada apoiada em uma viga, além dos perfis metálicos soldados à tubulação que constituem a trava, de tal forma que a tubulação tem a sua movimentação axial restrita.

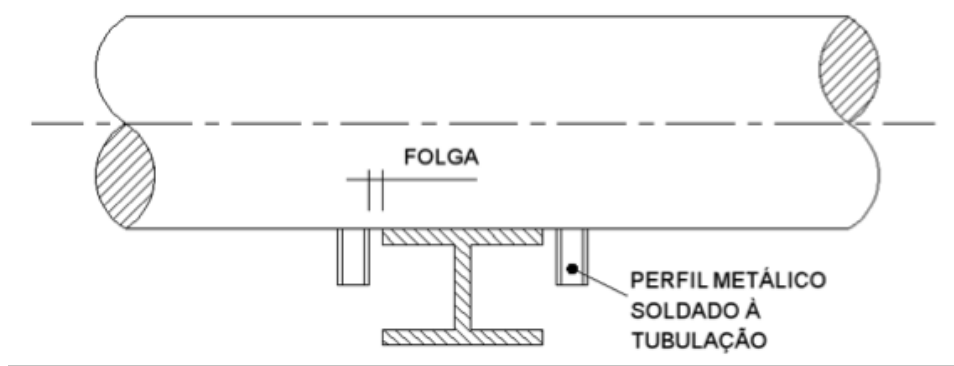

Figura 1.2: Representação da trava vista em elevação.

As travas ou ancoragens são suportes de tubulação imprescindíveis, uma vez que elas direcionam a dilatação fixando o tubo em um determinado ponto.

Silva Telles (1999) mostra a mecânica clássica para configurações 3D usada pela Engenharia de Tubulação para computar as forças e tensões em sistemas de tubulação. A tubulação é considerada como um elemento estrutural no qual forças axiais a esta não provocam deformações e o coeficiente de atrito é constate. Para uma configuração simétrica 1D, como a dos exemplos ilustrativos apresentados a seguir, o esquema da Fig. 1.3 demonstra como as forças são computadas.

As forças verticais são calculadas com as Eq. (1.1) e (1.2): 


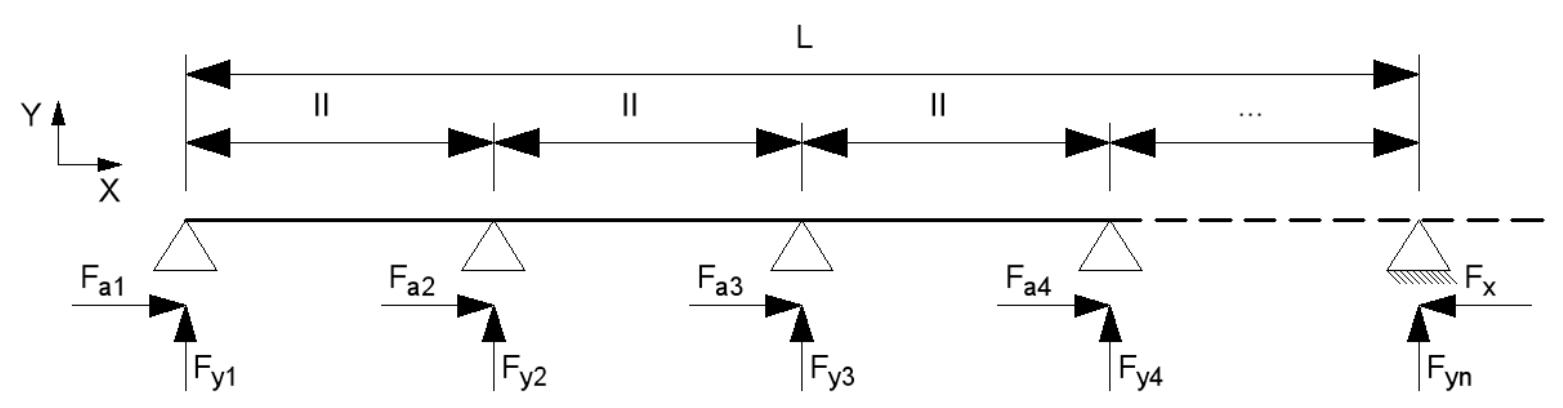

Figura 1.3: Representação da forças computadas em uma configuração 1D.

$$
\begin{gathered}
F_{y 1}=0,5\left[\frac{P}{(n-1)}\right] \\
F_{y 2}=F_{y 3}=F_{y 4}=F_{y n}=\frac{P}{(n-1)}
\end{gathered}
$$

onde,

$$
P=\frac{\pi}{4} g L\left(\rho_{f} D_{i}^{2}+\rho_{t}\left(D_{e}{ }^{2}-D_{i}^{2}\right)\right)
$$

e $n$ é o número de apoios.

As forças horizontais (atrito) em apoios simples são calculadas com a Eq. (1.4):

$$
F_{a}=\mu F_{y}
$$

Já a força devido ao atrito nos pontos onde a tubulação está travada ou ancorada, computada apenas para o trecho compreendido no comprimento $L$ indicado na Fig. 1.3, é calculada com a Eq. (1.5):

$$
F_{x}=\sum_{n=1}^{n-1} F_{a n}
$$

Na primeira simulação, toda a tubulação está igualmente aquecida com a temperatura de projeto, conforme estabelecido pela ASME, e a trava não possui folga. A Tab. 1.1 mostra os resultados obtidos com o Caesar II. O nó 110 é o nó onde a trava está localizada.

\begin{tabular}{|r|c|c|c|c|c|c|c|}
\hline Node & Load Case & $F_{x}(N)$ & $F_{y}(N)$ & $F_{z}(N)$ & $M_{x}(N m)$ & $M_{y}(N m)$ & $M_{z}(N m)$ \\
\hline 110 & \multicolumn{6}{|c|}{ Rigid + Y; Rigid X } \\
\hline & $(\mathrm{OPE})$ & 0 & -6573 & 0 & 0 & 0 & 0 \\
\hline
\end{tabular}

Tabela 1.1: Tubulação uniformemente aquecida.

Verifica-se que o programa calculou carga axial $\left(F_{x}\right)$ nula, como consequência da simetria do modelo e do regime permanente térmico, uma vez que a dilatação linear da 
tubulação a montante e a jusante da trava é máxima e dessa forma as forças de atrito, que são consequência do deslocamento da tubulação sobre as vigas que a suportam, se anularam. Tal resultado é verificado independentemente da configuração da trava.

Na segunda simulação, metade da tubulação compreendida entre os nós 10 e 110 experimenta um aquecimento abrupto, enquanto a outra metade continua à temperatura ambiente. A trava não possui folga. O resultado é mostrado na Tab.1.2.

\begin{tabular}{|r|c|l|c|c|c|c|c|}
\hline Node & Load Case & $F_{x}(N)$ & $F_{y}(N)$ & $F_{z}(N)$ & $M_{x}(N m)$ & $M_{y}(N m)$ & $M_{z}(N m)$ \\
\hline 110 & \multicolumn{6}{l}{ Rigid +Y; Rigid X } \\
\hline & $(\mathrm{OPE})$ & 18732 & -6573 & 0 & 0 & 0 & 0 \\
\hline
\end{tabular}

Tabela 1.2: Aquecimento abrupto com trava sem folga.

Nessa simulação, a tubulação passa a aplicar $18732 N$ à estrutura por intermédio da trava. Essa carga é devido a força de atrito calculada nos nós de 10 a 100 devido a expansão térmica. Essa condição nunca é avaliada já que o cálculo é feito para o regime permanente com a temperatura de projeto definida pela norma. Tal aquecimento abrupto, conforme o aqui simulado, não é real; entretanto é factível, conforme será provado por essa dissertação, a existência de um instante de tempo no qual o lado a montante da trava experimenta um diferencial de temperatura enquanto o lado a jusante permanece à temperatura ambiente.

A terceira simulação é similar à segunda, com exceção de que agora a trava passa a ter folga de $3 \mathrm{~mm}$. O resultado é mostrado na Tab. 1.3.

\begin{tabular}{|r|c|c|c|c|c|c|c|}
\hline Node & Load Case & $F_{x}(N)$ & $F_{y}(N)$ & $F_{z}(N)$ & $M_{x}(N m)$ & $M_{y}(N m)$ & $M_{z}(N m)$ \\
\hline 110 & \multicolumn{6}{l}{ Rigid +Y; Rigid X } \\
\hline & $(\mathrm{OPE})$ & 1972 & -6573 & 0 & 0 & 0 & 0 \\
\hline
\end{tabular}

Tabela 1.3: Aquecimento abrupto com trava com folga.

Verifica-se na terceira simulação que a carga na trava, e consequentemente na estrutura que suporta a tubulação, é bem menor do que na segunda simulação. Tal diferença se deve ao fato de que a "folga" faz com que a força de atrito calculada a jusante da trava entre no somatório de forças.

As simulações no Caesar II ilustram o porque do transiente térmico ser importante quando se analisa um sistema de tubulação, principalmente no que tange as cargas transmitidas pela tubulação a estruturas e equipamentos, cargas estas que não fazem parte do escopo da ASME B31.3.

O processo de dilatação térmica da tubulação tem estreita relação com o processo de aquecimento ou de resfriamento da mesma. A análise da expansão térmica linear e principalmente das forças relacionadas à dilatação térmica em qualquer um dos diversos programas de análise estrutural de tubulação que existem no mercado faz com que alguns engenheiros de tubulação se equivoquem em suas análises, já que tais programas analisam 
o sistema apenas em regime permanente, desconsiderando inclusive que há gradiente de temperatura na tubulação mesmo quando está atinge o equilíbrio térmico.

Conforme mostrado por Bokaian (2004), mesmo considerando o regime permanente térmico e que a configuração da tubulação é simétrica, apenas o gradiente térmico ao longo da tubulação provocado pela condição de contorno externa convectiva, provocará o desbalanceamento das forças no ponto de ancoragem/trava desta tubulação.

\subsection{Pipe racks}

Os pipe racks são provavelmente um dos elementos que compõe uma planta industrial mais superdimensionados, uma vez que em geral as cargas relacionadas a tubulação são sobrepostas e se associam a altos fatores de projeto devidos as incertezas. A Fig. 1.4 monstra a representação, em planta, do pipe rack PR-02 que suporta um feixe de tubulações oriundos do pipe rack PR-01 e o transfere para o pipe rack PR-03.

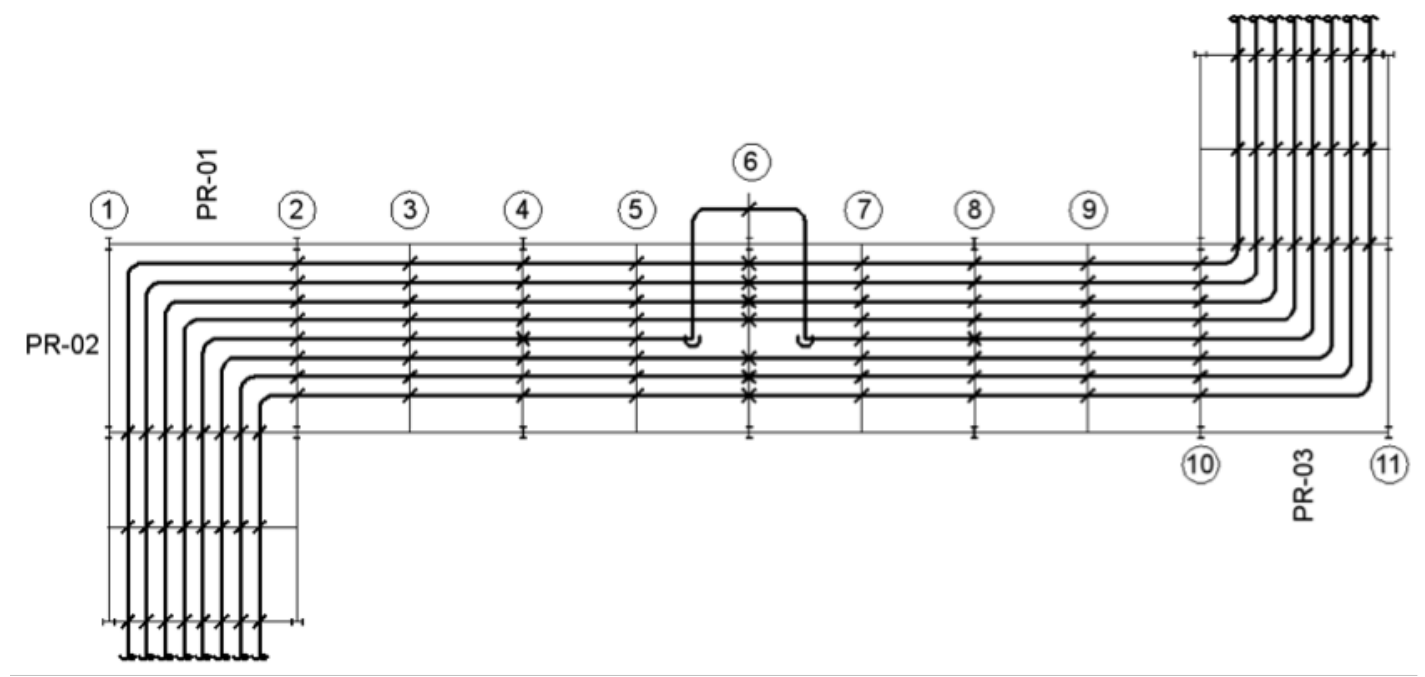

Figura 1.4: Representação de um pipe rack visto em planta.

Na Fig. 1.4 os eixos representam vigas do pipe rack PR-02 onde o feixe de tubulação está apoiado. Em desenhos de tubulações industriais:

× representa um suporte de tubulação do tipo trava ou ancoragem;

/ representa um apoio simples;

$\cup$ representa uma curva na vertical; no caso da Fig. 1.4, a tubulação sobe, passa por cima de 4 tubos, faz uma configuração em C denominada lira (ou looping) e retorna a sua posição original;

$\delta$ representa o seccionamento da tubulação.

Liras são artifícios utilizados quando a dilatação térmica linear extrapola a limites pré-estabelecidos. Tais limites visam, por exemplo, impedir que uma tubulação se choque contra outra nas mudanças de direção. 
No projeto de pipe racks é recomendável que o feixe de tubulação seja travado/ancorado na mesma viga ${ }^{1}$, conforme representado pelo eixo 6 da Fig. 1.4, garantido assim que uma única estrutura receberá as forças relacionadas à expansão térmica deste feixe de tubulação, sendo que tal feixe pode ser composto por tubos com diâmetros, materiais e fluidos diferentes, o que faz com que estimar as forças em pontos de trava/ancoragem não seja uma tarefa exatamente determinística.

Um dos critérios mais utilizados no Brasil sobrepõe todas as forças axiais em pontos de trava/ancoragem de tubulações em pipe racks e multiplica a força total por um fator que considera que as tubulações não entrarão em serviço simultaneamente. Essa dissertação propiciará um melhor entendimento dos tempos envolvidos no transiente térmico e, desta forma, poderá ajudar na elaboração de critérios de projetos menos conservadores.

\subsection{Objetivos}

Através de método numérico, o objetivo é quantificar o processo de expansão térmica linear de um tubo durante o regime de transiente térmico considerando diferentes diâmetros, velocidades médias do escoamento interno e materiais de tubulação.

Com base nos resultados, discutir como os diferentes parâmetros influenciam no processo de aquecimento e de expansão térmica linear da tubulação e, com base na mecânica clássica utilizada pela Engenharia de Tubulação para computar forças em sistemas de tubulação, discutir o comportamento das forças de origem térmica durante o regime transitório.

\subsection{Revisão bibliográfica}

O escoamento interno em tubos e dutos, devido a sua vasta aplicação na engenharia, talvez seja um dos ramos da ciência mais investigados. Entretanto, algumas das literaturas mais clássicas que abordam a transferência de calor devido ao escoamento interno através de tubos e dutos não tratam do problema quando em regime transiente. É o caso de Arpaci e Larsen (1984), Bejan (1995), Kays e Crawford (1993), Schlichting et al. (2003) e Eckert (1959). Da mesma forma, no caso da dilatação térmica, as literaturas especializadas em Engenharia de Tubulação, como Littleton (1951), Kellogg (1955), Silva Telles (1999) e Nayyar (2000), tratam do problema apenas no regime permanente.

Apesar desta lacuna deixada pela literatura, muitos pesquisadores, após a primeira metade do século 20, vêm investigando o problema do transiente térmico em tubos e dutos apresentando modelos matemáticos com diferentes graus de complexidade, assim como os métodos empregados para resolvê-los.

\footnotetext{
${ }^{1}$ Em pipe racks, a estrutura onde o feixe de tubulação é travado/ancorado é chamada de pórtico de ancoragem.
} 
Desde o início do século 21 até o presente momento, aparentemente poucos pesquisadores publicaram trabalhos relevantes relacionados à transferência de calor em regime transiente envolvendo escoamento interno através de tubos e dutos. Shih et al. (2010) realizaram uma extensa catalogação de trabalhos publicados entre o ano 2000 e 2009 relativos à transferência de calor e, dos 5506 trabalhos listados, apenas 3 fazem referência direta ao problema de transferência de calor em regime transiente envolvendo escoamento interno em tubos e dutos. Entretanto, no citado período, os estudos ganharam sofisticação com o aperfeiçoamento e a maior disponibilidade de programas de CFD, como demonstra o trabalho de Escobedo, Nieckele e Azevedo (2005), onde se realizou estudo do transiente térmico em tubulações submersas transportando fluido bifásico altamente viscosos.

Grande parte das pesquisas envolvendo transferência de calor no regime transiente devido ao escoamento interno através de tubos e dutos aparentemente se concentram entre os anos 1960 e 2000. O pesquisadores consideraram tanto condições de contorno convectivas na superfície externa do tubo quanto fluxo de calor constante, além de temperatura da superfície constante. Tais pesquisas procuraram entender o papel da condutividade e da difusividade térmica do fluido e do tubo, a influência do número de Peclet e do número de Nusselt (interno e externo), da espessura da parede do tubo e da condutividade térmica axial tanto do fluido quanto do tubo. Alguns dos pesquisadores realizaram experimentos cujos resultados foram comparados com soluções analíticas e numéricas.

Conforme mostrado por Jiji (2009), a transferência de calor em regime transiente pode ser descrita por uma função exponencial, na qual a temperatura do meio que cede (no caso de aquecimento) ou que recebe calor (no caso de resfriamento) de um corpo define o limite assintótico desta função exponencial. Boa parte dos pesquisadores que serão citados a seguir demonstraram graficamente o caráter exponencial da variação da temperatura do fluido e do tubo em função do tempo em uma dada seção da tubulação, assim como a temperatura de regime permanente como o limite assintótico desta função exponencial.

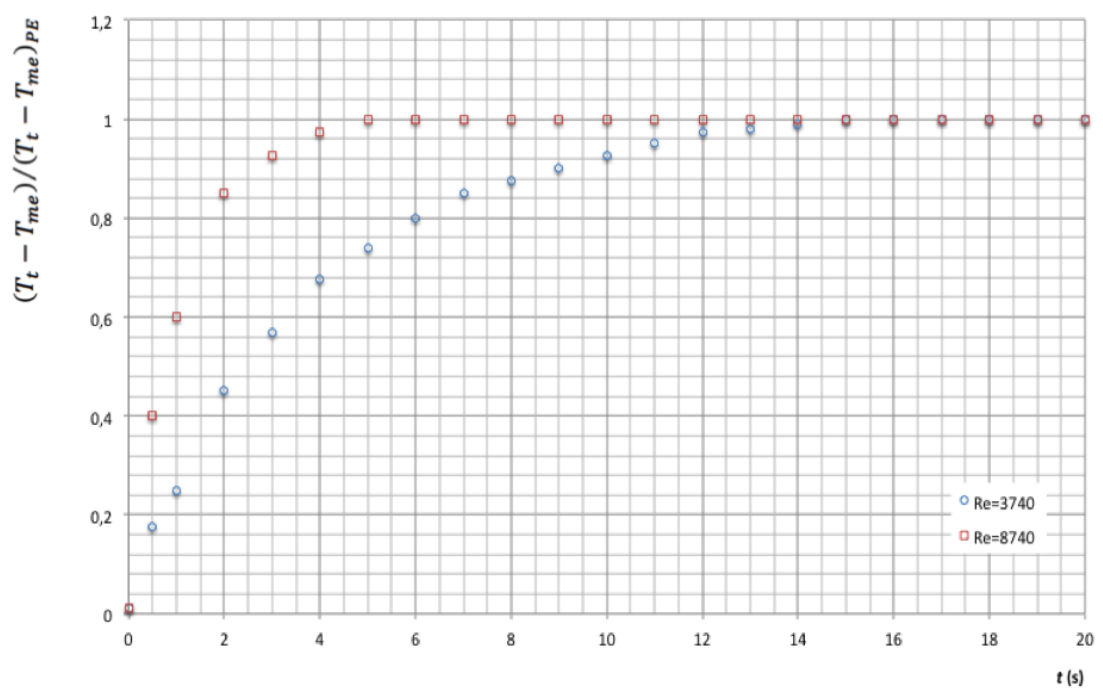

Figura 1.5: Variação da temperatura do tubo em função do tempo em uma dada seção. 
A Fig. 1.5 é uma adaptação dos resultados apresentados por Kawamura (1976) e mostra a variação da temperatura do tubo em função do tempo em uma dada seção transversal do tubo. Na mesma figura, é possível ver a influência do número de Reynolds. O subscrito "PE" representa o regime permanente.

\subsubsection{Zargary e Brock (1973)}

Os autores apresentam um modelo matemático para a solução exata do transiente térmico em tubos usando funções de Bessel e o procedimento de Lowan. Considerou-se superfície externa do tubo bem isolada termicamente, escoamento laminar com velocidade uniforme, tubo e fluido inicialmente à mesma temperatura e que, repentinamente, a temperatura do fluido na entra no tubo é elevada.

Os autores não fazem conclusões já que apresentam resultados preliminares, entretanto, a forma como o problema foi formulado se tornou a principal referência do modelo matemático desse trabalho.

\subsubsection{Kawamura (1976)}

Neste trabalho o autor verificou como o coeficiente de convecção interno em escoamento forçado varia com o tempo. Realizou-se experimento considerando escoamento constante e turbulento de água aquecida por fluxo constante de calor originado pela passagem de corrente elétrica através de uma dada seção do tubo.

O autor comparou os resultados experimentais com os obtidos por método numérico onde, além das formas apropriadas da equação da conservação de momento e da energia, foi usado o modelo turbulento $k-\varepsilon$.

Foi encontrada grande convergência entre os resultados experimentais e os obtidos por método numérico, entretanto, quando se considerou o coeficiente de convecção constante e igual ao do regime permanente (solução quase-estática), verificou-se um desvio para pequenos números de Reynolds, sobretudo nos tempos iniciais do transiente térmico e na região de entrada.

A pesquisa do autor fundamenta a decisão de considerar o coeficiente de convecção interno constante no modelo matemático dessa dissertação.

\subsubsection{Vich, Özişik e Ullrich (1983)}

Os autores analisam o efeito da condução de calor axial no fluido. Foi considerado escoamento laminar (Poseuille) plenamente desenvolvido, condições de contorno convectivas externas ao tubo e espessura da parede do tubo desprezível.

Os autores concluêm que ao se considerar condução axial, a transferência de calor é influenciada principalmente na região de entrada, caso o número de Peclet seja pequeno. 


\subsubsection{Lin e Kuo (1988)}

Neste trabalho foi estudado o efeito, na transferência de calor transiente, da espessura da parede do tubo, da difusividade térmica (fluido e tubo), da condutividade térmica (fluido e tubo), do número de Nusselt e de Peclet na transferência de calor transiente. Considerou-se escoamento laminar (Poiseuille) constante e fluxo de calor uniforme. Não se desprezou, na equação da energia, os termos relacionados à condução axial tanto no fluido quanto no tubo.

Os pesquisadores resolveram o problema usando o método das diferenças finitas e definiram este como o melhor método, já que a equação da energia é "elíptica no espaço e parabólica no tempo" (LIN; KUO, 1988, p. 1095).

Concluiu-se que a parede do tubo exerce papel importante na transferência de calor transiente, assim como o número de Peclet. Observou-se ainda que quanto maior a espessura do tubo e menores são o diâmetro, $\alpha_{t} / \alpha_{f}, k_{t} / k_{f}$ e o número de Peclet, maiores são os tempos para se atingir o regime permanente.

\subsubsection{Yan, Tsay e Lin (1989)}

Os pesquisadores estudaram a transferência de calor em escoamento laminar (Poiseuille) através de tubo com temperatura da parede externa constante. Foi estudada a influência da espessura da parede do tubo durante o regime transiente.

Os autores validaram o seu modelo numérico, resolvido por diferenças finitas, comparando-o com um modelo analítico, verificando grande convergência entre os resultados. As conclusões são similares às de Lin e Kuo (1988).

\subsubsection{Negiz, Hastaoglu e Heidemann (1993)}

Neste trabalho se analisou o transiente térmico em tubulações enterradas. Os autores usaram um modelo tridimensional e considerou escoamento laminar constante (Poiseuille).

O problema foi resolvido numericamente por diferenças finitas e os resultados foram comparados com os obtidos por uma solução analítica simplificada.

\subsubsection{Hastaoglu, Negiz e Heidemann (1995)}

Os pesquisadores analisaram o transiente térmico em tubulações enterradas com o propósito de entender a evolução do congelamento (temperatura da superfície do solo muito abaixo da temperatura de solidificação do fluido). Considerou escoamento laminar do tipo Poiseuille e modelou o problema tridimensionalmente.

O problema foi resolvido computacionalmente por meio do método das diferenças finitas. Foi avaliada também a importância de se considerar a espessura da parede do tubo. 


\subsubsection{Lee e Yan (1996)}

Os autores deram sequência ao trabalho publicado por Yan, Tsay e Lin (1989) considerando, agora, a condução de calor axial através da parede do tubo.

Os autores argumentam que, ao se considerar a condução axial, o problema passa a não ter solução analítica. O problema é então resolvido numericamente por diferenças finitas.

Conclui-se que ao não considerar a parede do tubo, o modelo não é realístico na região de entrada do tubo e que a condutividade térmica do tubo exerce importante papel em relação aos tempos requeridos para se atingir o regime permanente.

\subsubsection{Jackson, Büyükalaca e He (1998)}

Neste trabalhou se realizou experimentos para avaliar o transiente térmico em tubos após variação controlada da vazão. Foi considerado fluxo de calor uniforme na superfície do tubo. Após estabelecido o regime térmico e hidráulico, a vazão foi gradualmente aumentada.

Verificou-se que os resultados obtidos experimentalmente não convergem bem com alguns modelos computacionais enquanto o regime permanente hidráulico não é estabelecido.

\subsubsection{Espinosa Paredes et al. (2001)}

Os autores apresentaram um programa desenvolvido para o cálculo do transiente térmico em um sistema de perfuração de poços (a broca é resfriada por um fluido através de canais circulares). Foram mostradas as equações utilizadas e a forma de discretização para a solução do problema por diferenças finitas.

Em especial, para o caso de escoamento turbulento, foi usado o coeficiente de convecção interno como condição de contorno na fronteira entre o fluido e a parede do tubo, além de terem sido apresentadas as correlações utilizadas para o cálculo do coeficiente de convecção interno.

\subsubsection{Bilir e Ateş (2003)}

Neste trabalho os autores estudaram a transferência de calor transiente no escoamento interno do tipo Poiseuille. Foi considerado inicialmente que o tubo e o fluido estavam a temperatura ambiente quando, repentinamente, a temperatura do ambiente externo $\left(T_{\infty}\right)$ é elevada.

Os autores consideraram condução axial tanto no fluido como no tubo e resolveram o problema numericamente por diferenças finitas. Chegou-se a conclusões semelhantes às de Lin e Kuo (1988). 


\subsubsection{Luna, Méndez e Mar (2003)}

Os pesquisadores estudaram a transferência de calor transiente na região de entrada do tubo. Foi considerado escoamento laminar, fluxo de calor uniforme na superfície do tubo e condução axial no fluido. O fluido é não newtoniano.

Os autores concluíram que é importante considerar a condução axial na região de entrada, porém, para razões entre a espessura do tubo e o comprimento do tubo muito menores que $1(d / L \ll 1)$, tal consideração passa a ser desprezível. Mostrou-se ainda que para $d / L \ll 1$, o gradiente de temperatura na direção radial é muito maior no fluido que no tubo.

\subsubsection{Bhowmik e Tou (2004)}

Neste trabalho foi realizado um experimento de escoamento forçado em duto a fim de estudar o comportamento de um sistema de resfriamento de microchips.

Os autores compararam os resultados experimentais com os obtidos por correlações e encontraram grande convergência. Verificou-se ainda o comportamento do número de Nusselt em função do tempo.

\subsubsection{Boumaza e Omara (2013)}

Neste trabalho os autores estudaram o escoamento descendente através de tubo vertical submetido a fluxo de calor constante. O escoamento é permanente e laminar e foi considerada condução térmica axial tanto no fluido quanto no tubo.

Os pesquisadores usaram o método dos volumes finitos para resolver o modelo matemático e concluiram que o tempo para se atingir o regime permanente térmico é inversamente proporcional à razão entre a condutividade térmica do tubo e do fluido.

\subsubsection{Bokaian (2004)}

Neste trabalho o autor estudou as forças e tensões relacionadas à dilatação térmica de tubulações encamisadas, onde, apesar da complexidade da geometria analisada, muitos dos conceitos empregados podem ser considerados em tubulações simples.

O pesquisador considerou as dilatações totais, ou o regime permanente, ponderando, no entanto, que haverá um gradiente de temperatura na tubulação devido às condições externas convectivas, o que, assim como a posição da ancoragem desta tubulação, causa desbalanceamento das forças e tensões. 


\section{Capítulo 2}

\section{Equações envolvidas na análise da dilatação térmica linear transiente}

As equações da conservação e a metodologia empregada para resolvê-las são o pilar dessa dissertação, já que somente após a definição do modelo matemático e da sua resolução foi possível atingir os objetivos desse trabalho: um estudo da dilatação durante o transiente térmico.

A revisão bibliográfica apresentada na Sec. 1.5 foi fundamental para a definição do modelo matemático, uma vez que, conforme colocado, algumas das literaturas mais tradicionais não tratam do problema da transferência de calor devido ao escoamento interno através de tubos e dutos no regime transiente.

\subsection{Modelo matemático}

O modelo matemático considera uma tubulação através da qual escoa um fluido à temperatura ambiente. Repentinamente, a temperatura do fluido na entrada do tubo é elevada. As condições externas são convectivas e a temperatura é a ambiente.

As principais considerações usadas para a definição do modelo matemático são as que seguem:

- As propriedades termofísicas são constantes.

- O escoamento é incompressível.

- A dissipação viscosa e a condução axial tanto no fluido quanto no tubo são desprezíveis quando comparadas à transferência de calor com a parede do tubo.

- O escoamento é turbulento.

- O escoamento na região de entrada está completamente desenvolvido. 
- A temperatura na região de entrada é uniforme.

- A convecção externa é natural e uniforme.

- A variação da energia cinética e potencial é desprezível.

A seguir serão apresentadas as equações que constituem o modelo matemático. Por se tratar de escoamento turbulento, a temperatura do fluido $\hat{T}_{f}$, a pressão $\hat{p}$ e a velocidade do escoamento interno $\hat{u}$ devem ser entendidas como as médias temporais locais.

\subsubsection{Equação da continuidade}

$$
\begin{gathered}
\hat{u}=\hat{u}(r) \\
\hat{u}_{\theta}=\hat{u}_{r}=0
\end{gathered}
$$

onde, $r$ é a coordenada na direção radial e $\theta$ é a coordenada na direção angular.

\subsubsection{Equação da conservação de momento}

$$
\frac{1}{r} \frac{\partial}{\partial r}\left[\left(\nu+\varepsilon_{M}\right) r \frac{\partial \hat{u}}{\partial r}\right]=\frac{1}{\rho_{f}} \frac{\partial \hat{p}}{\partial x}
$$

onde, para escoamentos laminares, a difusividade turbulenta de momento $\varepsilon_{M}$ é nula e a velocidade $\hat{u}$ e a pressão $\hat{p}$ são instantâneas. O termo $\frac{\partial \hat{p}}{\partial x}$ é a perda de carga por unidade de comprimento de tubo

As condições de contorno são:

$$
\begin{gathered}
\left(\frac{\partial \hat{u}}{\partial r}\right)_{r=0}=0 \\
\hat{u}\left(r_{0}\right)=0
\end{gathered}
$$

onde, $r_{0}$ é o raio interno do tubo.

A difusividade turbulenta de momento $\varepsilon_{M}$ será avaliada através de uma equação empírica atribuída a Reichardt (KAYS; CRAWFORD, 1993).

$$
\frac{\varepsilon_{M}}{\nu}=\frac{0,4 y^{+}}{6}\left(1+\frac{r}{r_{0}}\right)\left[1+2\left(\frac{r}{r_{0}}\right)^{2}\right]
$$

com,

$$
y^{+}=\left(r_{0}-r\right) \frac{U \sqrt{f / 8}}{\nu}
$$


Para escoamentos turbulentos, a perda de carga por unidade de comprimento de tubo $\frac{\partial \hat{p}}{\partial x}$, conforme Darcy-Weisbach, é definida como:

$$
\frac{\partial \hat{p}}{\partial x}=-f \frac{\rho_{f} U^{2}}{2 D_{i}}
$$

com,

$$
f=1,325\left\{\ln \left[0,27\left(\frac{e}{D_{i}}\right)+5,74\left(\frac{1}{R e}\right)^{0,9}\right]\right\}^{-2}
$$

A Eq. (2.7) é atribuída a Swamee e Jain (POTTER; WIGGERT; HONDZO, 1997) e é uma correlação indicada para o cálculo do fator de atrito para $5000<\operatorname{Re}<10^{8}$.

\subsubsection{Equação da energia}

\subsubsection{Para o fluido}

Aplicadas as considerações e a Eq. (2.1), resulta:

$$
\frac{\partial \hat{T}_{f}}{\partial t}+\hat{u} \frac{\partial \hat{T}_{f}}{\partial x}=\frac{1}{r} \frac{\partial}{\partial r}\left[r\left(\alpha_{f}+\varepsilon_{H}\right) \frac{\partial \hat{T}_{f}}{\partial r}\right] \quad\left(0 \leqslant r \leqslant r_{0}\right)
$$

onde, para escoamentos laminares, a difusividade turbulenta de temperatura $\varepsilon_{H}$ é nula e a temperatura $\hat{T}_{f}$ e a velocidade $\hat{u}$ são instantâneas.

A condição inicial e as condições de contorno são:

Condição inicial, válida para $0 \leq r \leq r_{0}$ e $0 \leq x \leq \infty$ :

$$
\begin{gathered}
\hat{T}_{f}=f(x, r, t) \\
\hat{T}_{f}(x, r, 0)=T_{\infty}
\end{gathered}
$$

Condições de contorno:

$$
\begin{gathered}
\hat{T}_{f}(0, r, t)=T_{m e} \\
k_{f}\left(\frac{\partial \hat{T}_{f}}{\partial r}\right)_{r=r_{0}}=h_{i}\left[T_{t}\left(x, r_{0}, t\right)-\bar{T}_{f}(x, t)\right] \\
\left(\frac{\partial \hat{T}_{f}}{\partial r}\right)_{r=0}=0
\end{gathered}
$$

O coeficiente de convecção interno pode ser calculado com a Eq. (2.13) atribuída a Gnielinski (KAYS; CRAWFORD, 1993).

$$
h_{i}=\frac{k_{f}}{D_{i}} \frac{(R e-1000) \operatorname{Pr}(f / 8)}{1+12,7(f / 8)^{1 / 2}\left(\operatorname{Pr}^{2 / 3}-1\right)}
$$


A Eq. (2.13) é uma correlação indicada para $0,5 \leq \operatorname{Pr} \leq 2000$ e $2300 \leq R e \leq 5 \times 10^{6}$.

A temperatura média do fluido, tendo em vista que a sua temperatura local é função da posição $x$, do raio $r$ e do tempo $t$, é calculada com a seguinte equação:

$$
\bar{T}_{f}(x, t)=\frac{2}{U r_{0}^{2}} \int_{0}^{r_{0}} \hat{u}(r) \hat{T}_{f}(x, r, t) r d r
$$

O fator de atrito $f$ pode ser obtido a partir da Eq. (2.7). Neste estudo será adotada a analogia de Reynolds e, portanto, $\varepsilon_{H}=\varepsilon_{M}$, com $\varepsilon_{M}$ avaliado com a Eq. (2.5).

\subsubsection{Para o tubo}

$$
\frac{\partial T_{t}}{\partial t}=\frac{1}{r} \frac{\partial}{\partial r}\left(r \alpha_{t} \frac{\partial T_{t}}{\partial r}\right) \quad\left(r_{0} \leq r \leq r_{e}\right)
$$

A condição inicial e as condições de contorno são:

Condição inicial, válida para $r_{0} \leq r \leq r_{e}$ e $0 \leq x \leq \infty$ :

$$
\begin{gathered}
T_{t}=f(x, r, t) \\
T_{t}(x, r, 0)=T_{\infty}
\end{gathered}
$$

Condição de contorno:

$$
\begin{gathered}
k_{t}\left(\frac{\partial T_{t}}{\partial r}\right)_{r=r_{0}}=h_{i}\left[T_{t}\left(x, r_{0}, t\right)-\bar{T}_{f}(x, t)\right] \\
k_{t}\left(\frac{\partial T_{t}}{\partial r}\right)_{r=r_{e}}=h_{e}\left[T_{\infty}-T_{t}\left(x, r_{e}, t\right)\right]
\end{gathered}
$$

O coeficiente de convecção externo pode ser calculado com a Eq. (2.19) atribuída a Churchill e Chu (INCROPERA; DE WITT, 2003).

$$
h_{e}=\frac{k_{a r}}{D_{e}}\left\{0,6+\frac{0,387 R a^{1 / 6}}{\left[1+(0,559 / P r)^{9 / 16}\right]^{8 / 27}}\right\}^{2}\left(R a \leq 10^{12}\right)
$$

com,

$$
R a=\frac{g \beta\left(T_{t}-T_{\infty}\right) D_{e}^{3}}{\nu \alpha}
$$

e

$$
\beta=\frac{1}{T_{a b s}}
$$

A Eq. (2.20) é válida apenas para gases perfeitos. 


\subsection{Dilatação térmica transiente}

Conhecida a distribuição da temperatura do tubo em função do tempo, a dilatação transiente poderá ser calculada com a Eq. (2.21):

$$
\delta(x, t)=\int_{0}^{x} \varphi\left[\bar{T}_{t}(\xi, t)-\bar{T}_{t}(\xi, 0)\right] d \xi
$$

sendo $\xi$ uma variável auxiliar com unidade de comprimento. A temperatura média do tubo, $\bar{T}_{t}$, será calculada com a Eq. (2.22).

$$
\bar{T}_{t}(x, t)=\frac{2}{\left(r_{e}^{2}-r_{0}^{2}\right)} \int_{r_{0}}^{r_{e}} T_{t}(x, r, t) r d r
$$

\subsubsection{Coeficiente de dilatação}

Para o desenvolvimento desse trabalho, o aço e o cobre serão considerados como materiais de tubulação. A seguir são apresentadas as equações utilizadas para se obter o coeficiente de dilatação linear do tubo, equações estas adaptadas de ASME B31.3 (2010).

\subsubsection{Dilatação do aço}

O coeficiente de dilatação linear total do aço em $\mu m /\left(m^{\circ} C\right)$ é dado pela seguinte equação:

$$
\varphi=0,0077 \bar{T}_{t}+10,721
$$

onde, a temperatura média do tubo $\bar{T}_{t}$ é dada em ${ }^{\circ} C$.

\subsubsection{Dilatação do cobre}

O coeficiente de dilatação linear total do cobre $\mu m /\left(m^{\circ} C\right)$ em é dado pela seguinte equação:

$$
\varphi=0,0058 \bar{T}_{t}+16,651
$$

onde, a temperatura média do tubo $\bar{T}_{t}$ é dada em ${ }^{\circ} C$. 


\section{Capítulo 3}

\section{Metodologia}

Para a elaboração da revisão bibliográfica apresentada na Sec. 1.5, foi utilizada a biblioteca da USP e o acesso a base de dados como o ScienceDirect (www.sciencedirect.com) e o Portal de Periódicos CAPES/MEC (www.periodicos.capes.gov.br). Terminada a pesquisa bibliográfica e definido o modelo matemático, conforme apresentado no Cap. 2, o programa Mathematica ${ }^{\circledR}$ (Wolfram Research, 2015) foi a ferramenta adotada para a resolução, por meio de métodos numéricos, do modelo matemático, já que este dispõe de uma ampla biblioteca de métodos para a solução de EDAs, EDOs e EDPs.

O primeiro passo é conhecer o campo de velocidade através da solução da equação da conservação de momento. Tal objetivo, no Mathematica ${ }^{\circledR}$, é facilmente atingido por intermédio do comando "NDSolve" (numerical differential equation solver), através do qual é implementado o Método Numérico de Runge Kutta. Neste passo tanto o tempo de aprendizado quanto o de processamento são curtos. O apêndice C mostra todos os perfis de velocidade obtidos nesse estudo.

Uma restrição importante acerca da solução do campo de velocidade, que limitou a quantidade de simulações realizadas, está relacionada ao fato de que para escoamentos a velocidades recomendadas pela literatura especializada em tubulações de processo, com exceção da água, líquidos com propriedades frequentemente tabeladas pela literatura especializada em transferência de calor, como o óleo, não estão na zona de escoamento completamente turbulento, o que leva a resultados insatisfatórios, já que a Eq. (2.5) se torna inadequada.

Conhecido o campo de velocidade, pode-se então resolver a equação da energia por intermédio do comando "NDSolve", através do qual, agora, é implementado o Método Numérico das Características.

O Método Numérico das Características é uma técnica para a resolução de EDPs ou sistema de EDPs através da discretização por diferenças finitas desta EDP ou sistema de EDPs em todas as dimensões exceto uma (tempo), para então integrar o sistema semi-discreto como um sistema de EDOs ou EDAs. Tal método exige condições iniciais consistentes e se destina à resolução de uma grande variedade de EDPs, exceto EDPs 
totalmente elípticas. Ainda que o Mathematica ${ }^{\circledR}$ facilite bastante a sua implementação, essa etapa é bem mais trabalhosa já que o tempo de aprendizado é longo por exigir uma série de configurações para que a solução seja satisfatória, além de ser necessário que a condição inicial e de contorno sejam consistentes. Por exemplo, a condição inicial para o fluido ficou definida como:

$$
\begin{gathered}
T_{f}(x, r, t) \\
T_{f}(x, r, 0)=\left(T_{m e}-T_{\infty}\right) e^{-1000 x}+T_{\infty}
\end{gathered}
$$

Ou seja, para $x=0$ a temperatura inicial é $T_{m e}$ e para $x>0$ a temperatura inicial cai abruptamente para $T_{\infty}$, o que é consistente com a condição de contorno na entrada onde a temperatura é uniformemente igual a $T_{m e}$. Tal forma de apresentar a condição inicial é uma sugestão dada pelo serviço de ajuda do Mathematica ${ }^{\circledR}$. Sofroniou e Knapp (2008) trazem maiores informações a respeito do Método Numérico das Características e de como este é implementado no Mathematica ${ }^{\circledR}$.

Somando-se a isso, o Mathematica ${ }^{\circledR}$, na versão $9^{1}$, é capaz de resolver sistemas de EDPs "apenas" para equações dependentes de uma única variável e, no caso, a temperatura é dependente da posição $x$, do raio $r$ e do tempo $t$. Desta feita, foi preciso programar no Mathematica ${ }^{\circledR}$ para que a equação do tubo e do fluido fossem resolvidas simultaneamente de forma iterativa.

O fluxograma da Fig. 3.1 mostra como funciona o programa e como a equação da energia para o fluido e para o tubo são resolvidas simultaneamente.

O erro $\epsilon$ é calculado com a Eq. (3.1):

$$
\epsilon=\left|\frac{\int_{t_{\min }}^{t_{\max }} \int_{x_{\min }}^{x_{\max }} \bar{T}_{f p r e d}(x, t) d x d t}{\int_{t_{\min }}^{t_{\max }} \int_{x_{\min }}^{x_{\max }} \bar{T}_{f}(x, t) d x d t}-1\right|
$$

Conforme pode ser verificado na Fig. 3.1, o NDSolve é capaz de integrar a Equação da energia em $x, r$ e $t$, em sendo $x$ e $t$ variáveis parabólicas e $r$ uma variável elíptica.

Obtida a distribuição de temperatura no tubo $T_{t}=f(x, r, t)$ será, então, possível estudar a dilatação térmica no período de transiente térmico por intermédio da Eq. (2.21). O Mathematica ${ }^{\circledR}$ é também utilizado no pós-processamento dos dados e na geração de todos os gráficos apresentados nesse trabalho.

Dois comentários pertinentes a respeito do uso do Mathematica ${ }^{\circledR}$ como ferramenta para resolver a equação da energia precisam ser feitos. O primeiro é que cada simulação demanda, em um computador com processador de $4.2 \mathrm{GHz}$ e 8 MB de RAM, aproximadamente 36 horas de processamento, tempo este que pode ser explicado pelo fato do Mathematica ${ }^{\circledR}$ utilizar um método geral para a solução de EDPs e por este programa, mesmo para cálculos puramente numéricos, ter como padrão retornar soluções "simbó-

\footnotetext{
${ }^{1} \mathrm{O}$ Mathematica ${ }^{\circledR}$ se encontra na versão 10. Nesta ele é capaz de resolver sistemas de EDPs com três variáveis independentes.
} 


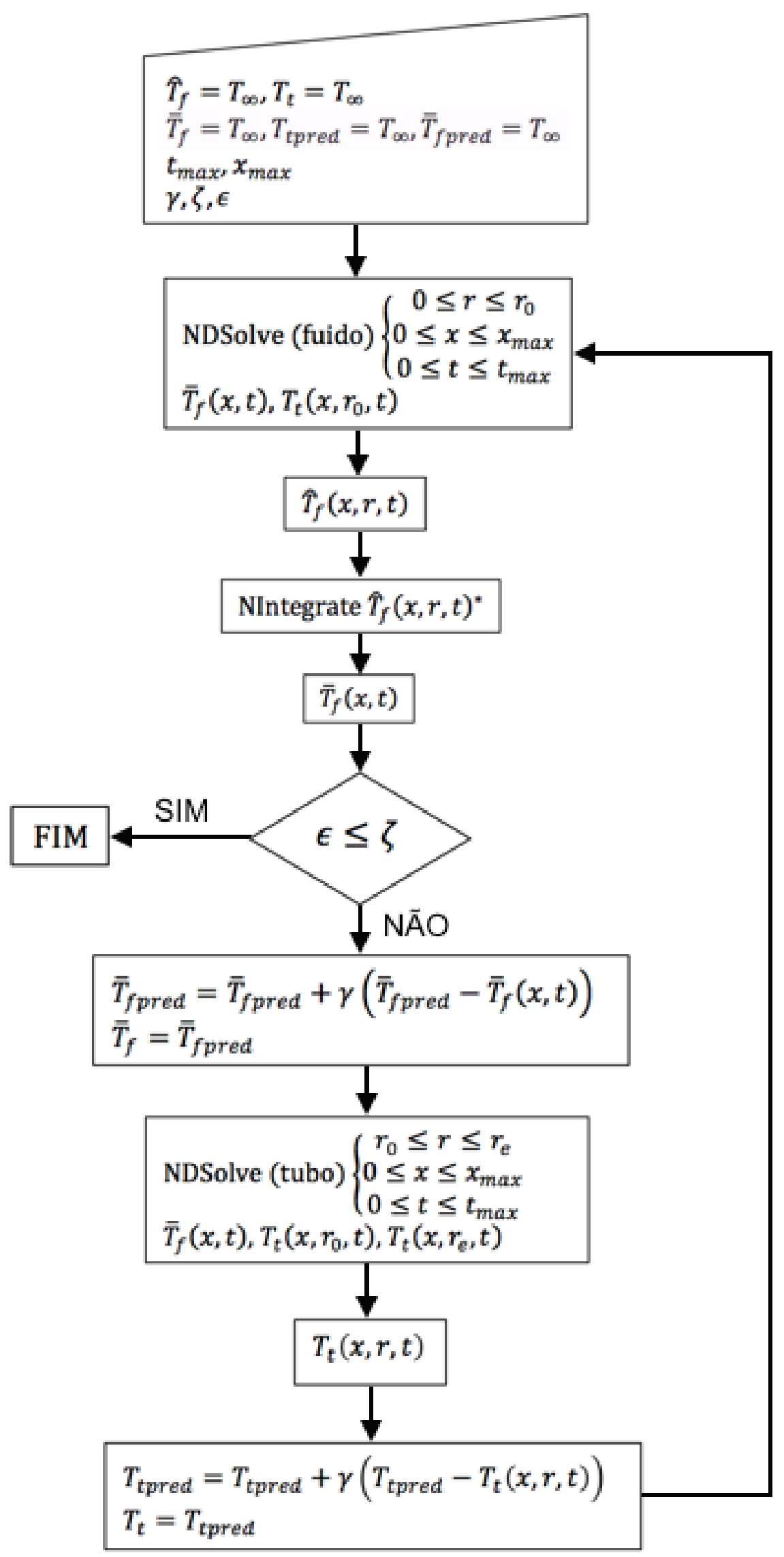

Figura 3.1: Fluxograma do programa.

* NIntregrate é o comando para se calcular integrais numericamente. A temperatura média é calculada com a Eq. (2.14). 
licas" (escritas como função de funções matemáticas conhecidas), além de, devido ao tamanho do domínio estudado, trabalhar-se com um número de nós da ordem de $2 \times 10^{7}$. O segundo comentário se refere ao fato de que, devido a difusão numérica, para ordens de diferenciação maiores que um a solução é altamente instável, razão pela qual se optou pela diferenciação de ordem um, o que se traduz em menor precisão quando comparado a ordens superiores, sem prejuízo, no entanto, para os objetivos dessa dissertação. A Sec. 3.2 traz informações complementares a respeito da difusão numérica.

\subsection{Caso de estudo}

Definido o modelo matemático no Cap. 2 e a metodologia para resolver a equação da conservação de momento e da energia, assim como a ferramenta empregada para esta finalidade, o transiente térmico foi estudado em uma região entre 50 e 200 metros após a origem do escoamento $(x=0)$. O tubo, conforme a Fig. 3.2, encontra-se ancorado nos pontos "A" e "B" e o elemento flexível permite a sua dilatação livremente.

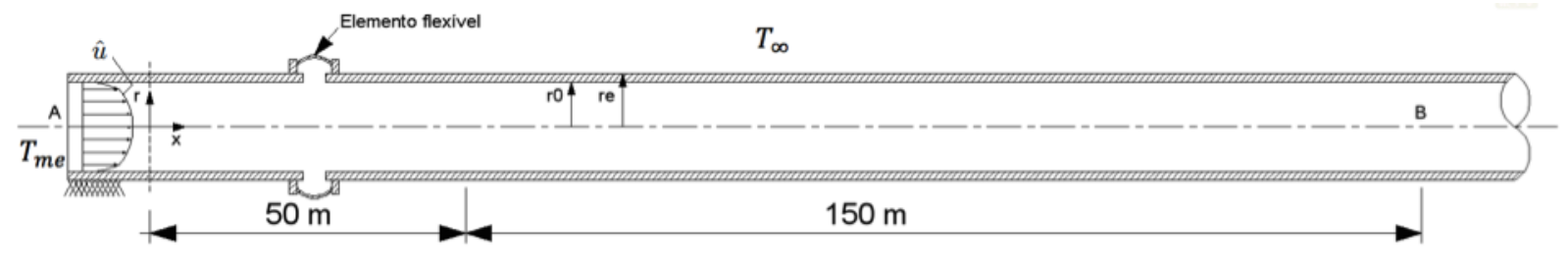

Figura 3.2: Representação do modelo do caso de estudo.

A Eq. (2.21) passa, então, a ser definida como:

$$
\delta(x, t)=\int_{x_{\max }}^{x} \varphi\left[\bar{T}_{t}(\xi, 0)-\bar{T}_{t}(\xi, t)\right] d \xi \quad(50 \leq x \leq 200 m)
$$

sendo, conforme Fig. 3.2, $x_{\max }=200 \mathrm{~m}$.

O modelo visa simular, por exemplo, uma instalação composta por um tanque onde o fluido se encontra à temperatura uniforme e superior a temperatura atmosférica. Tal fluido é bombeado e, 50 metros após o bocal do tanque, a tubulação passa a percorrer um pipe rack. Após 150 metros neste pipe rack, a tubulação está travada ou ancorada. O pipe rack é simétrico e possui 300 metros de comprimento, sendo que as vigas de apoio estão espaçadas em 5 metros.

A velocidade do escoamento foi variada de 2 a $5 \mathrm{~m} / \mathrm{s}$. Foram considerados a água como fluido e o aço e o cobre como material de tubulação. A temperatura média de entrada do fluido $T_{m e}$ é $373 K\left(100^{\circ} C\right)$ e a temperatura infinita $T_{\infty}$ é $298 K\left(25^{\circ} C\right)$. Os tubos são, conforme definido pela norma ASME B36.10 (1996), Standard com diâmetros de 4, 6, 8 e 10 polegadas. 
A temperatura de entrada de $373 K$ é a temperatura de saturação da água à pressão ambiente, sendo, entretanto, apenas um valor numérico para o estudo. O comprimento de $150 \mathrm{~m}$ desde a ancoragem "B" até a posição $x=50 \mathrm{~m}$ se deve ao fato de que à $373 \mathrm{~K}$ o aço, por exemplo, terá dilatação total de aproximadamente $130 \mathrm{~mm}$, o limite aceitável para, em feixes de tubulação, evitar-se que uma tubulação se choque contra a tubulação adjacente em mudanças de direção horizontais sem que seja necessário o uso de liras ${ }^{2}$ (ver Sec. 1.3 para definição). No caso do cobre, que possui coeficiente de dilatação consideravelmente maior do que o do aço, tal limite é extrapolado já que a dilatação dotal deste material, nas mesmas condições, será de aproximadamente $194 \mathrm{~mm}$. Desta feita, como a dilatação máxima é um critério de projeto importante, foi considerado um comprimento menor para o tubo de cobre $(98 \mathrm{~m})$.

As velocidade de 2 a $5 \mathrm{~m} / \mathrm{s}$ estão na faixa recomendada pela literatura especializada em tubulações de processo enquanto que os diâmetros foram selecionados por serem frequentemente empregados em tubulações industriais.

\subsection{Discussões acerca do modelo matemático e da metodologia}

A pesquisa realizada por Kawamura (1976) demonstra que ao se estudar o transiente térmico, considerar o coeficiente de convecção interno $h_{i}$ constante e com as propriedades avaliadas na temperatura do regime permanente $T_{m s}$ resultará em considerável discrepância em relação aos dados experimentais apenas para pequenos números de Reynolds e na região de entrada.

Conforme as Fig. 3.3 e 3.4, obtidas com as Eq. (A.1) e (A.4) apresentadas no apêndice A, na escala de comprimento considerada no estudo, a temperatura do regime permanente $T_{m s}$ não varia consideravelmente em relação a temperatura média de entrada $T_{m e}$, o que justifica o fato de que todas as propriedades termofísicas do fluido em escoamento e do tubo foram avaliadas à $T_{m e}$.

Uma outra conclusão importante obtida da análise das Fig. 3.3 e 3.4 é que as curvas, calculadas com as Eq. (A.1) e (A.4) estão sobrepostas, o que confirma que a dissipação viscosa pode ser desprezada nesse estudo.

Um dos perfis de velocidade tipicamente obtido com o modelo matemático descrito no Cap. 2 e a metodologia descrita no Cap. 3 é apresentado na Fig. 3.5.

\footnotetext{
${ }^{2}$ Em tubulações com sapatas, o comprimento destas também limita a dilatação máxima. Sapatas com $300 \mathrm{~mm}$ de comprimento, as mais frequentemente usadas, também não poderão se deslocar mais do que $130 \mathrm{~mm}$.
} 


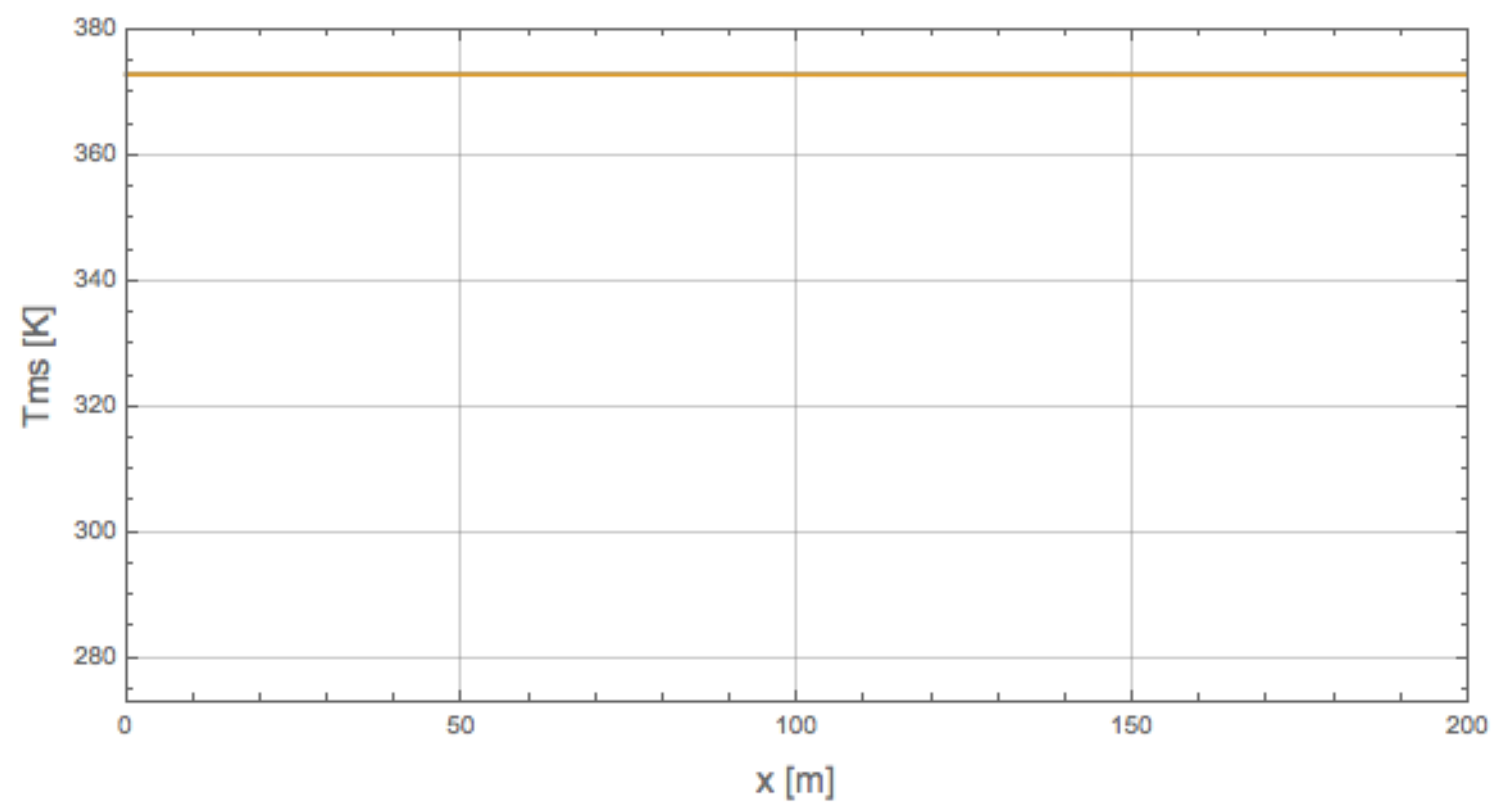

Equação A.4 - Equação A.1

Figura 3.3: Temperatura média do fluido no regime permanente. $D_{n}=10 ", U=5 \mathrm{~m} / \mathrm{s}$.

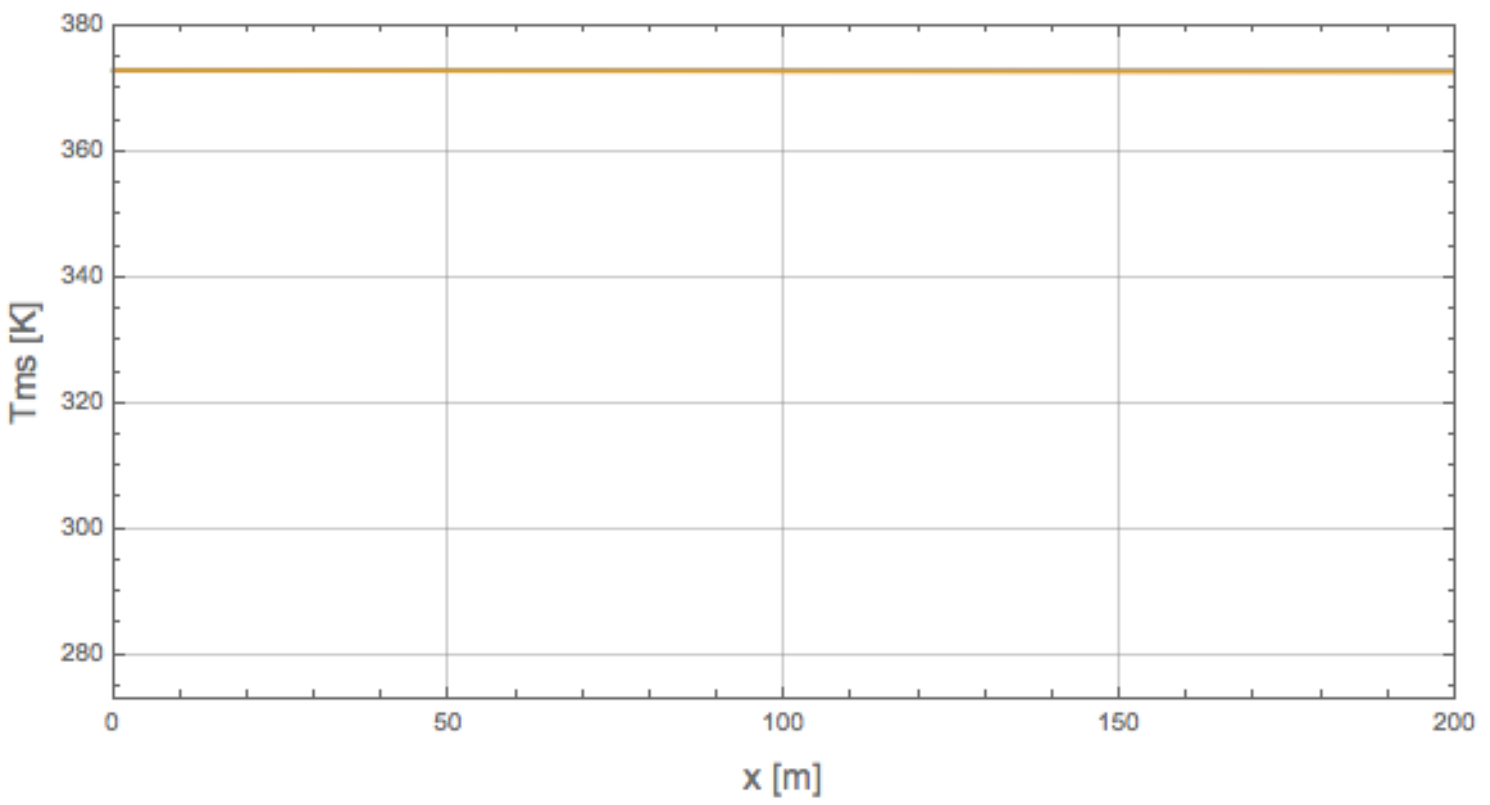

Equação A.4 - Equação A.1

Figura 3.4: Temperatura média do fluido no regime permanente. $D_{n}=4 ", U=5 \mathrm{~m} / \mathrm{s}$. 


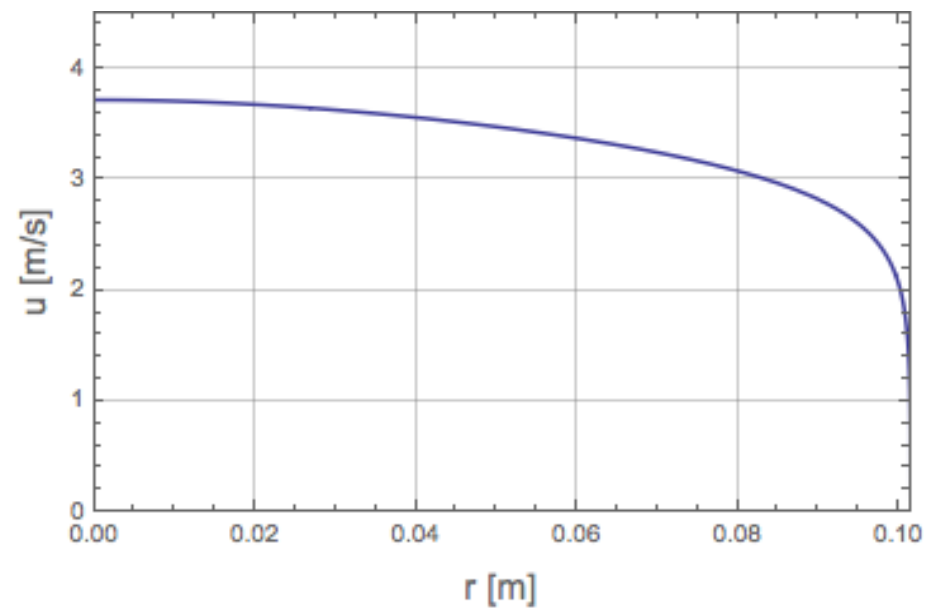

Figura 3.5: Perfil de velocidade obtido numericamente. $D_{n}=8$ ", $U=3 \mathrm{~m} / \mathrm{s}, R e=2,09 \times 10^{6}$.

A Fig. 3.6 mostra um gráfico de perfis de velocidade elaborado com dados experimentais atribuído a Nikuradse (SCHLICHTING et al., 2003) para vários números de Reynolds. Ao compará-lo com a Tab. 3.1, elaborada com dados da Fig. 3.5, verifica-se que há boa convergência entre os dados experimentais e os obtidos por método numérico, sendo a pequena divergência observada relacionada ao fato do tubo considerado nesse trabalho ser rugoso.

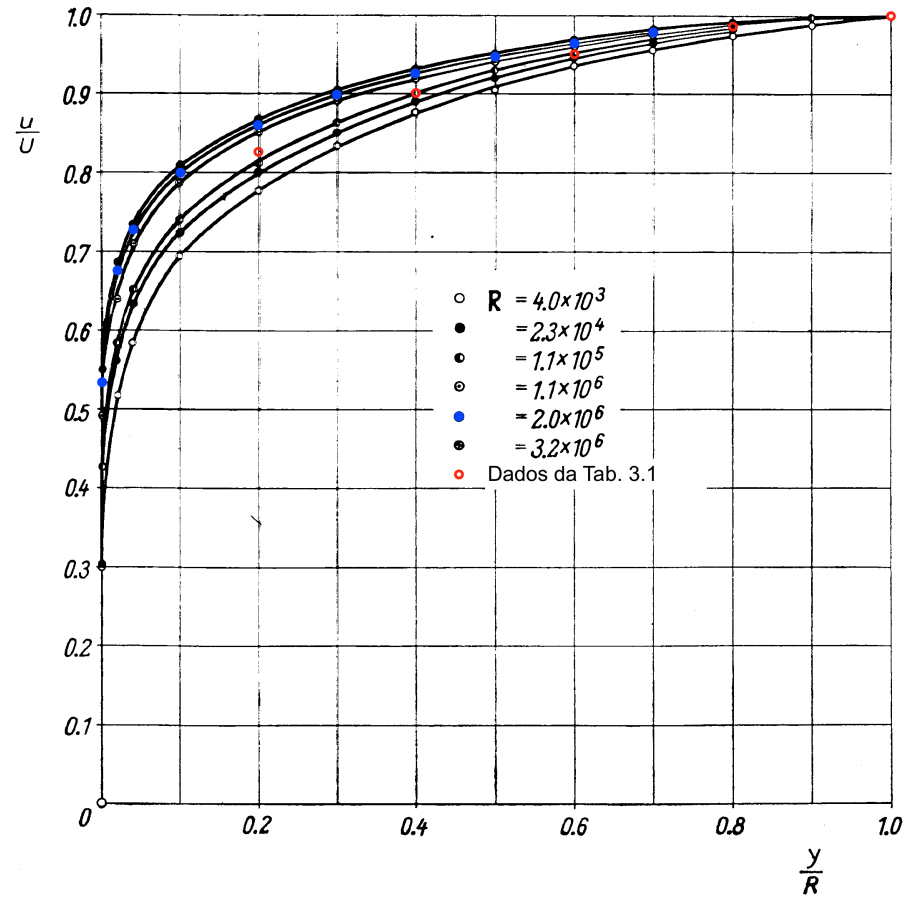

Figura 3.6: Perfis de velocidade obtidos experimentalmente em tubos não rugosos, atribuído a Nikuradse (SCHLICHTING et al., 2003).

Na Fig. 3.6, " $U$ " representa a velocidade máxima (em " $y "=0)$, " $u$ " a velocidade medida na posição " $y$ " e " $R$ " o raio do tubo. "R" é o número de Reynolds. 


\begin{tabular}{|l|l|}
\hline$y / R$ & $u / U$ \\
\hline 0,2 & 0,83 \\
\hline 0,4 & 0,90 \\
\hline 0,6 & 0,95 \\
\hline 0,8 & 0,988 \\
\hline 1,0 & 1,0 \\
\hline
\end{tabular}

Tabela 3.1: Dados obtidos da Fig. 3.5.

O apêndice C contém todos os perfis de velocidade que foram utilizados nesse trabalho. Conforme colocado no Cap. 2, o modelo usado nesse estudo considera uma tubulação através da qual escoa um fluido à temperatura ambiente quando, repentinamente, a temperatura do fluido na entrado do tubo é elevada. A Fig. 3.7 mostra o output do Mathematica ${ }^{\circledR}$ com a condição inicial sendo rigorosamente respeitada, onde a temperatura inicial é $298 K$, com exceção da temperatura em $x=0$, que é $373 K$. Já a Fig. 3.8 mostra a condição de contorno sendo respeitada, onde para $x=0$, independentemente do tempo, a temperatura é $373 \mathrm{~K}$.

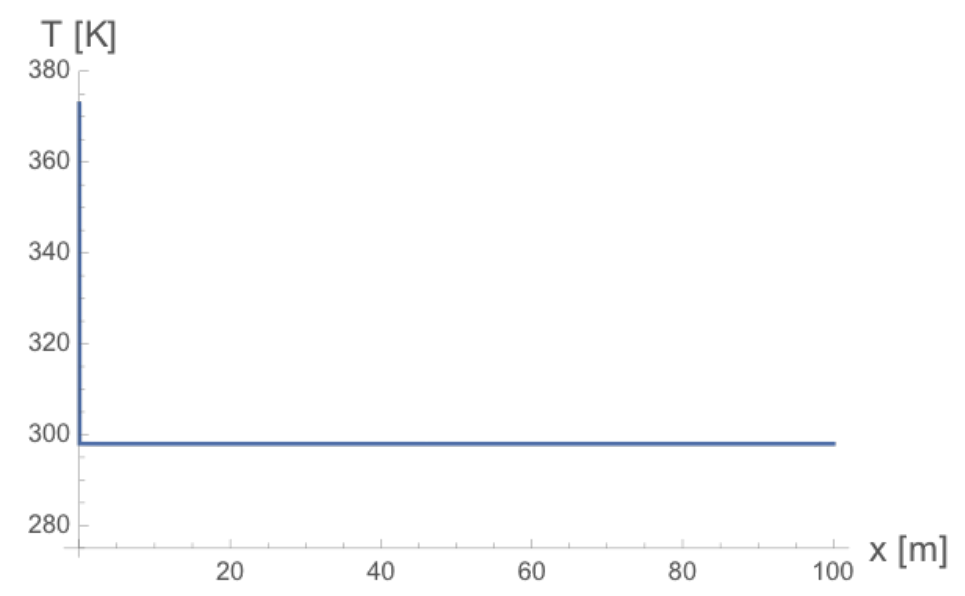

Figura 3.7: Condição inicial da temperatura do fluido.

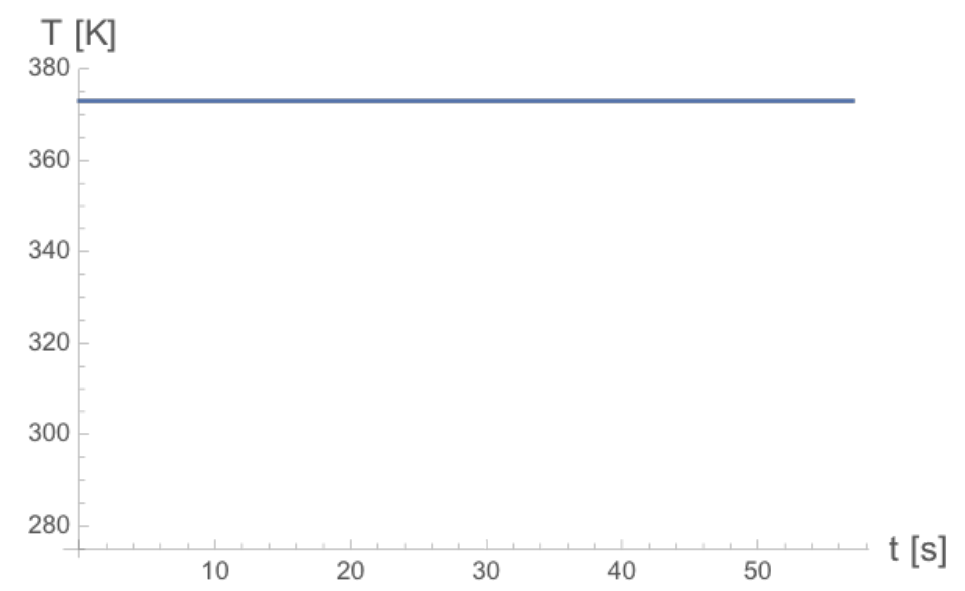

Figura 3.8: Condição de contorno do fluido em $x=0$. 
A Fig. 3.9 mostra a evolução temporal da temperatura média do fluido tipicamente obtida com a metodologia utilizada nesse trabalho. Tal solução está dentro do esperado verifica-se que a temperatura se mantém em $T_{\infty}$ até o momento em que o fluido aquecido atinge a posição estudada e que $T_{m s}$ é o limite assintótico da curva.

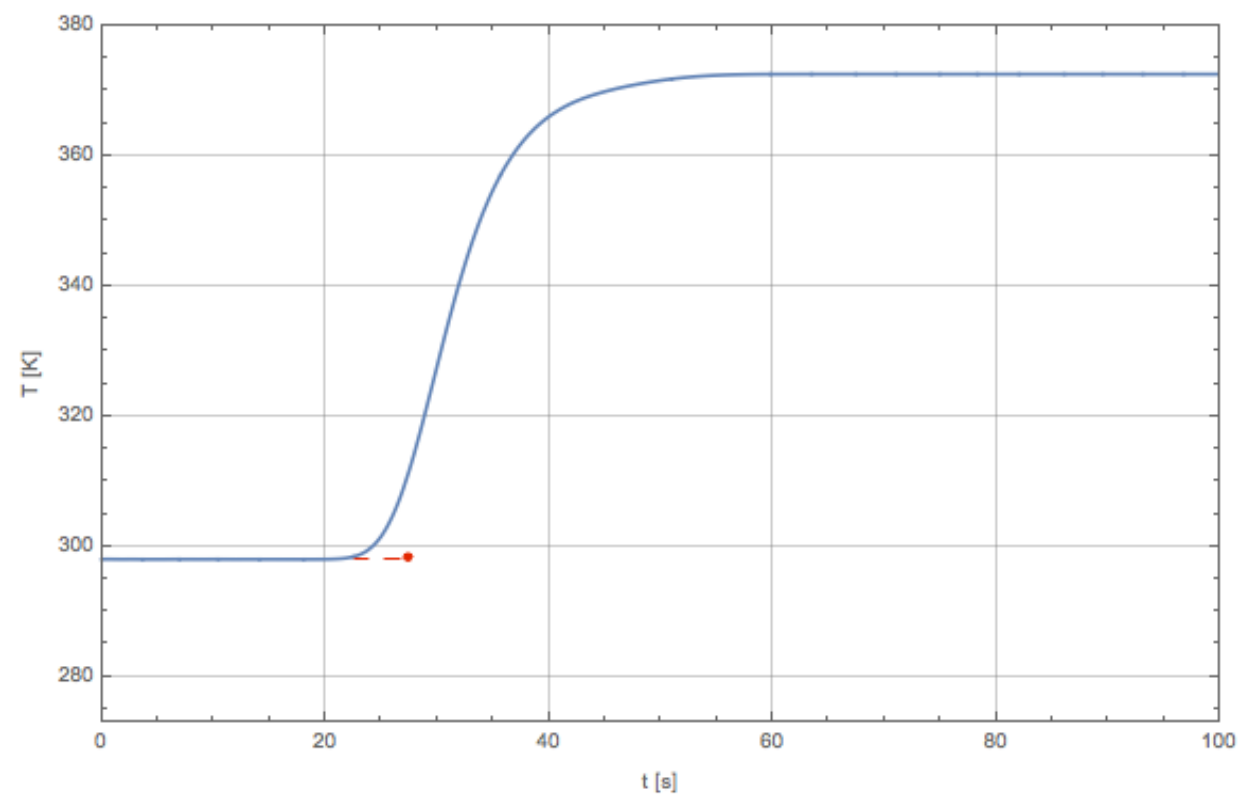

Figura 3.9: Evolução temporal da temperatura média do fluido obtida com a metodologia empregada.

A Fig. 3.9 foi obtida considerando tubo com $D_{n}=10$ ", $U=5 \mathrm{~m} / \mathrm{s}$ e $x=100 \mathrm{~m}$. Conforme a Fig. C.13, a velocidade $\hat{u}$ no centro do tubo é de $3,65 \mathrm{~m} / \mathrm{s}$, o que indica que a frente térmica leva 27,4 segundos para atingir a posição $x=100 \mathrm{~m}$ (ponto vermelho indicado na Fig. 3.9), o que mostra que o perfil térmico, não fosse a difusão numérica, seria um pouco mais achatado.

A pequena divergência atribuída a difusão numérica, sempre presente nos métodos numéricos independentemente da ordem de diferenciação (FORTUNA, 2000), no entanto, não afeta significativamente os objetivos dessa dissertação. 


\section{Capítulo 4}

\section{Resultados}

\subsection{Análise da dilatação no transiente térmico}

Conforme demonstrado nas simulações ilustrativas realizadas com o programa Caesar II na Sec. 1.1, ainda que a ASME B31.3 e a literatura especializada em tubulação se omitem em relação às forças associadas ao transiente térmico, tais forças existem e em pontos onde a tubulação tem seu deslocamento axial restrito por travas ou ancoragens, estas podem ser de considerável magnitude. Mostrou-se ainda que as características desta restrição - se uma trava com ou sem folga - é um dos fatores que influenciam na magnitude das forças calculadas.

Comprovadas as forças associadas ao transiente térmico através das simulações apresentadas na Sec. 1.1, uma ressalva deve ser feita: o aquecimento abrupto considerado não é real, conforme será demonstrado.

Dos mecanismos de forças externas ao tubo classicamente considerados pela literatura especializada em tubulação, as reações normais e o atrito são os únicos presentes no modelo da Fig. 3.2 e, portanto, serão os únicos considerados nesta seção.

A Tab. 4.1 mostra as propriedades termofísicas pertinentes utilizadas nesse trabalho. Com exceção das propriedades do ar, que foram avaliadas com a média aritmética entre a temperatura média de entrada $T_{m e}(373 K)$ e a temperatura ambiente $T_{\infty}(298 K)$, as demais propriedade foram avaliadas à $T_{m e}$, conforme justificado na Sec. 3.2. A gravidade $g$ é $9,81 \mathrm{~m} / \mathrm{s}^{2}$.

Na Tab. 4.1, assim como na Tab. 4.2, os valores de número de Pandtl foram obtidos das tabelas de Incropera e De Witt (2003) por interpolação. Tais valores, entretanto, podem ser diretamente calculados. 


\begin{tabular}{|l|l|l|c|c|}
\hline \multirow{2}{*}{ Propriedades } & \multicolumn{2}{|c|}{ Fluido } & \multicolumn{2}{c|}{ Tubo } \\
\cline { 2 - 5 } & água & ar & aço & cobre \\
\hline$\nu\left(\mathrm{m}^{2} / \mathrm{s}\right)$ & $2,91 \times 10^{-7}$ & $1,97 \times 10^{-5}$ & - & - \\
\hline$\rho\left(\mathrm{kg} / \mathrm{m}^{3}\right)$ & $9,57 \times 10^{2}$ & - & $7,85 \times 10^{3}$ & $8,93 \times 10^{3}$ \\
\hline$P r$ & 1,76 & $7,02 \times 10^{-1}$ & - & - \\
\hline$k(\mathrm{~W} / \mathrm{mK})$ & $6,80 \times 10^{-1}$ & $2,89 \times 10^{-2}$ & $5,77 \times 10^{1}$ & $3,95 \times 10^{2}$ \\
\hline$c(\mathrm{~J} / \mathrm{kgK})$ & $4,21 \times 10^{3}$ & - & $4,72 \times 10^{2}$ & $3,93 \times 10^{2}$ \\
\hline$e(\mathrm{~mm})$ & - & - & $1,50 \times 10^{-1}$ & $1,50 \times 10^{-3}$ \\
\hline$\alpha\left(\mathrm{m}^{2} / \mathrm{s}\right)$ & $1,68 \times 10^{-7}$ & $3,37 \times 10^{-5}$ & $1,55 \times 10^{-5}$ & $1,12 \times 10^{-4}$ \\
\hline$\beta\left(\mathrm{K}^{-1}\right)$ & - & $2,98 \times 10^{-3}$ & - & - \\
\hline
\end{tabular}

Tabela 4.1: Propriedades termofísicas.

\subsubsection{Análise da dilatação no transiente térmico para tubo de aço $\operatorname{com} D_{n}=8 "$ e $U=3 \mathrm{~m} / \mathrm{s}$}

A simulação dessa seção é utilizada como referência para as demais simulações apresentadas nesse capítulo, possibilitando a avaliação dos principais parâmetros que regem o problema do transiente térmico em tubulações e da dilatação associada a este transiente térmico. Considerou-se a água como fluido, tubo de aço com $D_{n}=8$ " e $U=3 \mathrm{~m} / \mathrm{s}$. A temperatura de entrada $T_{m e}$ é $373 K$.

A Fig. 4.1 mostra o gráfico da temperatura média do fluido em função do tempo obtido com o modelo matemático apresentado no Cap. 2 e a metodologia do Cap. 3.

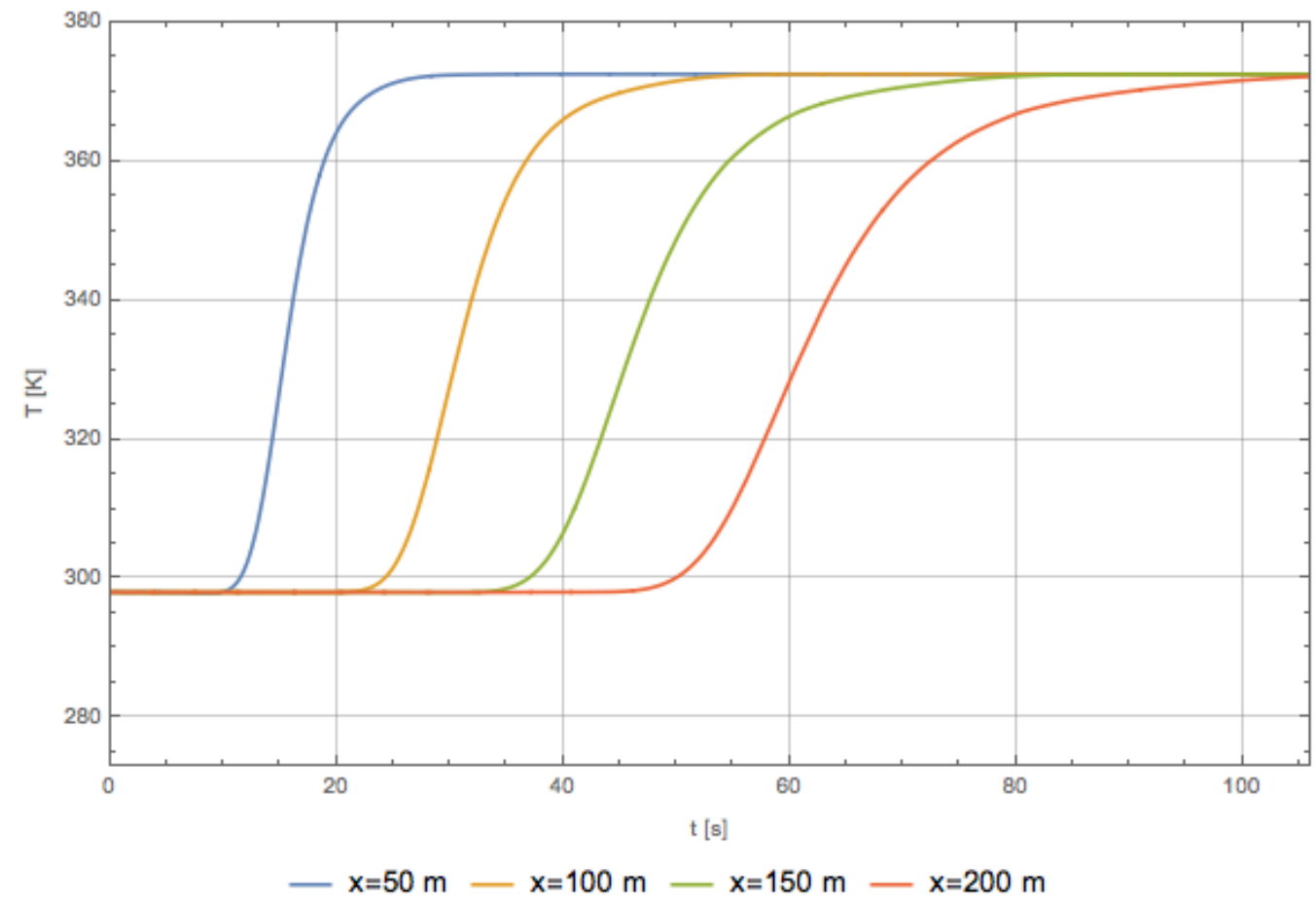

Figura 4.1: Evolução temporal da temperatura média do fluido. Tubo de aço, $D_{n}=8$ ", $U=$ $3 \mathrm{~m} / \mathrm{s}, \mathrm{Re}=2,09 \times 10^{6}, \mathrm{Nu}=6,65 \times 10^{3}, h_{i}=2,22 \times 10^{4} \mathrm{~W} / \mathrm{m}^{2} \mathrm{~K}, \mathrm{Gr}=4,12 \times 10^{1}$, $h_{e}=5,44 \mathrm{~W} / \mathrm{m}^{2} \mathrm{~K}$. 


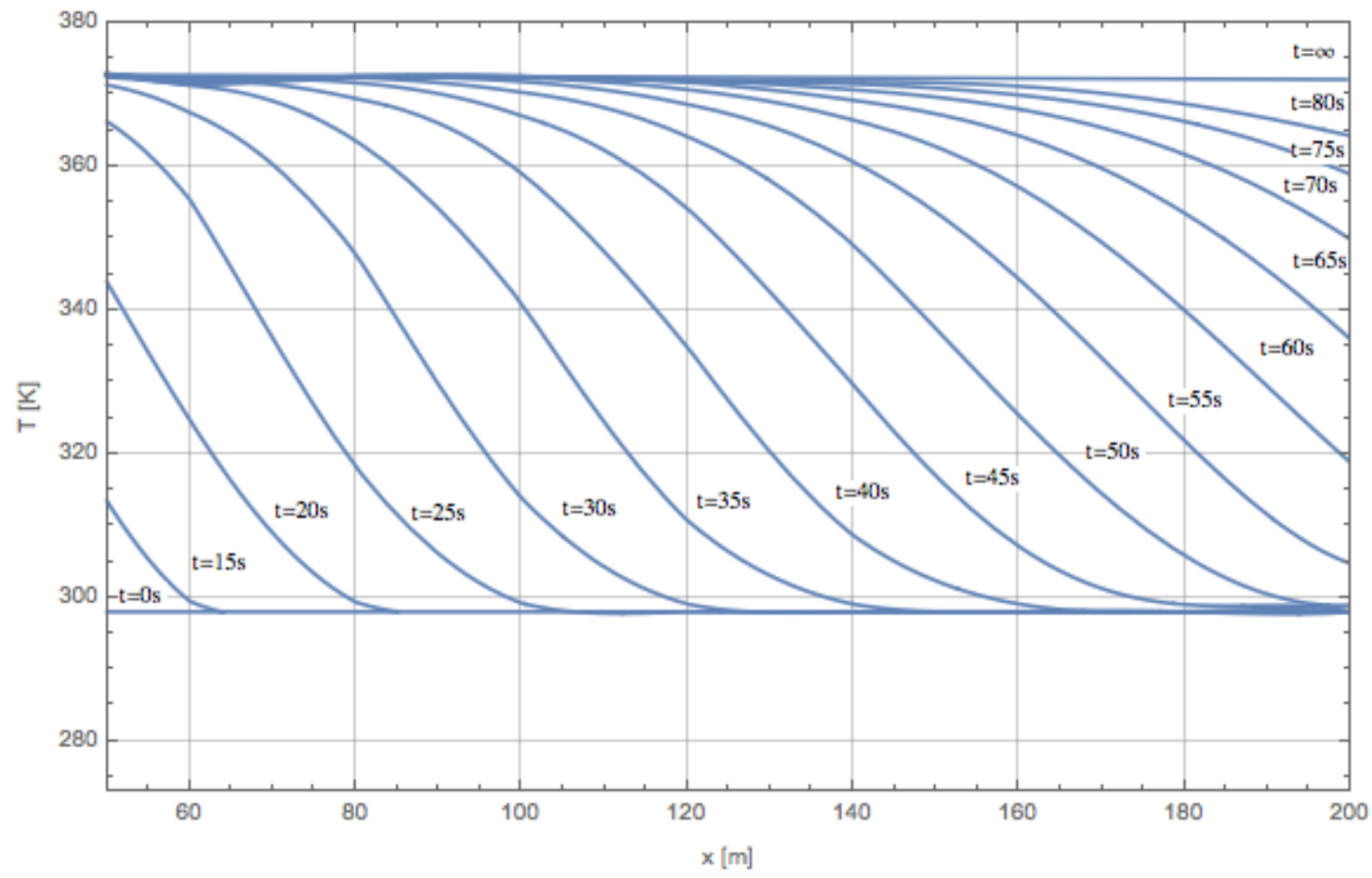

Figura 4.2: Perfil da temperatura média do tubo. Tubo de aço, $D_{n}=8$ ", $U=3 \mathrm{~m} / \mathrm{s}, R e=$ $2,09 \times 10^{6}, N u=6,65 \times 10^{3}, h_{i}=2,22 \times 10^{4} \mathrm{~W} / \mathrm{m}^{2} \mathrm{~K}, \mathrm{Gr}=4,12 \times 10^{1}, h_{e}=$ $5,44 \mathrm{~W} / \mathrm{m}^{2} \mathrm{~K}$.

A Fig. 4.2 mostra o aquecimento gradual e progressivo da tubulação, como resultado do avanço do fluido aquecido, além da resistência e da capacidade térmica da parede do tubo. Ao, por exemplo, fixar-se um eixo vertical na posição $x=100 \mathrm{~m}$, verificase que, nesta posição, o tubo leva aproximadamente 60 segundos para atingir o regime permanente, o que é confirmado pela Fig. 4.1.

O gráfico mais importante para os objetivos desse trabalho é o representado na Fig. 4.3 , onde, considerando o modelo físico proposto neste capítulo, tem-se a dilatação transiente entre a posição $x=50 \mathrm{~m}$ e $x=200 \mathrm{~m}$.

No gráfico do perfil da dilatação do tubo é mostrado como a tubulação dilatará a partir da posição $x=200 \mathrm{~m}$, onde a tubulação está fixada por uma ancoragem (ver Fig. 3.2). Verifica-se que em 20 segundos o comprimento compreendido entre $50 \leq x \leq$ $75 \mathrm{~m}$ dilatou. No tempo 40 segundos o comprimento compreendido entre $50 \leq x \leq$ $155 \mathrm{~m}$ dilatou, enquanto que no tempo aproximado de 48 segundos toda a tubulação a montante da ancoragem tende a se deslocar ao passo que o trecho a jusante continua à temperatura ambiente. Por volta do tempo 108 segundos o trecho entre $50 \leq x \leq 200 \mathrm{~m}$ atinge a dilatação máxima de aproximadamente $126 \mathrm{~mm}$ (ver Fig. 4.1). Uma observação importante obtida da Fig. 4.2 é que no tempo 48 segundos, quando toda tubulação a montante da ancoragem tende a se deslocar, o comprimento compreendido entre $50 \leq$ $x \leq 85 \mathrm{~m}$ já atingiu a sua dilatação máxima. Convém salientar que a referência para $t=0 s$ é $x=0 \mathrm{~m}$. 


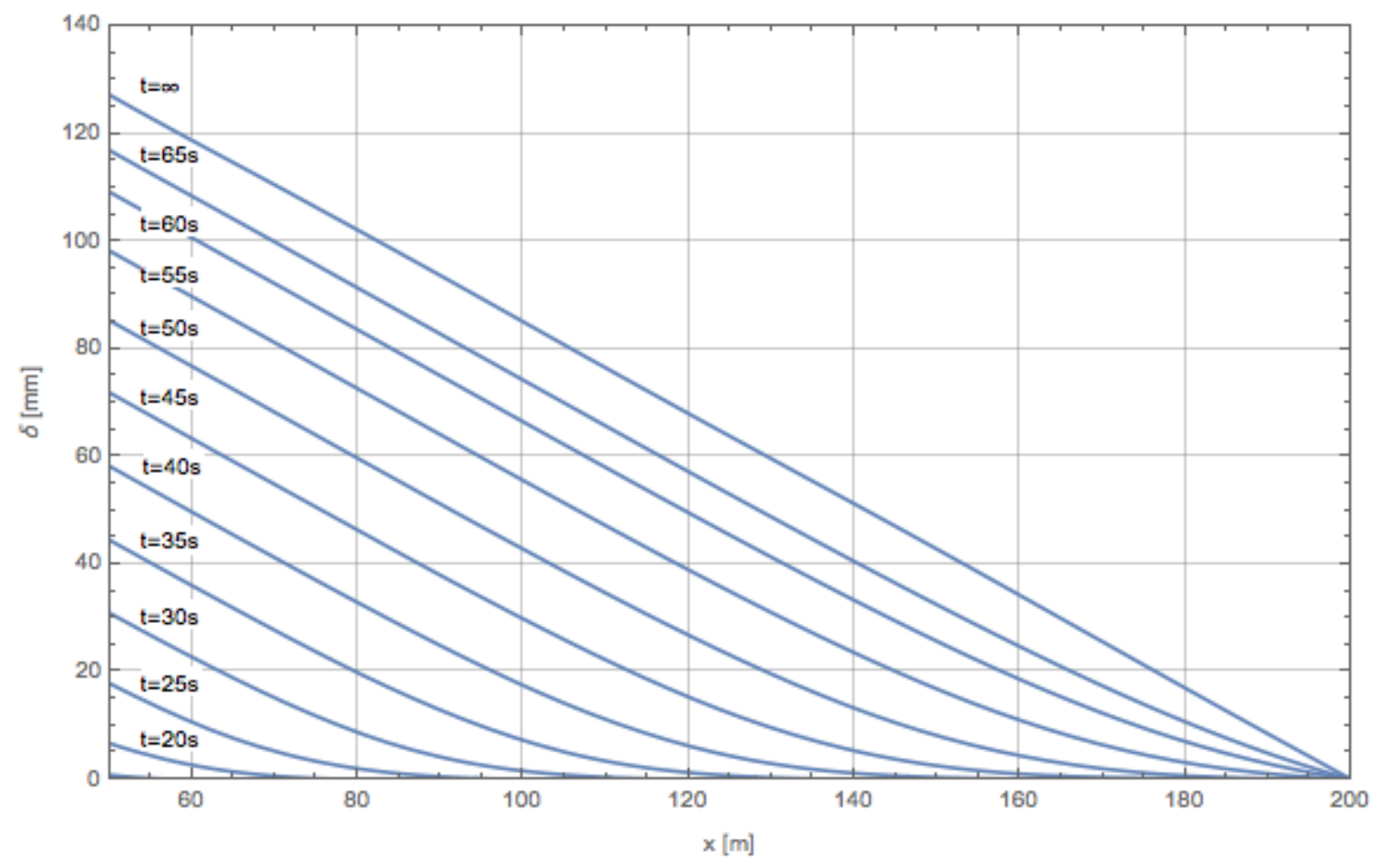

Figura 4.3: Perfil da dilatação linear do tubo. Tubo de aço, $D_{n}=8$ ", $U=3 \mathrm{~m} / \mathrm{s}, R e=2,09 \times$ $10^{6}, N u=6,65 \times 10^{3}, h_{i}=2,22 \times 10^{4} \mathrm{~W} / \mathrm{m}^{2} \mathrm{~K}, \mathrm{Gr}=4,12 \times 10^{1}, h_{e}=5,44 \mathrm{~W} / \mathrm{m}^{2} \mathrm{~K}$.

Derivando-se a equação 3.2 em relação ao tempo, é possível ainda obter o gráfico da taxa de dilatação do tubo em função do seu comprimento, conforme a Fig. 4.4.

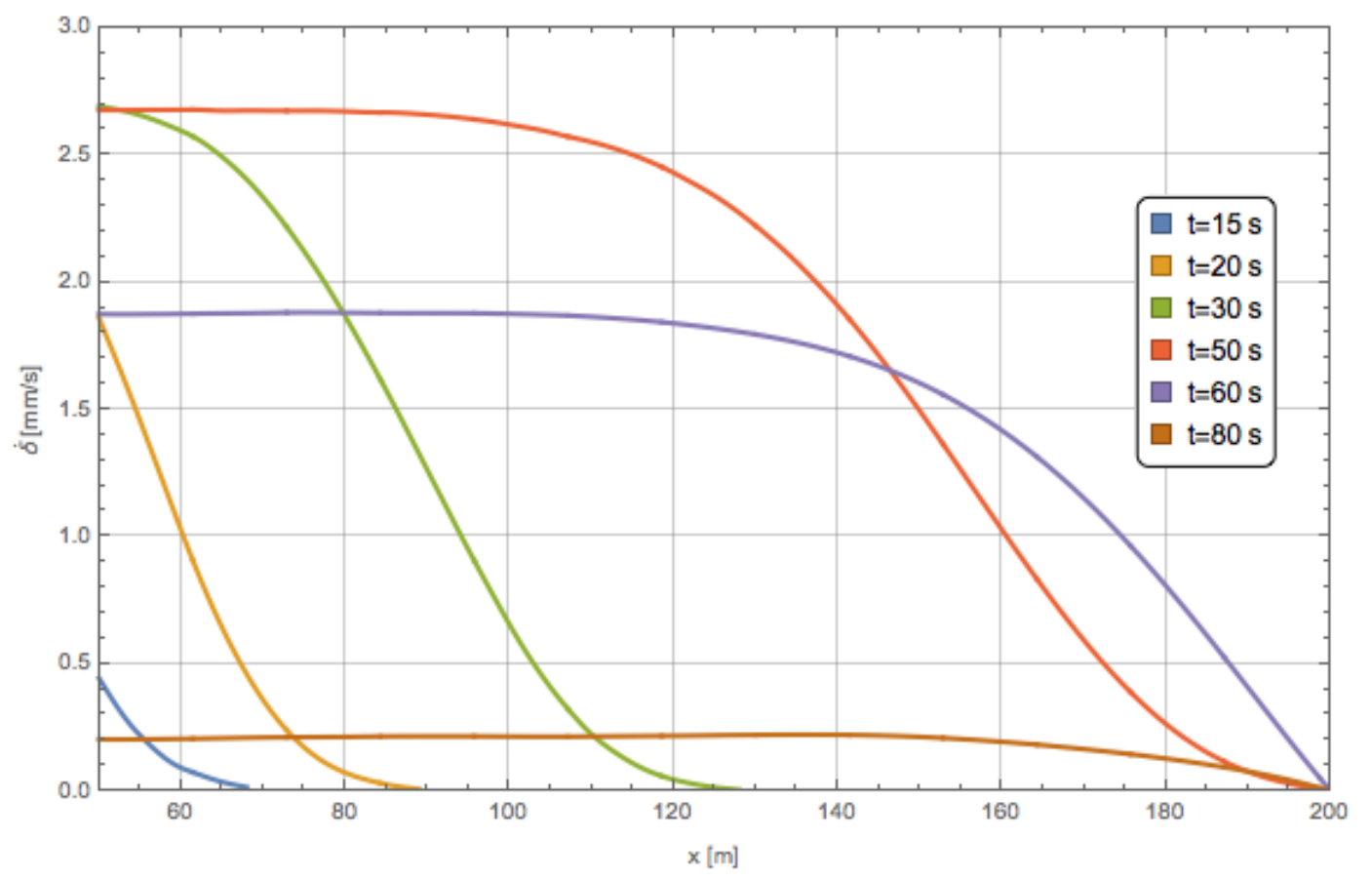

Figura 4.4: Perfil da taxa de dilatação do tubo. Tubo de aço, $D_{n}=8$ ", $U=3 \mathrm{~m} / \mathrm{s}, R e=2,09 \times$ $10^{6}, N u=6,65 \times 10^{3}, h_{i}=2,22 \times 10^{4} \mathrm{~W} / \mathrm{m}^{2} \mathrm{~K}, \mathrm{Gr}=4,12 \times 10^{1}, h_{e}=5,44 \mathrm{~W} / \mathrm{m}^{2} \mathrm{~K}$.

Na Fig. 4.4, verifica-se que a medida em que a frente térmica avança pelo tubo, a taxa 
de dilatação aumenta até o seu valor máximo, que ocorre em uma posição intermediária entre a posição $x=50$ e $x=200 \mathrm{~m}$ (ancoragem), e segue constante até a frente térmica atingir o ponto onde está localizada a ancoragem, quando então decai até o valor nulo, instante no qual toda a tubulação a montante da ancoragem atinge o regime permanente térmico. A taxa de dilatação máxima pode ser obtida diretamente do gráfico "perfil da dilatação do tubo".

\subsubsection{Efeito da velocidade média do escoamento interno $U$}

As Fig. 4.5, 4.6 e 4.7 foram obtidas considerando as mesmas propriedades e diâmetro de tubo utilizados na elaboração das Fig. 4.1, 4.2 e 4.3 mostradas na Sec. 4.1.1, com exceção de que a velocidade média $U$ passa a ser $5 \mathrm{~m} / \mathrm{s}$, ao invés de $3 \mathrm{~m} / \mathrm{s}$. Tal simulação ilustra o efeito da velocidade em relação ao transiente estudado.

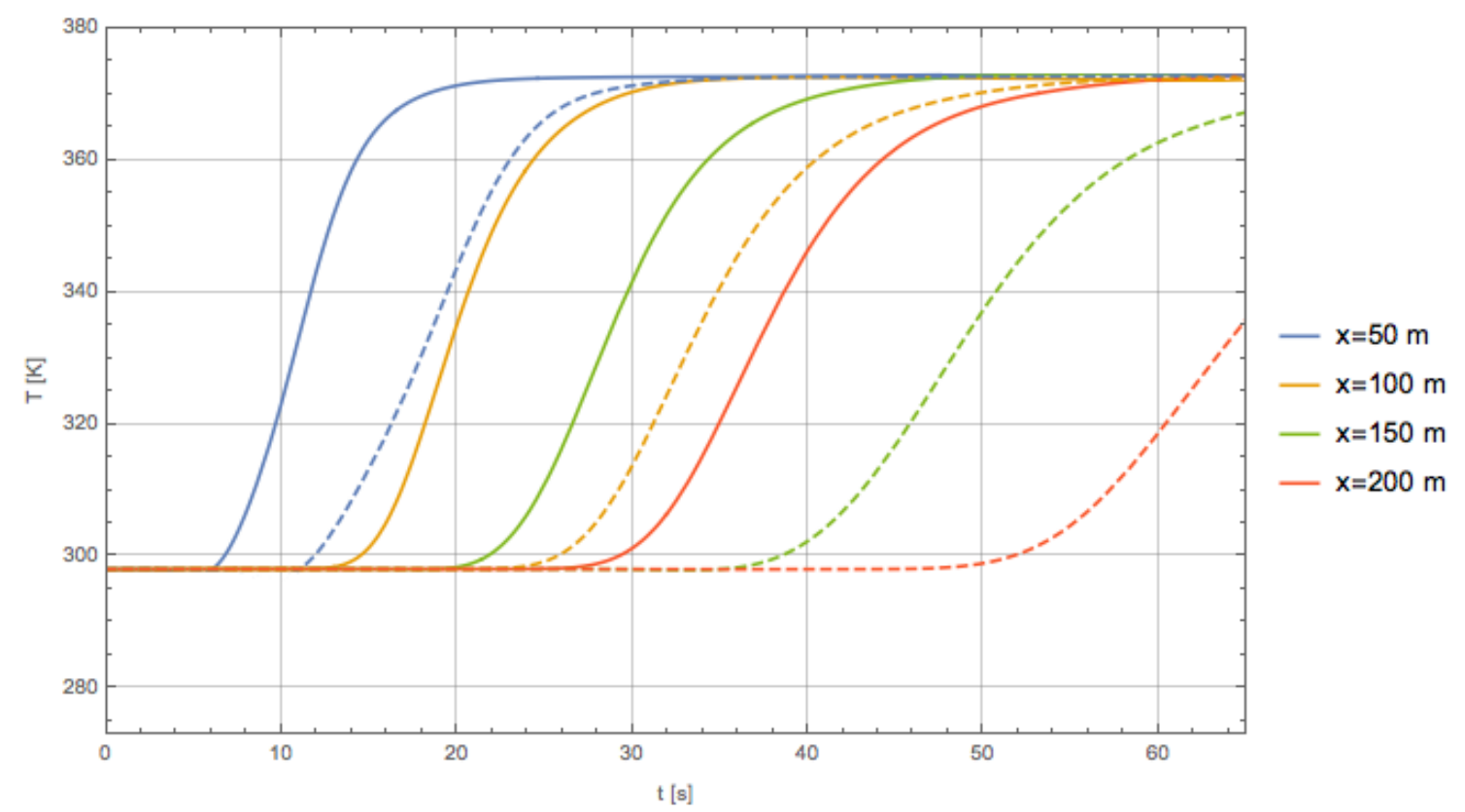

- Tubo de aço, Dn=8", $U=5 \mathrm{~m} / \mathrm{s}$ (Sec. 4.1.2)

Figura 4.5: Evolução temporal da temperatura média do tubo. Tubo de aço, $D_{n}=8$ ", $U=$ $5 \mathrm{~m} / \mathrm{s}, \mathrm{Re}=3,48 \times 10^{6}, \mathrm{Nu}=1,10 \times 10^{4}, h_{i}=3,70 \times 10^{4} \mathrm{~W} / \mathrm{m}^{2} \mathrm{~K}, \mathrm{Gr}=4,12 \times 10^{1}$, $h_{e}=5,44 \mathrm{~W} / \mathrm{m}^{2} \mathrm{~K}$. 


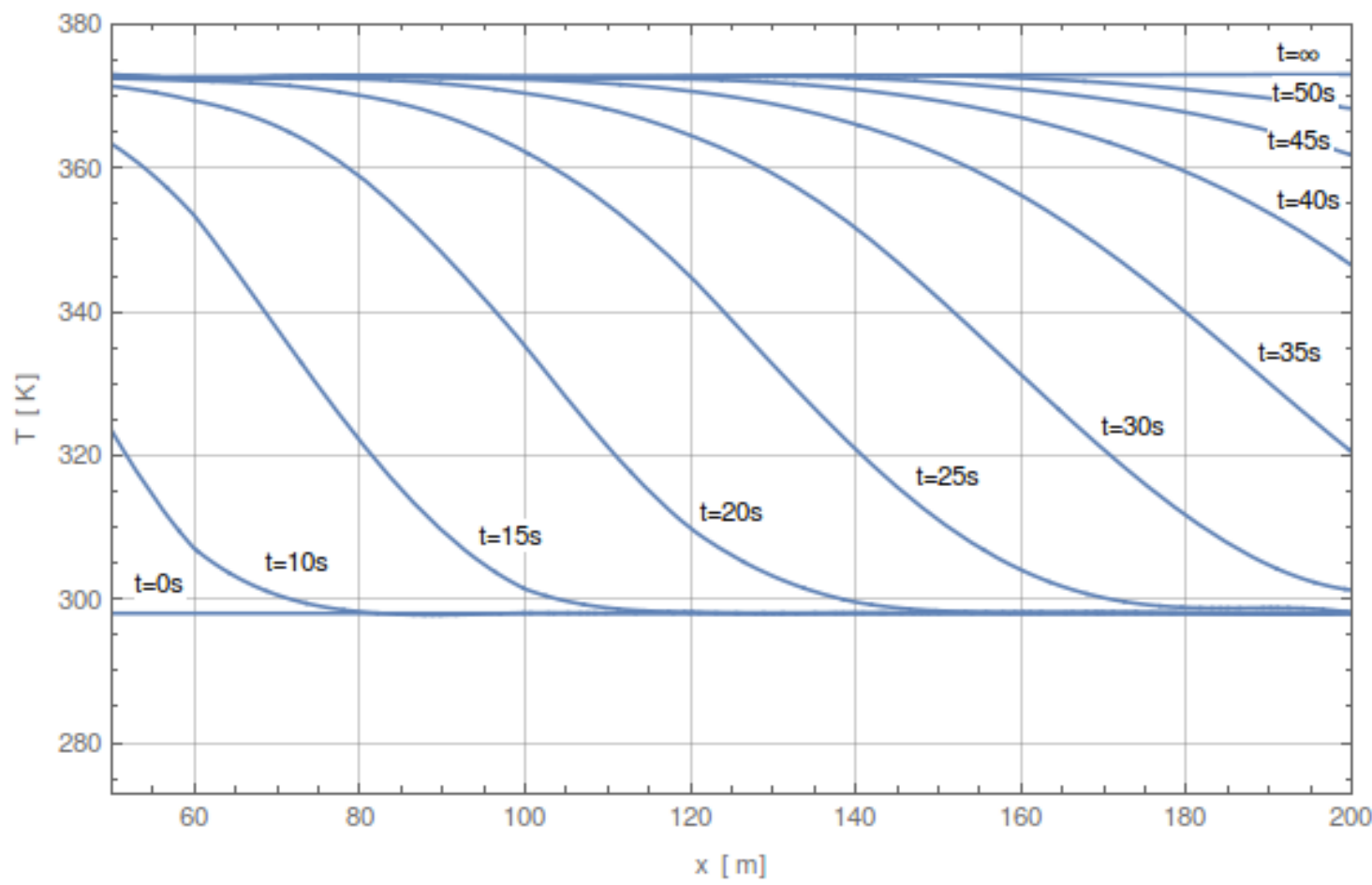

Figura 4.6: Perfil da temperatura média do tubo. Tubo de aço, $D_{n}=8$ ", $U=5 \mathrm{~m} / \mathrm{s}, R e=$ $3,48 \times 10^{6}, N u=1,10 \times 10^{4}, h_{i}=3,70 \times 10^{4} \mathrm{~W} / \mathrm{m}^{2} \mathrm{~K}, \mathrm{Gr}=4,12 \times 10^{1}, h_{e}=$ $5,44 \mathrm{~W} / \mathrm{m}^{2} \mathrm{~K}$.

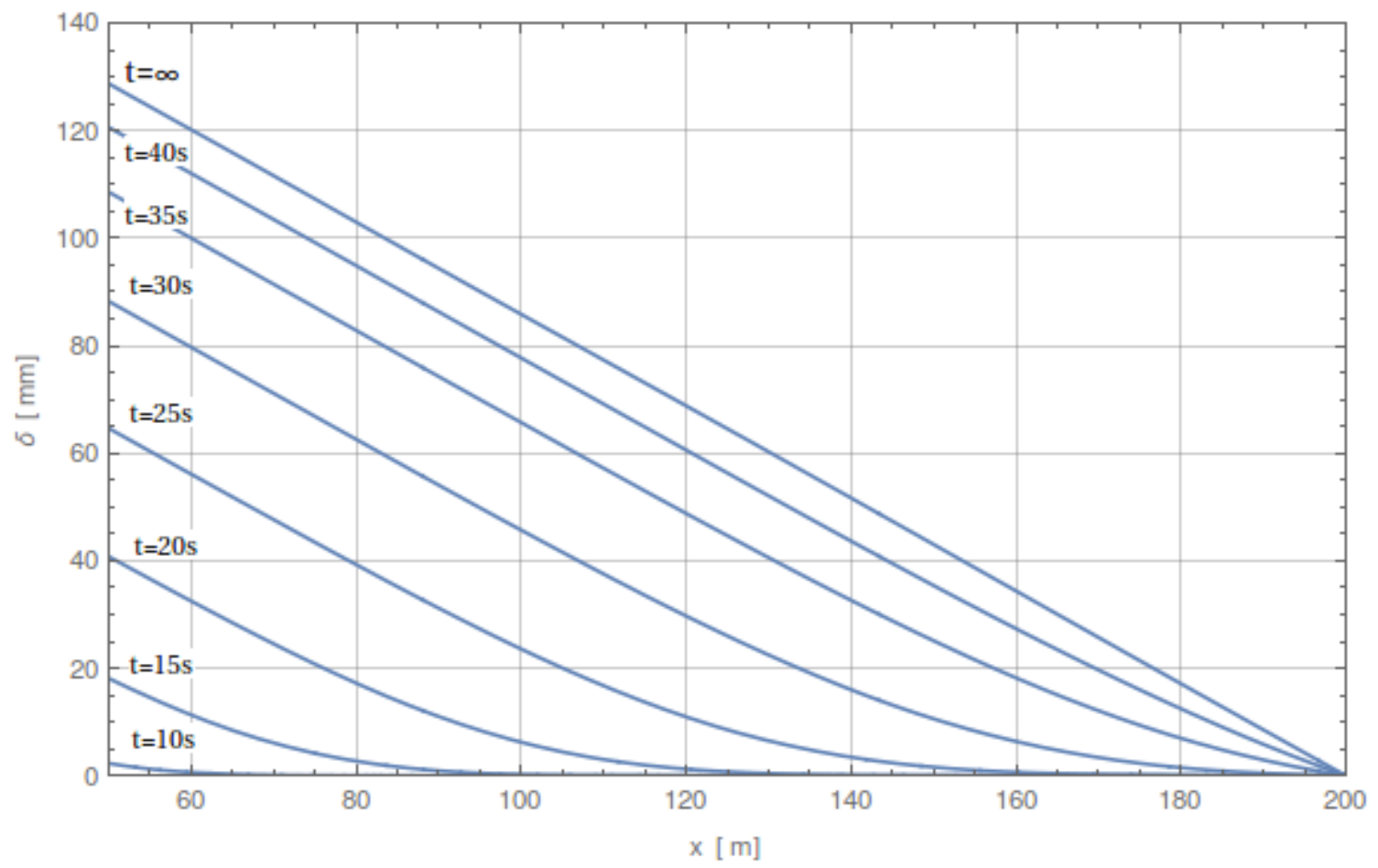

Figura 4.7: Perfil da dilatação linear do tubo. Tubo de aço, $D_{n}=8$ ", $U=5 \mathrm{~m} / \mathrm{s}, R e=3,48 \times$ $10^{6}, N u=1,10 \times 10^{4}, h_{i}=3,70 \times 10^{4} \mathrm{~W} / \mathrm{m}^{2} \mathrm{~K}, \mathrm{Gr}=4,12 \times 10^{1}, h_{e}=5,44 \mathrm{~W} / \mathrm{m}^{2} \mathrm{~K}$.

Ao aumentar-se a velocidade média do fluxo, o tempo para que a tubulação atinja a dilatação $\delta$ máxima é de aproximadamente 65 segundos. A aproximadamente 26 segundos, 
toda a tubulação a montante da trava tende a dilatar e, deste instante até a dilatação máxima, leva-se 39 segundos $(\sim 60 \mathrm{~s}$ com $U=3 \mathrm{~m} / \mathrm{s})$.

Tais resultados mostram que o aumento da velocidade média do fluxo provoca maiores taxas de aquecimento e, consequentemente, de dilatação, primeiramente devido ao menor tempo para se preencher a tubulação com fluido aquecido e, da mesma forma, devido ao aumento do número de Reynolds e o consequente aumento do número de Nusselt.

\subsubsection{Efeito do diâmetro do tubo $D_{n}$}

As Fig. 4.8, 4.9 e 4.10 mostram os resultados de simulação realizada com os mesmos parâmetros utilizados na simulação que originou as Fig. 4.1, 4.2 e 4.3 mostradas na Sec. 4.1.1, com exceção de que o diâmetro do tubo passa a ser 4", ao invés de 8". Tal simulação ilustra o efeito do diâmetro do tubo em relação ao transiente estudado.

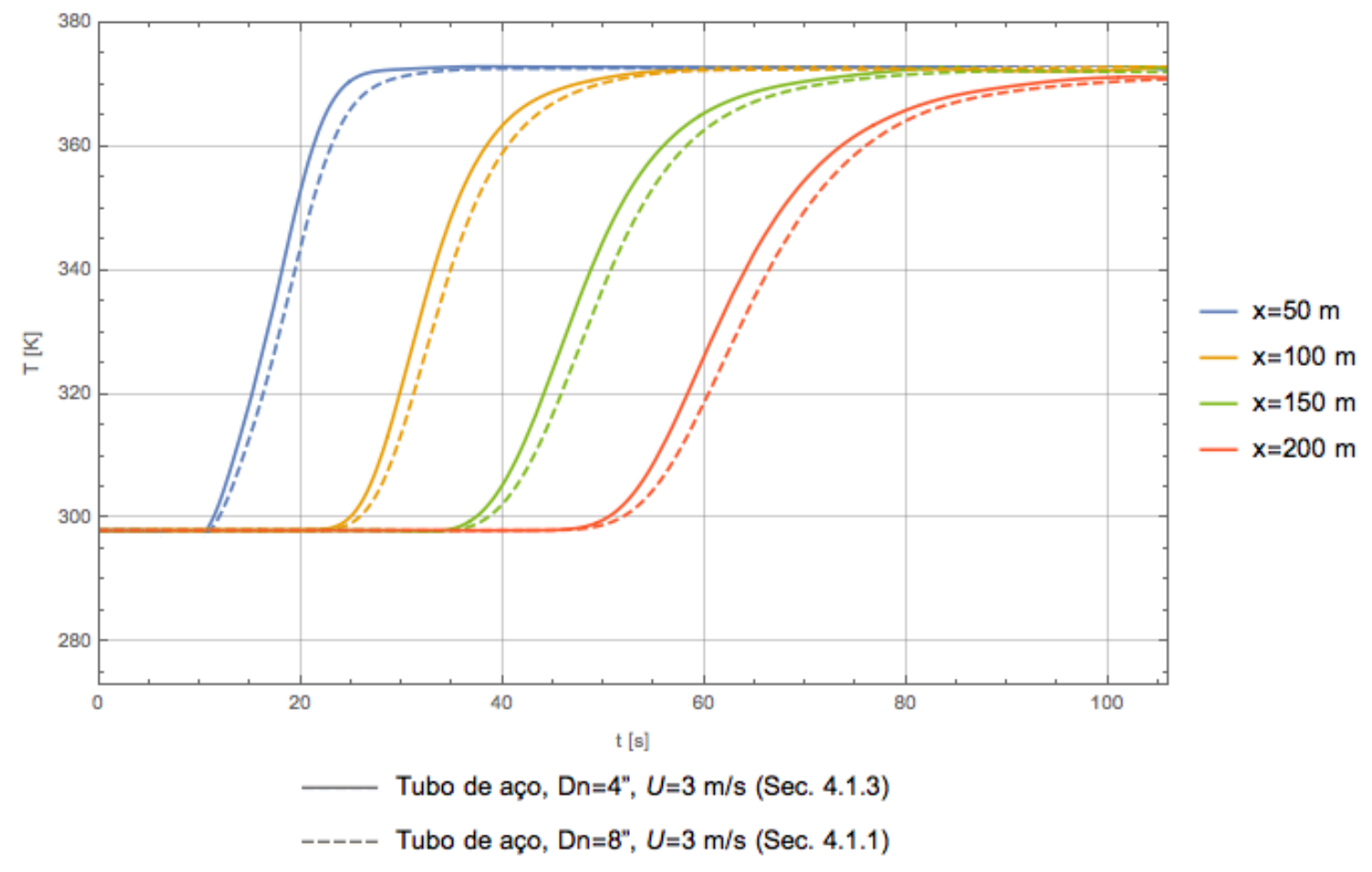

Figura 4.8: Evolução temporal da temperatura média do tubo, $D_{n}=4$ ", $U=3 \mathrm{~m} / \mathrm{s}, R e=1,05 \times$ $10^{6}, N u=3,88 \times 10^{3}, h_{i}=2,58 \times 10^{4} \mathrm{~W} / \mathrm{m}^{2} \mathrm{~K}, \mathrm{Gr}=2,31 \times 10^{1}, h_{e}=5,84 \mathrm{~W} / \mathrm{m}^{2} \mathrm{~K}$.

Ao comparar-se as Fig. 4.2 e 4.9, verifica-se que, em ambos os casos, a aproximadamente 48 segundos todo o tubo a montante da ancoragem tende a se deslocar, o que não surpreende já que em ambas as simulações a velocidade média $U$ é de $3 \mathrm{~m} / \mathrm{s}$.

No entanto, ainda que o tubo com $D_{n}=8$ " tenha maior espessura de parede - a temperatura média do tubo $\bar{T}_{t}$ é menor devido a maior resistência térmica, sobretudo nos tempos inicias devido a maior capacidade térmica - e o número de Grashof seja maior, - maiores $G r$ representam maior taxa de transferência de calor para a atmosfera e, consequentemente, menor taxa de aquecimento do tubo - quando comparado ao tubo 


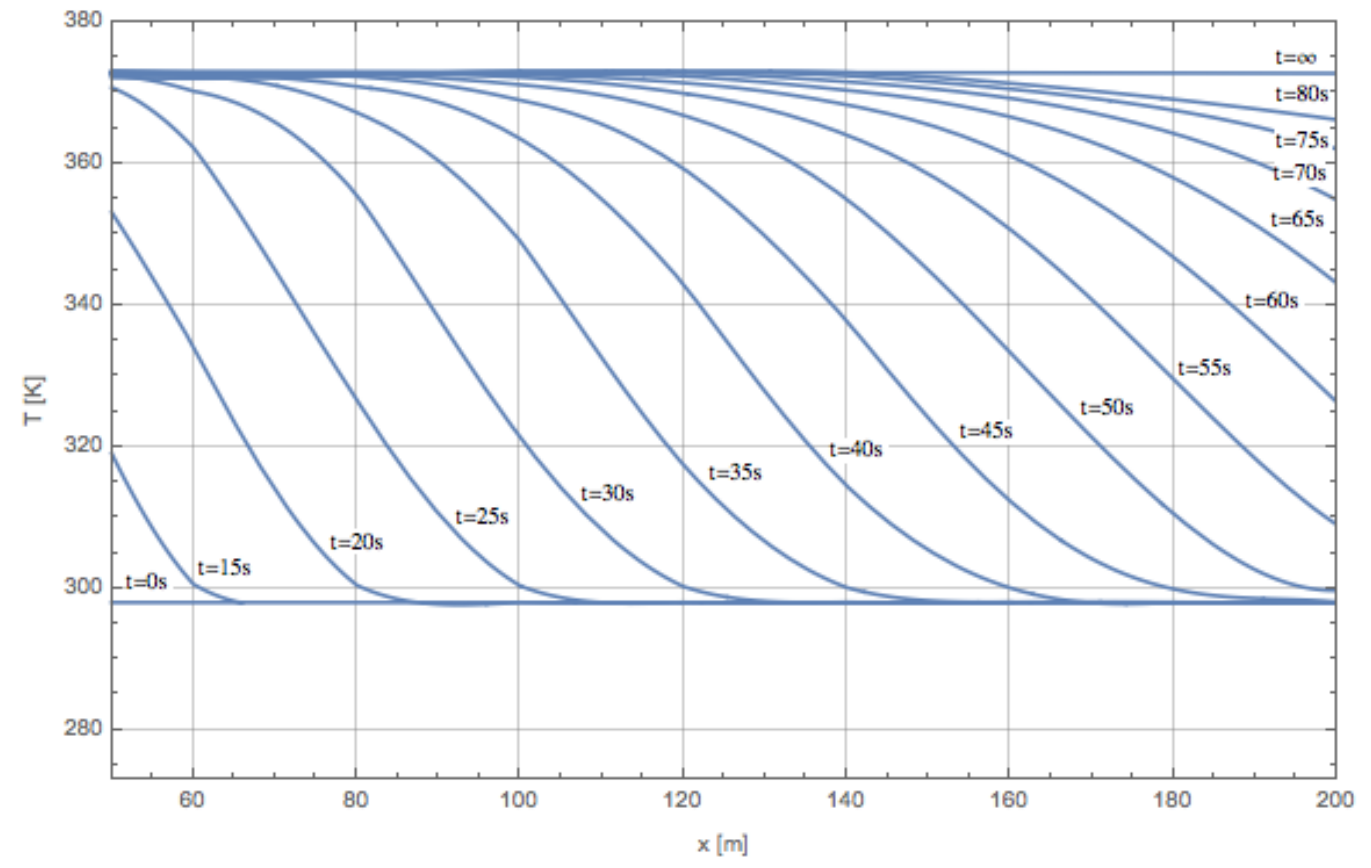

Figura 4.9: Perfil da temperatura média do tubo. Tubo de aço, $D_{n}=4$ ", $U=3 \mathrm{~m} / \mathrm{s}, R e=$ $1,05 \times 10^{6}, N u=3,88 \times 10^{3}, h_{i}=2,58 \times 10^{4} \mathrm{~W} / \mathrm{m}^{2} \mathrm{~K}, \mathrm{Gr}=2,31 \times 10^{1}, h_{e}=$ $5,84 \mathrm{~W} / \mathrm{m}^{2} \mathrm{~K}$.

com $D_{n}=4$ ", ainda que inicialmente a taxa de aquecimento do tubo com $D_{n}=4$ " seja maior (ver Fig. 4.8), a taxa média de aquecimento do tubo com $D_{n}=8$ " é ligeiramente maior como resultado do maior número de Reynolds e de Nusselt, o que é corroborado pelas conclusões de Lin e Kuo (1988) e Yan, Tsay e Lin (1989). As taxas de dilatação máximas são semelhantes (da ordem de $3 \mathrm{~mm} / \mathrm{s}$ ).

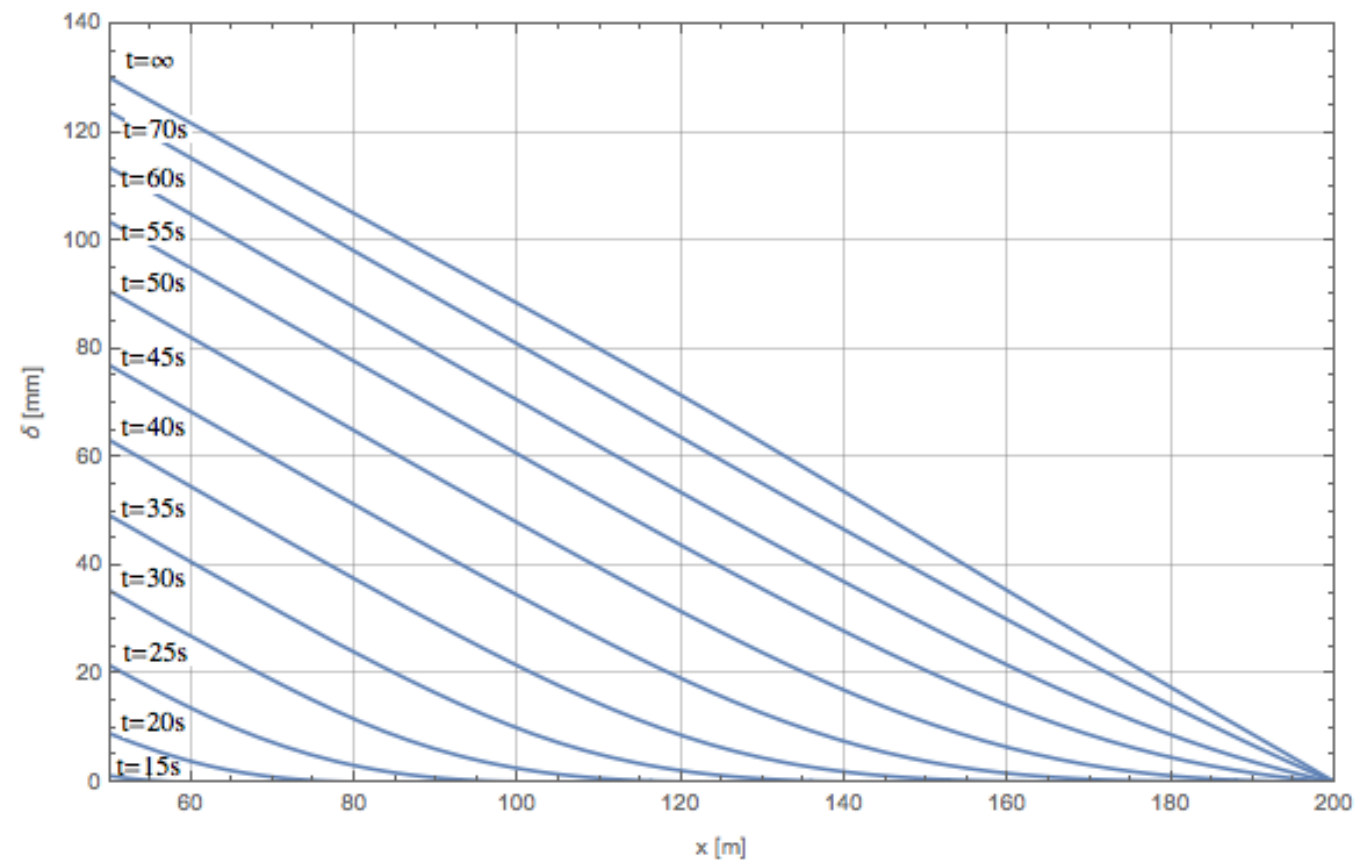

Figura 4.10: Perfil da dilatação linear do tubo. Tubo de aço, $D_{n}=4$ ", $U=3 \mathrm{~m} / \mathrm{s}, R e=1,05 \times$ $10^{6}, N u=3,88 \times 10^{3}, h_{i}=2,58 \times 10^{4} \mathrm{~W} / \mathrm{m}^{2} \mathrm{~K}, \mathrm{Gr}=2,31 \times 10^{1}, h_{e}=5,84 \mathrm{~W} / \mathrm{m}^{2} \mathrm{~K}$. 


\subsubsection{Efeito do material do tubo}

As Fig. 4.11, 4.12 e 4.13 mostram os resultados de simulação realizada com os mesmos parâmetros utilizados na simulação que originou as Fig. 4.1, 4.2 e 4.3 mostradas na Sec. 4.1.1, com exceção de que o material do tubo é o cobre e não mais o aço. Tal simulação visa verificar o efeito da difusividade térmica $\alpha$ e do coeficiente de dilatação $\varphi$ do material do tubo em relação às taxas de aquecimento e de dilatação.

A difusividade térmica é definida como:

$$
\alpha=\frac{k}{\rho c}
$$

Tal propriedade mede a capacidade do material de conduzir energia térmica em relação à sua capacidade de armazená-la. Quanto maior a difusividade térmica de um material, mais rapidamente este atingirá o equilíbrio térmico.

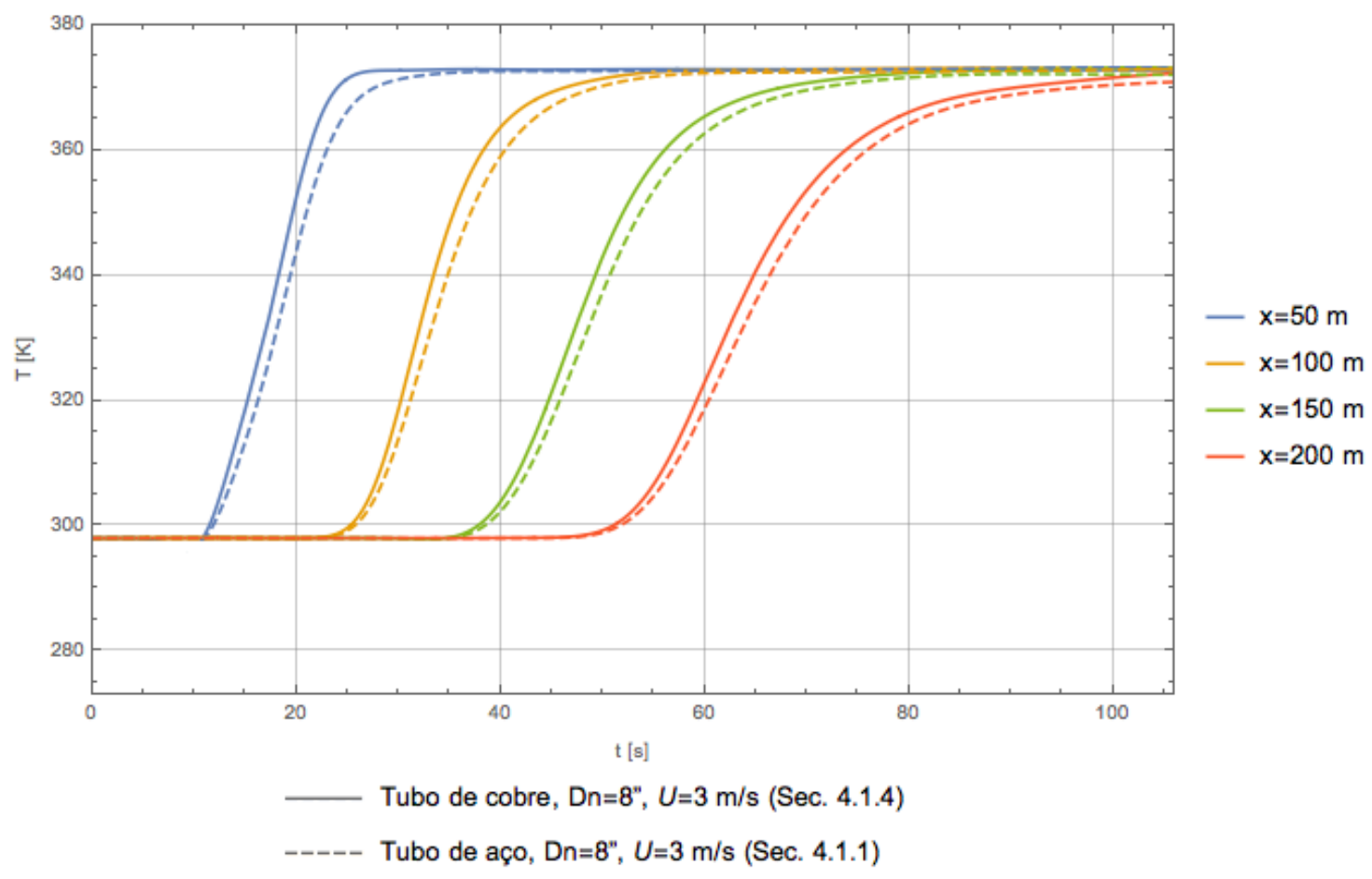

Figura 4.11: Evolução temporal da temperatura média do tubo. Tubo de cobre, $D_{n}=8$ ", $U=$ $3 \mathrm{~m} / \mathrm{s}, \mathrm{Re}=2,09 \times 10^{6}, \mathrm{Nu}=6,65 \times 10^{3}, h_{i}=2,22 \times 10^{4} \mathrm{~W} / \mathrm{m}^{2} \mathrm{~K}, \mathrm{Gr}=4,12 \times 10^{1}$, $h_{e}=5,44 \mathrm{~W} / \mathrm{m}^{2} \mathrm{~K}$.

Como os números de Grashof, assim como as velocidades médias $U$, são iguais e a difusividade térmica do cobre é maior do que a do aço (ver Tab. 4.1), a taxa de aquecimento do tubo de cobre é maior - nas Fig. 4.2 e 4.12, ao traçar-se uma linha vertical na posição $x=120 \mathrm{~m}$, por exemplo, verifica-se que no tempo 50 segundos a temperatura média do tubo de cobre $\bar{T}_{t}$ é $367^{\circ} \mathrm{C}$ enquanto que a temperatura do tubo de aço é $364^{\circ} \mathrm{C}$.

Em pipe racks, nas mudanças horizontais de direção, conforme discutido na Sec. 3.1, 


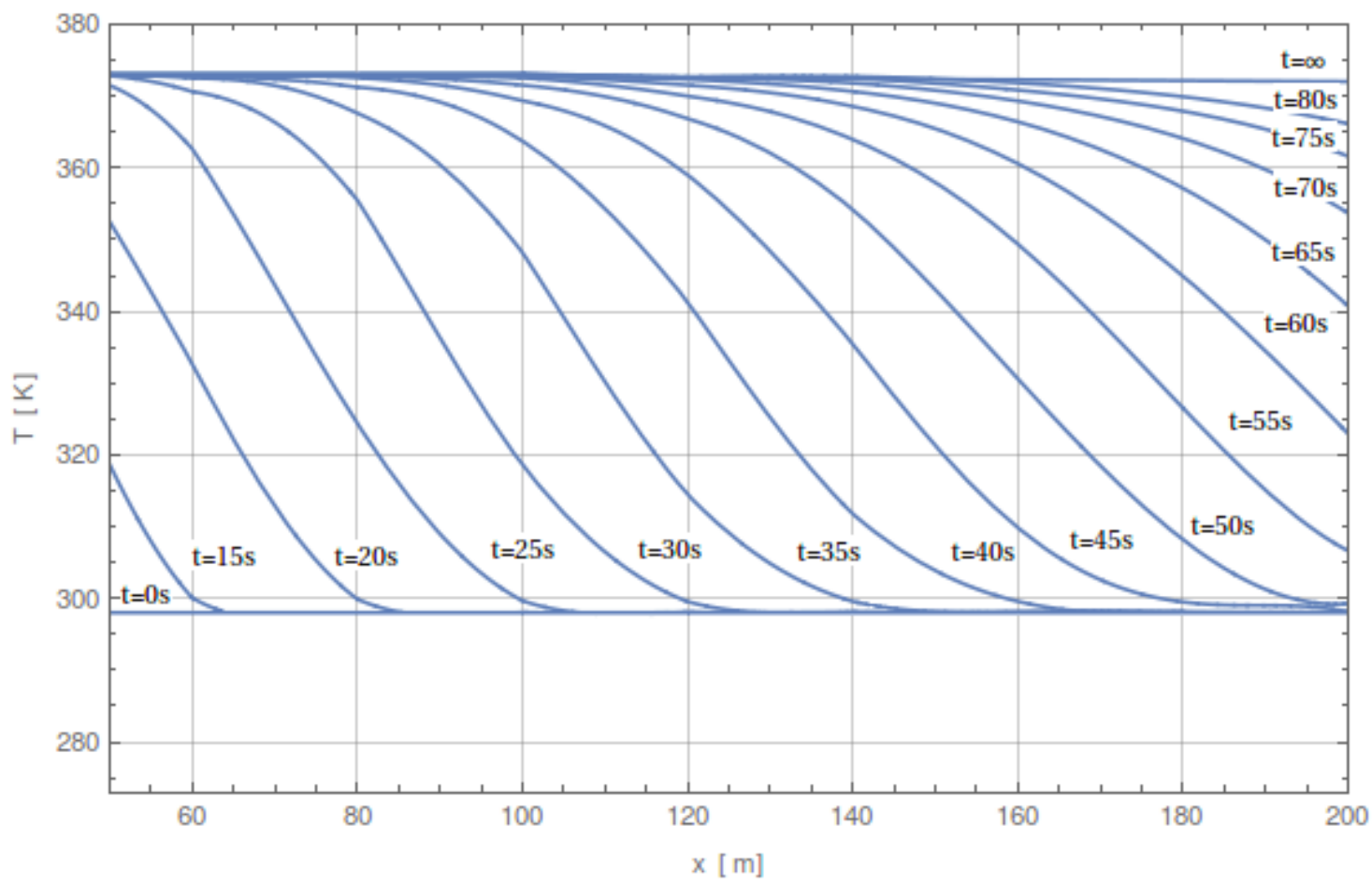

Figura 4.12: Perfil da temperatura média do tubo. Tubo de cobre, $D_{n}=8 ", U=3 \mathrm{~m} / \mathrm{s}$, $R e=2,09 \times 10^{6}, N u=6,65 \times 10^{3}, h_{i}=2,22 \times 10^{4} \mathrm{~W} / \mathrm{m}^{2} \mathrm{~K}, \mathrm{Gr}=4,12 \times 10^{1}$, $h_{e}=5,44 \mathrm{~W} / \mathrm{m}^{2} \mathrm{~K}$.

a dilatação máxima tolerável é de aproximadamente $130 \mathrm{~mm}$ e, conforme colocado, a dilatação total do tubo de cobre extrapola esse limite em $64 \mathrm{~mm}$.

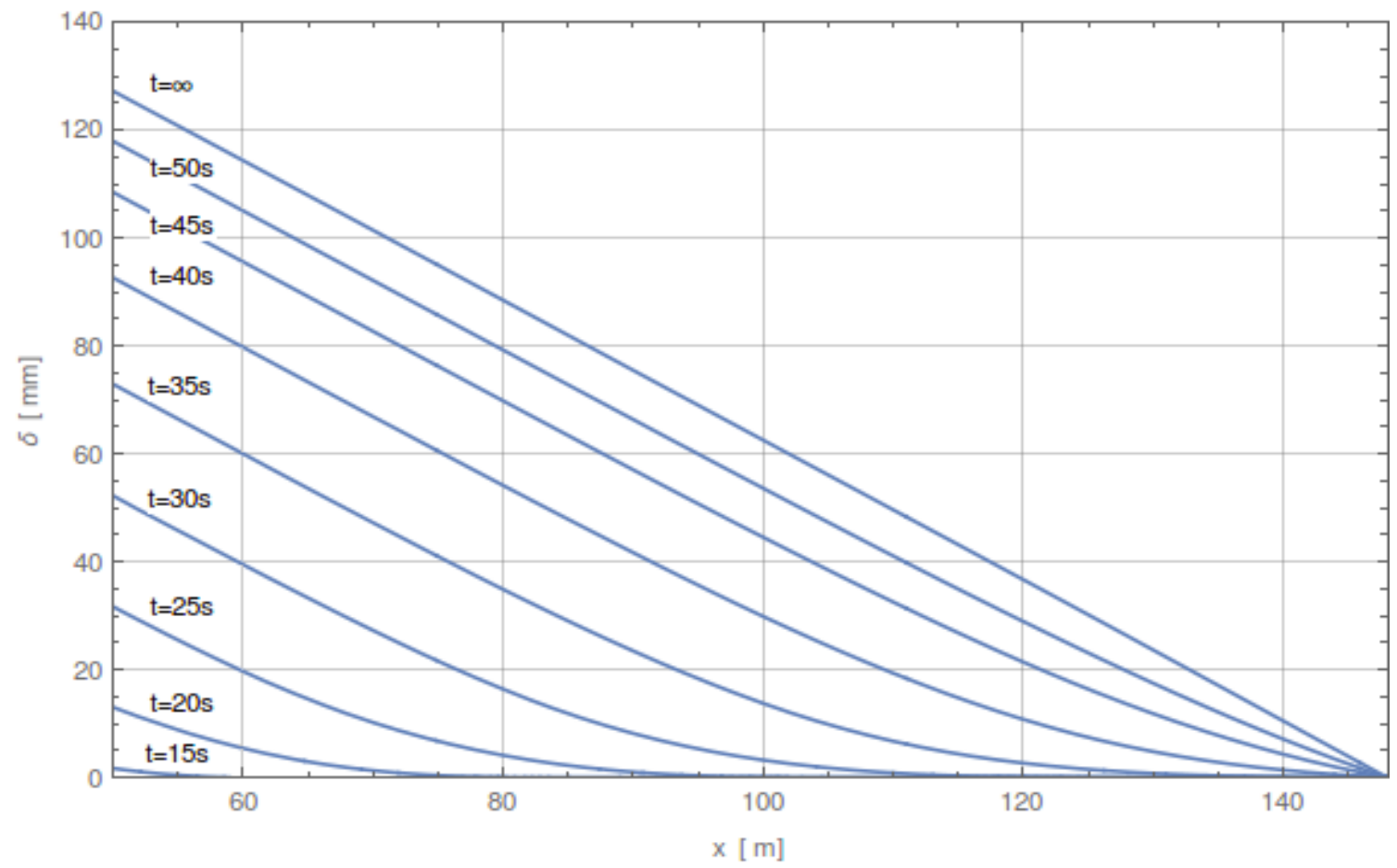

Figura 4.13: Perfil da dilatação linear do tubo. Tubo de cobre, $D_{n}=8 ", U=3 \mathrm{~m} / \mathrm{s}, R e=$ $2,09 \times 10^{6}, N u=6,65 \times 10^{3}, h_{i}=2,22 \times 10^{4} \mathrm{~W} / \mathrm{m}^{2} \mathrm{~K}, \mathrm{Gr}=4,12 \times 10^{1}, h_{e}=$ $5,44 \mathrm{~W} / \mathrm{m}^{2} \mathrm{~K}$. 
Fixando-se a dilatação máxima do cobre em $126 \mathrm{~mm}$, que é aproximadamente a dilatação máxima calculada para o tubo de aço, verifica-se que em aproximadamente 75 segundos o tubo de cobre atinge a dilatação máxima enquanto que são necessários aproximadamente 108 segundos para o tubo de aço atingir a mesma dilatação. Tal observação permite concluir que quanto maior o coeficiente de dilatação, maior será a taxa de dilatação, porém, há que se fazer uma ponderação: como o comprimento do tubo é menor e consequentemente o seu volume é menor, não necessariamente a força transmitida à ancoragem/trava será maior.

\subsubsection{Efeito da temperatura de entrada $T_{m e}$}

Para ilustrar o efeito da variação da temperatura de entrada $T_{m e}$, realizou-se uma simulação onde foi considerado o mesmo diâmetro, material do tubo e velocidade média do escoamento considerado na simulação que originou as Fig. 4.1 , 4.2 e 4.3. A temperatura média de entrada $T_{m e}$ considerada é $570 \mathrm{~K}$ e as propriedades termofísicas pertinentes correspondentes são mostradas na Tab. 4.2.

\begin{tabular}{|l|l|c|c|}
\hline \multirow{2}{*}{ Propriedades } & \multicolumn{2}{|c|}{ Fluido } & Tubo \\
\cline { 2 - 4 } & água & ar & aço \\
\hline$\nu\left(\mathrm{m}^{2} / \mathrm{s}\right)$ & $1,26 \times 10^{-7}$ & $3,04 \times 10^{-5}$ & - \\
\hline$\rho\left(\mathrm{kg} / \mathrm{m}^{3}\right)$ & $7,18 \times 10^{2}$ & - & $7,85 \times 10^{3}$ \\
\hline $\operatorname{Pr}$ & $9,40 \times 10^{-1}$ & $6,87 \times 10^{-1}$ & - \\
\hline$k(\mathrm{~W} / \mathrm{mK})$ & $5,48 \times 10-1$ & $3,61 \times 10^{-2}$ & $4,93 \times 10^{1}$ \\
\hline$c(\mathrm{~J} / \mathrm{kgK})$ & $5,68 \times 10^{3}$ & - & $5,48 \times 10^{2}$ \\
\hline$e(\mathrm{~mm}$ & - & - & $1,50 \times 10^{-3}$ \\
\hline$\alpha\left(\mathrm{m}^{2} / \mathrm{s}\right)$ & $1,34 \times 10^{-7}$ & $4,43 \times 10^{-5}$ & $1,14 \times 10^{-5}$ \\
\hline$\beta\left(\mathrm{K}^{-1}\right)$ & - & $2,30 \times 10^{-3}$ & - \\
\hline
\end{tabular}

Tabela 4.2: Propriedades termofísicas à $570 \mathrm{~K}$.

A Fig. 4.14 mostra o gráfico da evolução temporal da temperatura média do tubo dessa simulação e o compara com a simulação da Sec. 4.1.1, onde $T_{m e}=373 \mathrm{~K}$.

O coeficiente de dilatação $\varphi$ é função apenas da temperatura e aumenta linearmente com esta (ver Sec. 2.2.1), o que implica que, respeitados os $130 \mathrm{~mm}$ de dilatação máxima, o comprimento do tubo da ancoragem até a mudança de direção será menor. No caso, o comprimento considerado está compreendido entre $50 \leq x \leq 86 \mathrm{~m}$, o que resulta nos mesmos $126 \mathrm{~mm}$ de dilatação máxima das simulações anteriores. 


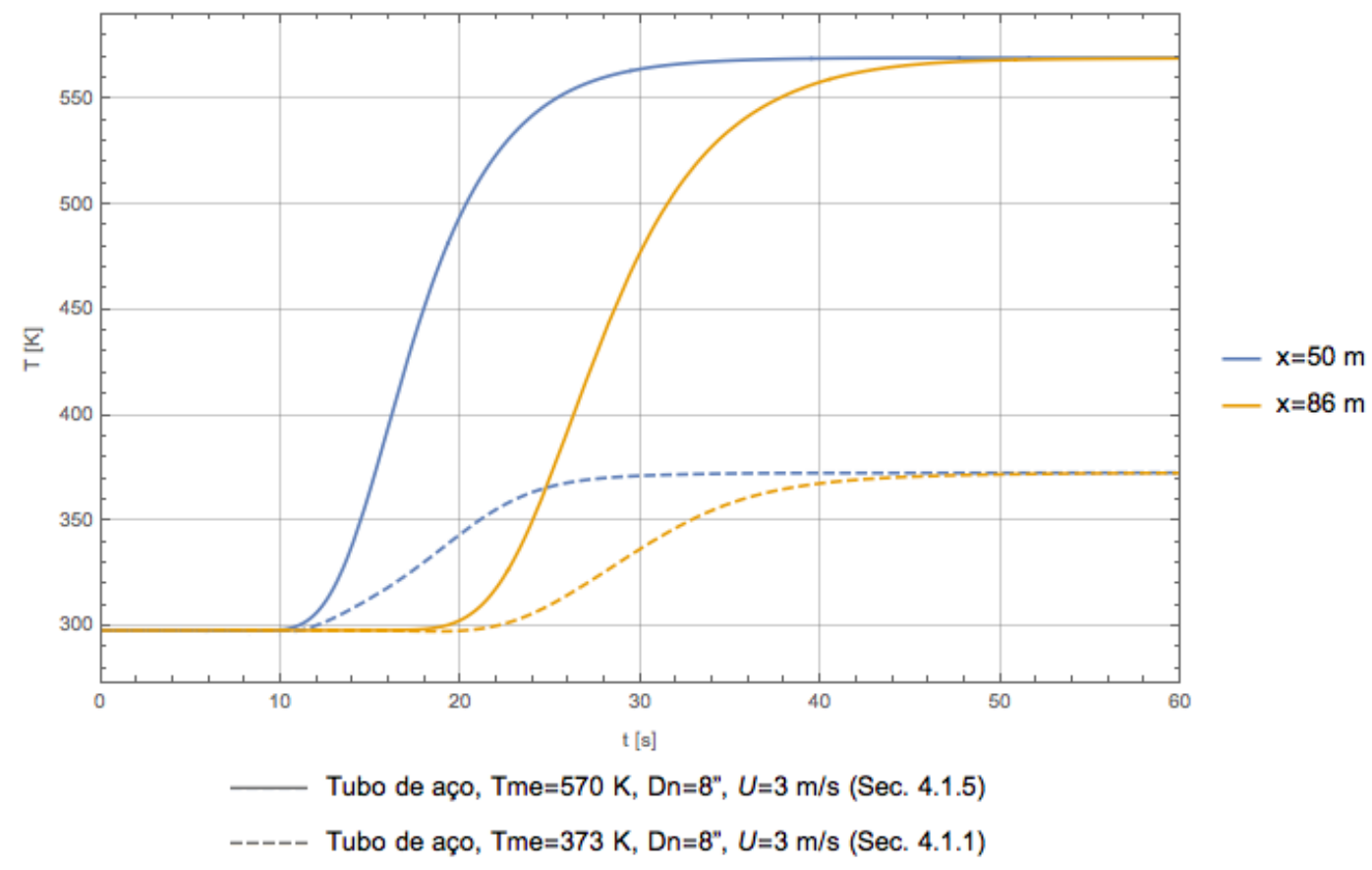

Figura 4.14: Evolução temporal da temperatura média do tubo. $T_{m e}=570 \mathrm{~K}$, tubo de aço, $D_{n}=8^{\prime \prime}, U=3 \mathrm{~m} / \mathrm{s}, R e=4,81 \times 10^{6}, N u=1,06 \times 10^{4}, h_{i}=2,87 \times 10^{4} \mathrm{~W} / \mathrm{m}^{2} \mathrm{~K}$, $G r=4,49 \times 10^{1}, h_{e}=7,42 \mathrm{~W} / \mathrm{m}^{2} \mathrm{~K}$.

A Fig. 4.15 mostra o perfil da temperatura média do tubo e a Fig. 4.16 mostra o perfil da dilatação linear do tubo obtidas a partir da simulação aqui realizada.

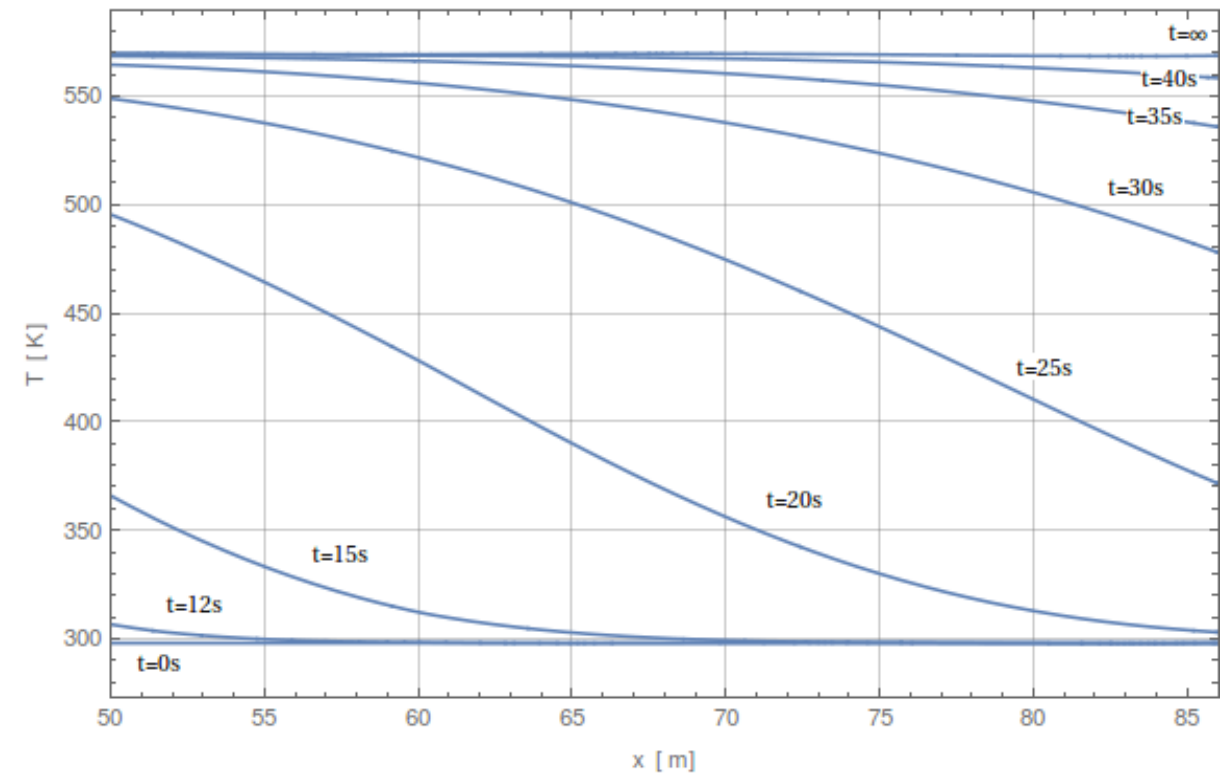

Figura 4.15: Perfil da temperatura média do tubo. $T_{m e}=570 \mathrm{~K}$, tubo de aço, $D_{n}=8$ ", $U=$ $3 \mathrm{~m} / \mathrm{s}, \mathrm{Re}=4,81 \times 10^{6}, N u=1,06 \times 10^{4}, h_{i}=2,87 \times 10^{4} \mathrm{~W} / \mathrm{m}^{2} \mathrm{~K}, \mathrm{Gr}=4,49 \times 10^{1}$, $h_{e}=7,42 \mathrm{~W} / \mathrm{m}^{2} \mathrm{~K}$.

Ao comparar-se as Fig. 4.2 e 4.15, verifica-se que, ainda que a difusividade térmica $\alpha$ do material do tubo na simulação à $570 K$ seja menor e o número de Grashof seja 
discretamente maior, a taxa de aquecimento da tubulação é consideravelmente maior como consequência do maior número de Reynolds e de Nusselt. É possível chegar facilmente a essa conclusão, sem a necessidade de cálculos, com a simples constatação de que ao aumentar-se a temperatura, diminui-se a viscosidade e, consequentemente, aumenta-se o número de Reynolds, entretanto, um detalhe surpreendente é que o regime permanente é atingido em um tempo ligeiramente menor.

Ao fixar-se uma linha vertical nas Fig. 4.2 e 4.15 na posição $x=60 m$, o regime permanente, considerando-se $T_{m e}=570 \mathrm{~K}$, é atingido por volta de $38 \mathrm{~s}$. Ao considerar $T_{m e}=373 \mathrm{~K}$, na mesma posição, o regime permanente é atingido por volta de $40 \mathrm{~s}$.

Já ao analisar-se as Fig. 4.3 e 4.16, verifica-se que, como resultado da maior taxa de aquecimento e principalmente pelo menor comprimento da tubulação, a taxa de dilatação é muito maior com $T_{m e}=570 \mathrm{~K}$. No tempo $30 \mathrm{~s}$, considerando $T_{m e}=570 \mathrm{~K}$, a dilatação é de $108 \mathrm{~mm}$ enquanto que ao considerar $T_{m e}=373 \mathrm{~K}$ a dilatação é de $31 \mathrm{~mm}$.

Da mesma forma que quando foi avaliado o efeito do coeficiente de dilatação $\varphi$, o aumento da temperatura de entrada $T_{m e}$, e a consequente maior taxa de dilatação, não necessariamente se traduzirá em maiores forças na ancoragem ou trava, já que o comprimento e o volume de tubulação são menores.

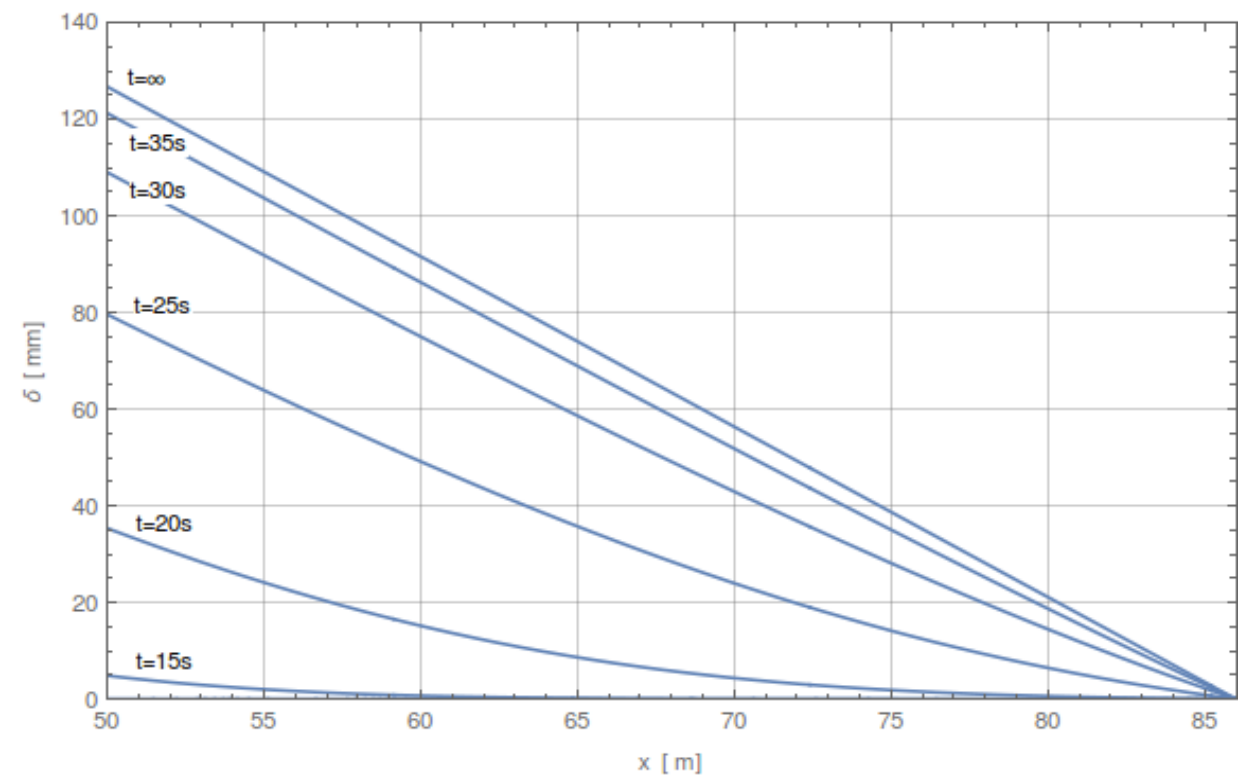

Figura 4.16: Perfil da dilatação linear do tubo. $T_{m e}=570 \mathrm{~K}$, tubo de aço, $D_{n}=8$ ", $U=3 \mathrm{~m} / \mathrm{s}$, $R e=4,81 \times 10^{6}, N u=1,06 \times 10^{4}, h_{i}=2,87 \times 10^{4} \mathrm{~W} / \mathrm{m}^{2} \mathrm{~K}, \mathrm{Gr}=4,49 \times 10^{1}$, $h_{e}=7,42 \mathrm{~W} / \mathrm{m}^{2} \mathrm{~K}$.

\subsubsection{Forças relacionadas à dilatação transitória}

A mecânica clássica adotada pela Engenharia de Tubulação para o cálculo de cargas em sistemas de tubulação, que foi apresentada na Sec. 1.2, será a adotada para discutir quantitativamente as forças relacionadas à dilatação transiente. Nesta metodologia a taxa 
de dilatação, que foi discutida na Sec. 4.1, não exerce qualquer influência em relação as forças de origem térmica computadas na ancoragem, entretanto, no apêndice B é feita uma discussão a respeito de como tal taxa poderia influir na magnitude da força calculada.

Como consequência da natureza gradual e progressiva do aquecimento da tubulação e da forma como as forças relacionadas ao atrito são computadas, uma conclusão importante é que estas forças de atrito não serão imediatamente transmitidas ao ponto onde a tubulação está travada ou ancorada a partir do instante em que o tubo, no domínio considerado nesse estudo, começa a ser aquecido.

Nos esquemas das Fig. 4.17 e 4.18 o sentido do fluxo é de "1" para "7", o espaçamento entre os suportes é igual e é considerado que o tubo está inicialmente cheio ${ }^{1}$. As forças de atrito são calculadas com a Eq. (1.4). Na Fig. 4.17 a frente térmica se encontra imediatamente antes do apoio " 4 " enquanto que na Fig. 4.18 a frente térmica se encontra imediatamente após o apoio " 4 ".

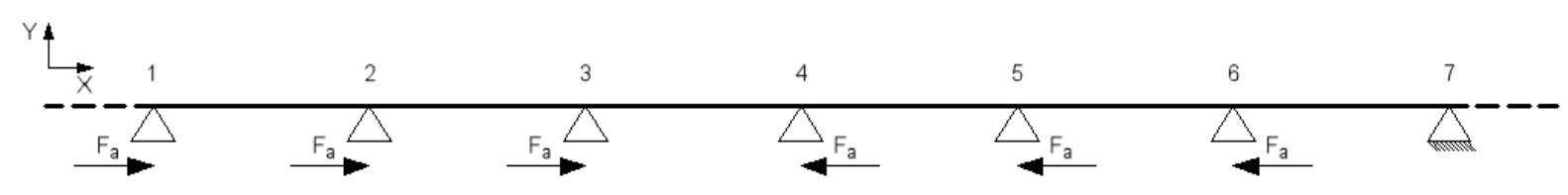

Figura 4.17: Instante imediatamente antes da transmissão de forças a ancoragem.

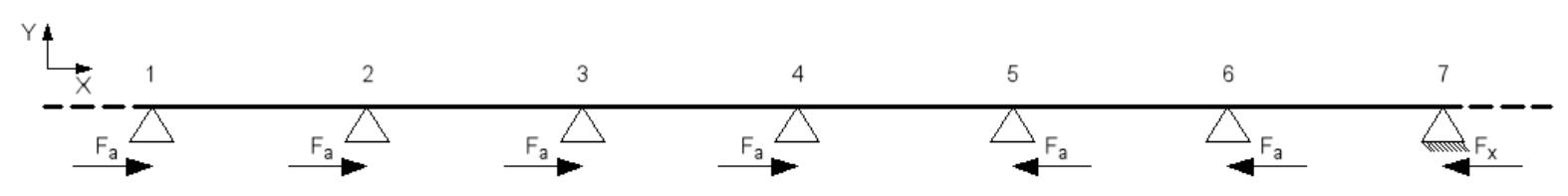

Figura 4.18: Instante imediatamente após o início da transmissão de forças a ancoragem.

Devido ao somatório de forças horizontal, verifica-se que as forças de origem térmica começam a ser transmitidas à ancoragem ou trava "T" quando a frente térmica se encontra no apoio localizado na metade ou imediatamente após a metade do trecho de tubulação a montante da trava ou ancoragem.

Para ilustrar o comportamento das forças ao longo do tempo como consequência do transiente térmico, será considerado o gráfico "perfil da dilatação linear do tubo" da Fig. 4.3, no qual a simulação considerou água como fluido, tubulação de aço com $D_{n}=8$ " e $U=3 \mathrm{~m} / \mathrm{s}$.

A tabela 4.3 mostra as forças calculadas com a mecânica classicamente adotada pela Engenharia de Tubulação. A força vertical $F_{y}$ foi calculada com a Eq. (1.2) e a força de atrito $F_{a}$ foi calculado com a Eq. (1.4). O coeficiente de atrito $\mu$ aço-aço é 0,3 (SILVA

\footnotetext{
${ }^{1} \mathrm{O}$ modelo matemático considera a tubulação cheia e à temperatura ambiente, quando repentinamente a temperatura na posição $x=0$ é elevada. Entretanto, a análise pode ser estendida para o caso onde a tubulação se encontrava inicialmente vazia.
} 
TELLES, 1999). Convém salientar que o modelo físico simula um pipe rack com $300 \mathrm{~m}$ de comprimento e espaçamento entre vigas de apoio de $5 \mathrm{~m}$.

\begin{tabular}{|c|c|c|c|}
\hline$x(m)$ & $t(s)$ & $F_{y}(N)$ & $F_{x}(N)$ \\
\hline 50 & 10,0 & $3,56 \times 10^{3}$ & 0,0 \\
\hline 55 & 11,3 & $3,56 \times 10^{3}$ & 0,0 \\
\hline 60 & 12,5 & $3,56 \times 10^{3}$ & 0,0 \\
\hline 65 & 13,8 & $3,56 \times 10^{3}$ & 0,0 \\
\hline 70 & 15,1 & $3,56 \times 10^{3}$ & 0,0 \\
\hline 75 & 16,3 & $3,56 \times 10^{3}$ & 0,0 \\
\hline 80 & 17,6 & $3,56 \times 10^{3}$ & 0,0 \\
\hline 85 & 18,9 & $3,56 \times 10^{3}$ & 0,0 \\
\hline 90 & 20,1 & $3,56 \times 10^{3}$ & 0,0 \\
\hline 95 & 21,4 & $3,56 \times 10^{3}$ & 0,0 \\
\hline 100 & 22,7 & $3,56 \times 10^{3}$ & 0,0 \\
\hline 105 & 23,9 & $3,56 \times 10^{3}$ & 0,0 \\
\hline 110 & 25,2 & $3,56 \times 10^{3}$ & 0,0 \\
\hline 115 & 26,5 & $3,56 \times 10^{3}$ & 0,0 \\
\hline 120 & 27,7 & $3,56 \times 10^{3}$ & 0,0 \\
\hline 125 & 29,0 & $3,56 \times 10^{3}$ & $2,13 \times 10^{3}$ \\
\hline 130 & 30,3 & $3,56 \times 10^{3}$ & $4,27 \times 10^{3}$ \\
\hline 135 & 31,5 & $3,56 \times 10^{3}$ & $6,41 \times 10^{3}$ \\
\hline 140 & 32,8 & $3,56 \times 10^{3}$ & $8,55 \times 10^{3}$ \\
\hline 145 & 34,1 & $3,56 \times 10^{3}$ & $1,06 \times 10^{4}$ \\
\hline 150 & 35,3 & $3,56 \times 10^{3}$ & $1,28 \times 10^{4}$ \\
\hline 155 & 36,6 & $3,56 \times 10^{3}$ & $1,49 \times 10^{4}$ \\
\hline 160 & 37,9 & $3,56 \times 10^{3}$ & $1,71 \times 10^{4}$ \\
\hline 165 & 39,1 & $3,56 \times 10^{3}$ & $1,92 \times 10^{4}$ \\
\hline 170 & 40,4 & $3,56 \times 10^{3}$ & $2,13 \times 10^{4}$ \\
\hline 175 & 41,7 & $3,56 \times 10^{3}$ & $2,35 \times 10^{4}$ \\
\hline 180 & 42,9 & $3,56 \times 10^{3}$ & $2,56 \times 10^{4}$ \\
\hline 185 & 44,2 & $3,56 \times 10^{3}$ & $2,77 \times 10^{4}$ \\
\hline 190 & 45,5 & $3,56 \times 10^{3}$ & $2,99 \times 10^{4}$ \\
\hline 195 & 46,7 & $3,56 \times 10^{3}$ & $3,20 \times 10^{4}$ \\
\hline 200 & 48,0 & $3,56 \times 10^{3}$ & 0,0 \\
\hline : & $\vdots$ & $\vdots$ & $\vdots$ \\
\hline 350 & 86,0 & $3,56 \times 10^{3}$ & 0,0 \\
\hline
\end{tabular}

Tabela 4.3: Forças associadas a simulação que originou a Fig. $4.3\left(T_{m e}=373 \mathrm{~K}, D_{n}=8\right.$ ", $U=3 \mathrm{~m} / \mathrm{s})$.

As forças indicadas na Tab. 4.3 são referentes ao instante imediatamente após a frente térmica ter atingido as posições indicadas.

A Fig. 4.19 mostra detalhadamente o comportamento da força na ancoragem "B" indicada na Fig. 3.2. Verifica-se que a tubulação passa a transmitir carga a ancoragem de forma abrupta e que essa carga cresce de forma intermitente até atingir o seu máximo 


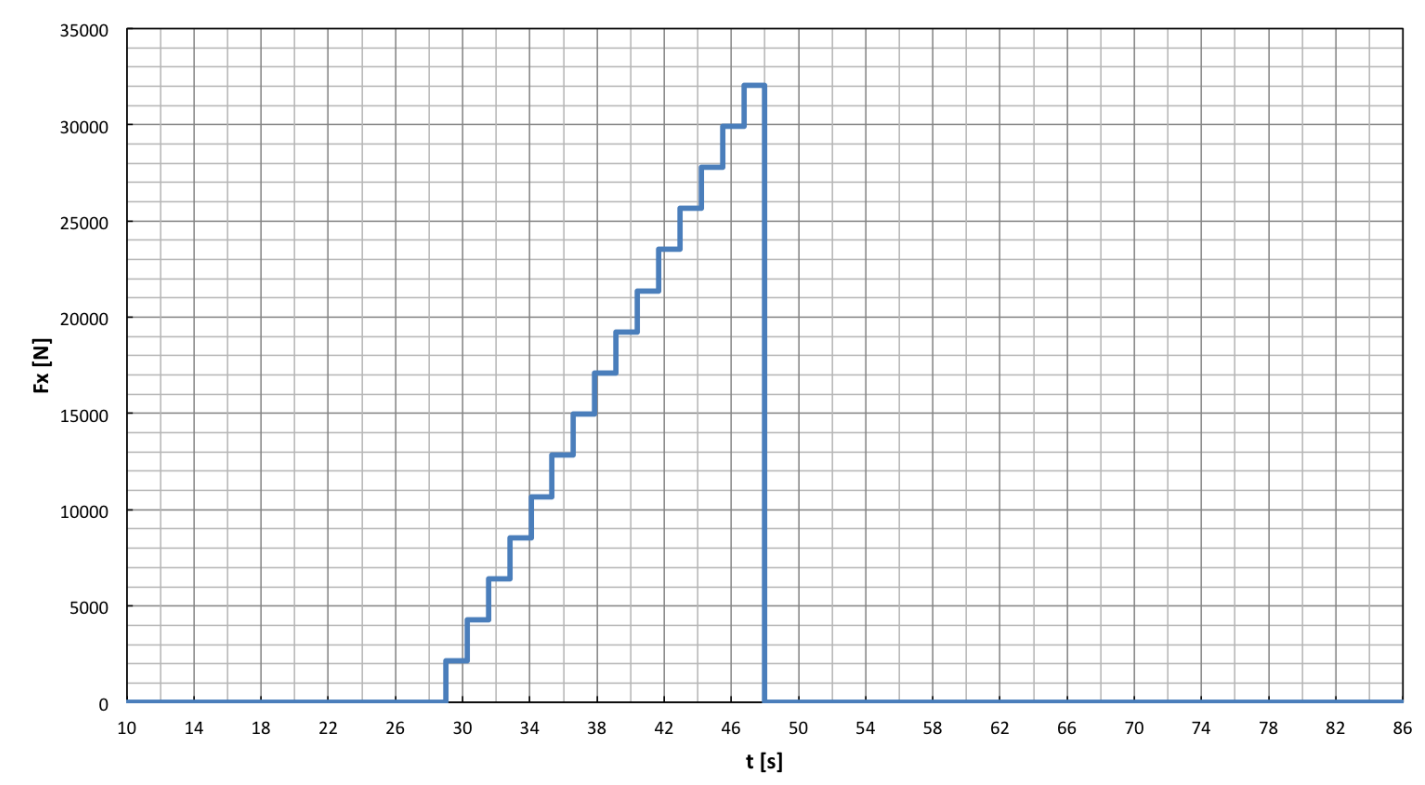

Figura 4.19: Comportamento da força na ancoragem "B" da Fig. 3.2 como consequência do transiente da Fig. $4.3\left(T_{m e}=373 K, D_{n}=8 ", U=3 \mathrm{~m} / \mathrm{s}\right)$.

valor. Após isto, a força decresce de forma extremamente abrupta já que a dilatação do tubo a jusante da ancoragem tende a deslocar todo este trecho de tubulação.

Para ilustrar o efeito da velocidade média $U$ em relação a força calculada na ancoragem ou trava, a Fig. 4.20 foi elaborada tendo como referência o gráfico do perfil da dilatação do tubo da Fig. 4.7.

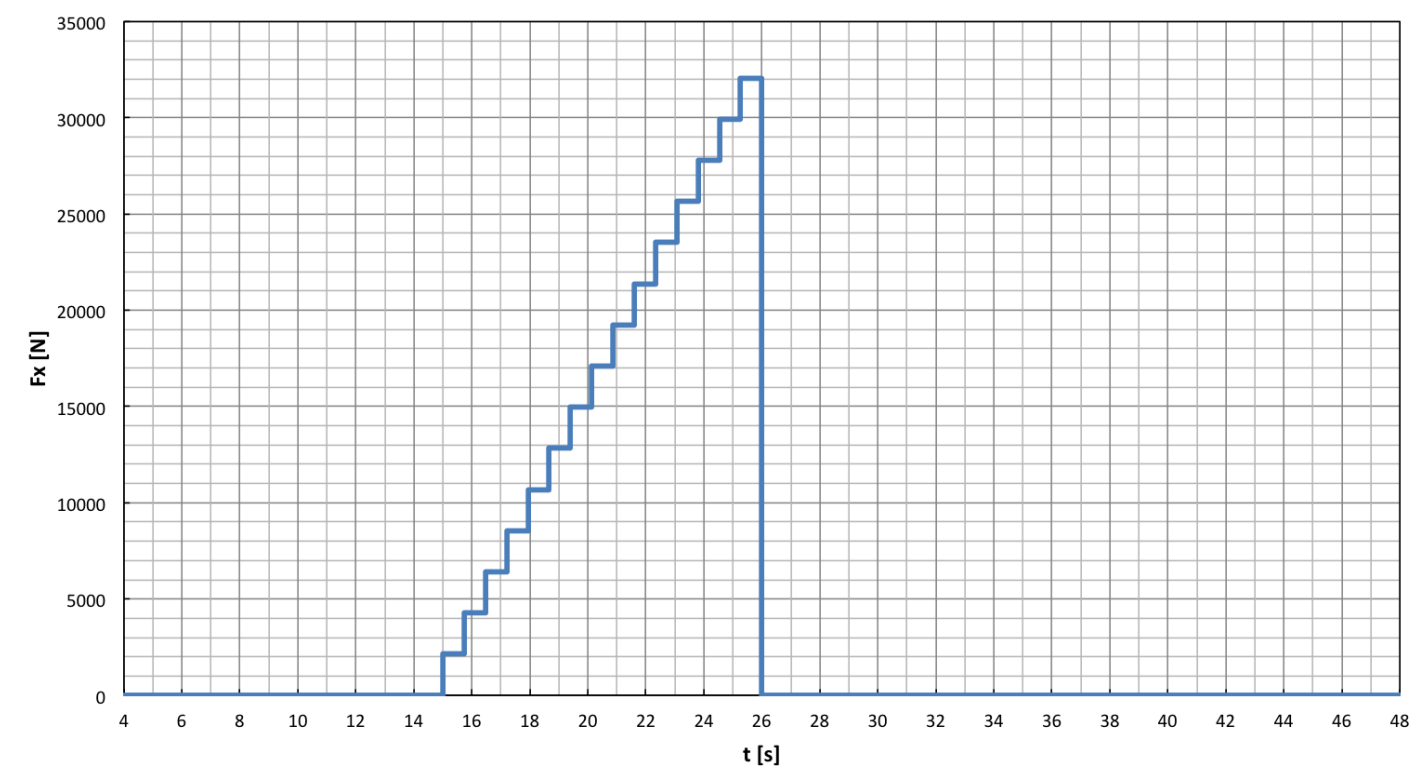

Figura 4.20: Comportamento da força na ancoragem "B" da Fig. 3.2 como consequência do transiente da Fig. $4.7\left(T_{m e}=373 \mathrm{~K}, D_{n}=8 ", U=5 \mathrm{~m} / \mathrm{s}\right)$.

Na comparação com a Fig. 4.19, devido a maior velocidade média $U$, os tempos para se atingir a força máxima e de duração desta força máxima são menores. Como os diâmetros 
dos tubos são iguais, a magnitude das forças são idênticas.

A análise do comportamento da força na ancoragem com a tubulação inicialmente vazia de fluido envolveria um modelo matemático não trivial (a Eq. (1.2) passaria a ser função explícita da densidade do fluido, da posição e do tempo). Entretanto, é evidente que o instante em que as forças de atrito passariam a ser transmitidas a ancoragem seria antecipado e que a carga aumentaria de forma gradual (não intermitente) até o valor máximo, quando então decresceria, inicialmente de forma abrupta, já que toda a tubulação vazia a montante da ancoragem tenderia a ser deslocada, para então decair de forma suave até o valor nulo. Tal constatação mostra que o dimensionamento considerando a tubulação inicialmente cheia de fluido é o mais crítico.

\subsubsection{Instante de máxima força}

Uma discussão interessante a respeito das forças relacionadas ao transiente térmico estudado está relacionada ao instante no qual a força no ponto onde a tubulação está fixada será máxima. No modelo utilizado nesse estudo (Fig. 3.2) a força na ancoragem "B" será máxima no instante de tempo no qual a frente térmica avança entre a ancoragem e o apoio que está imediatamente antes desta ancoragem, o que pode ser comprovado pelas Fig. 4.19 e 4.20. Tal discussão pode ser ampliada para o caso de travas com folga.

Nas Fig. 4.19 e 4.20 também se pode verificar que o instante de máxima força tem curta duração, aproximadamente $1,5 s$ e $0,8 s$, respectivamente, instante este no qual a força na ancoragem pode ser calculada com a Eq. (1.5).

Nesse ponto, uma conclusão importante é que em um pipe rack, como o ilustrado na Fig. 1.4, além da baixa probabilidade de que as tubulações que o percorrem entrem em serviço simultaneamente, tenham o mesmo comprimento e tenham as mesmas velocidades médias do fluxo $U$, é improvável que as forças aplicadas por cada tubo ao pórtico de ancoragem (ver Sec. 1.3) sejam máximas no mesmo instante de tempo, já que estas, após atingirem os seu valores máximos que têm duração da ordem de poucos segundos, decaem rapidamente. Somando-se a isso, o regime permanente térmico, mesmo em tubulações com centenas de metros de comprimento, é atingido em poucos minutos, o que faz com que não seja remota a probabilidade de que quando uma tubulação entra em serviço as forças devido ao mecanismo aqui discutido já estejam em seu valores mínimos na demais tubulações adjacentes.

No caso de travas com folga, as forças sempre serão de menor magnitude, já que o atrito do tubo a jusante da trava sempre entrará no somatório de forças, conforme demonstrado na simulação que originou a Tab. 1.3. 


\subsection{Resultados de simulações de transientes térmicos e de dilatações transientes para vários diâmetros e velocidades $U$}

No apêndice D são apresentados os resultados gráficos de várias simulações de transientes térmicos realizadas, considerando o modelo físico apresentado na Sec. 3.1. São considerados tubos de aço com diâmetros de 4 a 10 polegadas Standard e velocidades médias do escoamento interno $U$ de 2 a $5 \mathrm{~m} / \mathrm{s}$, conforme definido na Sec. 3.1. O fluido é sempre a água à $373 \mathrm{~K}\left(100^{\circ} \mathrm{C}\right)$. 


\section{Capítulo 5}

\section{Conclusões}

Nesse trabalho foi desenvolvida uma metodologia para calcular a dilatação térmica linear transiente e, por intermédio de simulações numéricas, avaliou-se a influência da temperatura de entrada do fluido, do diâmetro do tubo, da velocidade média do fluxo e do material do tubo em relação ao problema estudado.

Através dos resultados apresentados no Cap. 4, provou-se a existência de um instante de tempo em que a tubulação a montante de um ponto fixo se encontra com um diferencial de temperatura enquanto que a tubulação a jusante deste ponto se encontra à temperatura ambiente, o que demonstra que a análise tradicional de sistemas de tubulação, onde se considera o tubo em regime permanente térmico, não é suficiente para a avaliação das cargas externas provocadas pela tubulação que dilata.

Verificou-se ainda que para o mesmo fluido, quanto maiores são a temperatura de entrada $T_{m e}$, a velocidade do escoamento $U$, a difusividade térmica do tubo $\alpha$ e o diâmetro do tubo, maiores serão as taxas de aquecimento da tubulação. Consequentemente, quanto maior a taxa de aquecimento da tubulação e maior o coeficiente de dilatação $\varphi$, maior será a taxa de dilatação do tubo.

A velocidade do escoamento $U$ provou ser um dos principais parâmetros, já que quanto maior a velocidade, menor será o tempo para que toda a tubulação tenha contato com a frente térmica. De forma geral, quanto maior a velocidade do escoamento $U$, maior o número de Nusselt e maior a difusividade térmica do material do tubo, maior será a taxa de aquecimento da tubulação.

Em relação a força provocada pela tubulação no ponto onde esta está travada ou ancorada, mostrou-se que, para a configuração estudada, a força de atrito não é imediatamente transmitidas ao ponto fixo e que em um determinado momento, tais forças passam a ser transmitidas de forma abrupta e aumentam de forma intermitente até o seu máximo valor. Após atingir o máximo valor, instante que dura poucos segundos e que tem a velocidade do fluxo $U$ como o principal parâmetro governante, a força cai de forma extremamente abrupta até atingir o seu mínimo valor. No intervalo de tempo em que a força é máxima, quanto maior a taxa de dilatação do tubo, maior será a carga total aplicada pela tubulação 
ao ponto fixo.

A análise dos tempos e do comportamento das forças envolvidas no transiente térmico permite concluir que em pipe racks, conforme discutido na Sec. 4.1.6.1, é pouco provável que nas vigas destinadas a ancoragem do feixe de tubulação as forças relacionadas ao atrito aplicadas por cada tubo atuem simultaneamente e é improvável que estas forças sejam máximas no mesmo instante de tempo.

Com base no modelo considerado e na metodologia classicamente utilizada pela Engenharia de Tubulação, foi possível determinar o instante de máxima força em relação ao mecanismo do atrito. Entretanto, considerar fatores como a variação de diâmetro e de comprimento do tubo causada pela dilatação térmica, assim como diferenças entre o coeficiente de atrito estático e dinâmico, entre outros, conduziriam a uma solução mais refinada, o que no entanto representaria um grande desafio em termos matemático e computacional sem, contudo, alterar as conclusões desse trabalho.

Em relação ao trabalho de Bokaian (2004), que demonstra que mesmo no regime permanente o gradiente de temperatura ao longo da tubulação poderia provocar forças não normalmente calculadas, tal estudo não se mostrou aplicável ao tipo de tubulação considerada nessa dissertação, já que o trabalho do pesquisador considera tubulações onde, substancialmente, o coeficiente de convecção externo é muito maior (tubulações submarinas). Conforme verificado nas Fig. 3.3 e 3.4, no regime permanente o gradiente de temperatura em tubulações expostas ao ar atmosférico é muito pequeno.

Os resultados aqui apresentados mostram a importância de se levar em consideração o transiente térmico no estudo de sistemas de tubulação e permite esclarecer a comunidade que trabalha na Engenharia de Tubulação a respeito das forças relacionadas a este transiente, possibilitando o debate e o refinamento dos critérios adotados ao se calcular cargas estruturais relacionadas à tubulação. Sugere-se que as normas que governam o projeto de sistemas de tubulação alertem aos engenheiros a respeito do problema do transiente térmico. Da mesma forma, um critério para o cálculo de cargas em pipe racks que possuam um único pórtico de ancoragem e onde não há o uso de liras (ver Sec. 1.3 para definição) poderia considerar que apenas a tubulação mais crítica estará aplicando a carga total máxima, ponderando, no entanto, que um percentual das tubulações adjacentes estarão aplicando cargas intermediárias e mínimas. A tubulação mais crítica seria aquela cuja a carga total máxima atuando sobre a ancoragem possua a maior magnitude, não podendo ser desconsiderada a sua posição no pipe rack. Um fator que leve em conta as acelerações provocadas pela dilatação térmica, conforme demonstrado no apêndice B.2, deve ainda ser considerado. 


\section{Apêndice A}

\section{Solução analítica para o regime permanente térmico}

A pesquisa de Kawamura (1976) demonstra que, no estudo do transiente térmico em dutos, avaliar as propriedades na temperatura de regime permanente é uma boa aproximação, exceto para pequenos números de Reynolds. Desta feita, será introduzido um modelo analítico para o regime permanente térmico para definir a temperatura na qual as propriedades serão avaliadas e que permitirá discutir a consideração de dissipação viscosa desprezível, além de confirmar os resultados do modelo numérico, uma vez que:

$$
\begin{gathered}
\bar{T}_{f}=f(x, t) \\
\left.\bar{T}_{f}(x, t)\right|_{t \rightarrow \infty} \cong T_{m s}(x)
\end{gathered}
$$

O balanço de energia da Fig. A.1 mostra o volume de controle diferencial considerado na obtenção de uma solução analítica para o regime permanente térmico.

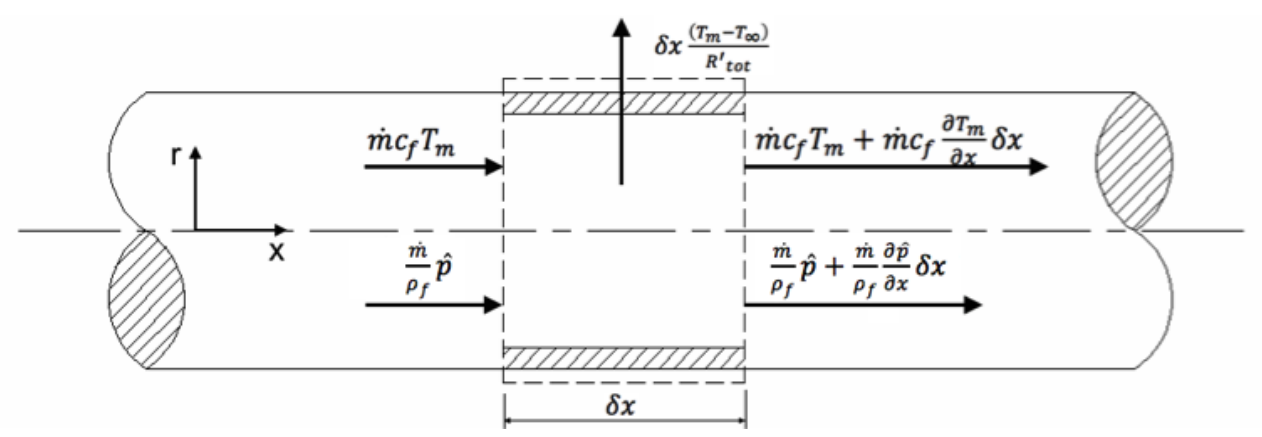

Figura A.1: Volume de controle diferencial considerado no balanço de energia.

Nellis e Klein (2009) determinou a solução para o caso de temperatura externa constate $\left(T_{\infty}=\right.$ cte $)$, sem, no entanto, considerar a variação de pressão.

$$
T_{m s}=T_{\infty}-\left(T_{\infty}-T_{m e}\right) \exp \left(-\frac{x}{\dot{m} c_{f} R_{\text {tot }}^{\prime}}\right)
$$


com,

$$
R_{t o t}^{\prime}=\frac{1}{\pi D_{e} h_{e}}+\frac{\ln \left(\frac{D_{e}}{D_{i}}\right)}{2 \pi k_{t}}+\frac{1}{\pi D_{i} h_{i}}
$$

A solução analítica considerando que há variação de pressão no volume de controle também pode ser facilmente obtida.

Aplicando-se o balanço de energia ao volume de controle diferencial da Fig. A.1, resulta:

$$
\dot{m} c_{f} \frac{\partial T_{m}}{\partial x}+\frac{\dot{m}}{\rho_{f}} \frac{\partial \hat{p}}{\partial x}+\frac{\left(T_{m}-T_{\infty}\right)}{R_{\text {tot }}^{\prime}}=0
$$

A Eq. (A.3) é uma equação diferencial linear de primeira ordem. O gradiente de pressão $\frac{\partial \hat{p}}{\partial x}$ é avaliado conforme a Eq. (2.6).

Como o escoamento é permanente, pode-se escrever:

$$
\frac{\partial \hat{p}}{\partial x}=c t e=c_{1}
$$

A Eq. (A.3) pode então ser resolvida por separação de variáveis e a sua solução é a que segue:

$$
T_{m s}=e^{-\frac{x}{\dot{m} c_{f} R_{t o t}^{\prime}}}\left(-\frac{\dot{m}}{\rho_{f}} c_{1} R_{t o t}^{\prime} e^{\frac{x}{\dot{m} c_{f} R_{t o t}^{\prime}}}+T_{\infty} e^{\frac{x}{\dot{m} c_{f} R_{t o t}^{\prime}}}+\frac{\dot{m}}{\rho_{f}} c_{1} R_{t o t}^{\prime}+T_{m e}-T_{\infty}\right)
$$




\section{Apêndice B}

\section{A influência da taxa de dilatação}

Nessa seção serão discutidos alguns mecanismos nos quais a taxa de dilatação exerce influência e que não foram discutidos no corpo principal dessa dissertação, quer seja porque no modelo estudado o mesmo não ocorria, quer seja porque o mesmo não é tratado pela mecânica classicamente utilizada pela Engenharia de Tubulação.

\section{B.1 Força devido à flecha}

Em configurações em "L", tipicamente encontradas em pipe racks, como o da Fig. 1.4, a dilatação provocará deflexões na tubulação. A Fig. B.1 ilustra esse mecanismo, historicamente tratado pela Engenharia de Tubulação. Nesta, a dilatação do trecho " $L$ " provoca a flecha $\delta$ no braço $B$.

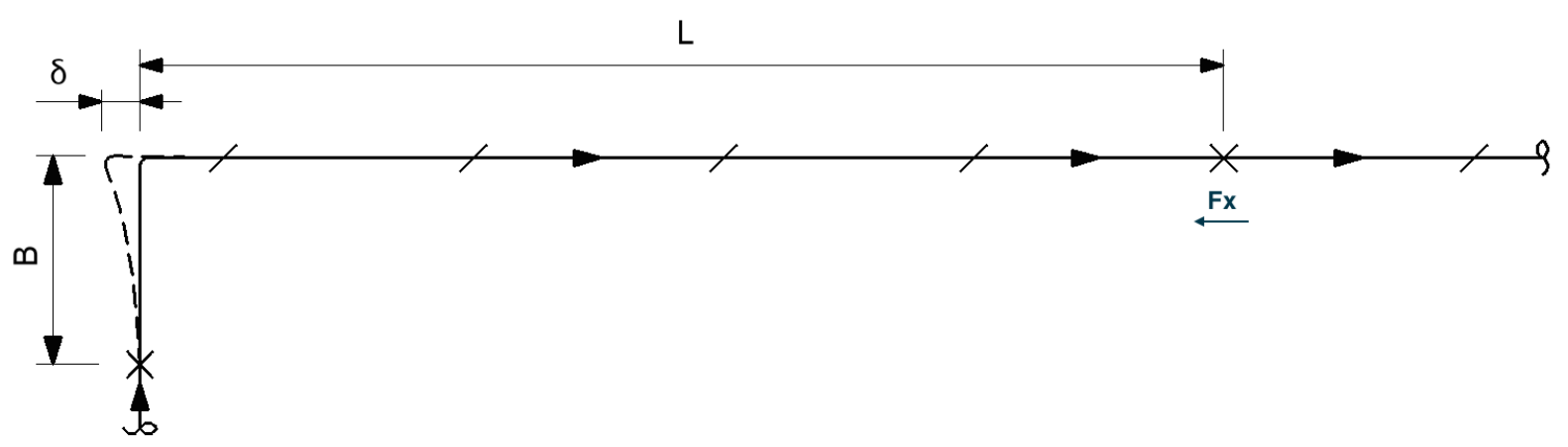

Figura B.1: Flecha $\delta$ como função da dilatação do trecho $L$. Tubulação vista em planta.

Na Fig. B.1 a linha tracejada ilustra a forma como se dará a deflexão do trecho $B$. Silva Telles (1999) indica a Eq. B.1 para o cálculo da força $F_{x}$ na ancoragem devido a flecha $\delta$.

$$
F_{x}=\frac{12 E I \delta}{B^{3}}
$$

Na simulação que originou o gráfico da Fig. 4.3, no instante em que a força devido ao atrito é máxima $(\sim 48 \mathrm{~s})$ o tubo dilatou-se aproximadamente $85 \mathrm{~mm}$, sendo que a 
dilatação total é de $126 \mathrm{~mm}$. Como após o tempo 48 segundos a força devido ao atrito cai abruptamente para o valor nulo (ver Fig. 4.19), pode-se concluir que, na configuração estudada, o somatório da força devido ao atrito e da força devido a flecha $\delta$ será máximo no instante imediatamente antes da frente térmica atingir a ancoragem. Além disso, no instante em que a força devido ao atrito passa a ser máxima, quanto maior a taxa de dilatação maior será a força total.

Em geral a força devido a flecha $\delta$ em pipe racks costuma ser secundária já que, conforme a Eq. (B.1), a magnitude dessa força decresce com o cubo do braço B. Da mesma forma como o atrito, após atingir o seu máximo valor, em configurações simétricas a tendência é que essa força também se anule na medida em que a frente térmica avançar pela tubulação a jusante da ancoragem.

\section{B.2 Força devido a variação da quantidade de movimento}

As forças relacionadas a variação da quantidade de movimento aqui não devem ser confundidas com aquelas calculadas com a equação da quantidade de movimento linear obtida a partir da aplicação combinada da segunda lei de Newton e do teorema de transporte de Reynolds no sistema e no conteúdo do volume de controle. Elas são relacionadas à massa de tubo que deixa o repouso ou o estado de inércia a partir do momento em que a tubulação se dilata e, desta feita, a taxa de dilatação da tubulação exerce grande influência neste mecanismo. Da mesma forma que a força de atrito, a força devido a variação da quantidade de movimento em pipe racks é horizontal e tem sentido axial (ou praticamente axial) à tubulação.

Classicamente a Engenharia de Tubulação não considera esse tipo de força, já que o seu foco é o regime permanente. A mecânica desse problema não é trivial, já que envolveria uma análise diferencial da massa de tudo e da taxa de dilatação associada a esta massa, que não é constante nem em função do tempo e nem em função da posição, como mostra o gráfico "perfil da taxa de dilatação do tubo" da Fig. 4.4, assim como as possíveis perturbações provocadas ao escoamento. A segunda derivada da Eq. (3.2) em relação ao tempo demonstra matematicamente as acelerações experimentadas pela tubulação como função da dilatação térmica, onde os valores não devem ser assumidos como exatos já que na prática, entre outros fatores, o atrito induzirá tensões de compressão na tubulação. 


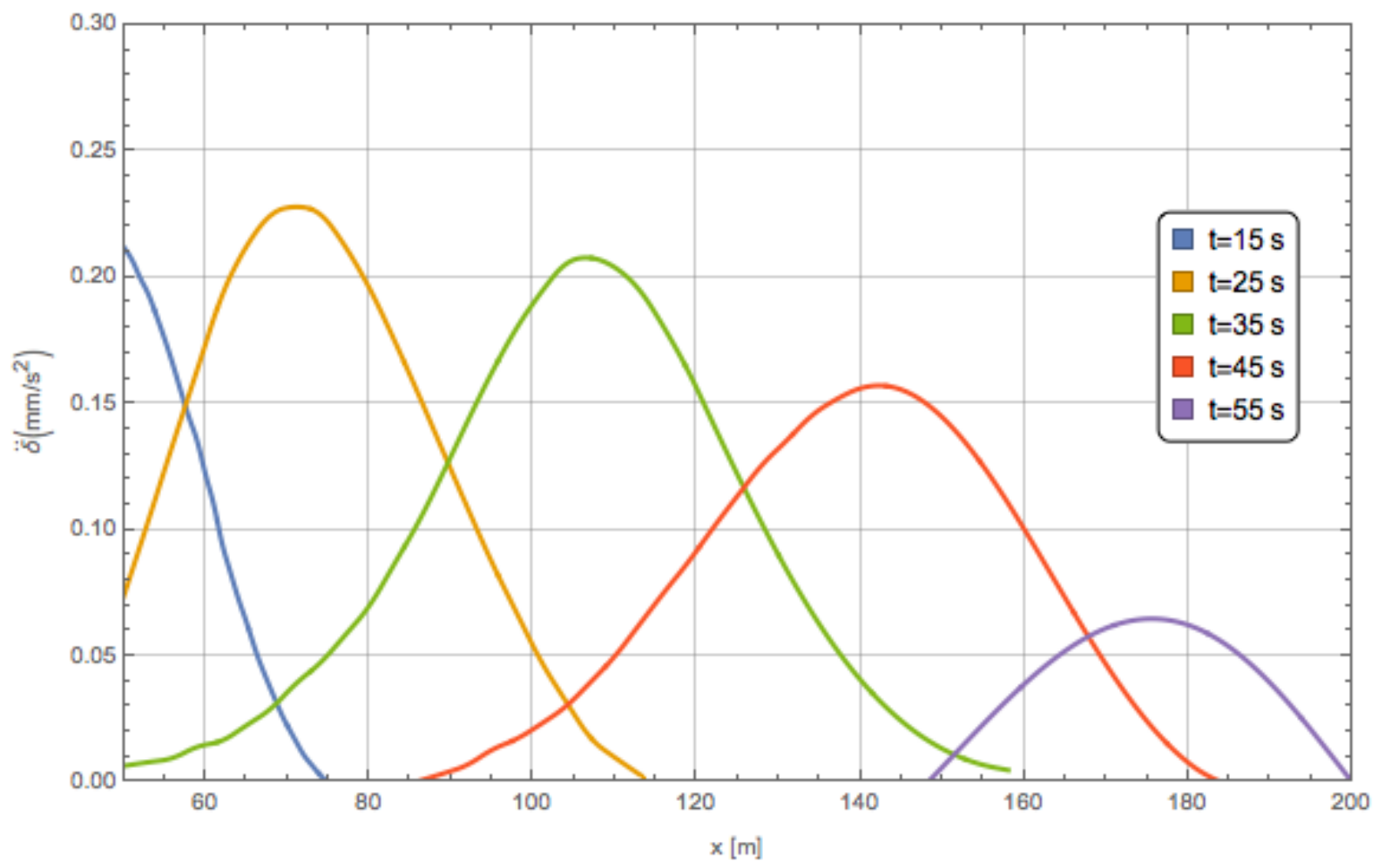

Figura B.2: Perfil da aceleração do tubo. Tubo de aço, $D_{n}=8$ ", $U=3 \mathrm{~m} / \mathrm{s}, R e=2,09 \times 10^{6}$, $N u=6654,4, h_{i}=22290,5 \mathrm{~W} / \mathrm{m}^{2} \mathrm{~K}, G r=41,2, h_{e}=5,44 \mathrm{~W} / \mathrm{m}^{2} \mathrm{~K}$.

A Fig. B.2 comprova a existência das forças aqui discutidas. Ainda que as acelerações sejam de pequena ordem, tal mecanismo não pode ser desprezado já que, conforme demonstrado nesse trabalho, a temperatura do fluido e o diâmetro da tubulação influenciam diretamente na taxa de dilatação.

O estudo de tal mecânica se afasta demasiadamente dos objetivos e do propósito dessa dissertação, entretanto, é evidente que quanto maior a taxa de dilatação maior será a força associada a variação da quantidade de movimento do tubo. 


\section{Apêndice C}

\section{Perfis de velocidade do escoamento interno}

Todos os perfis de velocidades aqui apresentados foram determinados com base nas equações apresentadas no Cap. 2 e a metodologia apresentada no Cap. 3. Considerou-se rugosidade $e=0,15 \mathrm{~mm}$ e água a $100^{\circ} \mathrm{C}$ como fluido, embora o número de Reynolds esteja indicado nos gráficos. Por se tratar de escoamento turbulento, a velocidade deve ser entendida como a velocidade média temporal.

\section{C.1 Tubo com $D_{n}=4 "$}

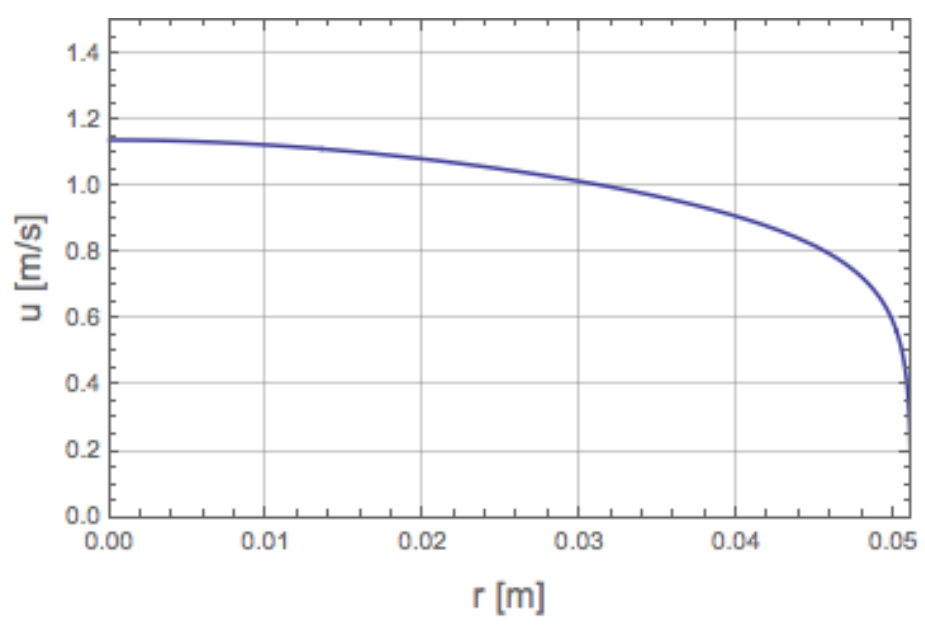

Figura C.1: $U=1 \mathrm{~m} / \mathrm{s}, R e=3,51 \times 10^{5}$. 


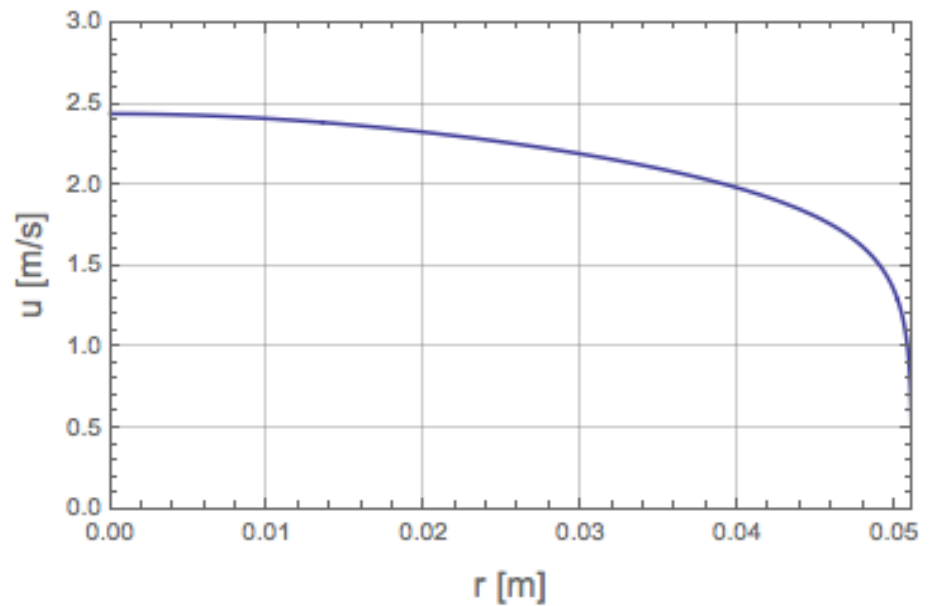

Figura C.2: $U=2 \mathrm{~m} / \mathrm{s}, R e=7,02 \times 10^{5}$.

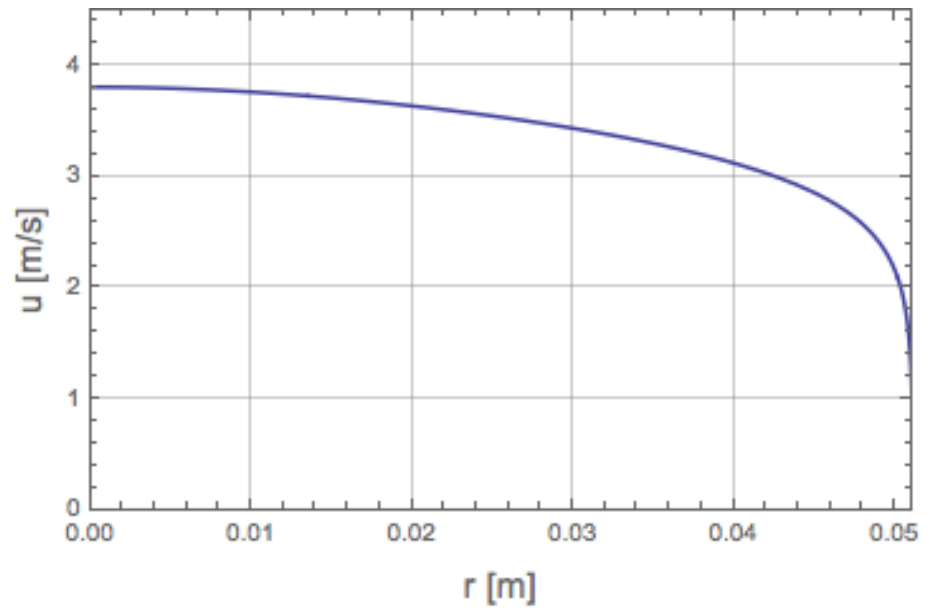

Figura C.3: $U=3 \mathrm{~m} / \mathrm{s}, R e=1,05 \times 10^{6}$.

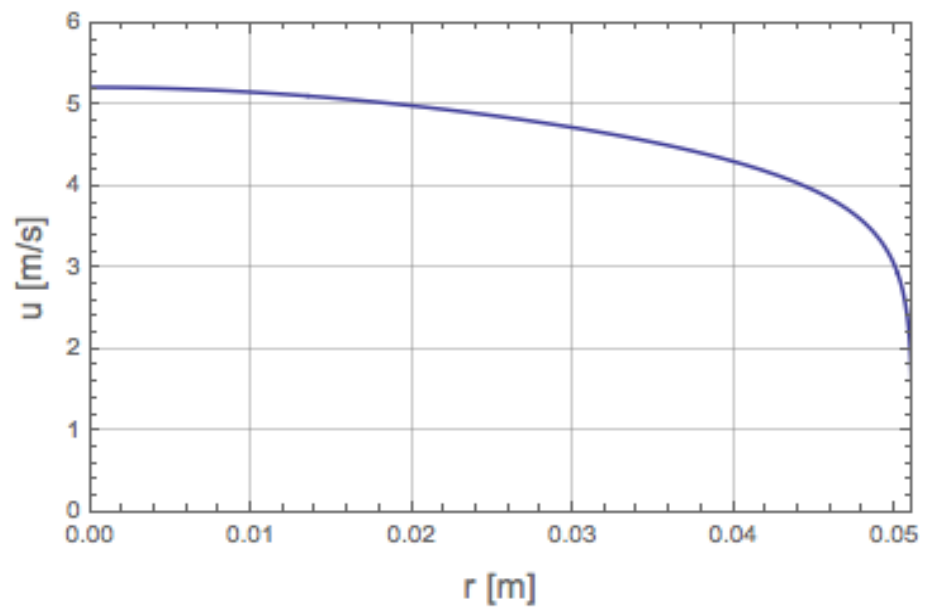

Figura C.4: $U=4 \mathrm{~m} / \mathrm{s}, R e=1,40 \times 10^{6}$. 


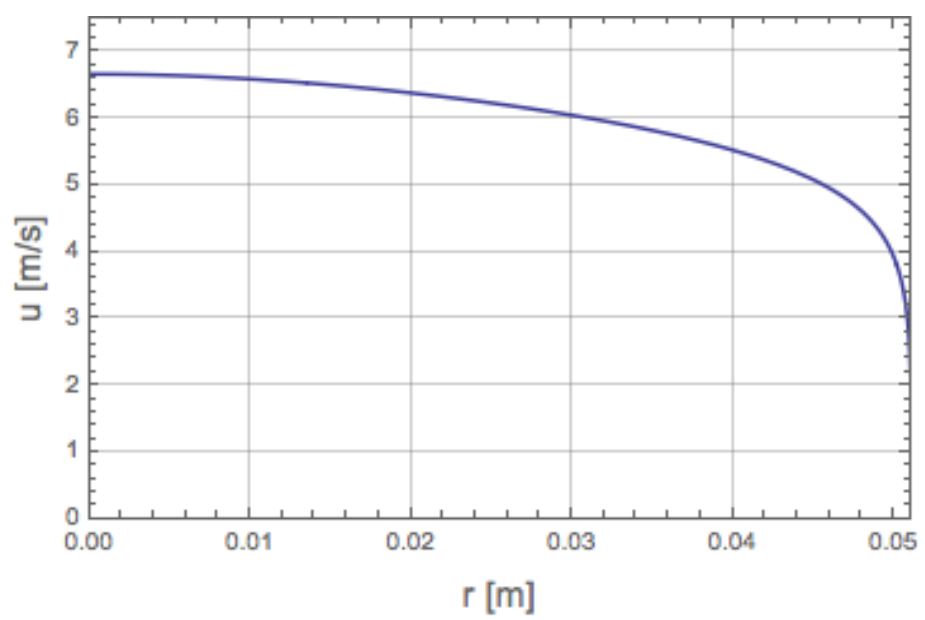

Figura C.5: $U=5 \mathrm{~m} / \mathrm{s}, R e=1,75 \times 10^{6}$.

\section{C.2 Tubo com $D_{n}=6 "$}

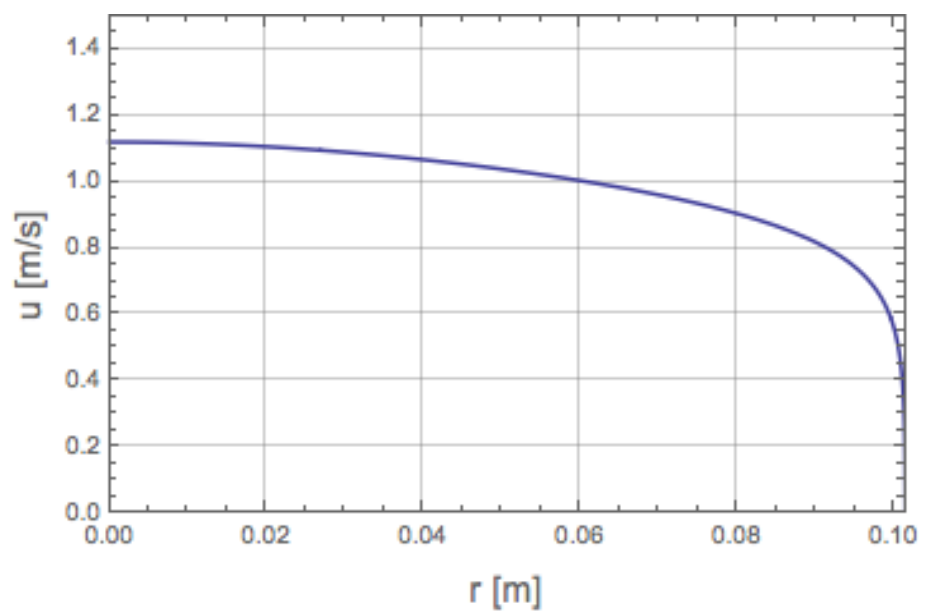

Figura C.6: $U=1 \mathrm{~m} / \mathrm{s}, R e=5,29 \times 10^{5}$.

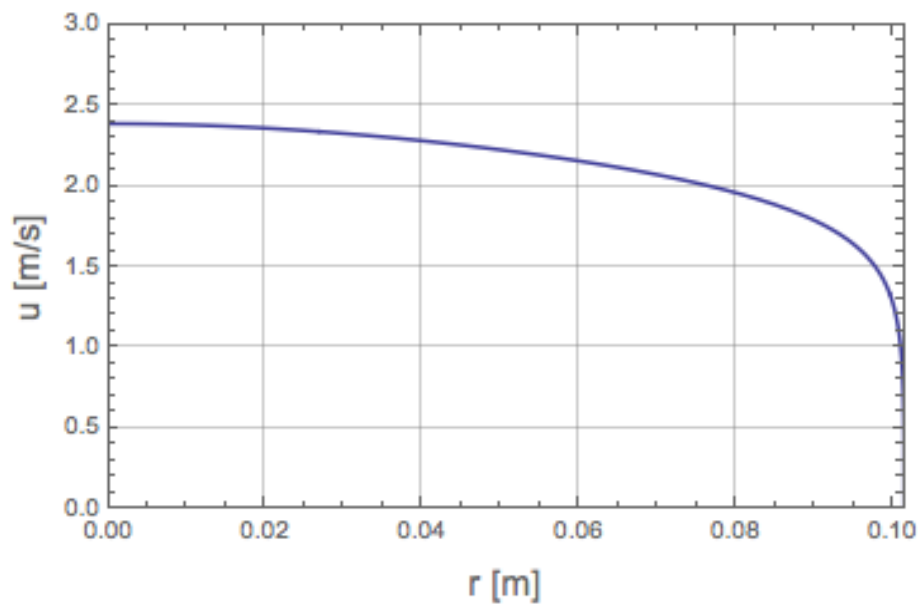

Figura C.7: $U=2 \mathrm{~m} / \mathrm{s}, R e=1,06 \times 10^{6}$. 


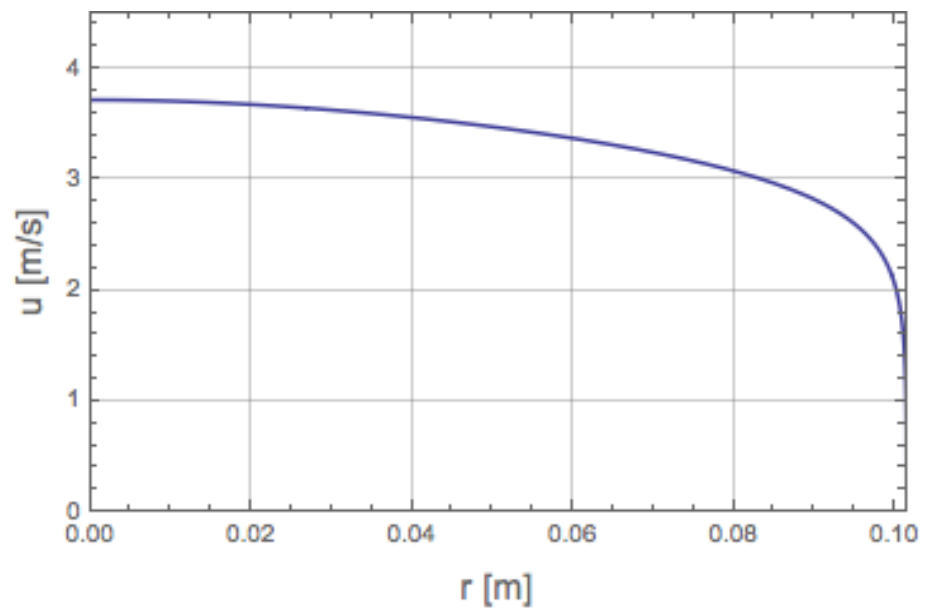

Figura C.8: $U=3 \mathrm{~m} / \mathrm{s}, R e=1,58 \times 10^{6}$.

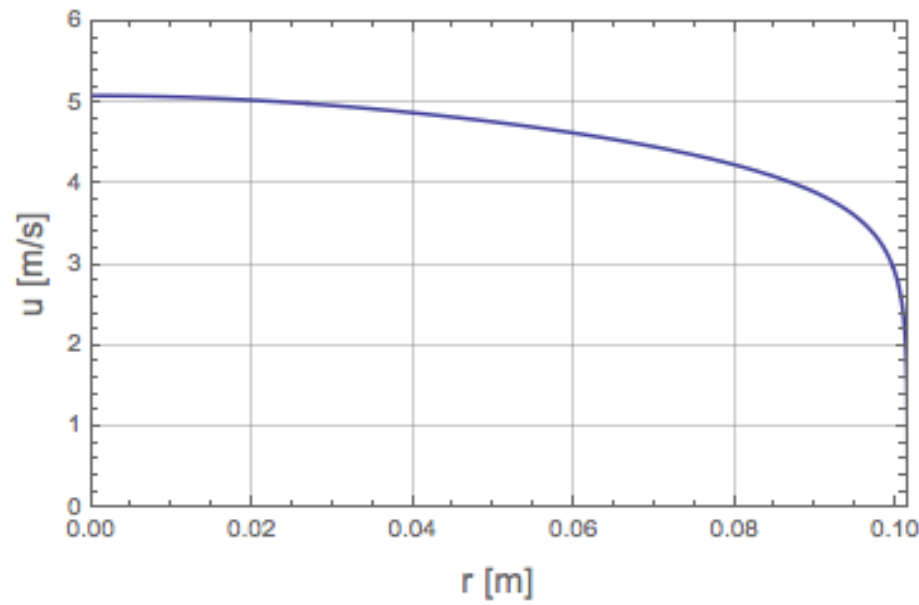

Figura C.9: $U=4 \mathrm{~m} / \mathrm{s}, R e=2,11 \times 10^{6}$.

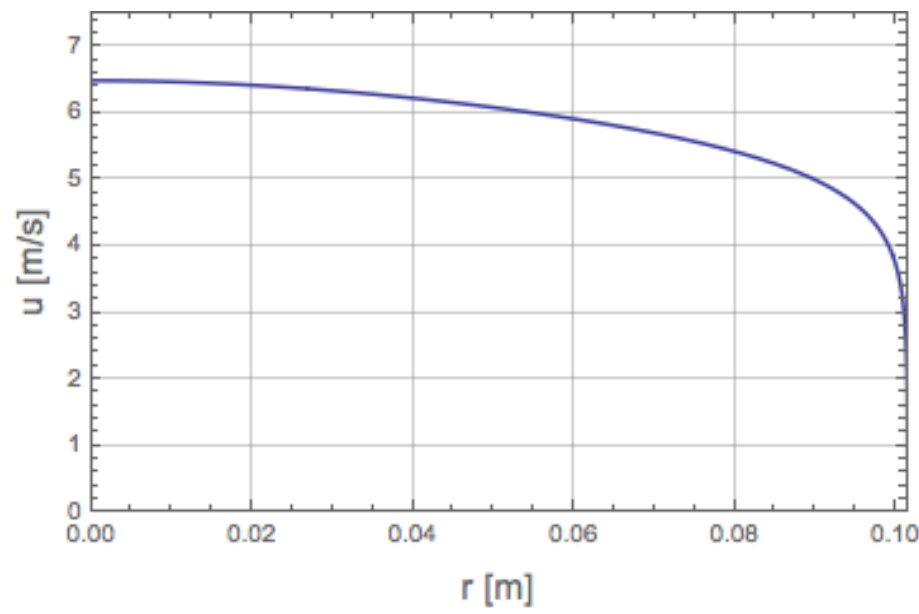

Figura C.10: $U=5 \mathrm{~m} / \mathrm{s}, R e=2,64 \times 10^{6}$. 
C.3 Tubo com $D_{n}=8$ "

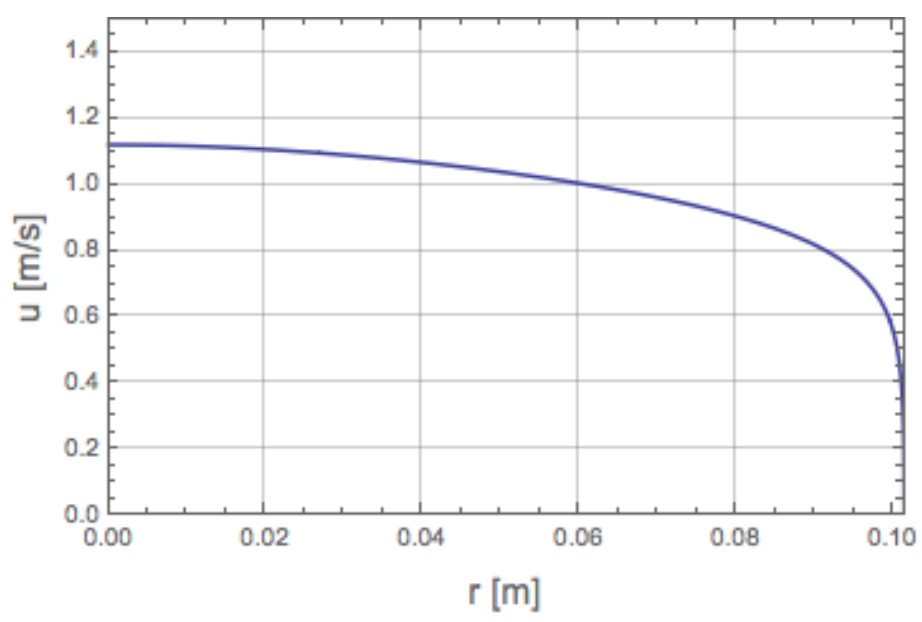

Figura C.11: $U=1 \mathrm{~m} / \mathrm{s}, R e=6,97 \times 10^{5}$.

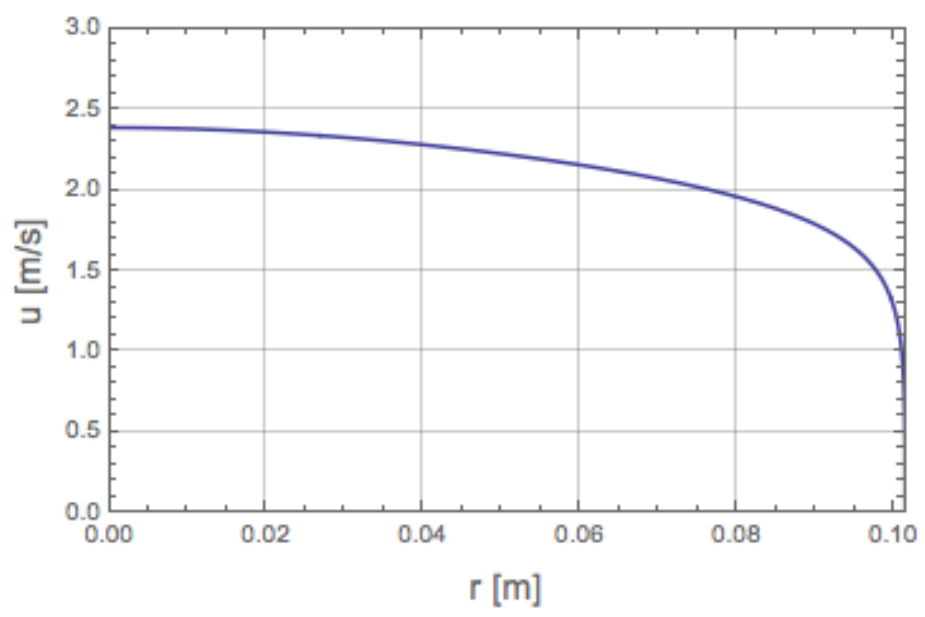

Figura C.12: $U=2 \mathrm{~m} / \mathrm{s}, \operatorname{Re}=1,39 \times 10^{6}$.

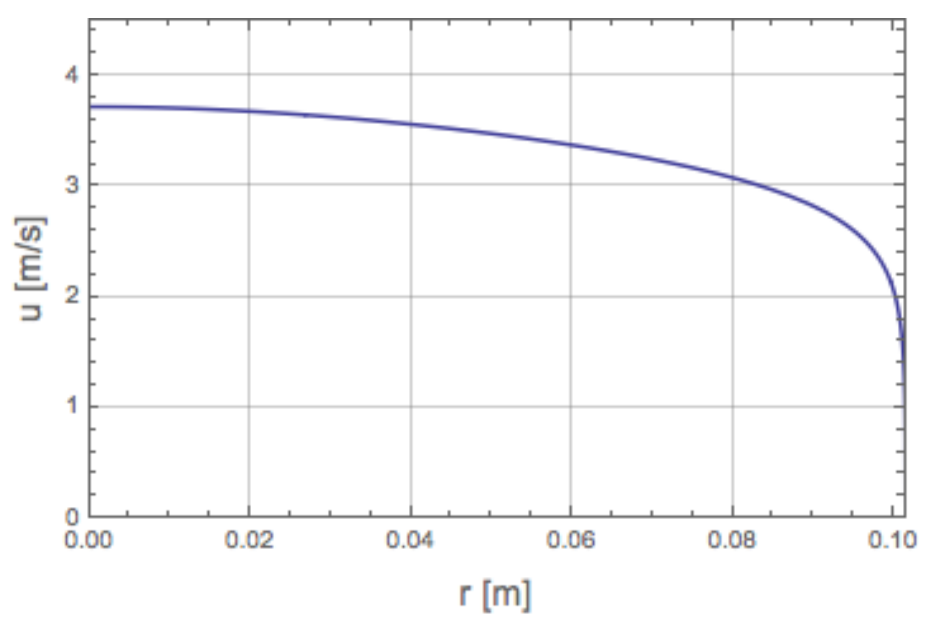

Figura C.13: $U=3 \mathrm{~m} / \mathrm{s}, R e=2,09 \times 10^{6}$. 


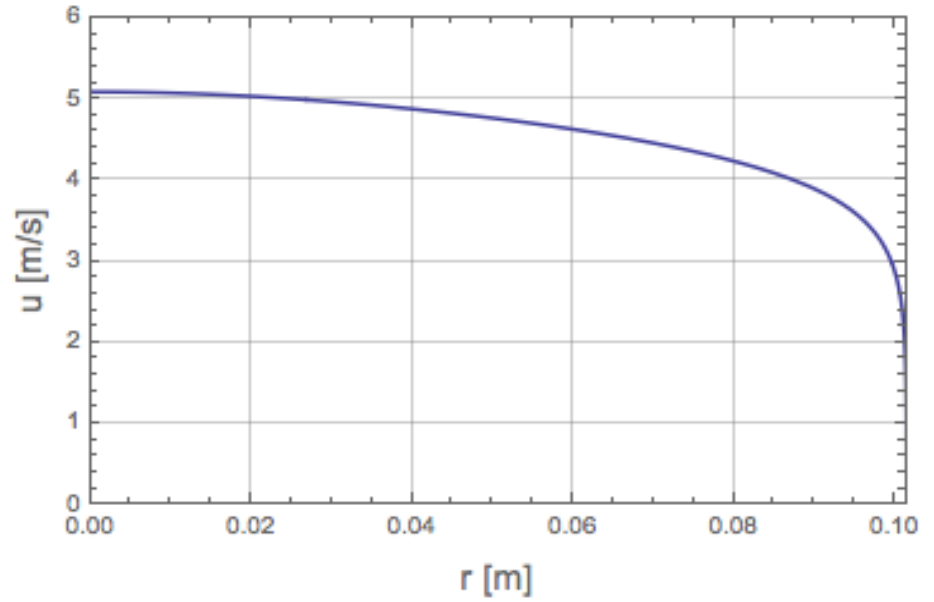

Figura C.14: $U=4 \mathrm{~m} / \mathrm{s}, R e=2,79 \times 10^{6}$.

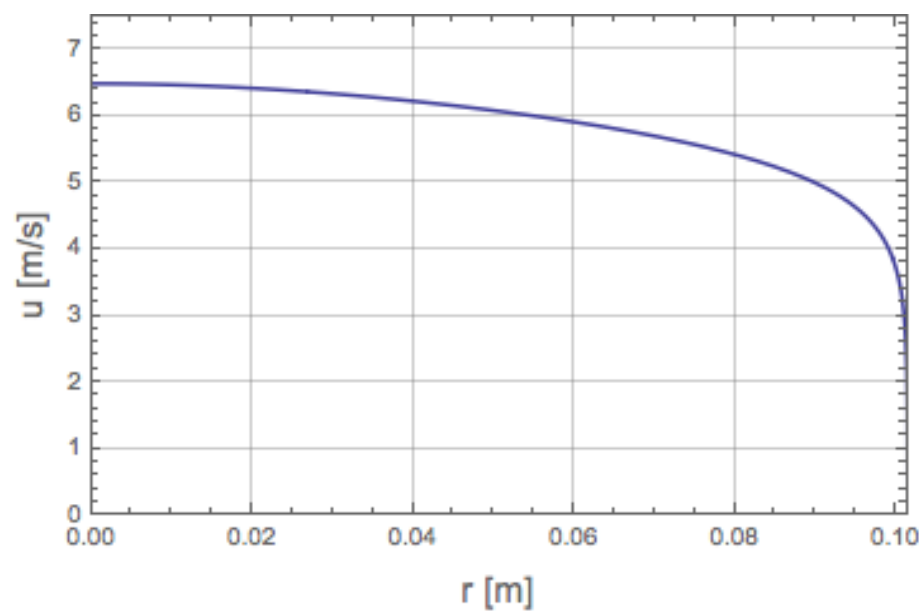

Figura C.15: $U=5 \mathrm{~m} / \mathrm{s}, R e=3,48 \times 10^{6}$.

\section{C.4 Tubo com $D_{n}=10 "$}

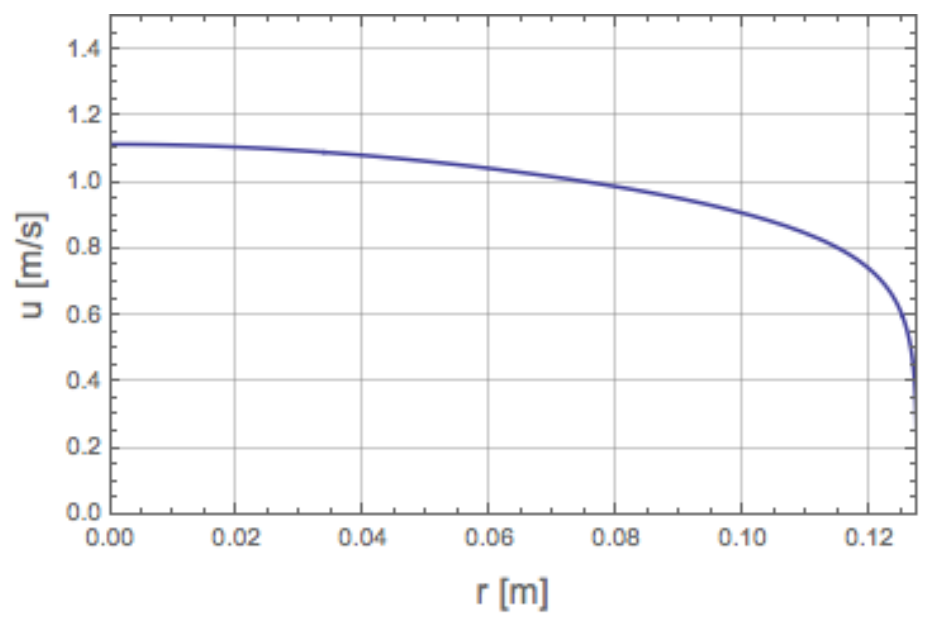

Figura C.16: $U=1 \mathrm{~m} / \mathrm{s}, R e=8,76 \times 10^{5}$. 


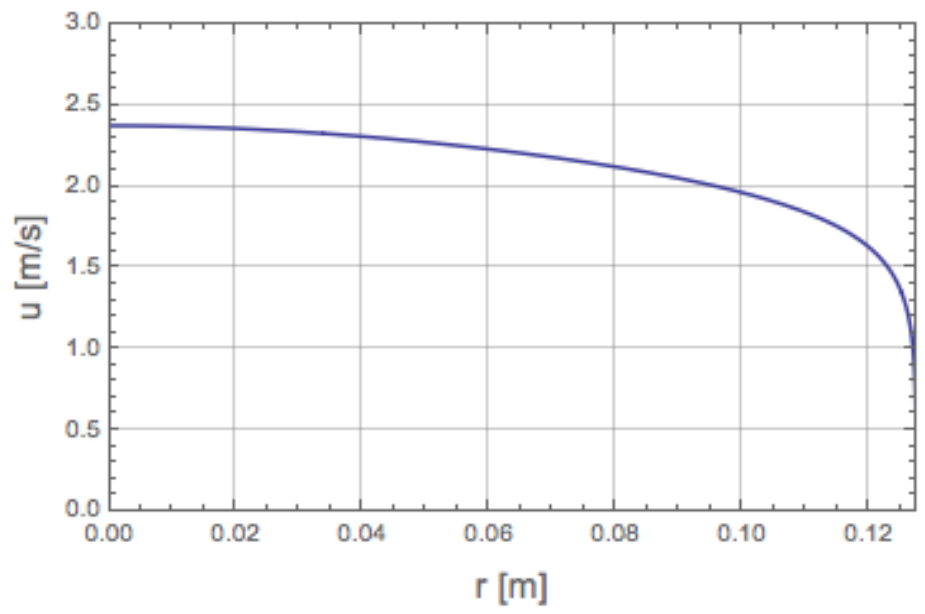

Figura C.17: $U=2 \mathrm{~m} / \mathrm{s}, R e=1,75 \times 10^{6}$.

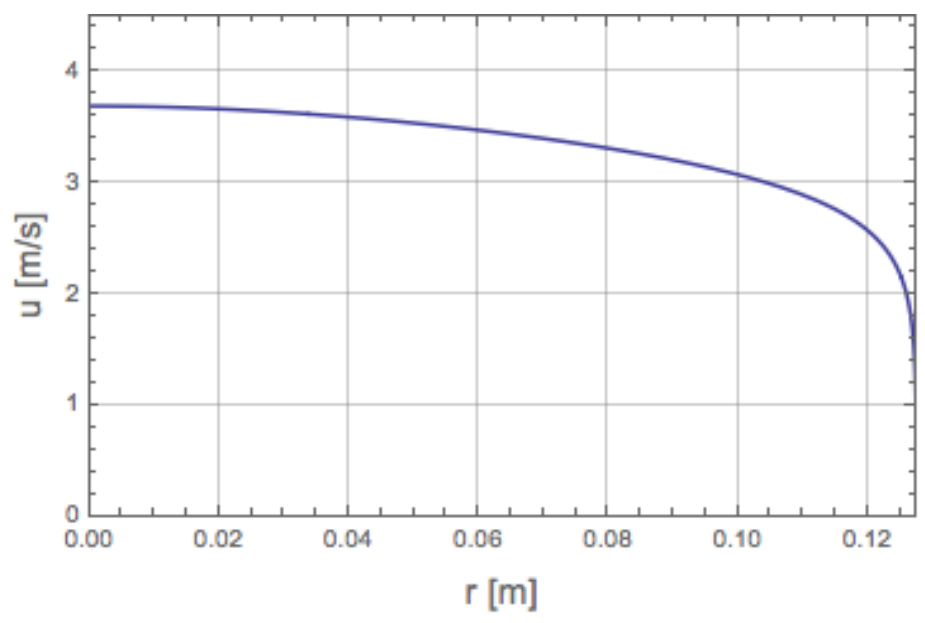

Figura C.18: $U=3 \mathrm{~m} / \mathrm{s}, R e=2,62 \times 10^{6}$.

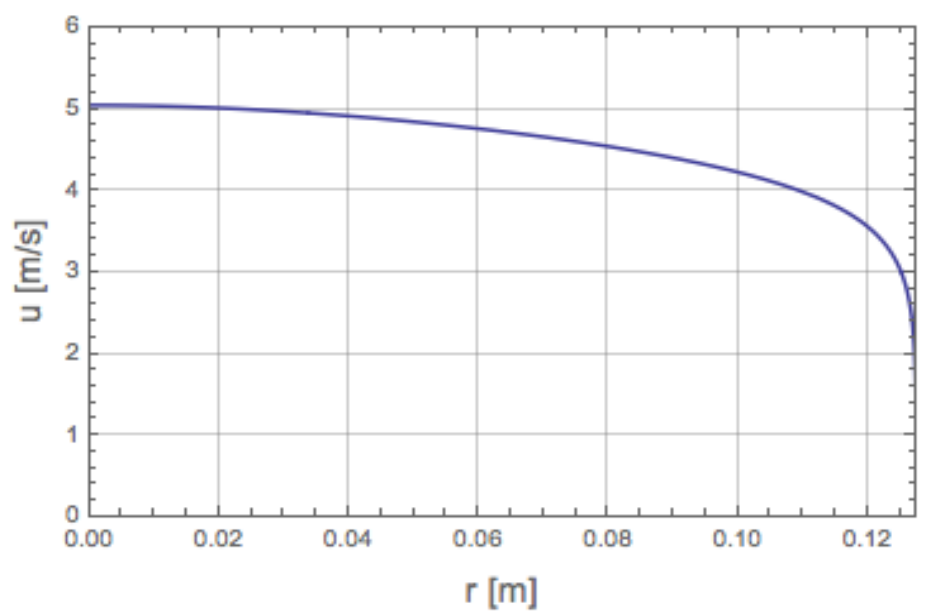

Figura C.19: $U=4 \mathrm{~m} / \mathrm{s}, R e=3,50 \times 10^{6}$. 


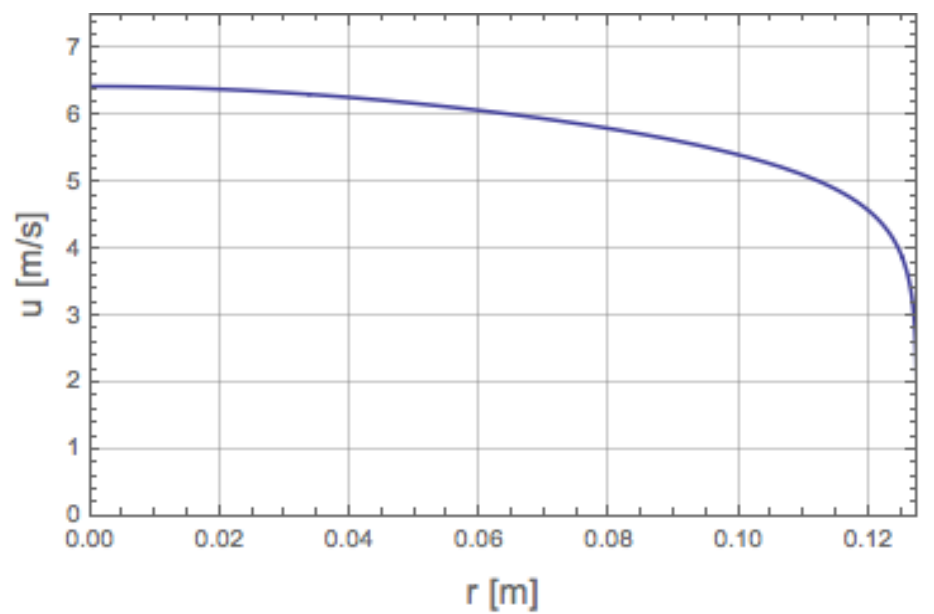

Figura C.20: $U=5 \mathrm{~m} / \mathrm{s}, R e=4,38 \times 10^{6}$. 


\section{Apêndice D}

\section{Gráficos da temperatura e da dilatação transitória para vários diâmetros e velocidades $U$}

Nessa seção são apresentados os resultados gráficos de simulações realizadas considerando o modelo físico apresentado na Sec. 3.1 e diâmetros e velocidades do escoamento $U$ distintos. O fluido é sempre a água, a temperatura média de entrada $T_{m e}$ é $100^{\circ} \mathrm{C}$ e a temperatura externa $T_{\infty}$ é $25^{\circ} \mathrm{C}$, embora o número de Reynolds, de Nusselt e de Grashof estejam indicados nos gráficos. 


\section{D.1 Tubo de aço com $D_{n}=4$ "}

D.1.1 $U=2 \mathrm{~m} / \mathrm{s}$

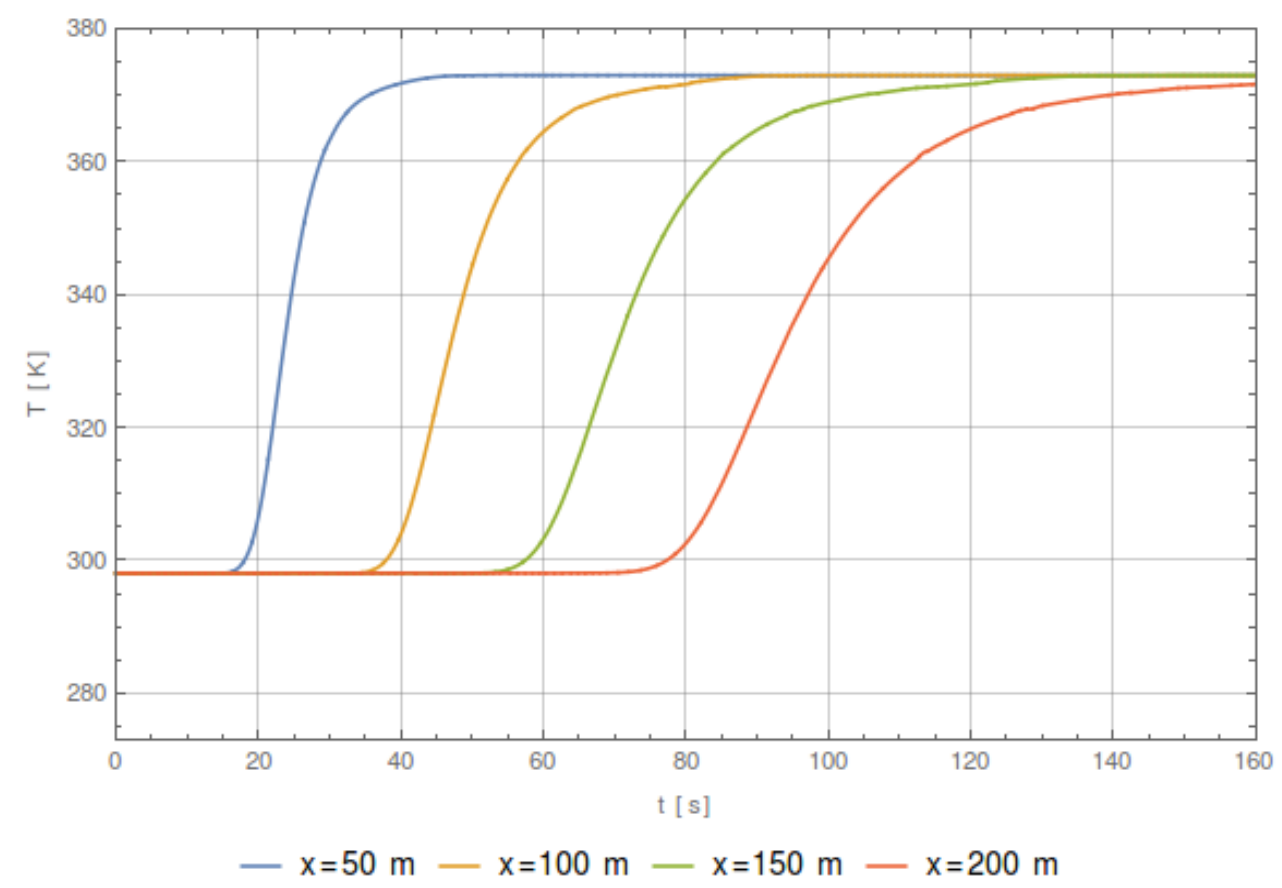

Figura D.1: Evolução temporal da temperatura média do fluido. $D_{n}=4$ ", $U=2 \mathrm{~m} / \mathrm{s}, R e=$ $7,02 \times 10^{5}, N u=2,60 \times 10^{3}, h_{i}=1,73 \times 10^{4} \mathrm{~W} / \mathrm{m}^{2} \mathrm{~K}, \mathrm{Gr}=2,31 \times 10^{1}, h_{e}=$ $5,84 \mathrm{~W} / \mathrm{m}^{2} \mathrm{~K}$.

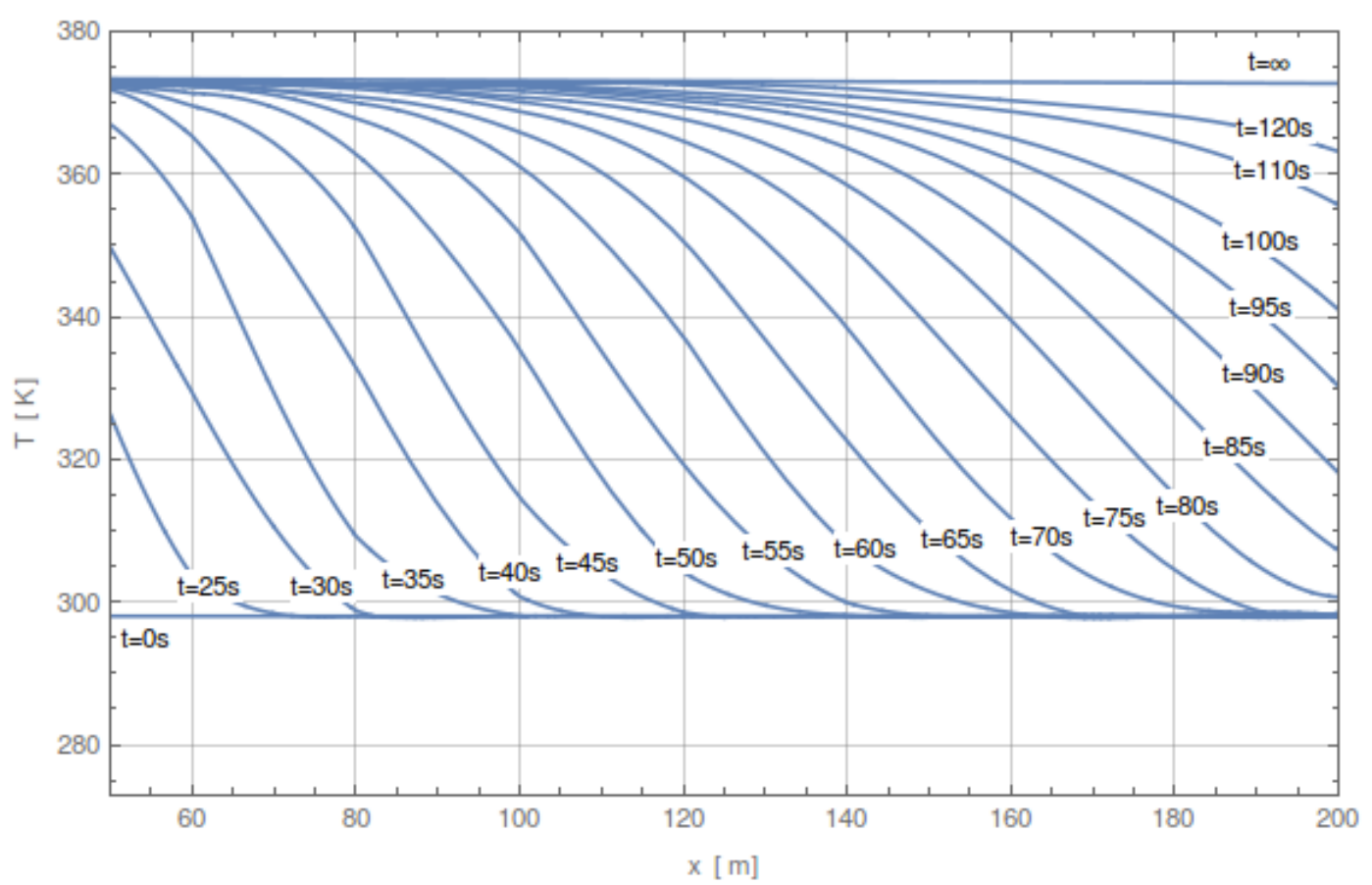

Figura D.2: Perfil da temperatura média do tubo. $D_{n}=4$ ", $U=2 \mathrm{~m} / \mathrm{s}, R e=7,02 \times 10^{5}$, $N u=2,60 \times 10^{3}, h_{i}=1,73 \times 10^{4} \mathrm{~W} / \mathrm{m}^{2} \mathrm{~K}, \mathrm{Gr}=2,31 \times 10^{1}, h_{e}=5,84 \mathrm{~W} / \mathrm{m}^{2} \mathrm{~K}$. 


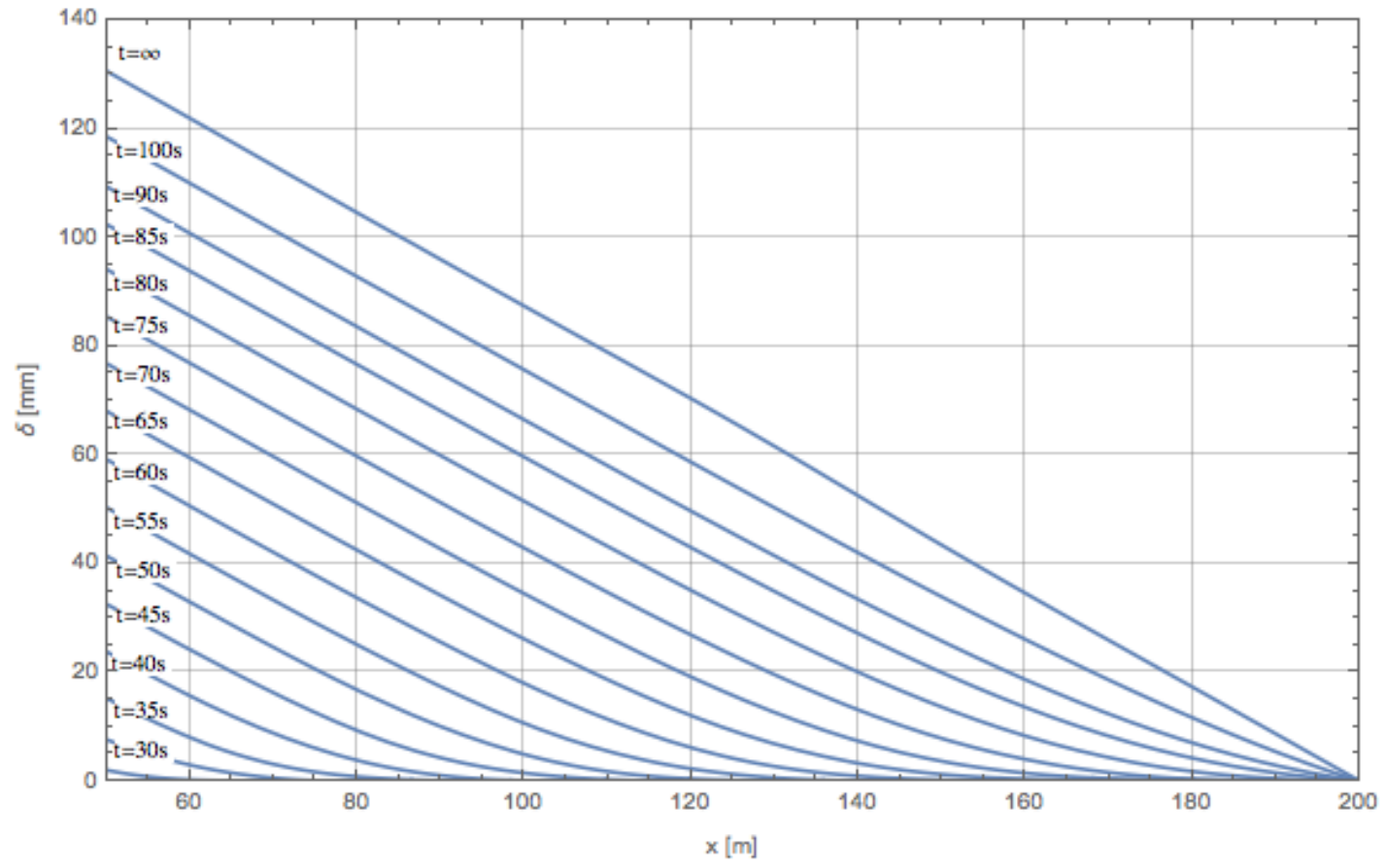

Figura D.3: Perfil da dilatação linear do tubo. $D_{n}=4$ ", $U=2 \mathrm{~m} / \mathrm{s}, R e=7,02 \times 10^{5}, N u=$ $2,60 \times 10^{3}, h_{i}=1,73 \times 10^{4} \mathrm{~W} / \mathrm{m}^{2} \mathrm{~K}, \mathrm{Gr}=2,31 \times 10^{1}, h_{e}=5,84 \mathrm{~W} / \mathrm{m}^{2} \mathrm{~K}$.

\section{D.1.2 $U=3 \mathrm{~m} / \mathrm{s}$}

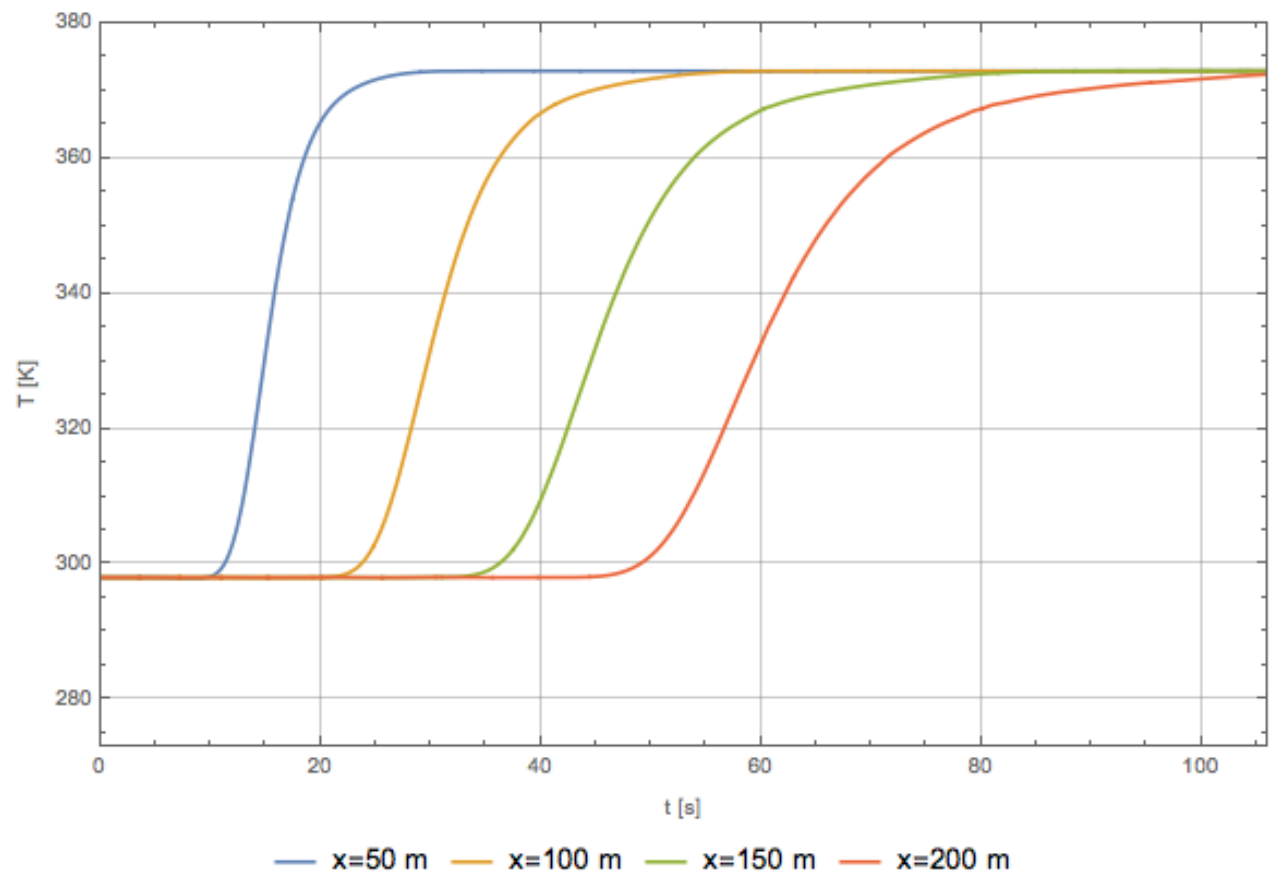

Figura D.4: Evolução temporal da temperatura média do fluido. $D_{n}=4 ", U=3 \mathrm{~m} / \mathrm{s}, R e=$ $1,05 \times 10^{6}, N u=3,88 \times 10^{3}, h_{i}=2,58 \times 10^{4} \mathrm{~W} / \mathrm{m}^{2} \mathrm{~K}, \mathrm{Gr}=2,31 \times 10^{1}, h_{e}=$ $5,84 \mathrm{~W} / \mathrm{m}^{2} \mathrm{~K}$. 


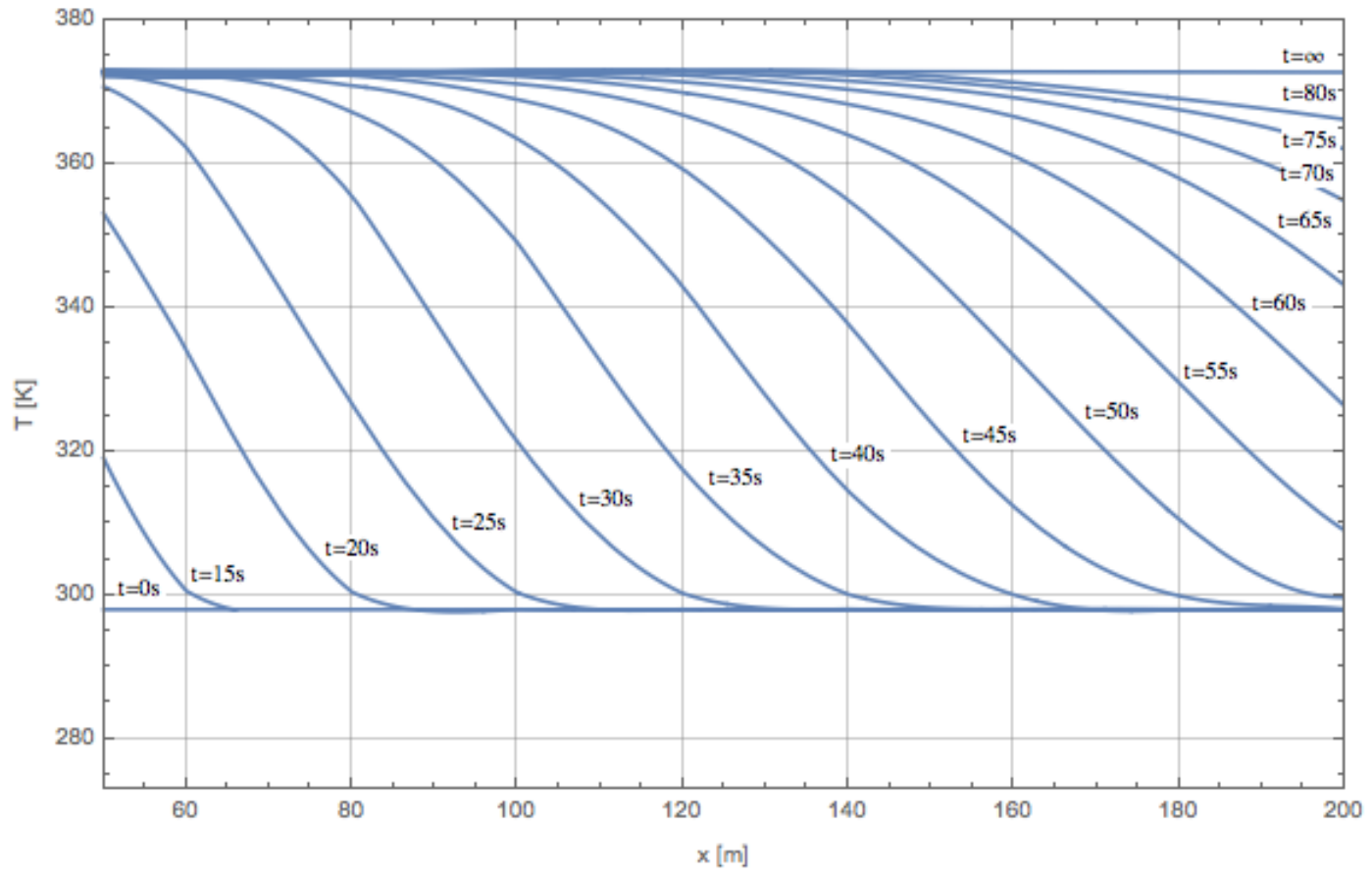

Figura D.5: Perfil da temperatura média do tubo. $D_{n}=4$ ", $U=3 \mathrm{~m} / \mathrm{s}, R e=1,05 \times 10^{6}$, $N u=3,88 \times 10^{3}, h_{i}=2,58 \times 10^{4} \mathrm{~W} / \mathrm{m}^{2} \mathrm{~K}, \mathrm{Gr}=2,31 \times 10^{1}, h_{e}=5,84 \mathrm{~W} / \mathrm{m}^{2} \mathrm{~K}$.

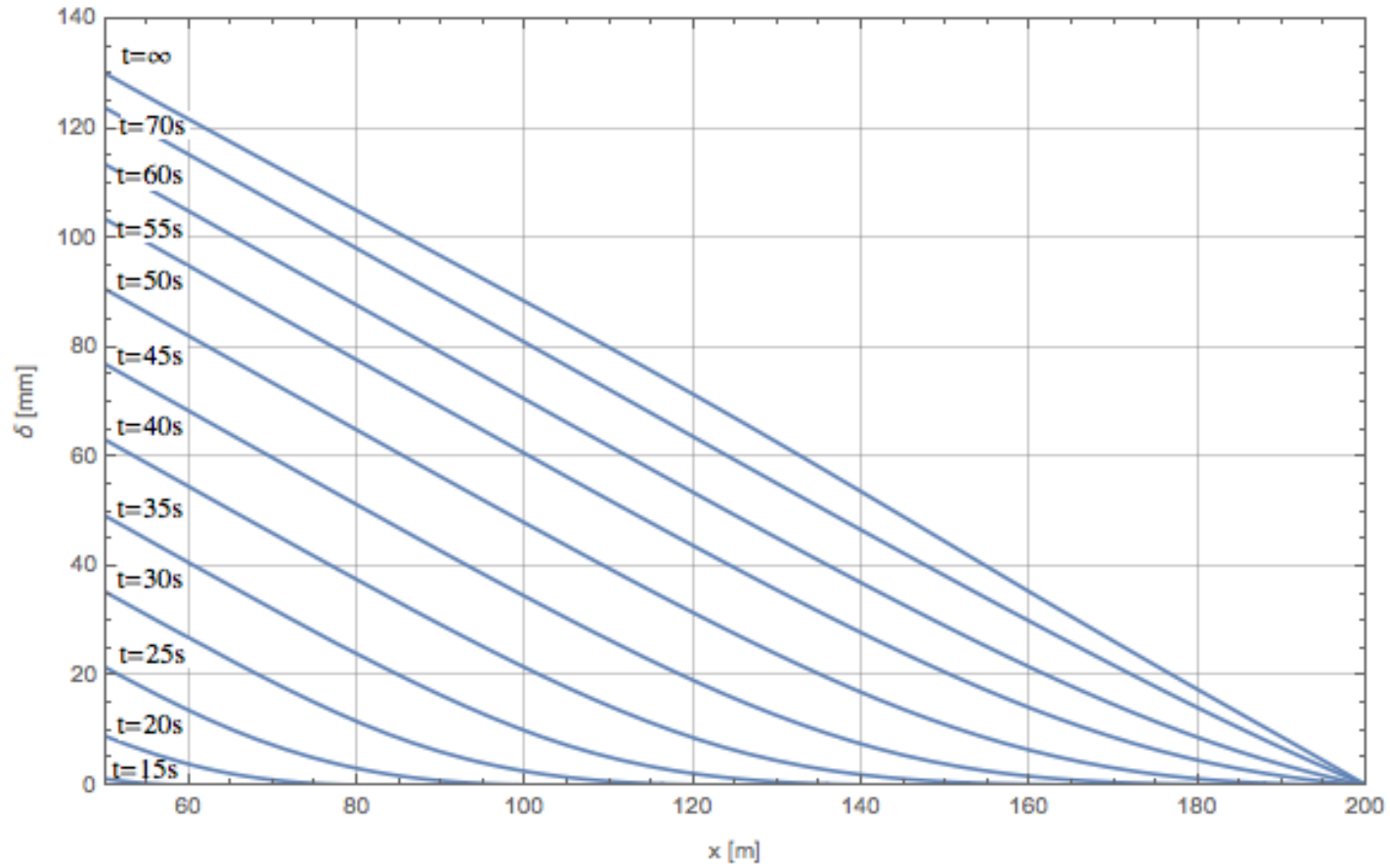

Figura D.6: Perfil da dilatação linear do tubo. $D_{n}=4$ ", $U=3 \mathrm{~m} / \mathrm{s}, R e=1,05 \times 10^{6}, N u=$ $3,88 \times 10^{3}, h_{i}=2,58 \times 10^{4} \mathrm{~W} / \mathrm{m}^{2} \mathrm{~K}, \mathrm{Gr}=2,31 \times 10^{1}, h_{e}=5,84 \mathrm{~W} / \mathrm{m}^{2} \mathrm{~K}$. 
D.1.3 $U=4 \mathrm{~m} / \mathrm{s}$

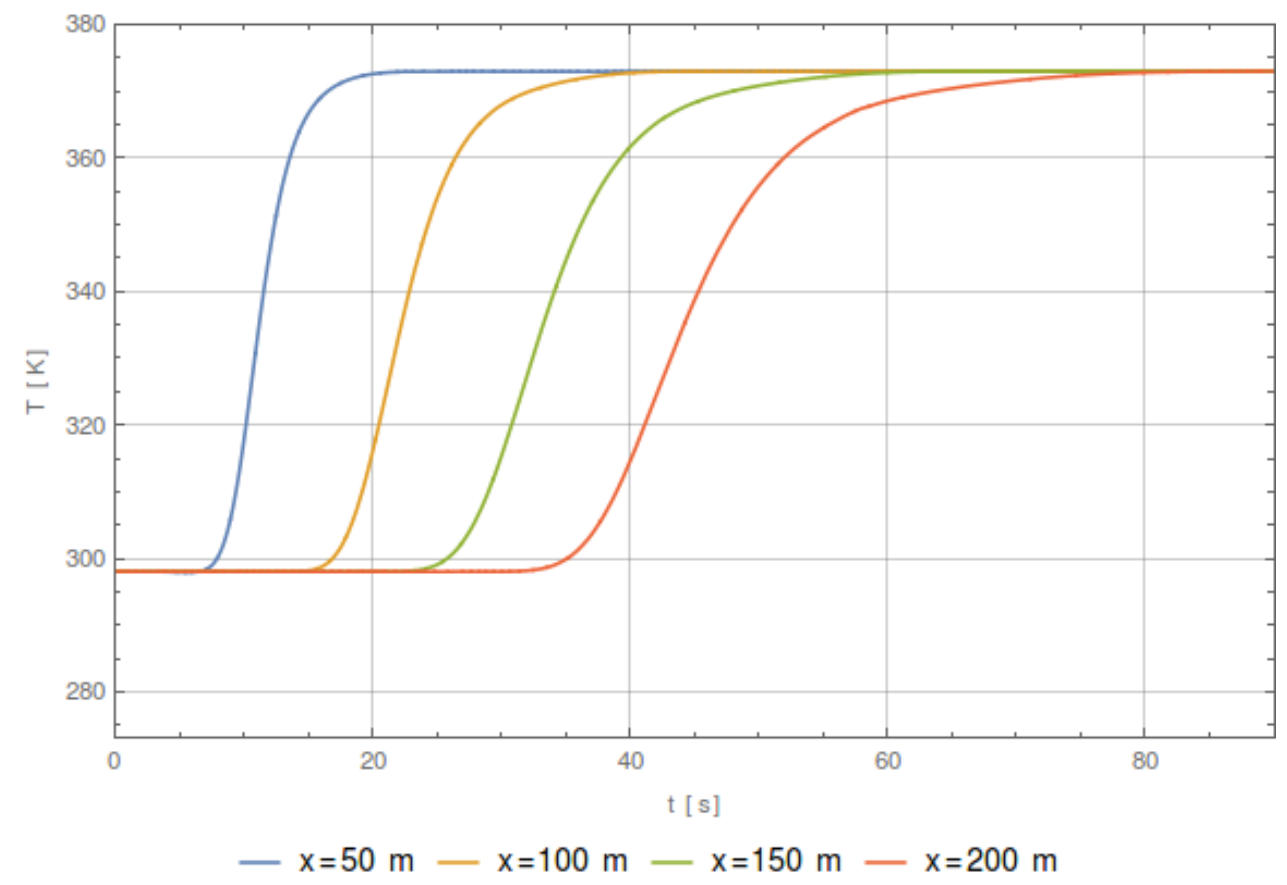

Figura D.7: Evolução temporal da temperatura média do fluido. $D_{n}=4 ", U=4 \mathrm{~m} / \mathrm{s}, R e=$ $1,40 \times 10^{6}, N u=5,17 \times 10^{3}, h_{i}=3,43 \times 10^{4} \mathrm{~W} / \mathrm{m}^{2} \mathrm{~K}, \mathrm{Gr}=2,31 \times 10^{1}, h_{e}=$ $5,84 \mathrm{~W} / \mathrm{m}^{2} \mathrm{~K}$.

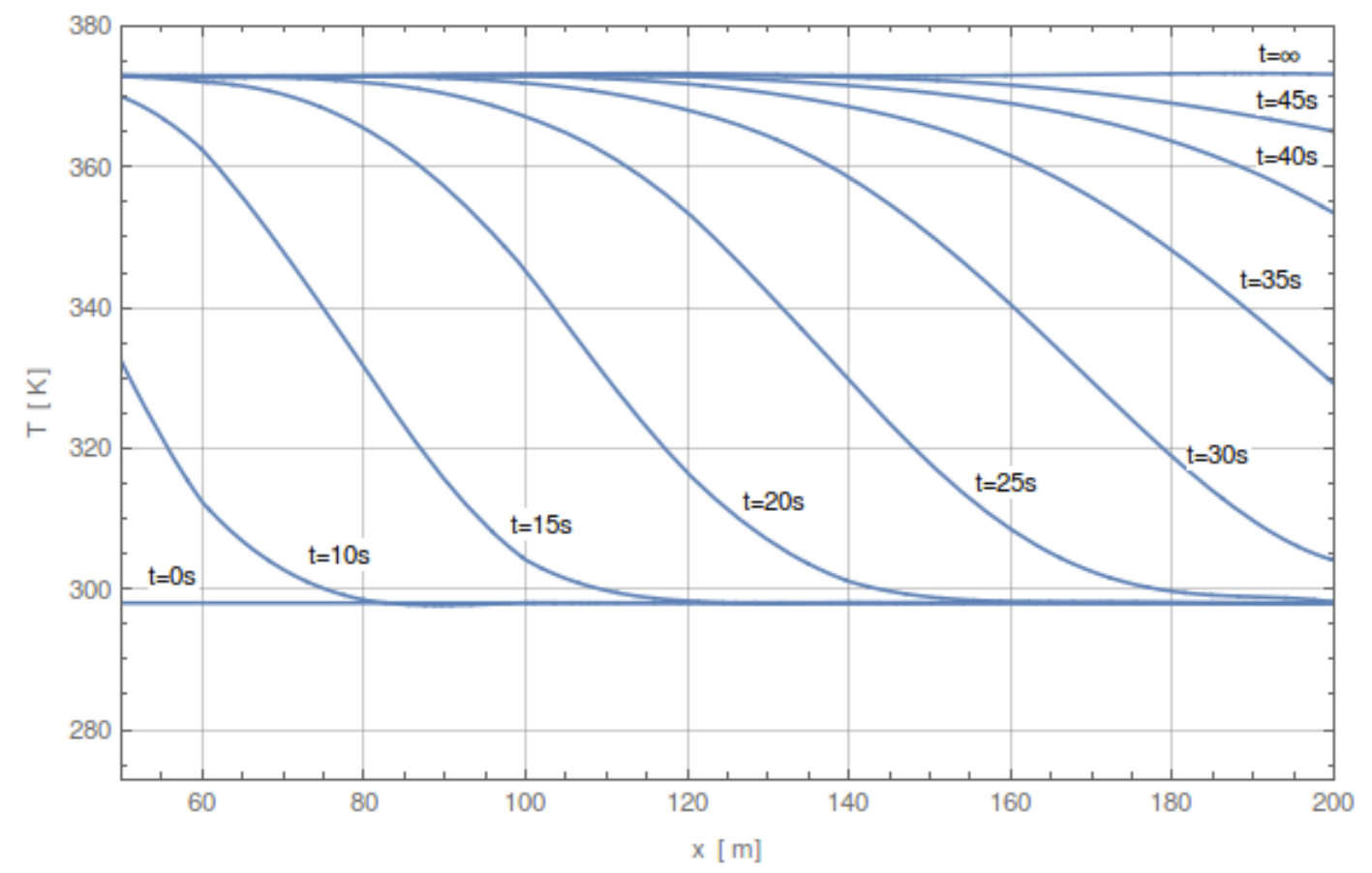

Figura D.8: Perfil da temperatura média do tubo. $D_{n}=4$ ", $U=4 \mathrm{~m} / \mathrm{s}, R e=1,40 \times 10^{6}$, $N u=5,17 \times 10^{3}, h_{i}=3,43 \times 10^{4} \mathrm{~W} / \mathrm{m}^{2} \mathrm{~K}, \mathrm{Gr}=2,31 \times 10^{1}, h_{e}=5,84 \mathrm{~W} / \mathrm{m}^{2} \mathrm{~K}$. 


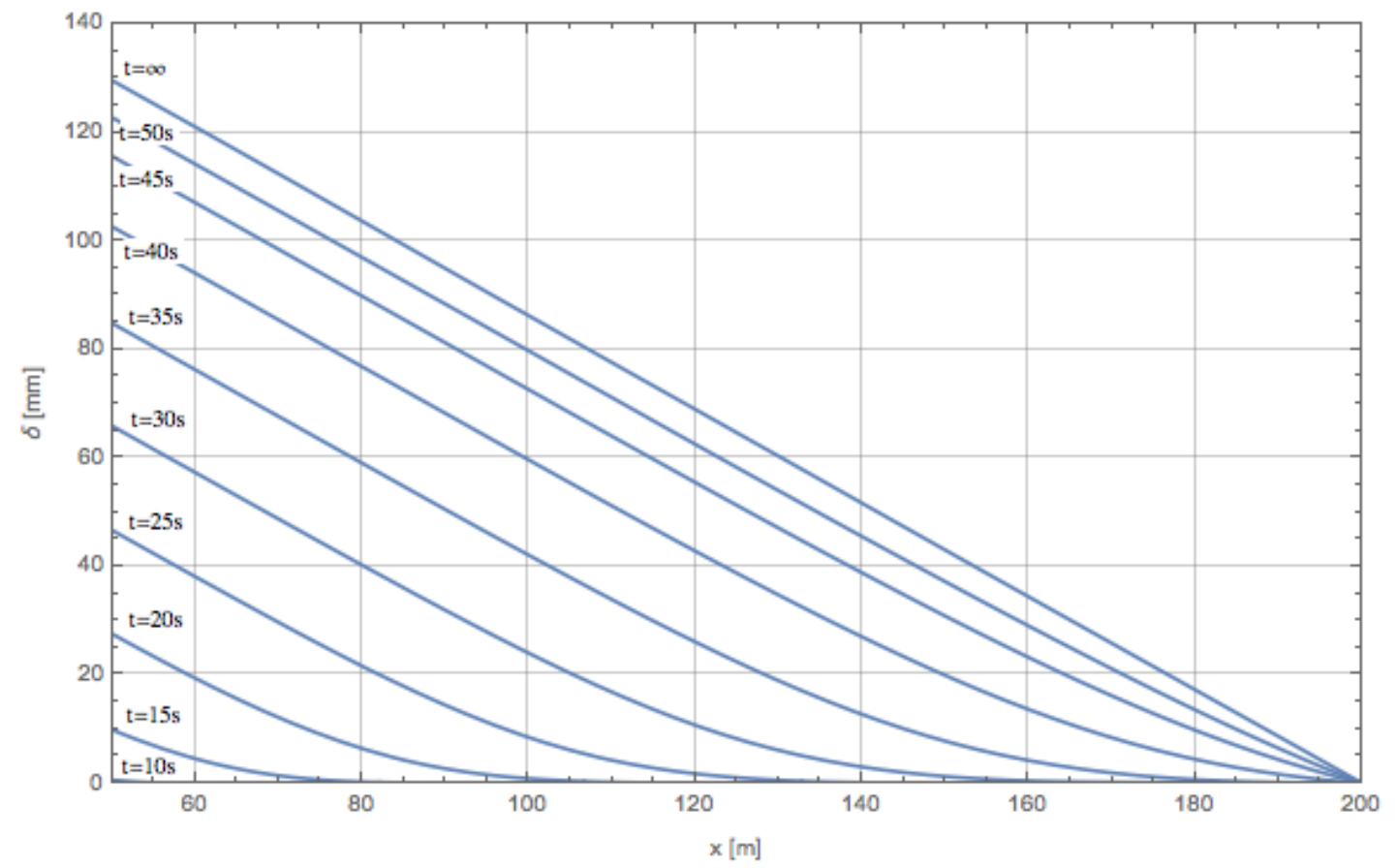

Figura D.9: Perfil da dilatação linear do tubo. $D_{n}=4$ ", $U=4 \mathrm{~m} / \mathrm{s}, R e=1,40 \times 10^{6}, N u=$ $5,17 \times 10^{3}, h_{i}=3,43 \times 10^{4} \mathrm{~W} / \mathrm{m}^{2} \mathrm{~K}, \mathrm{Gr}=2,31 \times 10^{1}, h_{e}=5,84 \mathrm{~W} / \mathrm{m}^{2} \mathrm{~K}$.

\section{D.1.4 $U=5 \mathrm{~m} / \mathrm{s}$}

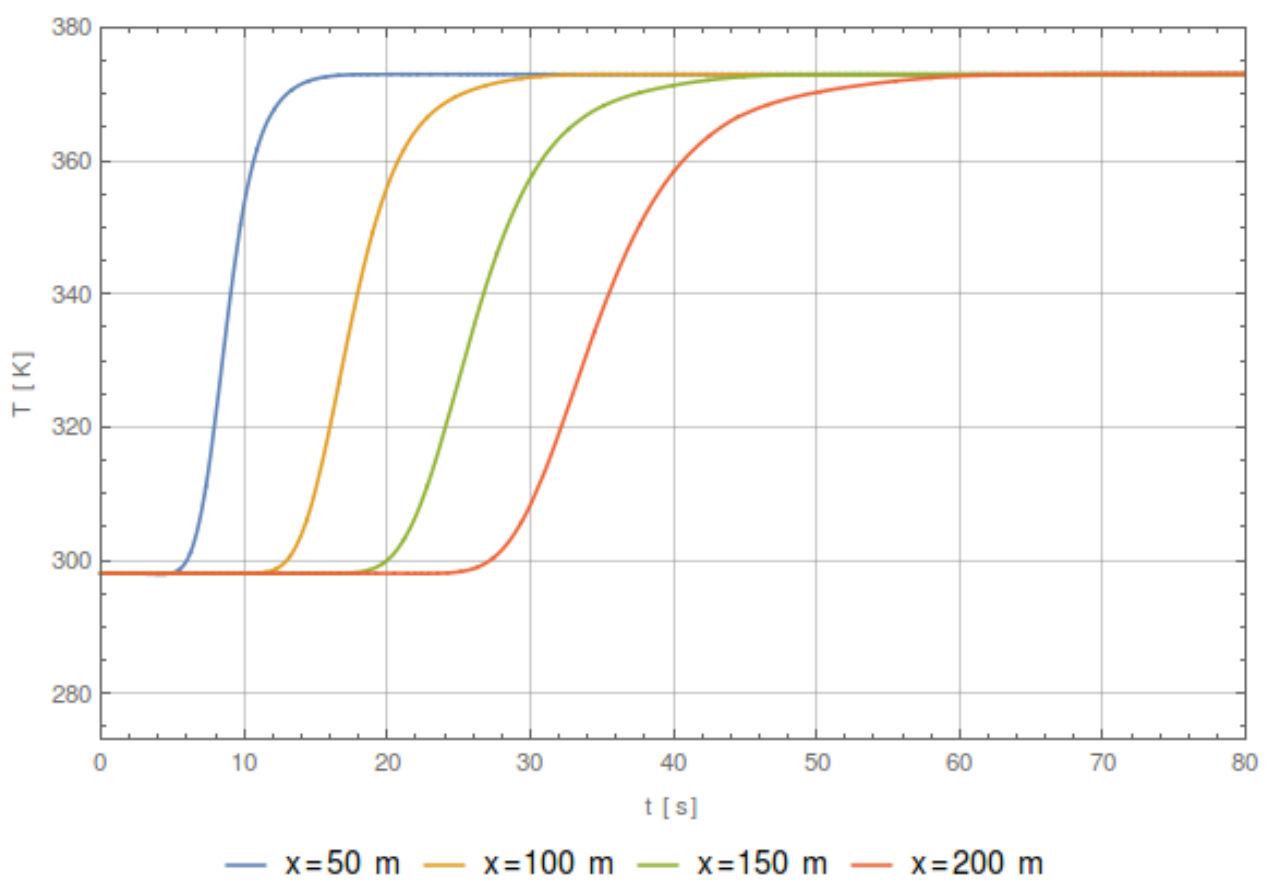

Figura D.10: Evolução temporal da temperatura média do fluido. $D_{n}=4 ", U=5 \mathrm{~m} / \mathrm{s}, R e=$ $1,75 \times 10^{6}, N u=6,45 \times 10^{3}, h_{i}=4,29 \times 10^{4} \mathrm{~W} / \mathrm{m}^{2} K, G r=2,31 \times 10^{1}, h_{e}=$ $5,84 \mathrm{~W} / \mathrm{m}^{2} \mathrm{~K}$. 


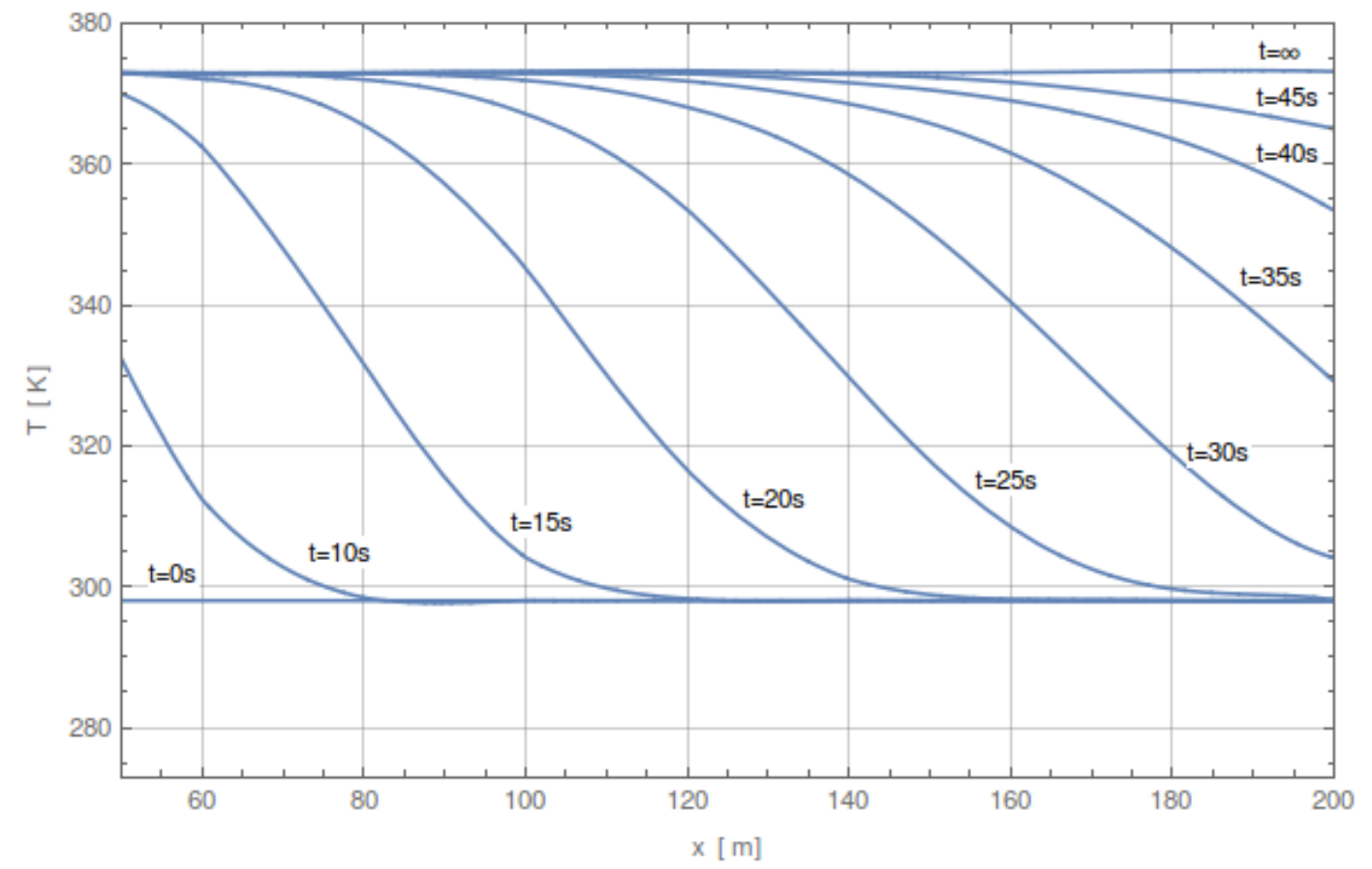

Figura D.11: Perfil da temperatura média do tubo. $D_{n}=4 ", U=5 \mathrm{~m} / \mathrm{s}, R e=1,75 \times 10^{6}$, $N u=6,45 \times 10^{3}, h_{i}=4,29 \times 10^{4} \mathrm{~W} / \mathrm{m}^{2} \mathrm{~K}, \mathrm{Gr}=2,31 \times 10^{1}, h_{e}=5,84 \mathrm{~W} / \mathrm{m}^{2} \mathrm{~K}$.

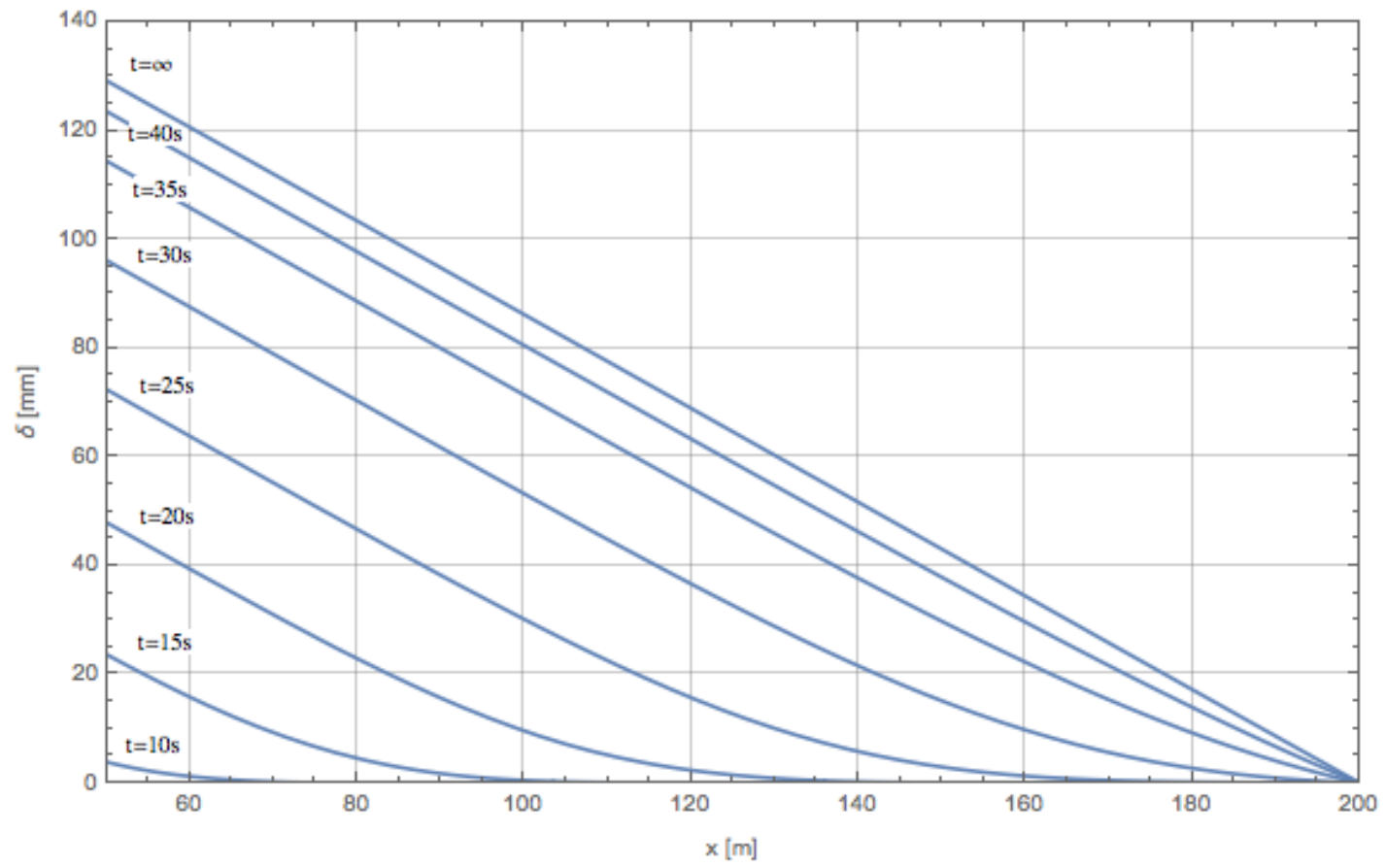

Figura D.12: Perfil da dilatação linear do tubo. $D_{n}=4 ", U=5 \mathrm{~m} / \mathrm{s}, R e=1,75 \times 10^{6}$, $N u=6,45 \times 10^{3}, h_{i}=4,29 \times 10^{4} \mathrm{~W} / \mathrm{m}^{2} \mathrm{~K}, \mathrm{Gr}=2,31 \times 10^{1}, h_{e}=5,84 \mathrm{~W} / \mathrm{m}^{2} \mathrm{~K}$. 


\section{D.2 Tubo de aço com $D_{n}=6$ "}

D.2.1 $U=2 \mathrm{~m} / \mathrm{s}$

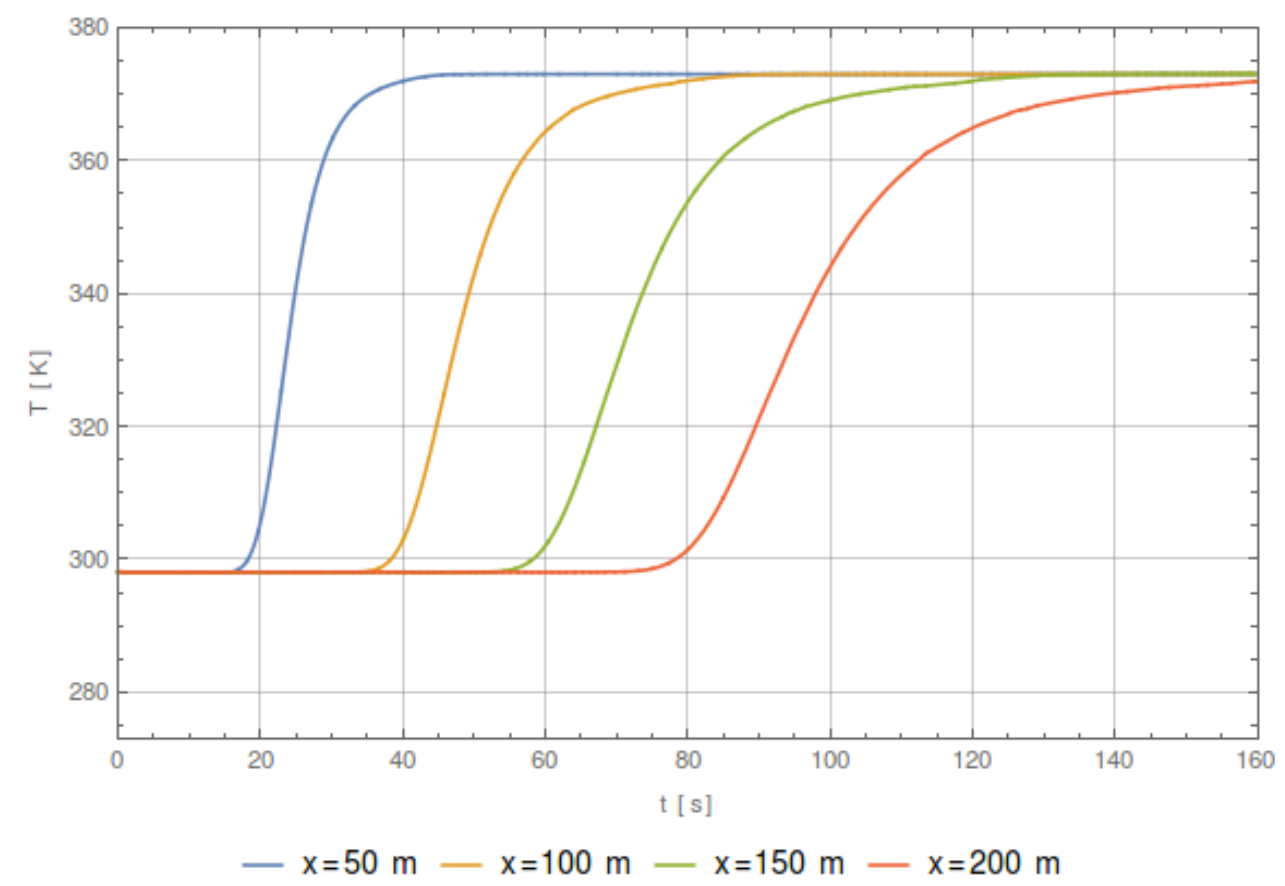

Figura D.13: Evolução temporal da temperatura média do fluido. $D_{n}=6$ ", $U=2 \mathrm{~m} / \mathrm{s}, R e=$ $1,06 \times 10^{6}, N u=3,58 \times 10^{3}, h_{i}=1,58 \times 10^{4} \mathrm{~W} / \mathrm{m}^{2} K, G r=3,25 \times 10^{1}, h_{e}=$ $5,58 \mathrm{~W} / \mathrm{m}^{2} \mathrm{~K}$.

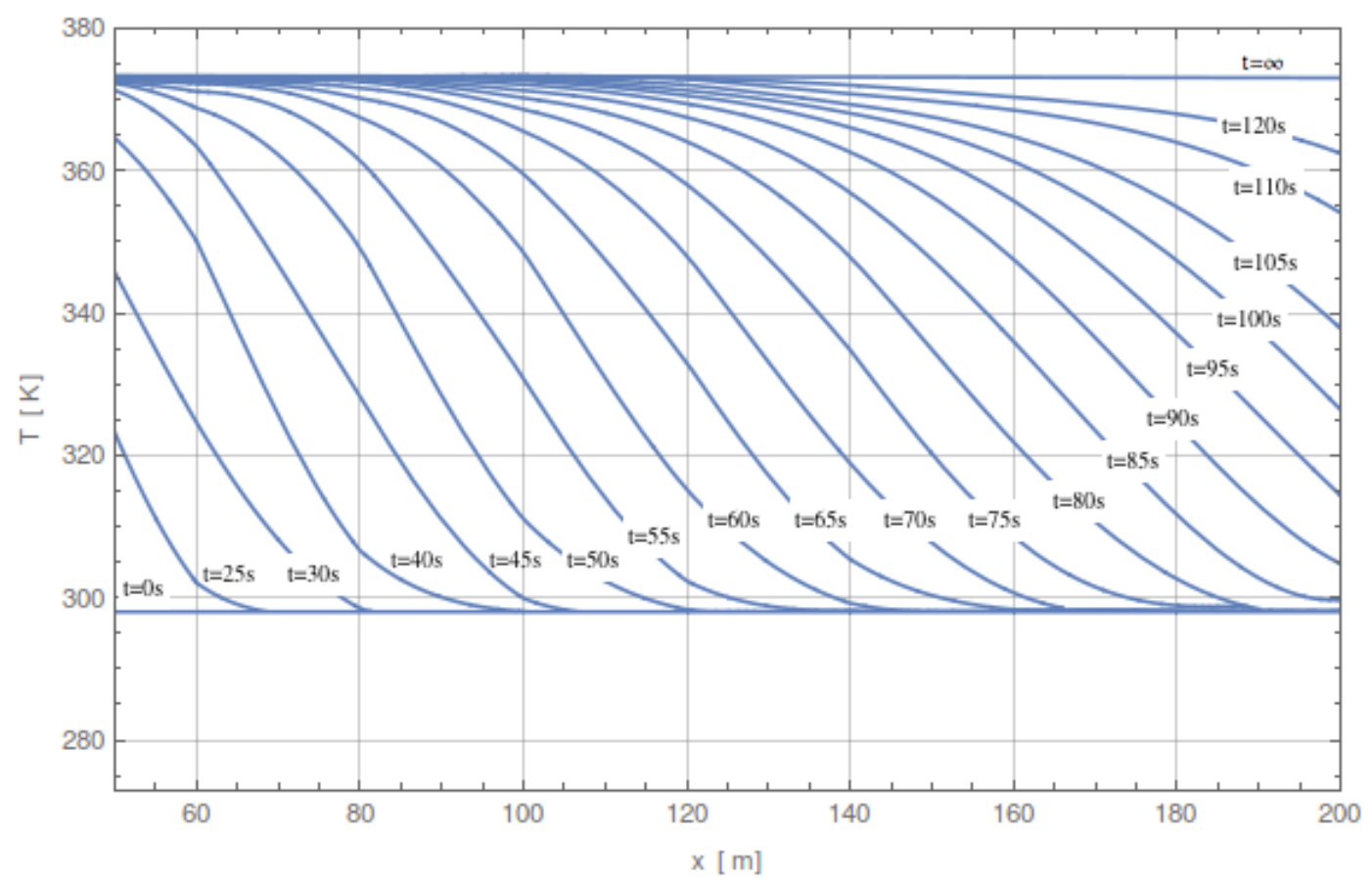

Figura D.14: Perfil da temperatura média do tubo. $D_{n}=6$ ", $U=2 \mathrm{~m} / \mathrm{s}, R e=1,06 \times 10^{6}$, $N u=3,58 \times 10^{3}, h_{i}=1,58 \times 10^{4} \mathrm{~W} / \mathrm{m}^{2} \mathrm{~K}, \mathrm{Gr}=3,25 \times 10^{1}, h_{e}=5,58 \mathrm{~W} / \mathrm{m}^{2} \mathrm{~K}$. 


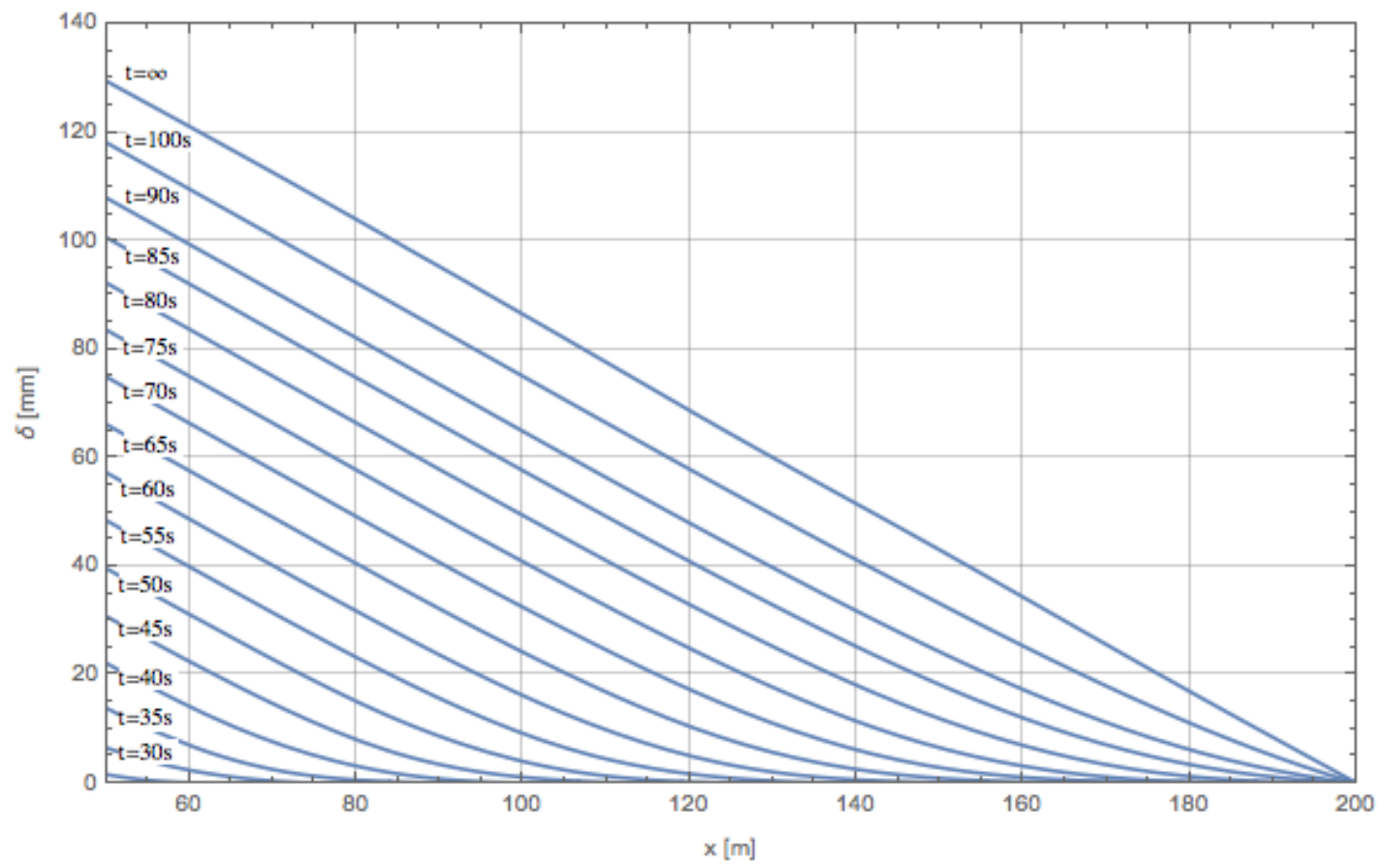

Figura D.15: Perfil da dilatação linear do tubo. $D_{n}=6$ ", $U=2 \mathrm{~m} / \mathrm{s}, R e=1,06 \times 10^{6}$, $N u=3,58 \times 10^{3}, h_{i}=1,58 \times 10^{4} \mathrm{~W} / \mathrm{m}^{2} \mathrm{~K}, \mathrm{Gr}=3,25 \times 10^{1}, h_{e}=5,58 \mathrm{~W} / \mathrm{m}^{2} \mathrm{~K}$.

\section{D.2.2 $U=3 \mathrm{~m} / \mathrm{s}$}

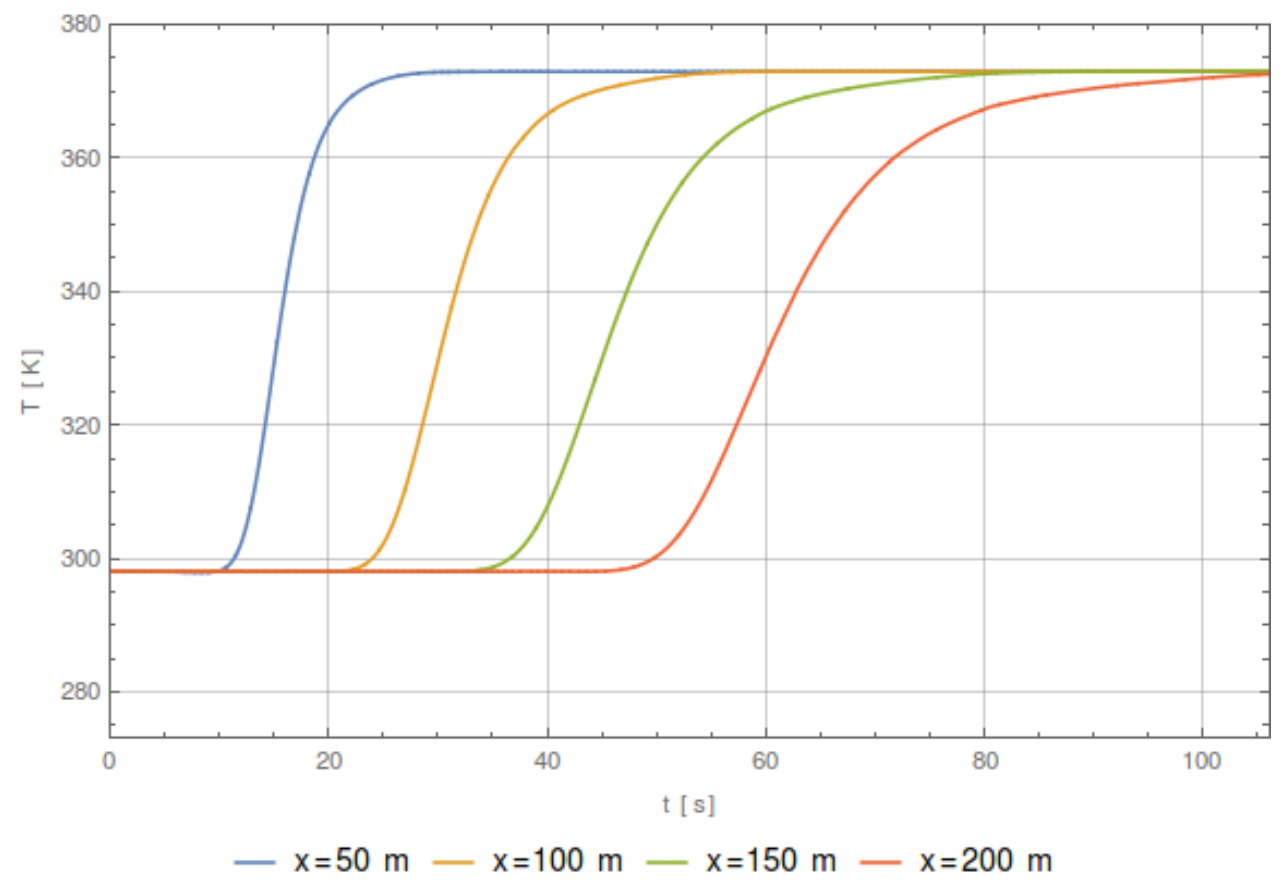

Figura D.16: Evolução temporal da temperatura média do fluido. $D_{n}=6 ", U=3 \mathrm{~m} / \mathrm{s}, R e=$ $1,58 \times 10^{6}, N u=5,35 \times 10^{3}, h_{i}=2,36 \times 10^{4} \mathrm{~W} / \mathrm{m}^{2} \mathrm{~K}, \mathrm{Gr}=3,25 \times 10^{1}, h_{e}=$ $5,58 \mathrm{~W} / \mathrm{m}^{2} \mathrm{~K}$. 


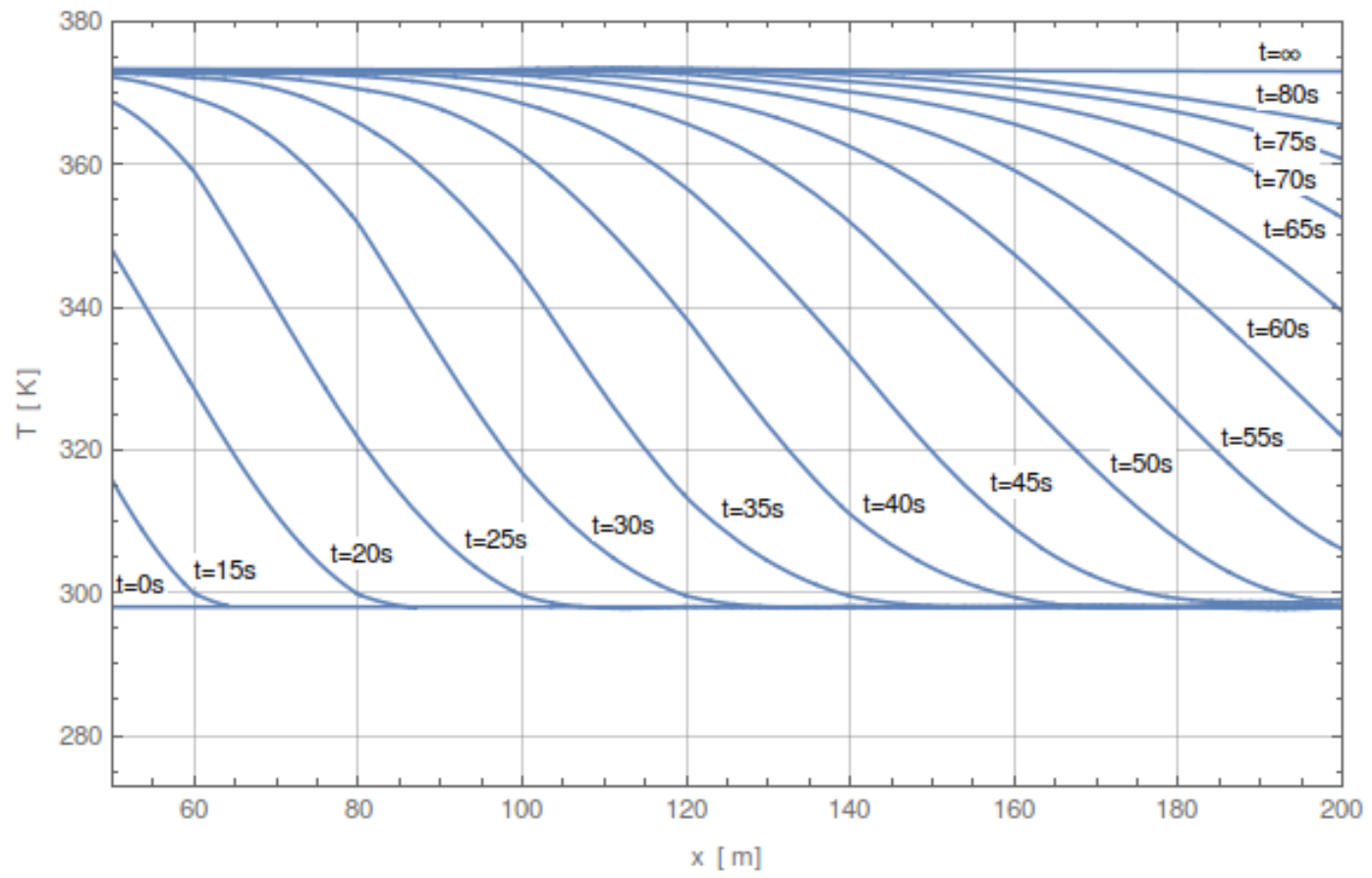

Figura D.17: Perfil da temperatura média do tubo. $D_{n}=6 ", U=3 \mathrm{~m} / \mathrm{s}, R e=1,58 \times 10^{6}$, $N u=5,35 \times 10^{3}, h_{i}=2,36 \times 10^{4} \mathrm{~W} / \mathrm{m}^{2} \mathrm{~K}, \mathrm{Gr}=3,25 \times 10^{1}, h_{e}=5,58 \mathrm{~W} / \mathrm{m}^{2} \mathrm{~K}$.

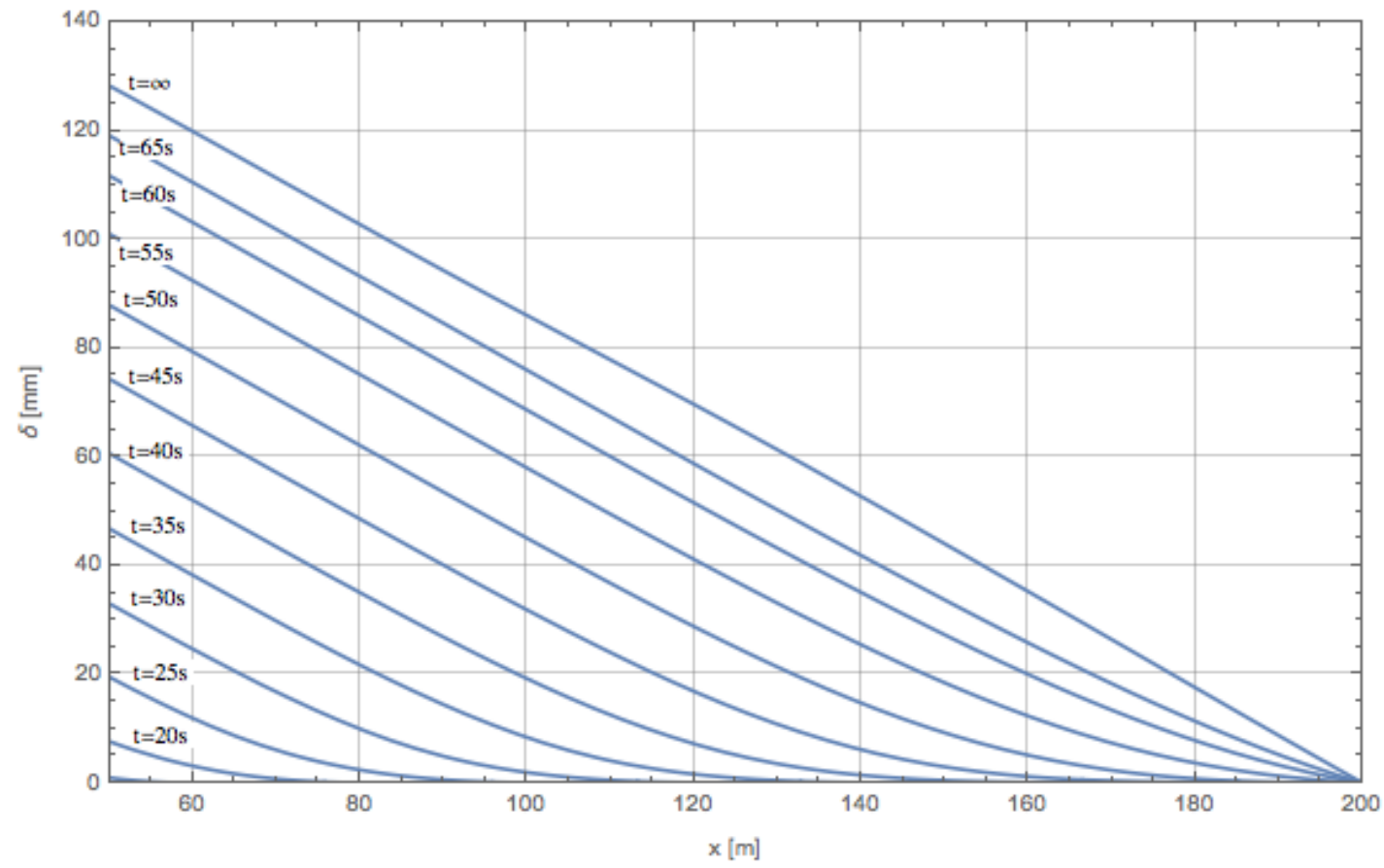

Figura D.18: Perfil da dilatação linear do tubo. $D_{n}=6$ ", $U=3 \mathrm{~m} / \mathrm{s}, R e=1,58 \times 10^{6}$, $N u=5,35 \times 10^{3}, h_{i}=2,36 \times 10^{4} \mathrm{~W} / \mathrm{m}^{2} \mathrm{~K}, \mathrm{Gr}=3,25 \times 10^{1}, h_{e}=5,58 \mathrm{~W} / \mathrm{m}^{2} \mathrm{~K}$. 
D.2.3 $U=4 \mathrm{~m} / \mathrm{s}$

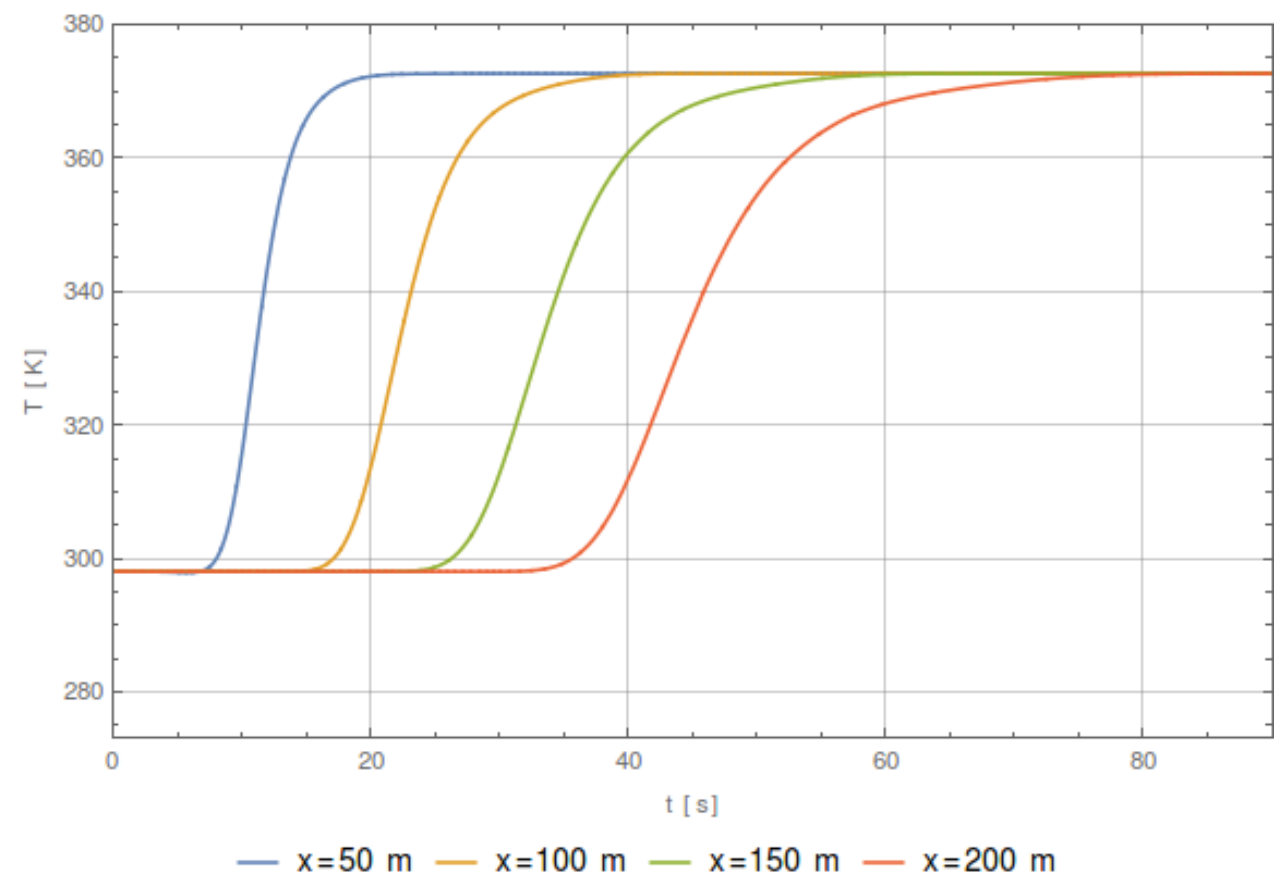

Figura D.19: Evolução temporal da temperatura média do fluido. $D_{n}=6 ", U=4 \mathrm{~m} / \mathrm{s}, R e=$ $2,11 \times 10^{6}, N u=7,12 \times 10^{3}, h_{i}=3,14 \times 10^{4} \mathrm{~W} / \mathrm{m}^{2} \mathrm{~K}, \mathrm{Gr}=3,25 \times 10^{1}, h_{e}=$ $5,58 \mathrm{~W} / \mathrm{m}^{2} \mathrm{~K}$.

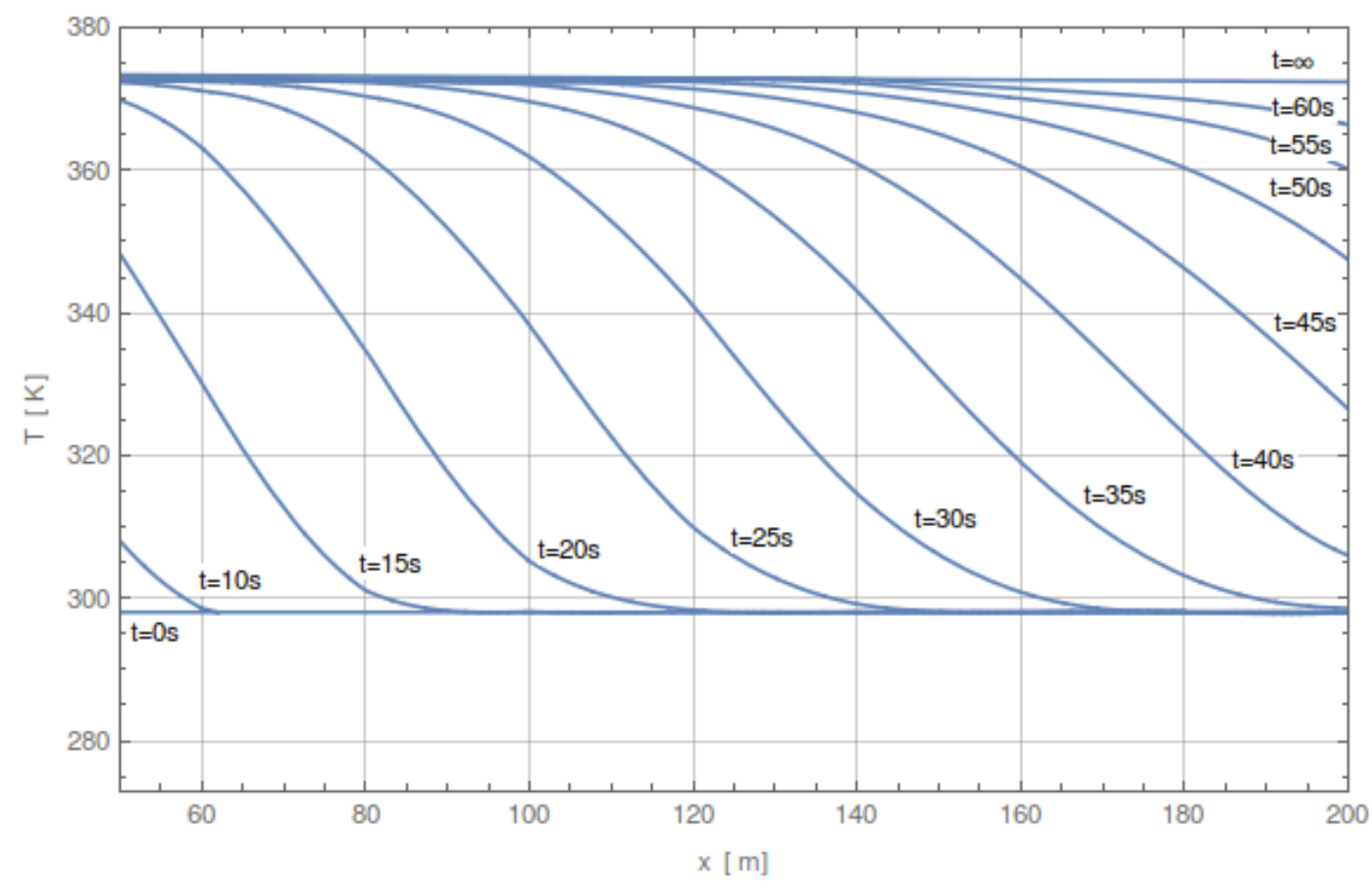

Figura D.20: Perfil da temperatura média do tubo. $D_{n}=6$ ", $U=4 \mathrm{~m} / \mathrm{s}, R e=2,11 \times 10^{6}$, $N u=7,12 \times 10^{3}, h_{i}=3,14 \times 10^{4} \mathrm{~W} / \mathrm{m}^{2} \mathrm{~K}, \mathrm{Gr}=3,25 \times 10^{1}, h_{e}=5,58 \mathrm{~W} / \mathrm{m}^{2} \mathrm{~K}$. 


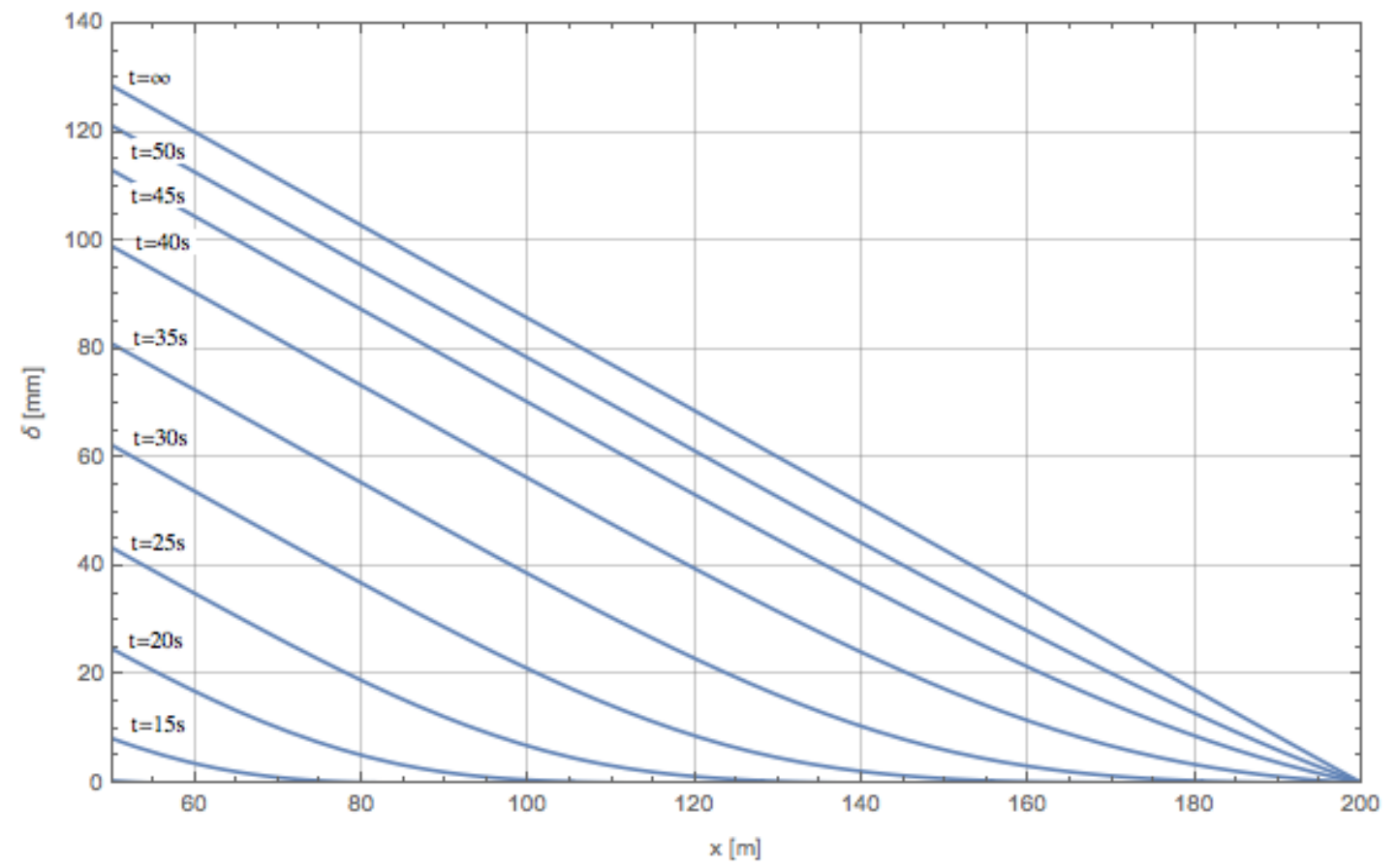

Figura D.21: Perfil da dilatação linear do tubo. $D_{n}=6$ ", $U=4 \mathrm{~m} / \mathrm{s}, R e=2,11 \times 10^{6}$, $N u=7,12 \times 10^{3}, h_{i}=3,14 \times 10^{4} \mathrm{~W} / \mathrm{m}^{2} \mathrm{~K}, \mathrm{Gr}=3,25 \times 10^{1}, h_{e}=5,58 \mathrm{~W} / \mathrm{m}^{2} \mathrm{~K}$.

\section{D.2.4 $U=5 \mathrm{~m} / \mathrm{s}$}

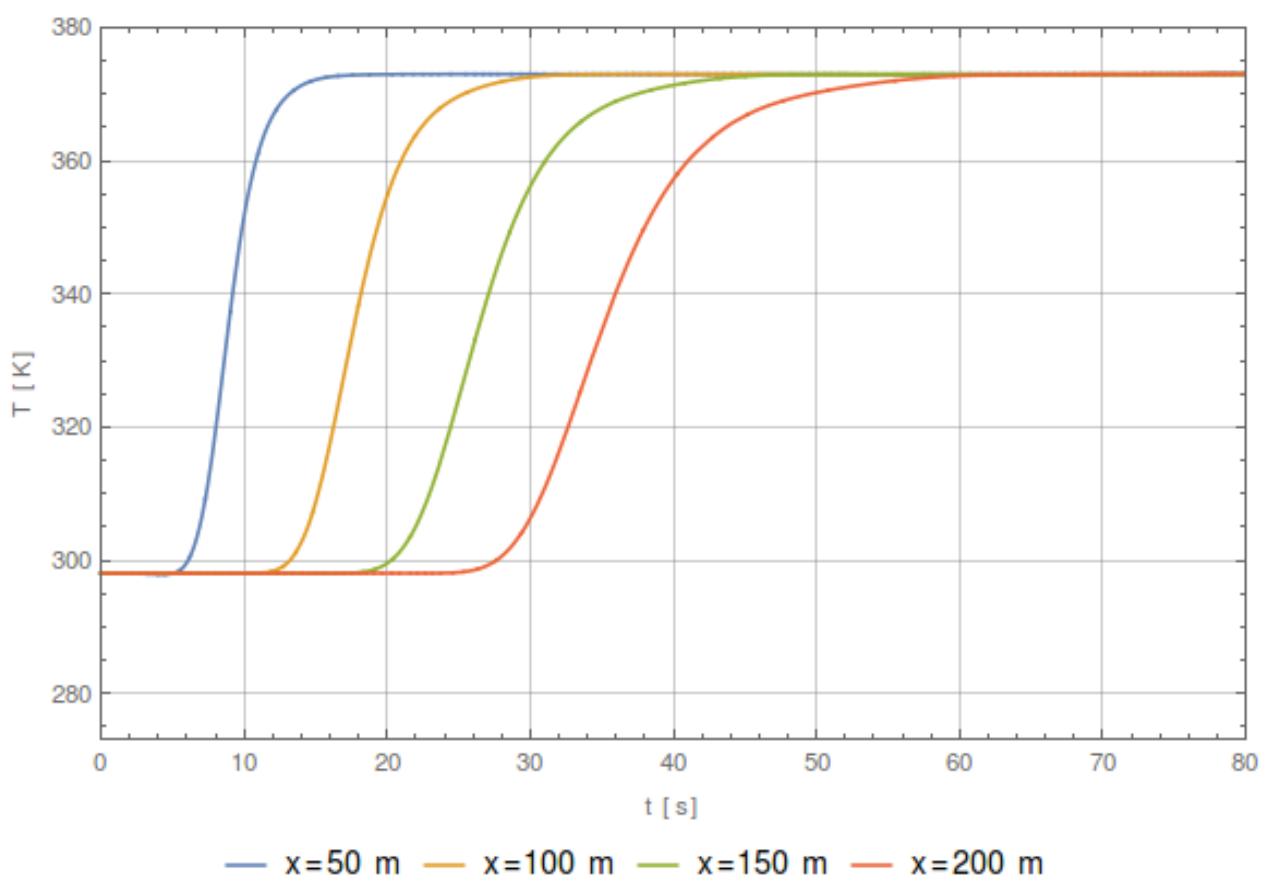

Figura D.22: Evolução temporal da temperatura média do fluido. $D_{n}=6$ "', $U=5 \mathrm{~m} / \mathrm{s}, R e=$ $2,64 \times 10^{6}, N u=8,88 \times 10^{3}, h_{i}=3,92 \times 10^{4} \mathrm{~W} / \mathrm{m}^{2} \mathrm{~K}, \mathrm{Gr}=3,25 \times 10^{1}, h_{e}=$ $5,58 \mathrm{~W} / \mathrm{m}^{2} \mathrm{~K}$. 


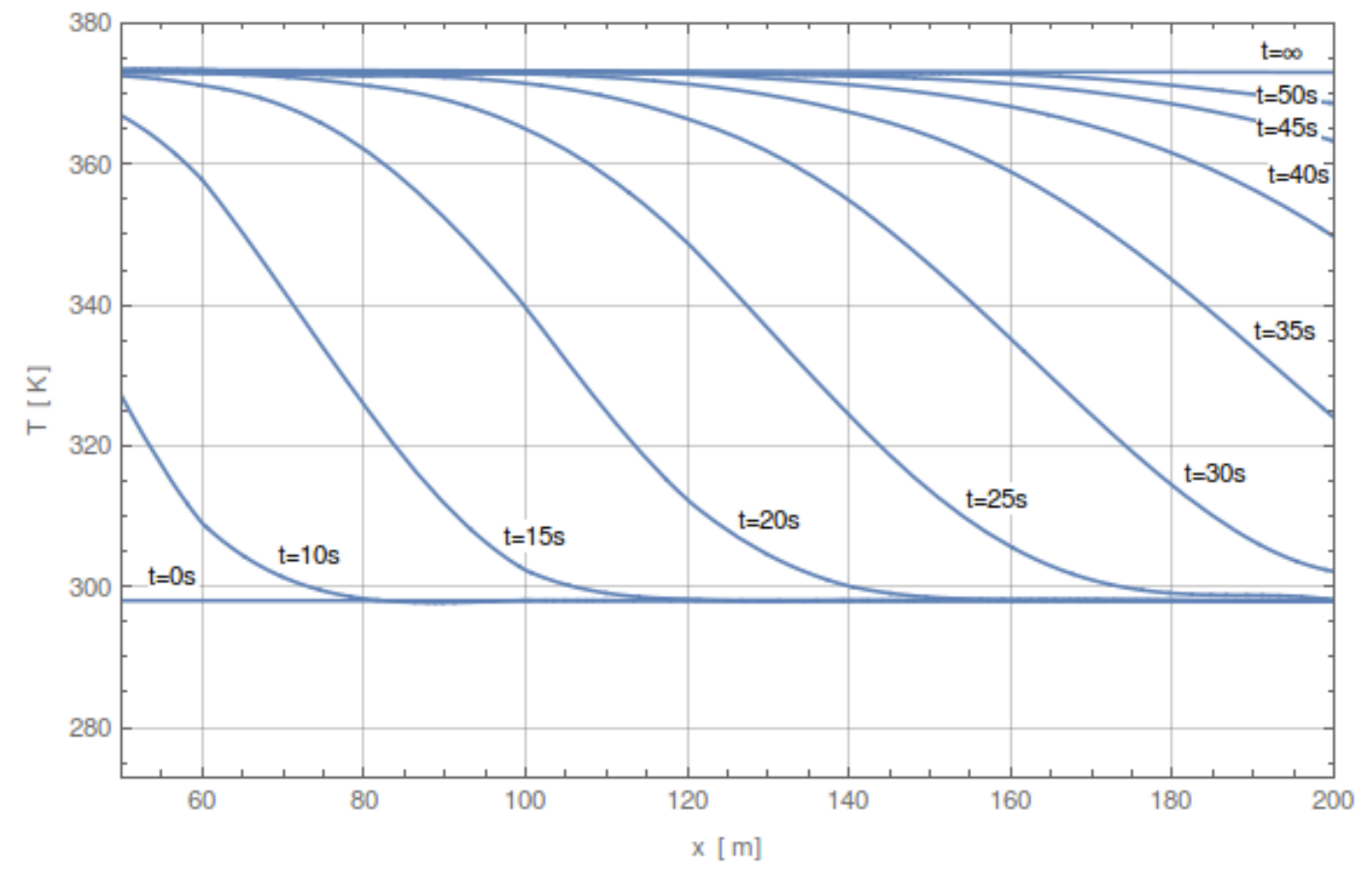

Figura D.23: Perfil da temperatura média do tubo. $D_{n}=6$ ", $U=5 \mathrm{~m} / \mathrm{s}, R e=2,64 \times 10^{6}$, $N u=8,88 \times 10^{3}, h_{i}=3,92 \times 10^{4} \mathrm{~W} / \mathrm{m}^{2} \mathrm{~K}, \mathrm{Gr}=3,25 \times 10^{1}, h_{e}=5,58 \mathrm{~W} / \mathrm{m}^{2} \mathrm{~K}$.

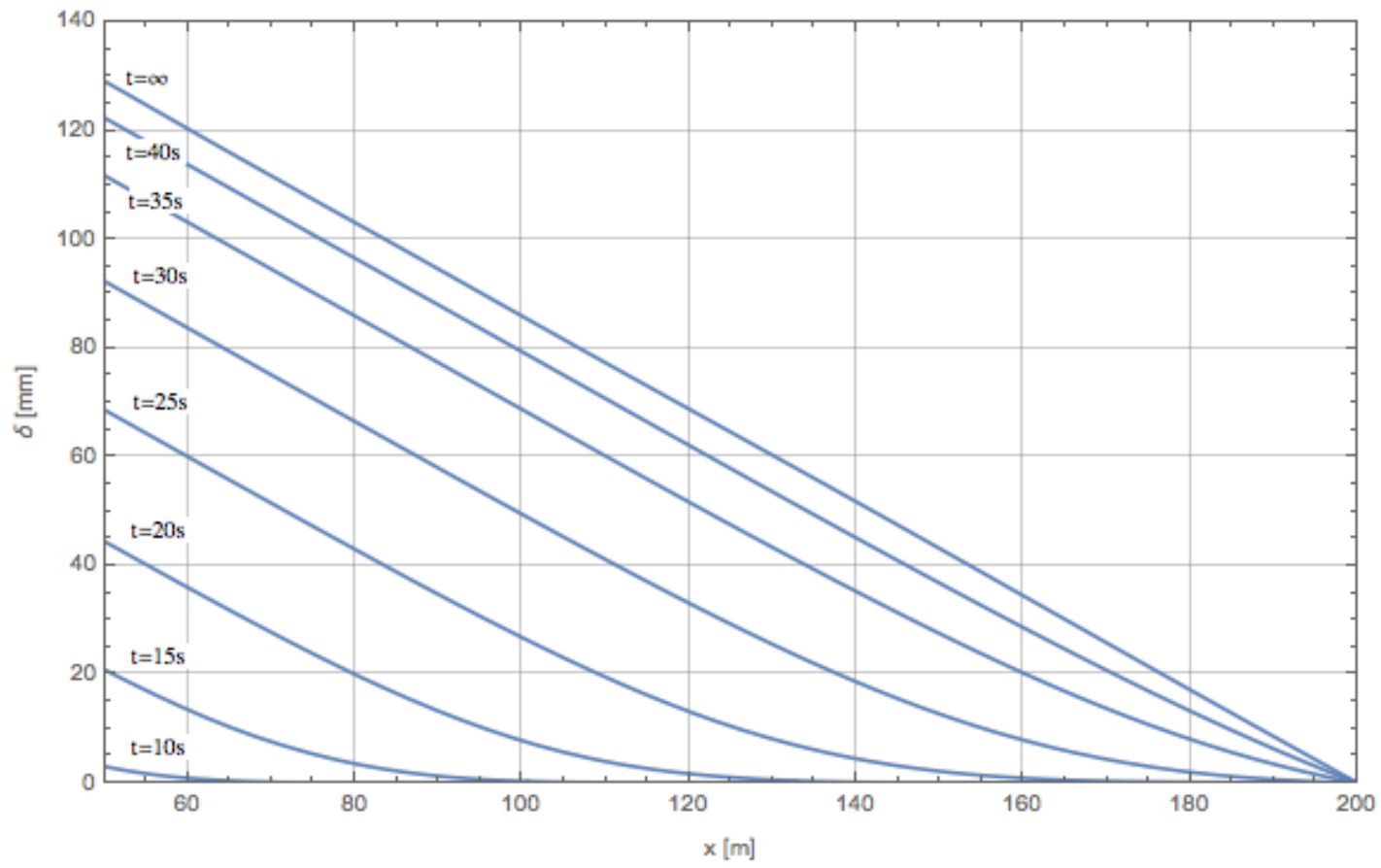

Figura D.24: Perfil da dilatação linear do tubo. $D_{n}=6$ "', $U=5 \mathrm{~m} / \mathrm{s}, R e=2,64 \times 10^{6}$, $N u=8,88 \times 10^{3}, h_{i}=3,92 \times 10^{4} \mathrm{~W} / \mathrm{m}^{2} \mathrm{~K}, \mathrm{Gr}=3,25 \times 10^{1}, h_{e}=5,58 \mathrm{~W} / \mathrm{m}^{2} \mathrm{~K}$. 


\section{D.3 Tubo de aço com $D_{n}=8$ "}

\section{D.3.1 $U=2 \mathrm{~m} / \mathrm{s}$}

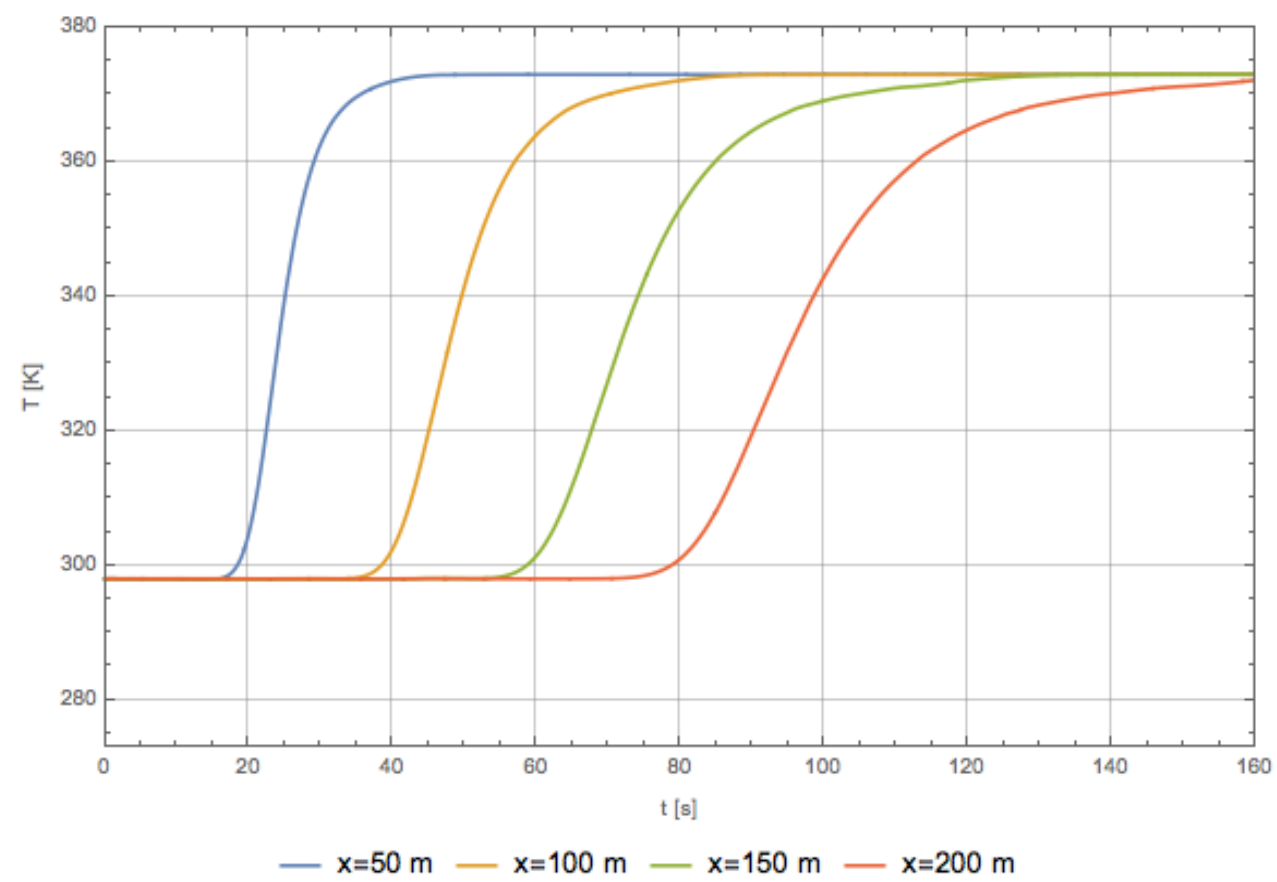

Figura D.25: Evolução temporal da temperatura média do fluido. $D_{n}=8$ ", $U=2 \mathrm{~m} / \mathrm{s}, R e=$ $1,39 \times 10^{6}, N u=4,45 \times 10^{3}, h_{i}=1,49 \times 10^{4} \mathrm{~W} / \mathrm{m}^{2} \mathrm{~K}, \mathrm{Gr}=4,12 \times 10^{1}, h_{e}=$ $5,44 \mathrm{~W} / \mathrm{m}^{2} \mathrm{~K}$.

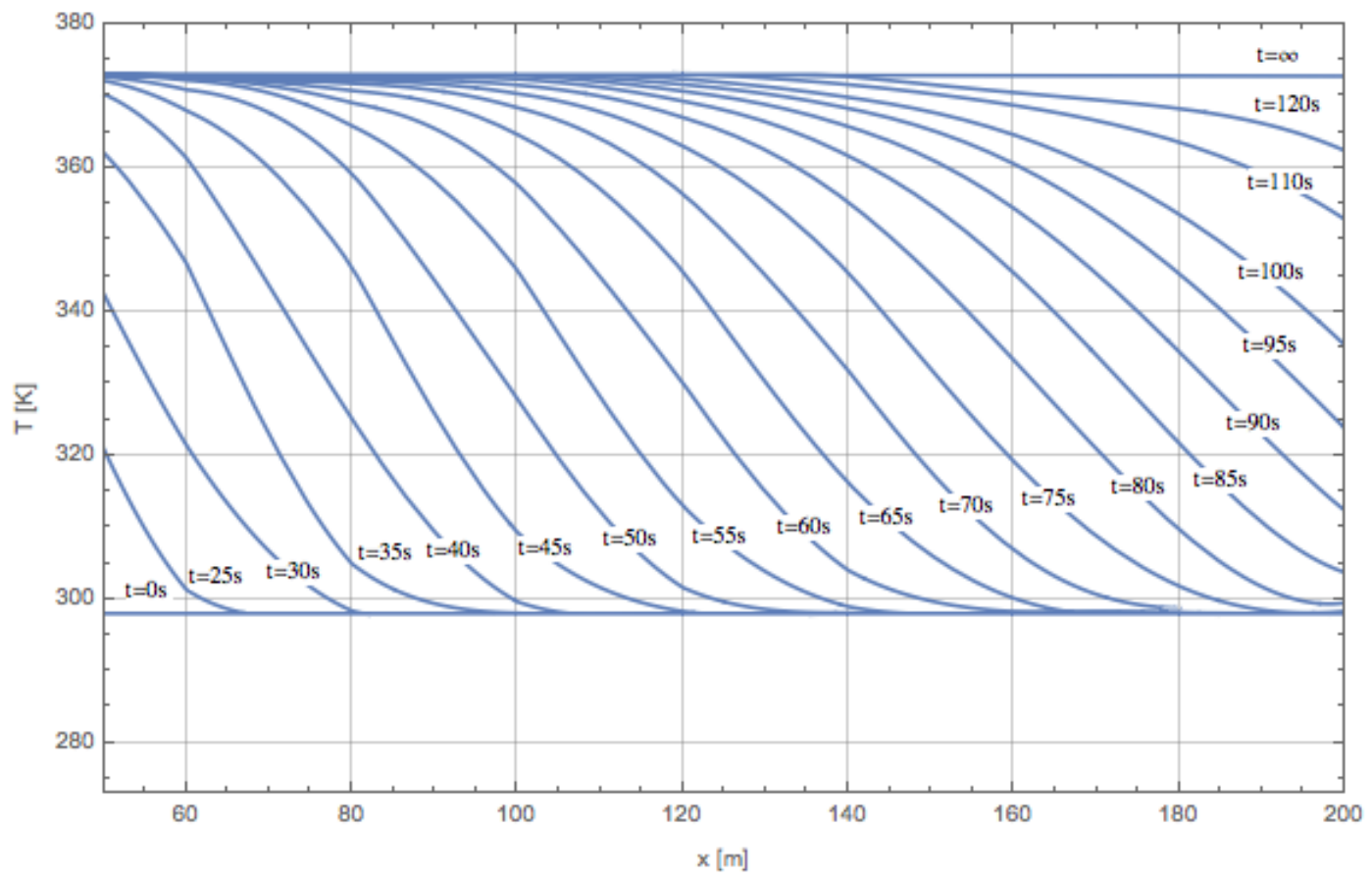

Figura D.26: Perfil da temperatura média do tubo. $D_{n}=8$ ", $U=2 \mathrm{~m} / \mathrm{s}, R e=1,39 \times 10^{6}$, $N u=4,45 \times 10^{3}, h_{i}=1,49 \times 10^{4} \mathrm{~W} / \mathrm{m}^{2} \mathrm{~K}, \mathrm{Gr}=4,12 \times 10^{1}, h_{e}=5,44 \mathrm{~W} / \mathrm{m}^{2} \mathrm{~K}$. 


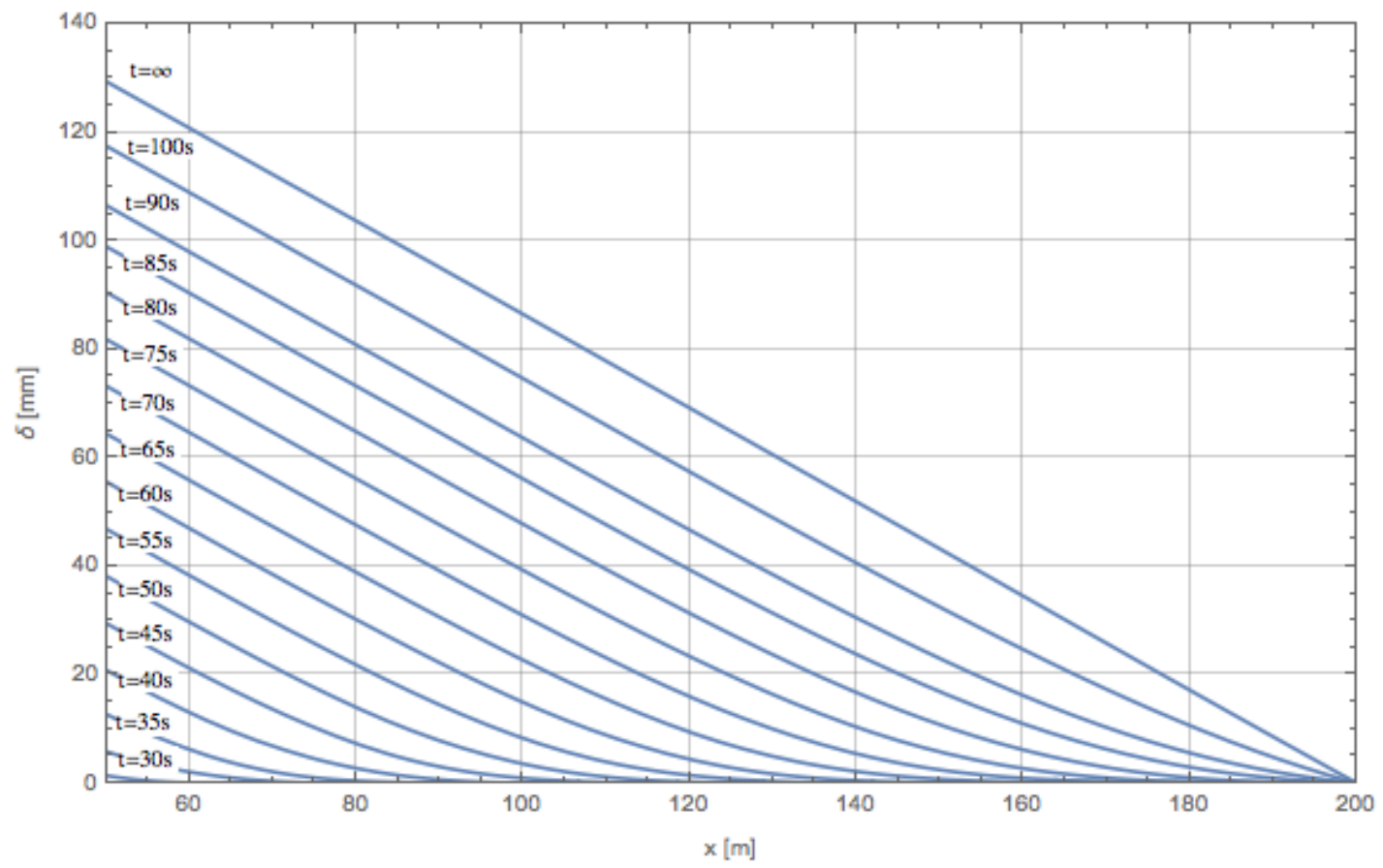

Figura D.27: Perfil da dilatação linear do tubo. $D_{n}=8^{\prime \prime}, U=2 \mathrm{~m} / \mathrm{s}, R e=1,39 \times 10^{6}$, $N u=4,45 \times 10^{3}, h_{i}=1,49 \times 10^{4} \mathrm{~W} / \mathrm{m}^{2} \mathrm{~K}, \mathrm{Gr}=4,12 \times 10^{1}, h_{e}=5,44 \mathrm{~W} / \mathrm{m}^{2} \mathrm{~K}$.

\section{D.3.2 $U=3 \mathrm{~m} / \mathrm{s}$}

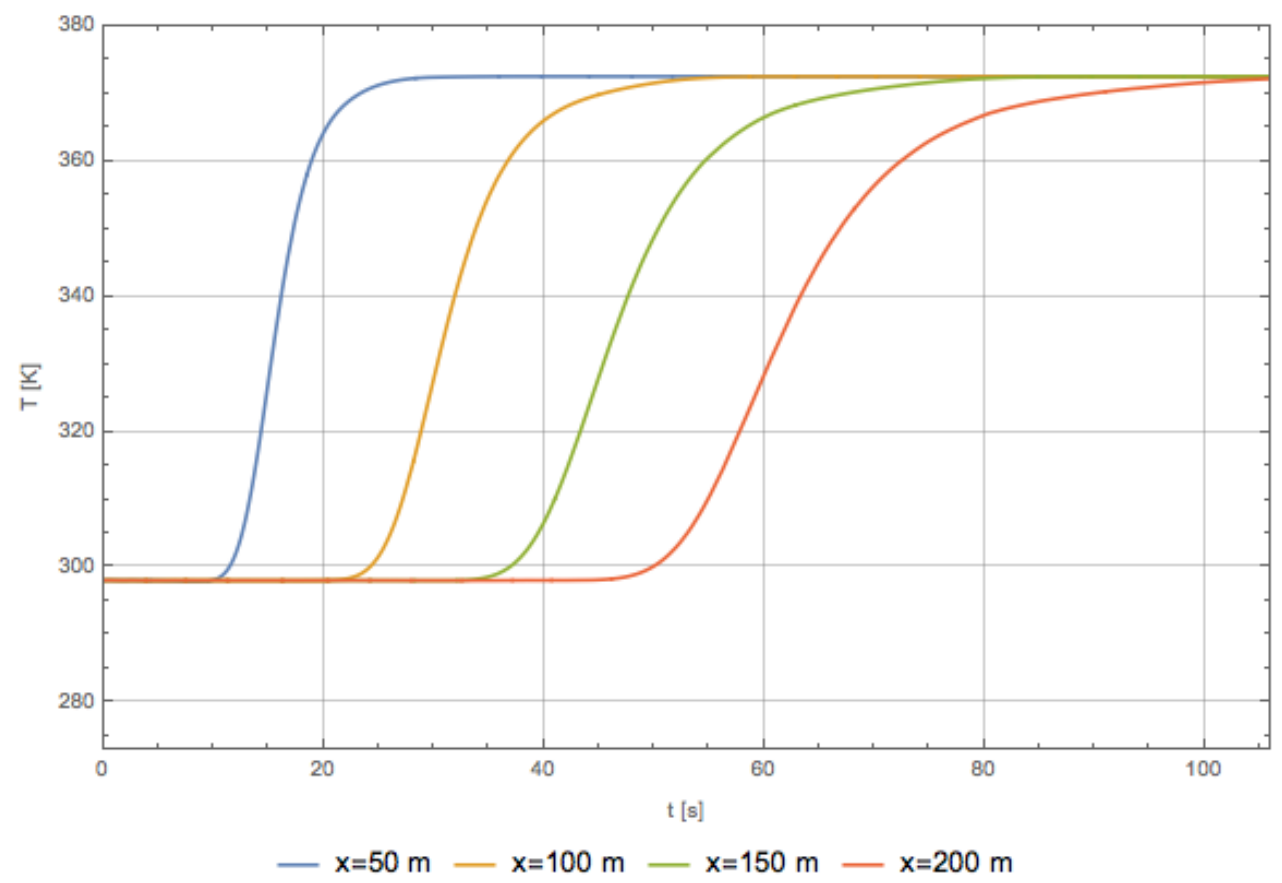

Figura D.28: Evolução temporal da temperatura média do fluido. $D_{n}=8$ ", $U=3 \mathrm{~m} / \mathrm{s}, R e=$ $2,09 \times 10^{6}, N u=6,65 \times 10^{3}, h_{i}=2,22 \times 10^{4} \mathrm{~W} / \mathrm{m}^{2} \mathrm{~K}, \mathrm{Gr}=4,12 \times 10^{1}, h_{e}=$ $5,44 \mathrm{~W} / \mathrm{m}^{2} \mathrm{~K}$. 


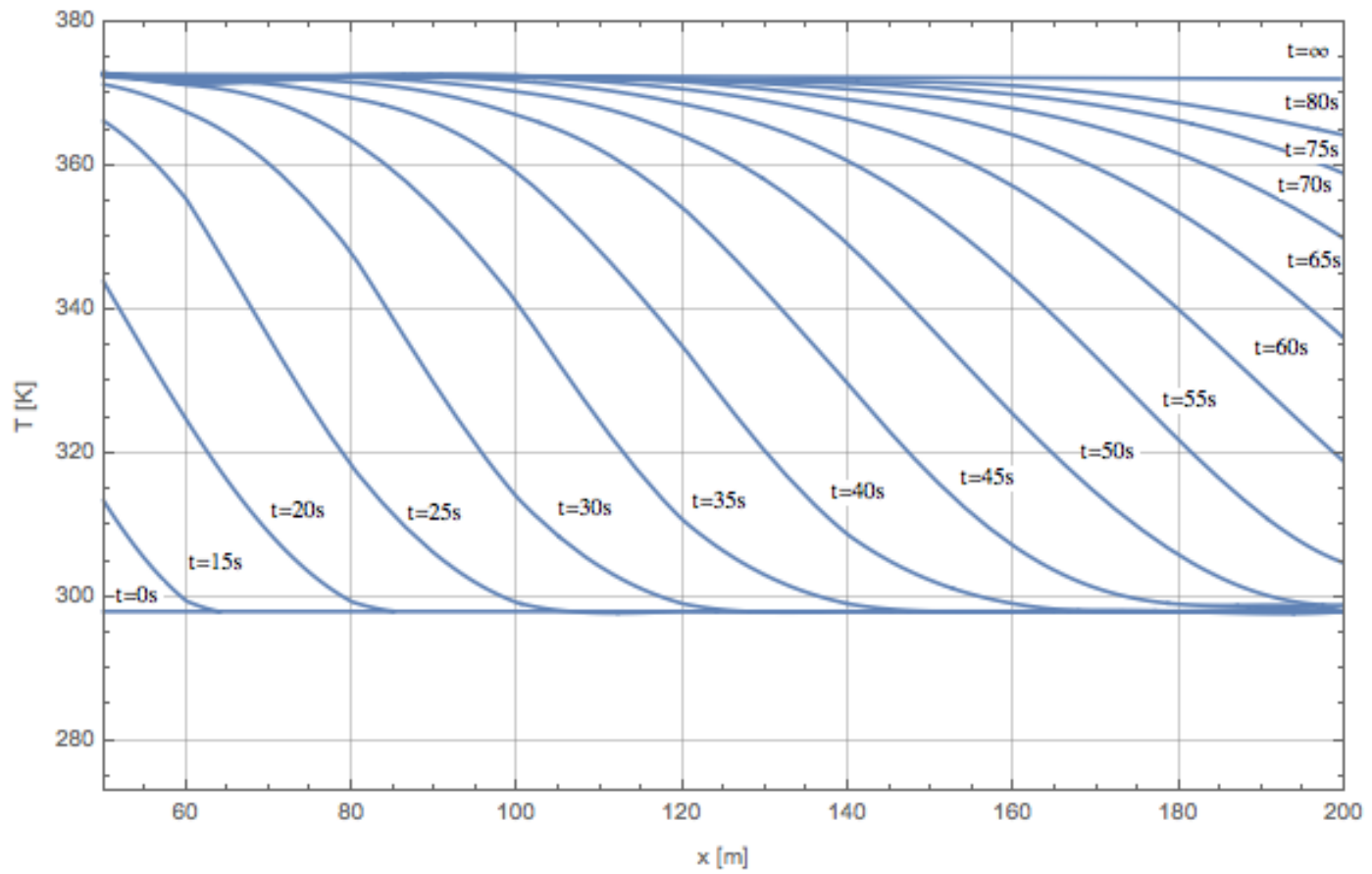

Figura D.29: Perfil da temperatura média do tubo. $D_{n}=8 ", U=3 \mathrm{~m} / \mathrm{s}, R e=2,09 \times 10^{6}$, $N u=6,65 \times 10^{3}, h_{i}=2,22 \times 10^{4} \mathrm{~W} / \mathrm{m}^{2} \mathrm{~K}, \mathrm{Gr}=4,12 \times 10^{1}, h_{e}=5,44 \mathrm{~W} / \mathrm{m}^{2} \mathrm{~K}$.

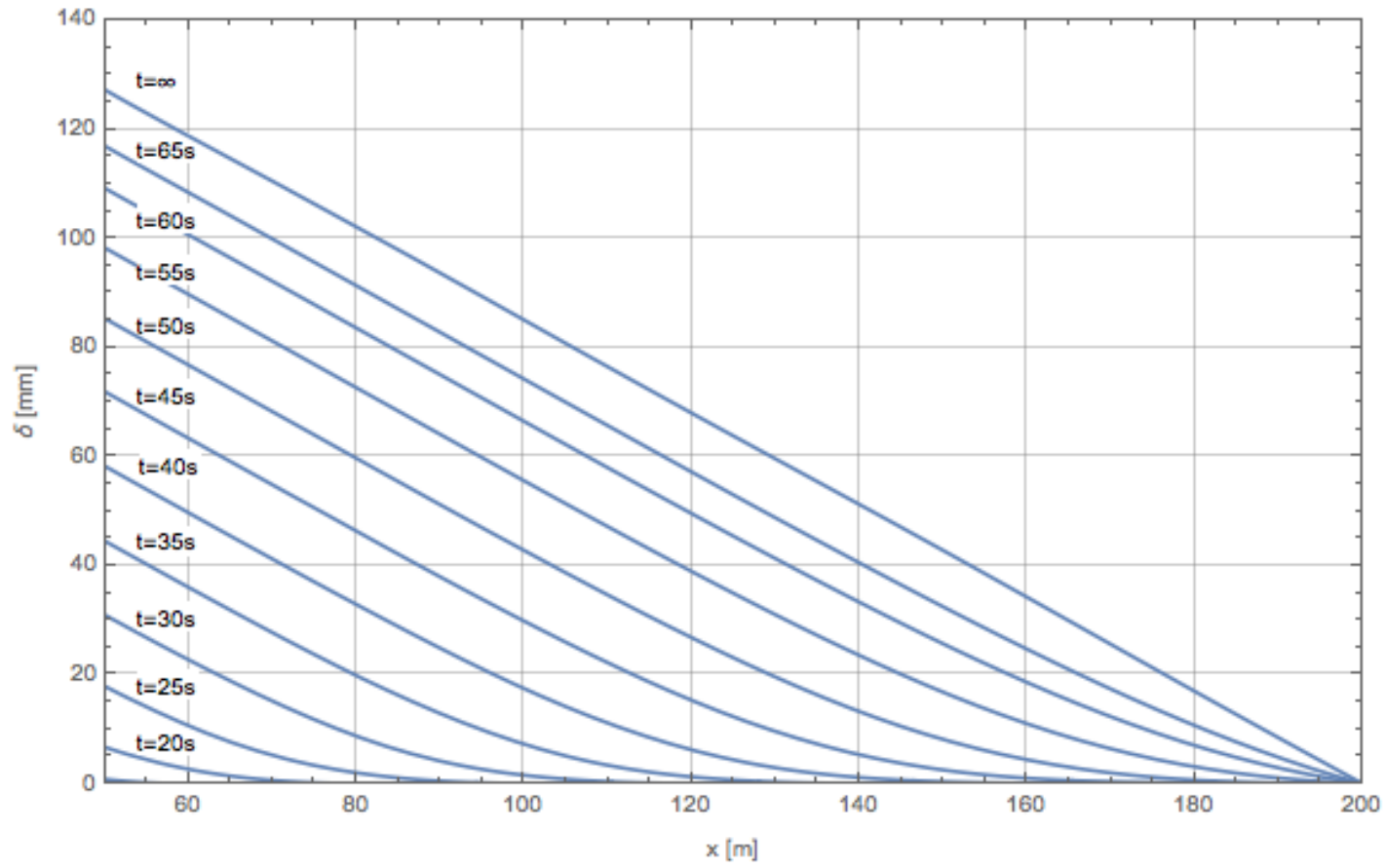

Figura D.30: Perfil da dilatação linear do tubo. $D_{n}=8$ ", $U=3 \mathrm{~m} / \mathrm{s}, R e=2,09 \times 10^{6}$, $N u=6,65 \times 10^{3}, h_{i}=2,22 \times 10^{4} \mathrm{~W} / \mathrm{m}^{2} \mathrm{~K}, \mathrm{Gr}=4,12 \times 10^{1}, h_{e}=5,44 \mathrm{~W} / \mathrm{m}^{2} \mathrm{~K}$. 
D.3.3 $U=4 \mathrm{~m} / \mathrm{s}$

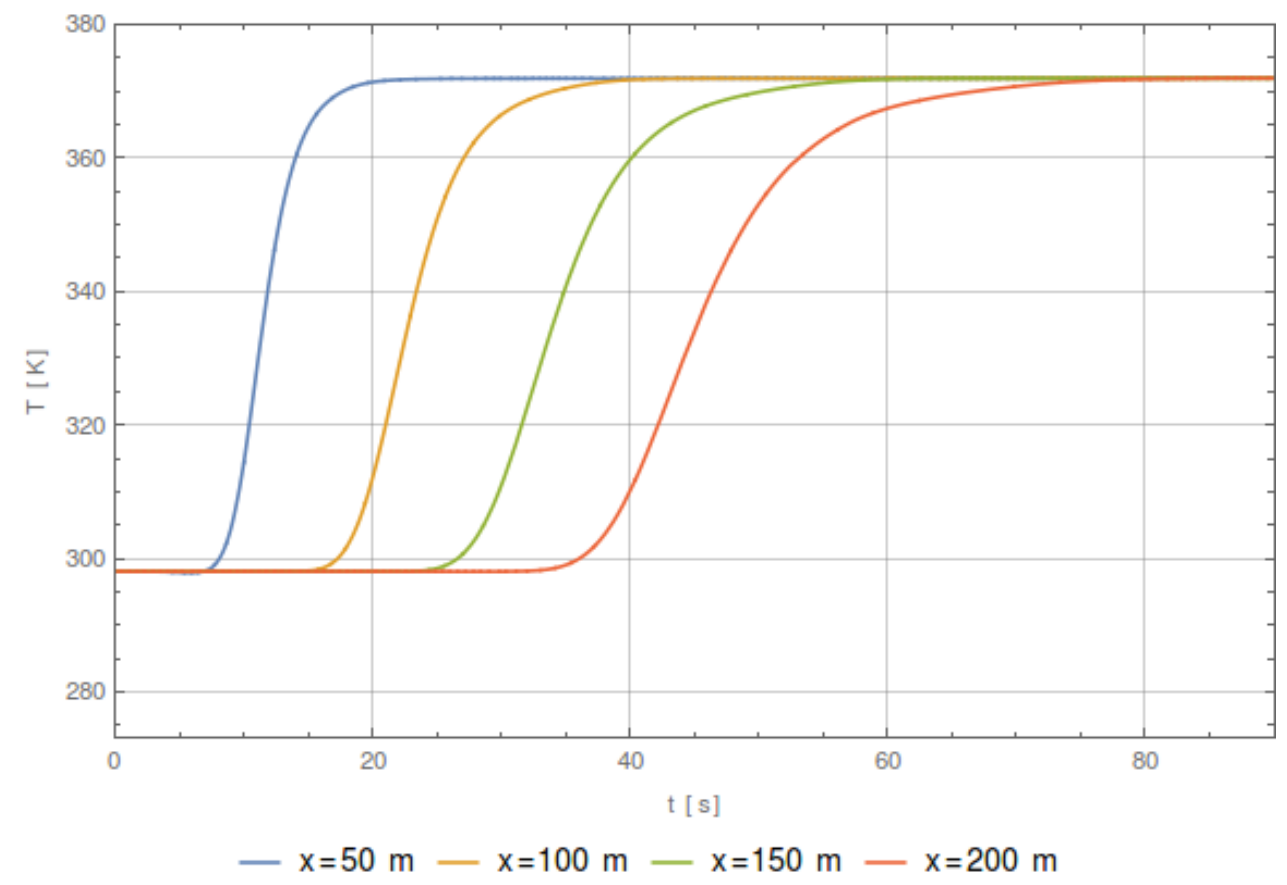

Figura D.31: Evolução temporal da temperatura média do fluido. $D_{n}=8$ ", $U=4 \mathrm{~m} / \mathrm{s}, R e=$ $2,79 \times 10^{6}, N u=8,84 \times 10^{3}, h_{i}=2,96 \times 10^{4} \mathrm{~W} / \mathrm{m}^{2} \mathrm{~K}, \mathrm{Gr}=4,12 \times 10^{1}, h_{e}=$ $5,44 \mathrm{~W} / \mathrm{m}^{2} \mathrm{~K}$.

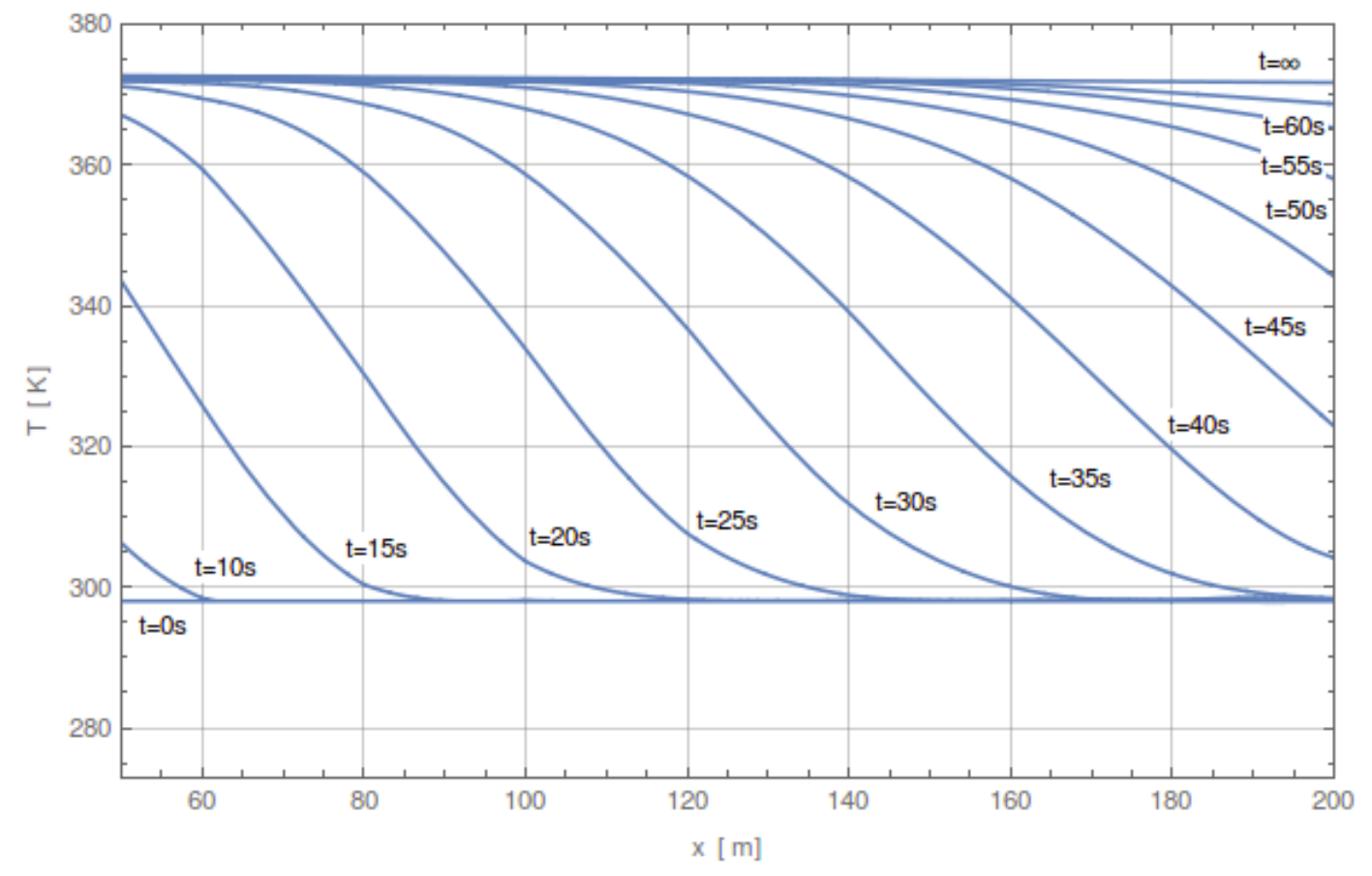

Figura D.32: Perfil da temperatura média do tubo. $D_{n}=8$ ", $U=4 \mathrm{~m} / \mathrm{s}, R e=2,79 \times 10^{6}$, $N u=8,84 \times 10^{3}, h_{i}=2,96 \times 10^{4} \mathrm{~W} / \mathrm{m}^{2} \mathrm{~K}, \mathrm{Gr}=4,12 \times 10^{1}, h_{e}=5,44 \mathrm{~W} / \mathrm{m}^{2} \mathrm{~K}$. 


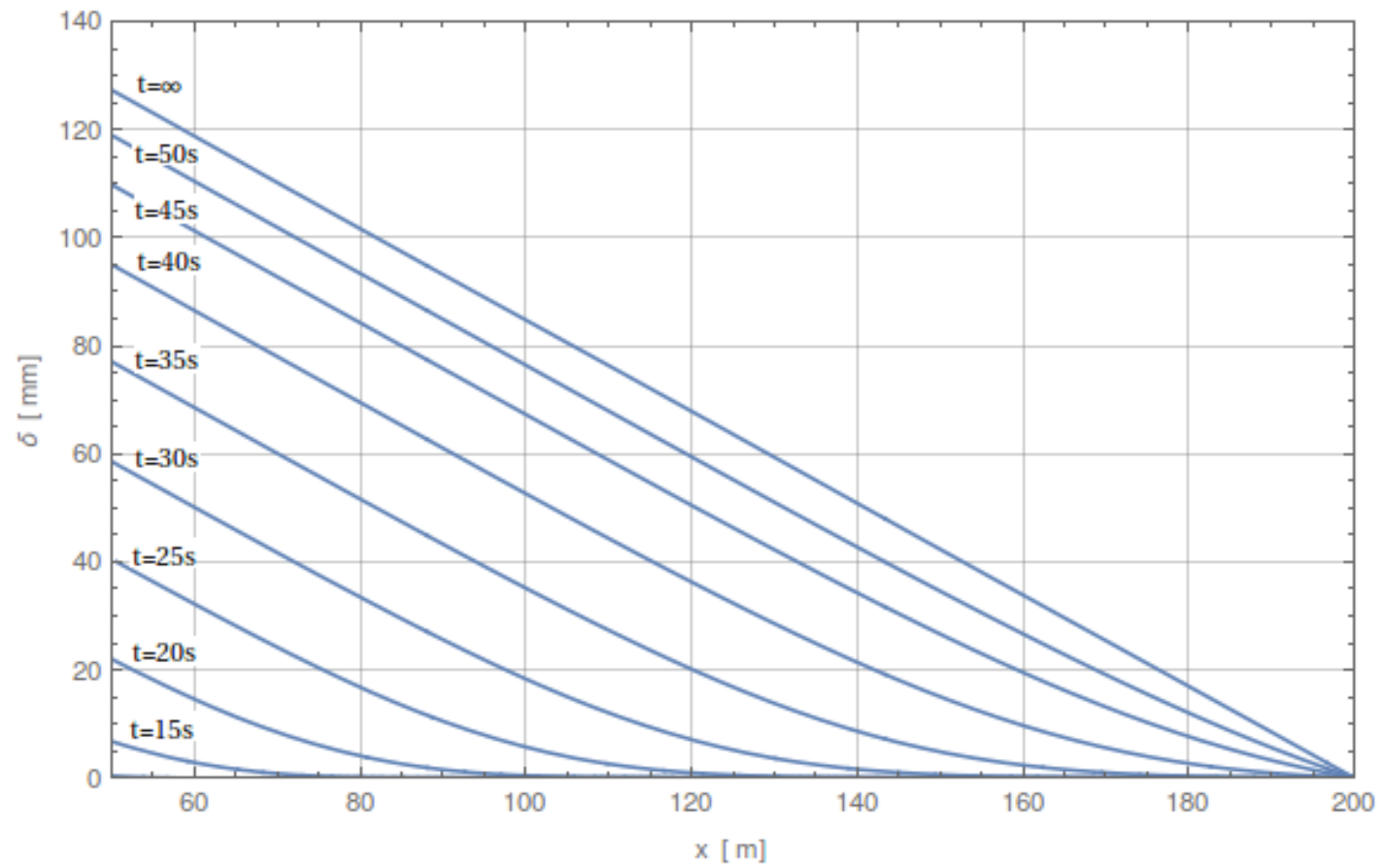

Figura D.33: Perfil da dilatação linear do tubo. $D_{n}=8^{\prime \prime}, U=4 \mathrm{~m} / \mathrm{s}, R e=2,79 \times 10^{6}$, $N u=8,84 \times 10^{3}, h_{i}=2,96 \times 10^{4} \mathrm{~W} / \mathrm{m}^{2} \mathrm{~K}, \mathrm{Gr}=4,12 \times 10^{1}, h_{e}=5,44 \mathrm{~W} / \mathrm{m}^{2} \mathrm{~K}$.

\section{D.3.4 $U=5 \mathrm{~m} / \mathrm{s}$}

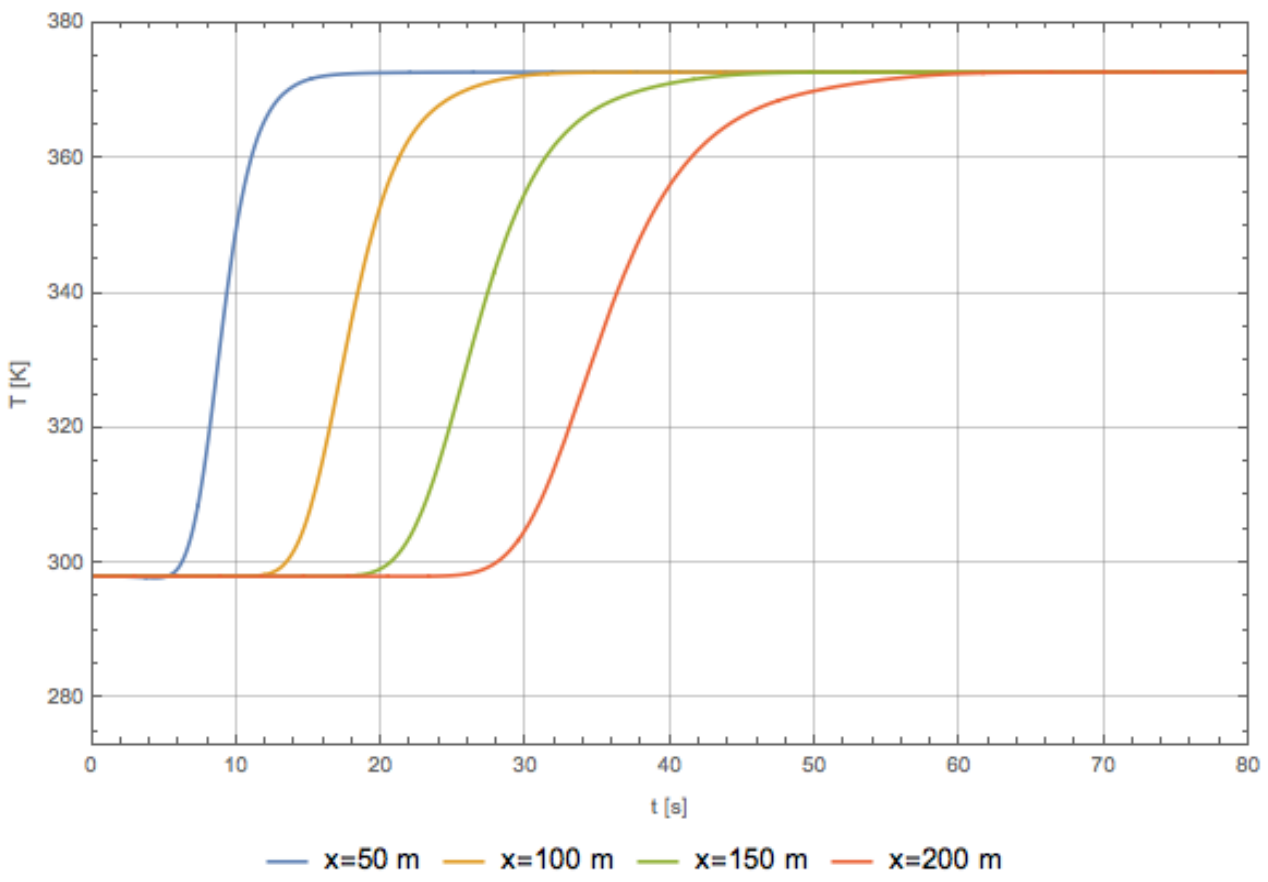

Figura D.34: Evolução temporal da temperatura média do fluido. $D_{n}=8$ ", $U=5 \mathrm{~m} / \mathrm{s}, R e=$ $3,48 \times 10^{6}, N u=1,10 \times 10^{4}, h_{i}=3,70 \times 10^{4} \mathrm{~W} / \mathrm{m}^{2} \mathrm{~K}, \mathrm{Gr}=4,12 \times 10^{1}, h_{e}=$ $5,44 \mathrm{~W} / \mathrm{m}^{2} \mathrm{~K}$. 


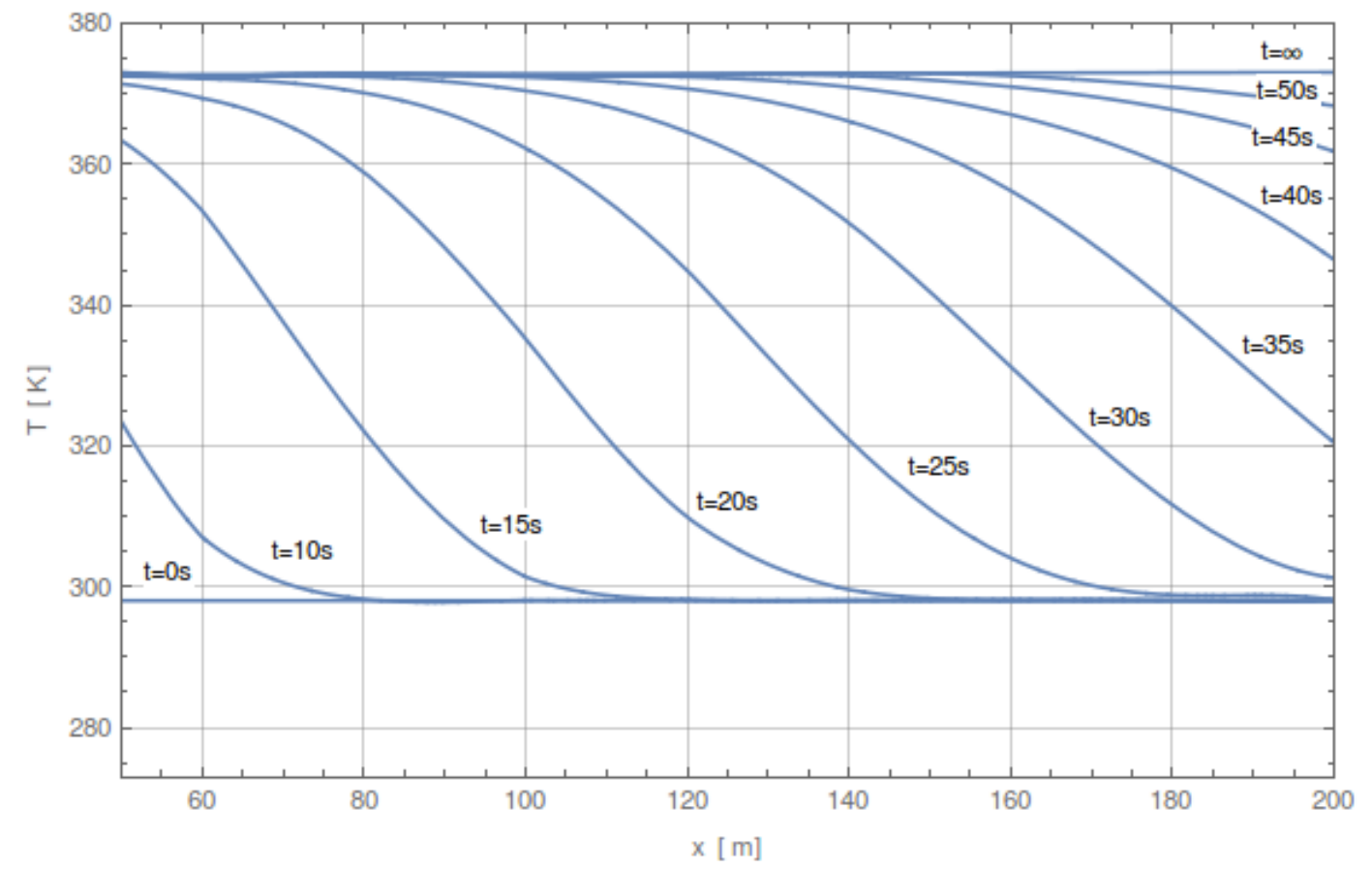

Figura D.35: Perfil da temperatura média do tubo. $D_{n}=8^{\prime \prime}, U=5 \mathrm{~m} / \mathrm{s}, R e=3,48 \times 10^{6}$, $N u=1,10 \times 10^{4}, h_{i}=3,70 \times 10^{4} \mathrm{~W} / \mathrm{m}^{2} \mathrm{~K}, \mathrm{Gr}=4,12 \times 10^{1}, h_{e}=5,44 \mathrm{~W} / \mathrm{m}^{2} \mathrm{~K}$.

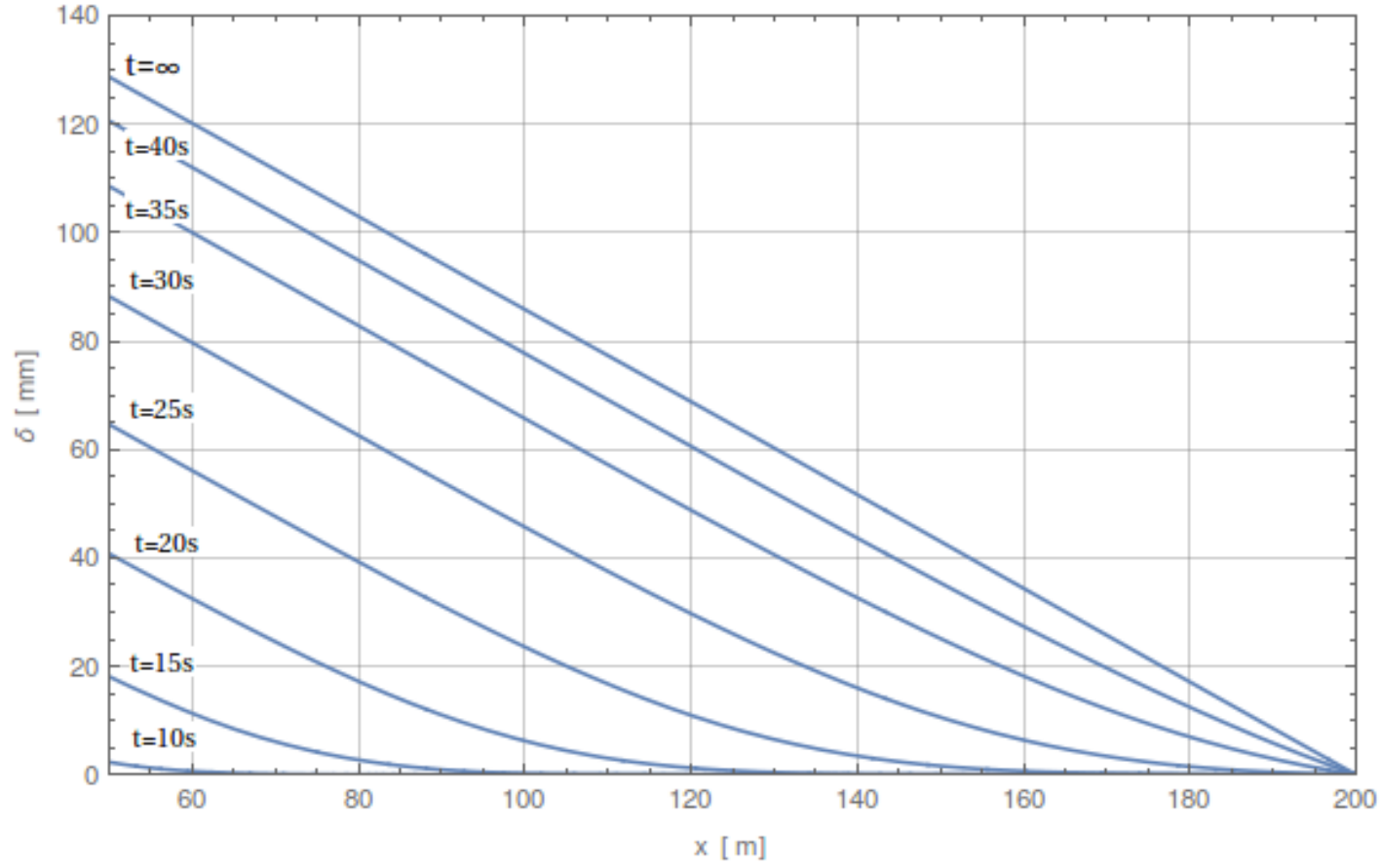

Figura D.36: Perfil da dilatação linear do tubo. $D_{n}=8 ", U=5 \mathrm{~m} / \mathrm{s}, \quad R e=3,48 \times 10^{6}$, $N u=1,10 \times 10^{4}, h_{i}=3,70 \times 10^{4} \mathrm{~W} / \mathrm{m}^{2} \mathrm{~K}, \mathrm{Gr}=4,12 \times 10^{1}, h_{e}=5,44 \mathrm{~W} / \mathrm{m}^{2} \mathrm{~K}$. 


\section{D.4 Tubo de aço com $D_{n}=10 "$}

D.4.1 $U=2 \mathrm{~m} / \mathrm{s}$

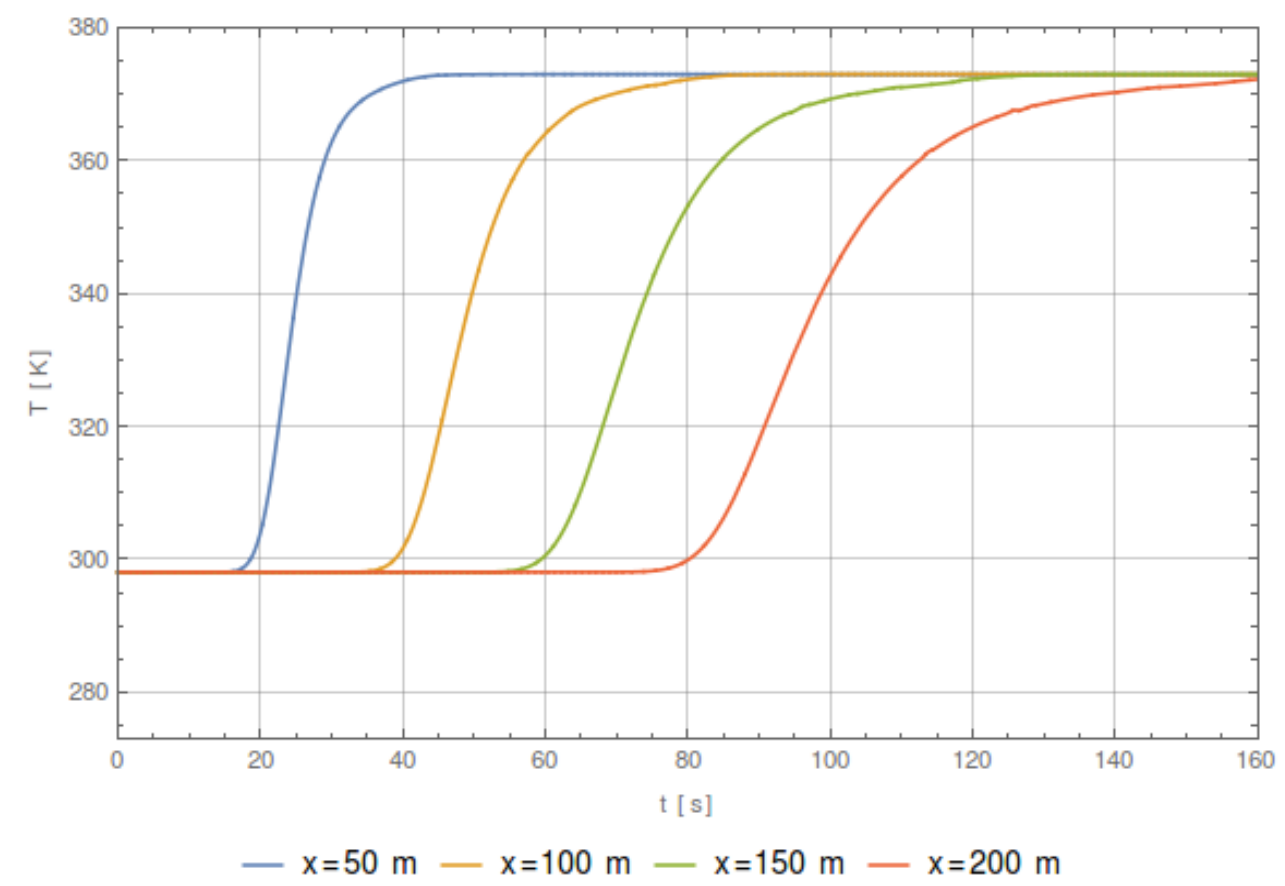

Figura D.37: Evolução temporal da temperatura média do fluido. $D_{n}=10 ", U=2 \mathrm{~m} / \mathrm{s}, R e=$ $1,75 \times 10^{6}, N u=5,34 \times 10^{3}, h_{i}=1,42 \times 10^{4} \mathrm{~W} / \mathrm{m}^{2} \mathrm{~K}, \mathrm{Gr}=5,03 \times 10^{1}, h_{e}=$ $5,33 \mathrm{~W} / \mathrm{m}^{2} \mathrm{~K}$.

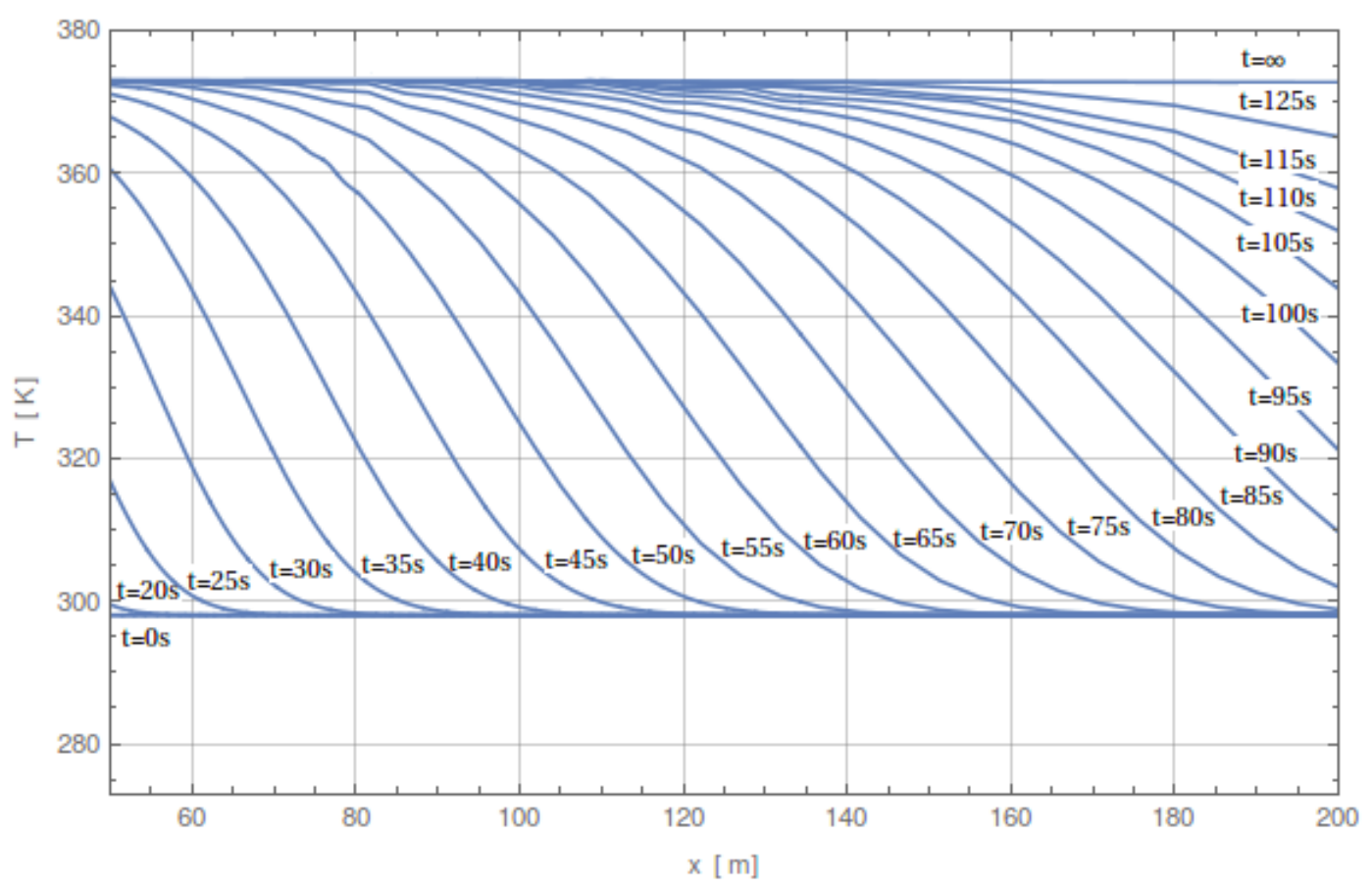

Figura D.38: Perfil da temperatura média do tubo. $D_{n}=10^{\prime \prime}, U=2 \mathrm{~m} / \mathrm{s}, R e=1,75 \times 10^{6}$, $N u=5,34 \times 10^{3}, h_{i}=1,42 \times 10^{4} \mathrm{~W} / \mathrm{m}^{2} \mathrm{~K}, \mathrm{Gr}=5,03 \times 10^{1}, h_{e}=5,33 \mathrm{~W} / \mathrm{m}^{2} \mathrm{~K}$. 


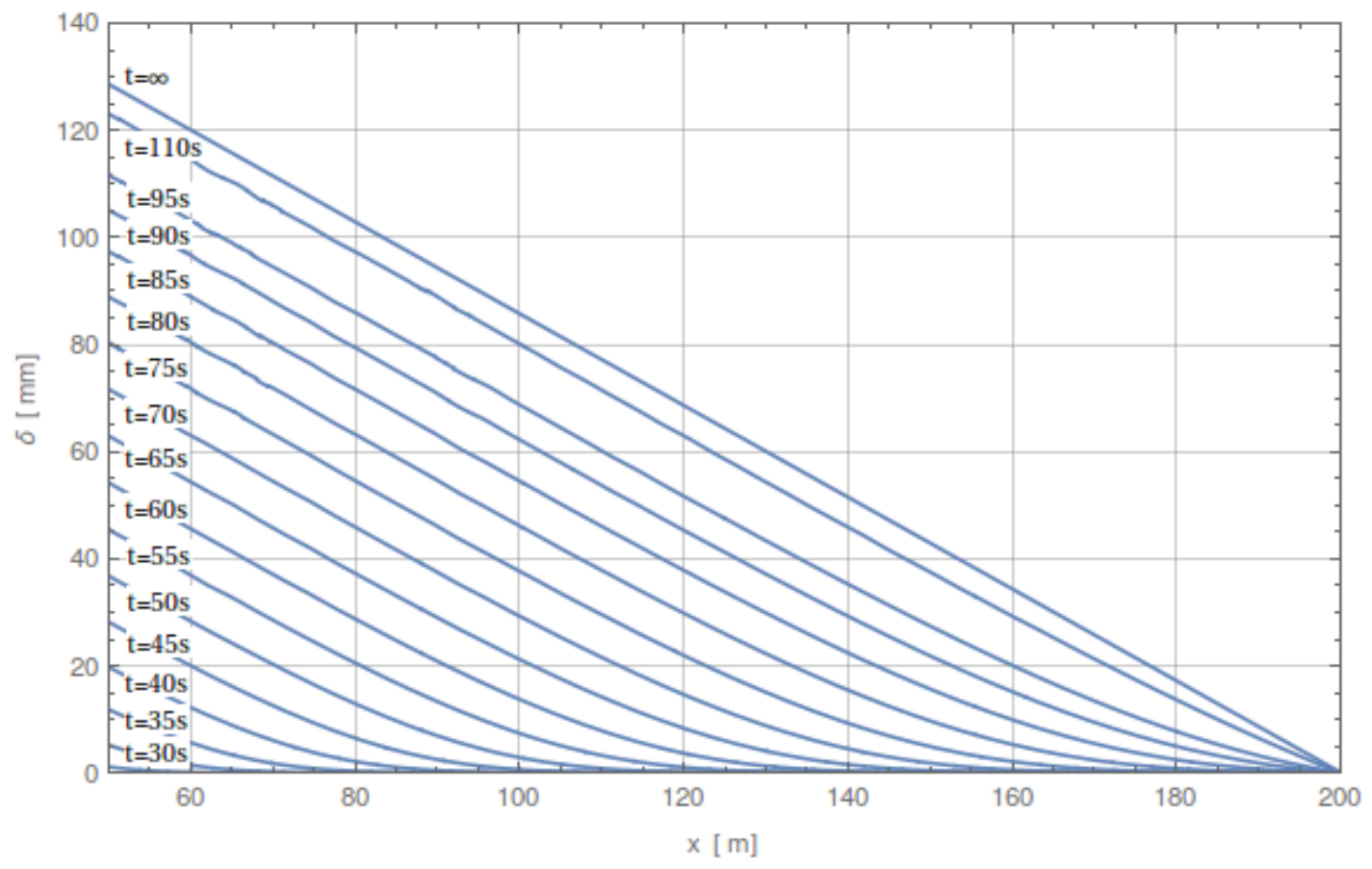

Figura D.39: Perfil da dilatação linear do tubo. $D_{n}=10^{\prime \prime}, U=2 \mathrm{~m} / \mathrm{s}, R e=1,75 \times 10^{6}$, $N u=5,34 \times 10^{3}, h_{i}=1,42 \times 10^{4} \mathrm{~W} / \mathrm{m}^{2} \mathrm{~K}, \mathrm{Gr}=5,03 \times 10^{1}, h_{e}=5,33 \mathrm{~W} / \mathrm{m}^{2} \mathrm{~K}$.

\section{D.4.2 $U=3 \mathrm{~m} / \mathrm{s}$}

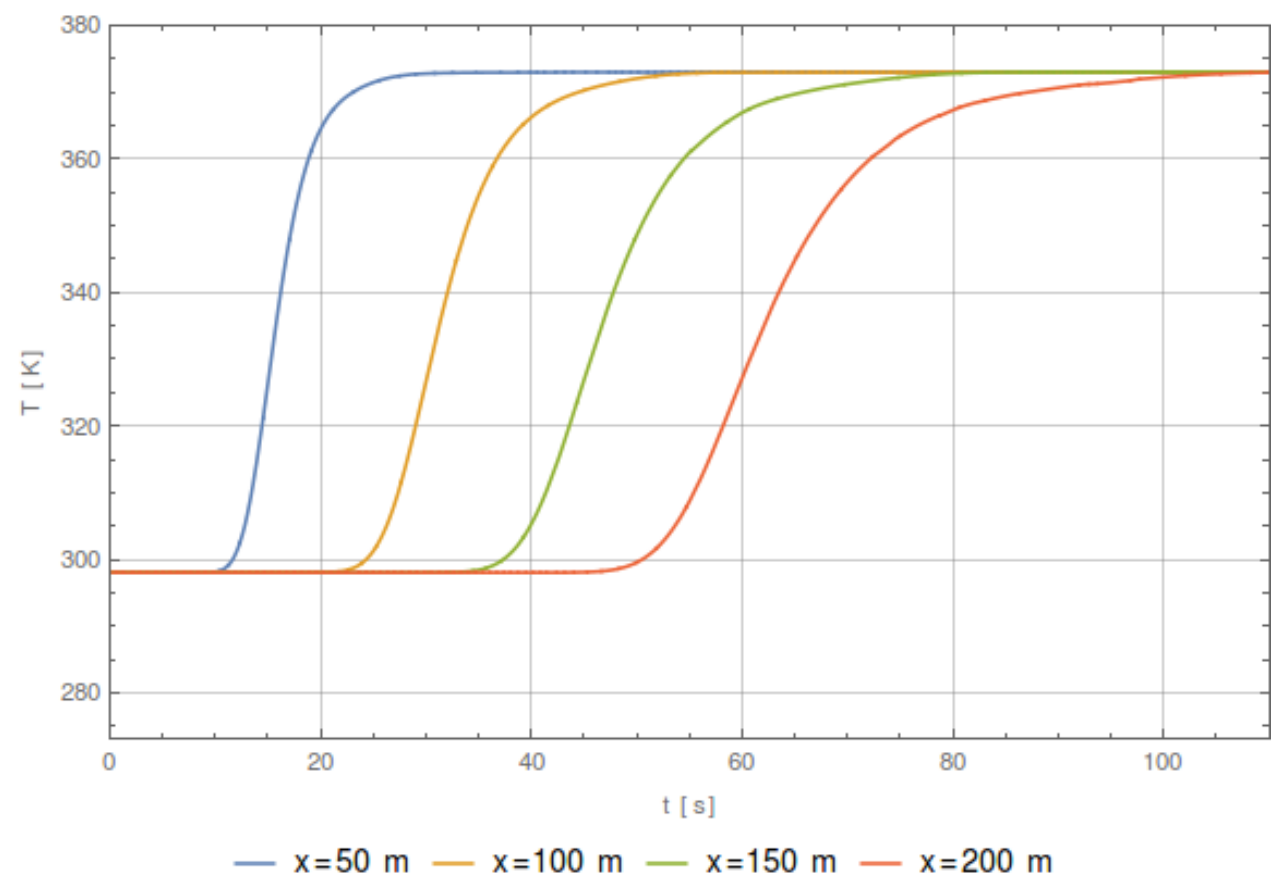

Figura D.40: Evolução temporal da temperatura média do fluido. $D_{n}=10$ ", $U=3 \mathrm{~m} / \mathrm{s}, R e=$ $2,62 \times 10^{6}, N u=7,97 \times 10^{3}, h_{i}=2,12 \times 10^{4} \mathrm{~W} / \mathrm{m}^{2} \mathrm{~K}, \mathrm{Gr}=5,03 \times 10^{1}, h_{e}=$ $5,33 \mathrm{~W} / \mathrm{m}^{2} \mathrm{~K}$. 


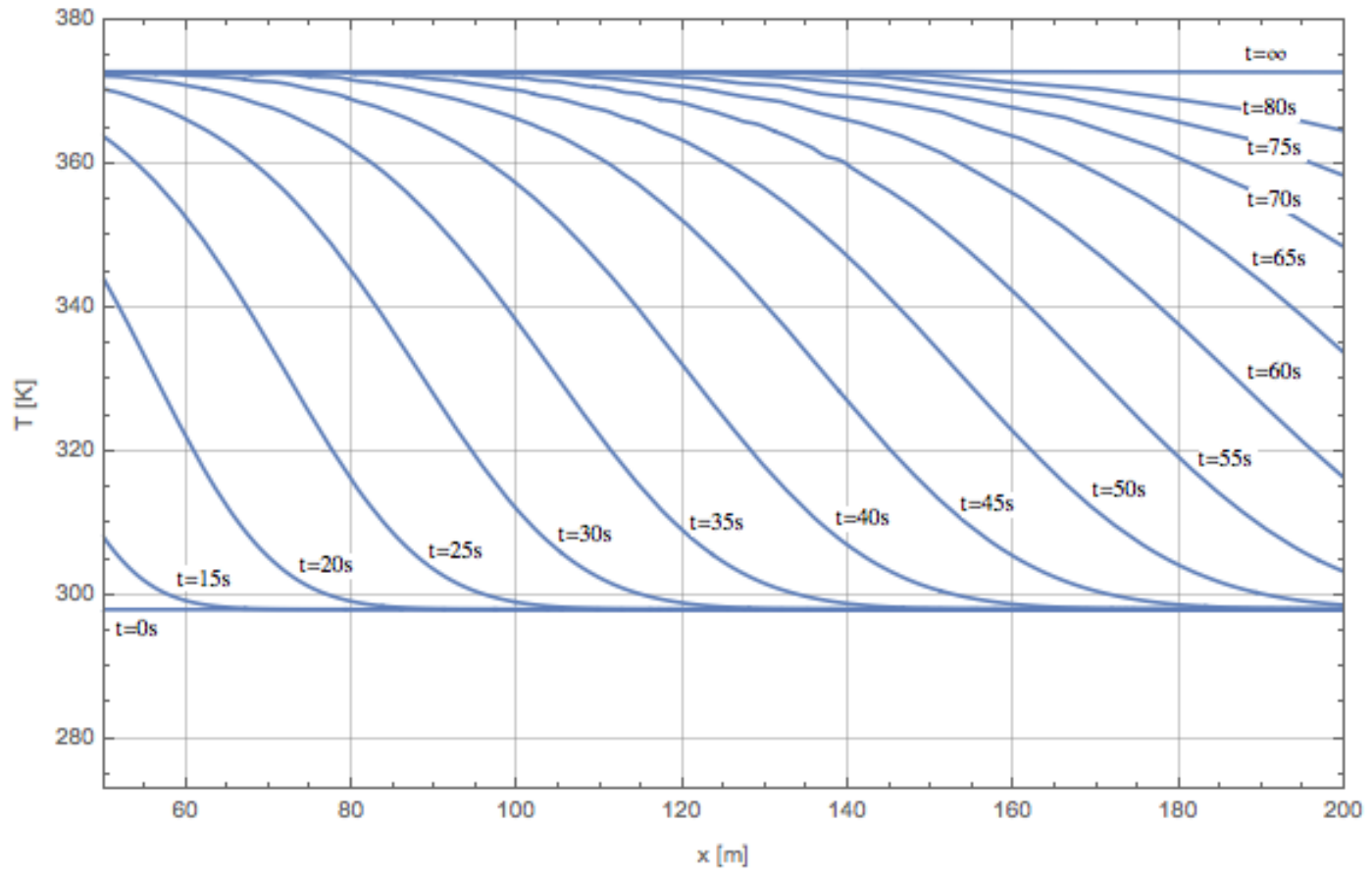

Figura D.41: Perfil da temperatura média do tubo. $D_{n}=10$ ", $U=3 \mathrm{~m} / \mathrm{s}, R e=2,62 \times 10^{6}$, $N u=7,97 \times 10^{3}, h_{i}=2,12 \times 10^{4} \mathrm{~W} / \mathrm{m}^{2} \mathrm{~K}, \mathrm{Gr}=5,03 \times 10^{1}, h_{e}=5,33 \mathrm{~W} / \mathrm{m}^{2} \mathrm{~K}$.

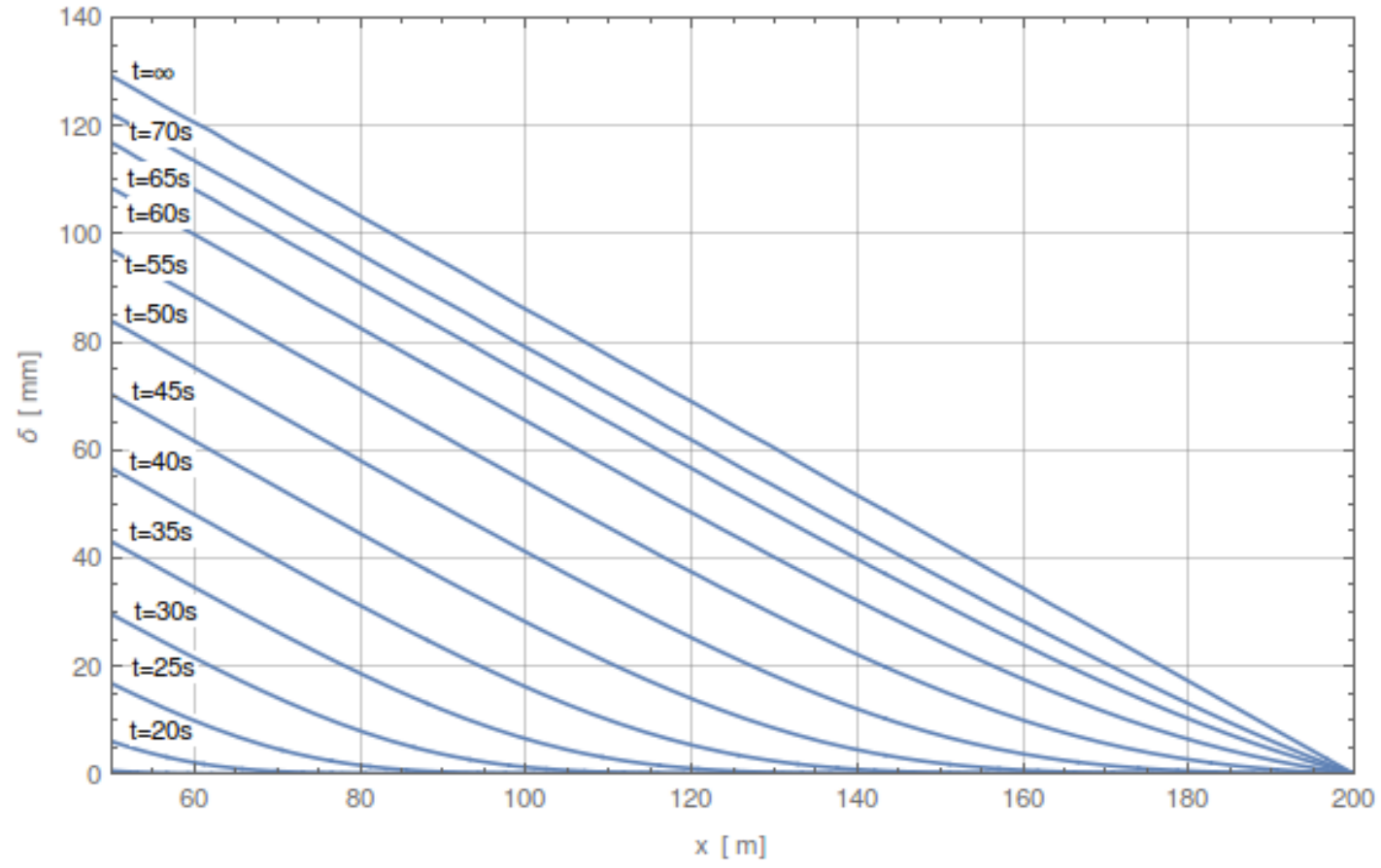

Figura D.42: Perfil da dilatação linear do tubo. $D_{n}=10^{\prime \prime}, U=3 \mathrm{~m} / \mathrm{s}, R e=2,62 \times 10^{6}$, $N u=7,97 \times 10^{3}, h_{i}=2,12 \times 10^{4} \mathrm{~W} / \mathrm{m}^{2} \mathrm{~K}, \mathrm{Gr}=5,03 \times 10^{1}, h_{e}=5,33 \mathrm{~W} / \mathrm{m}^{2} \mathrm{~K}$. 
D.4.3 $U=4 \mathrm{~m} / \mathrm{s}$

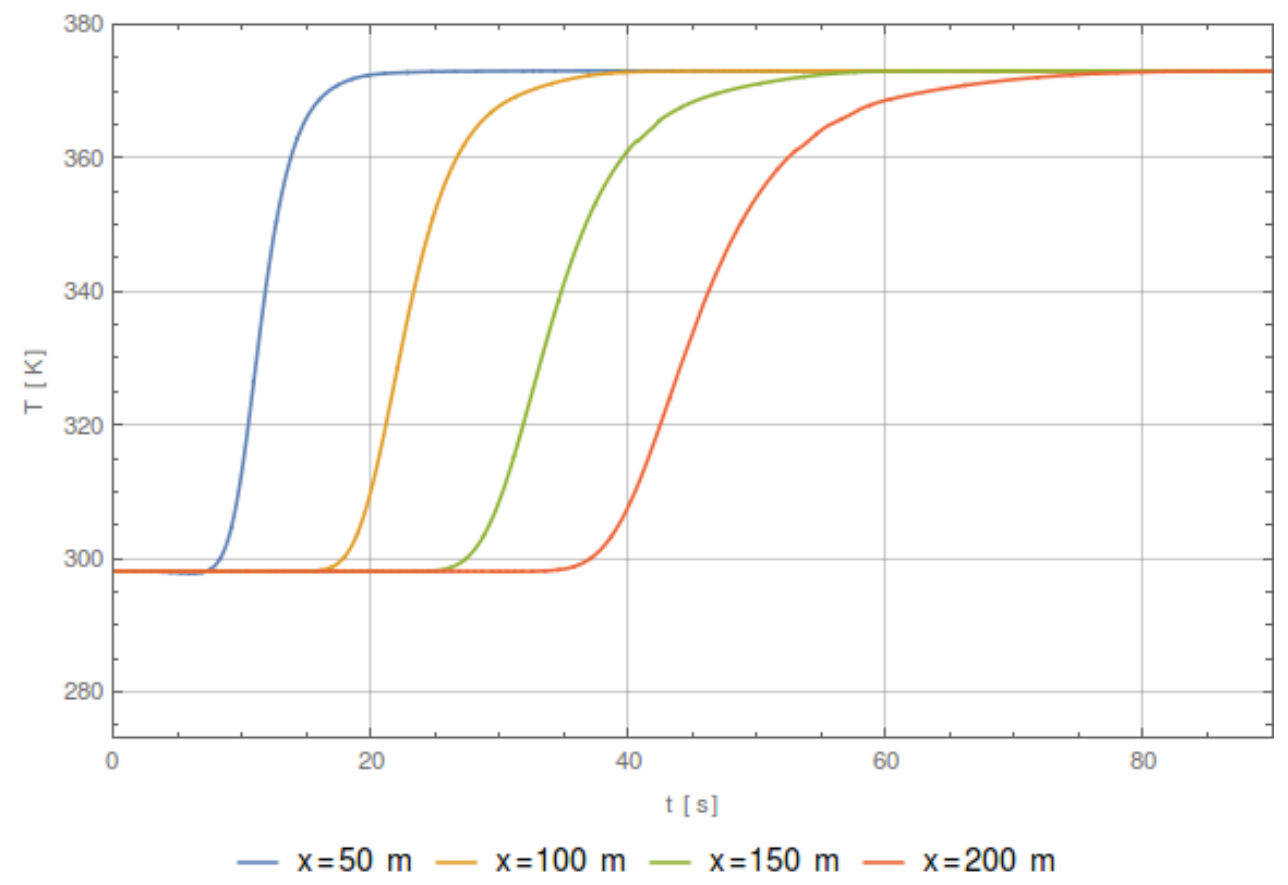

Figura D.43: Evolução temporal da temperatura média do fluido. $D_{n}=10$ ", $U=4 \mathrm{~m} / \mathrm{s}, R e=$ $3,50 \times 10^{6}, N u=1,06 \times 10^{4}, h_{i}=2,82 \times 10^{4} \mathrm{~W} / \mathrm{m}^{2} \mathrm{~K}, \mathrm{Gr}=5,03 \times 10^{1}, h_{e}=$ $5,33 \mathrm{~W} / \mathrm{m}^{2} \mathrm{~K}$.

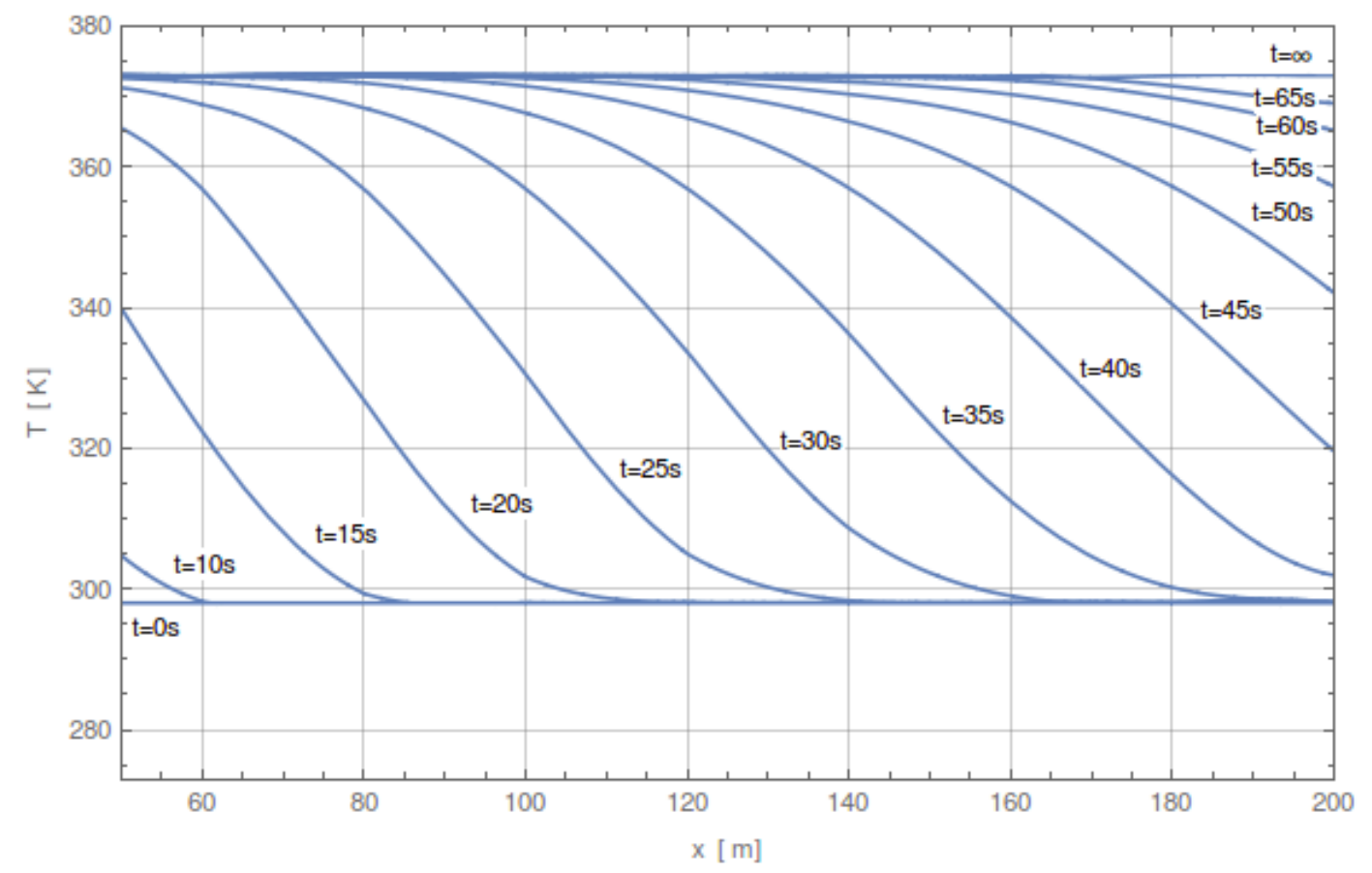

Figura D.44: Perfil da temperatura média do tubo. $D_{n}=10^{\prime \prime}, U=4 \mathrm{~m} / \mathrm{s}, R e=3,50 \times 10^{6}$, $N u=1,06 \times 10^{4}, h_{i}=2,82 \times 10^{4} \mathrm{~W} / \mathrm{m}^{2} \mathrm{~K}, \mathrm{Gr}=5,03 \times 10^{1}, h_{e}=5,33 \mathrm{~W} / \mathrm{m}^{2} \mathrm{~K}$. 


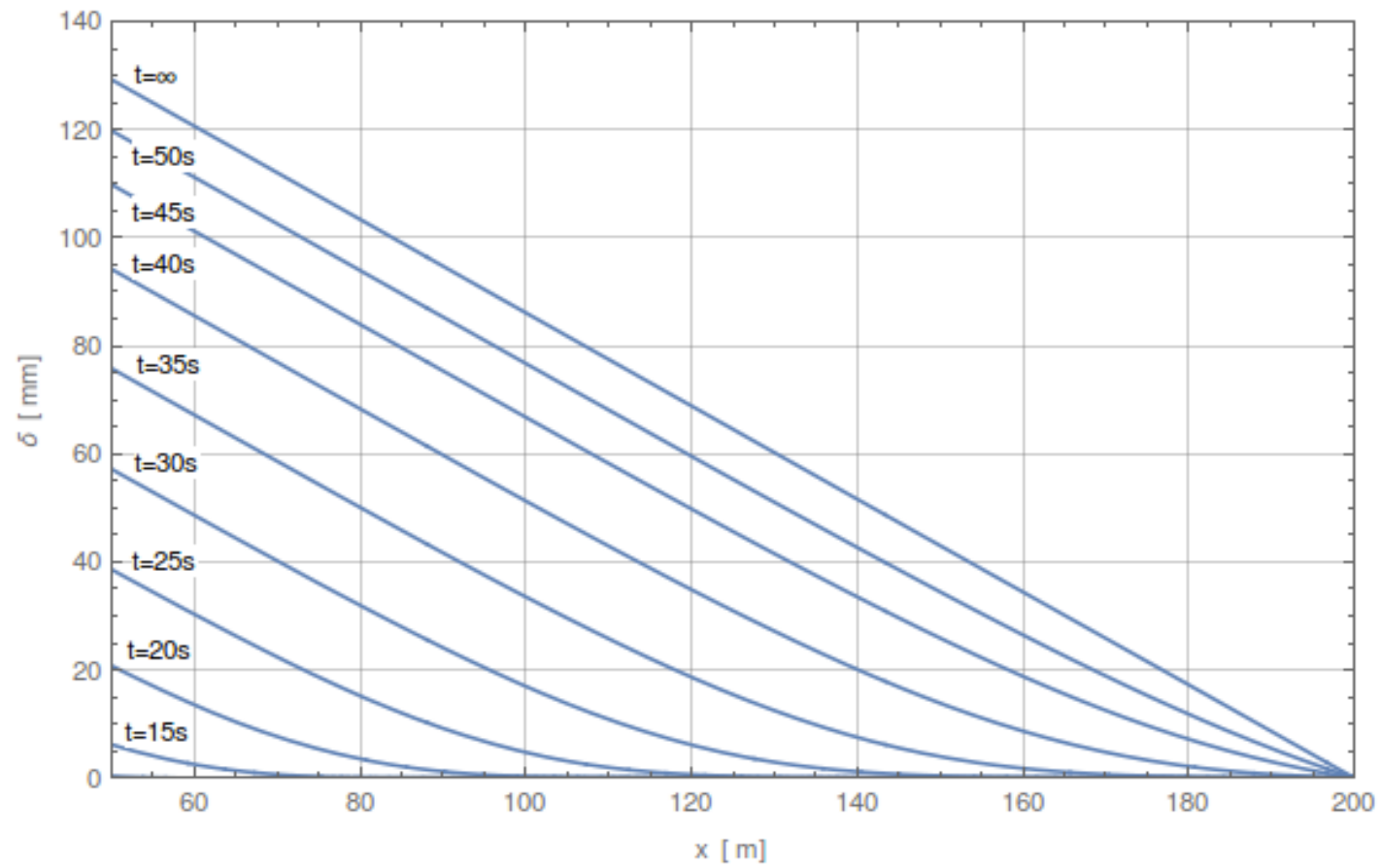

Figura D.45: Perfil da dilatação linear do tubo. $D_{n}=10^{\prime \prime}, U=4 \mathrm{~m} / \mathrm{s}, R e=3,50 \times 10^{6}$, $N u=1,06 \times 10^{4}, h_{i}=2,82 \times 10^{4} \mathrm{~W} / \mathrm{m}^{2} \mathrm{~K}, \mathrm{Gr}=5,03 \times 10^{1}, h_{e}=5,33 \mathrm{~W} / \mathrm{m}^{2} \mathrm{~K}$.

D.4.4 $U=5 \mathrm{~m} / \mathrm{s}$

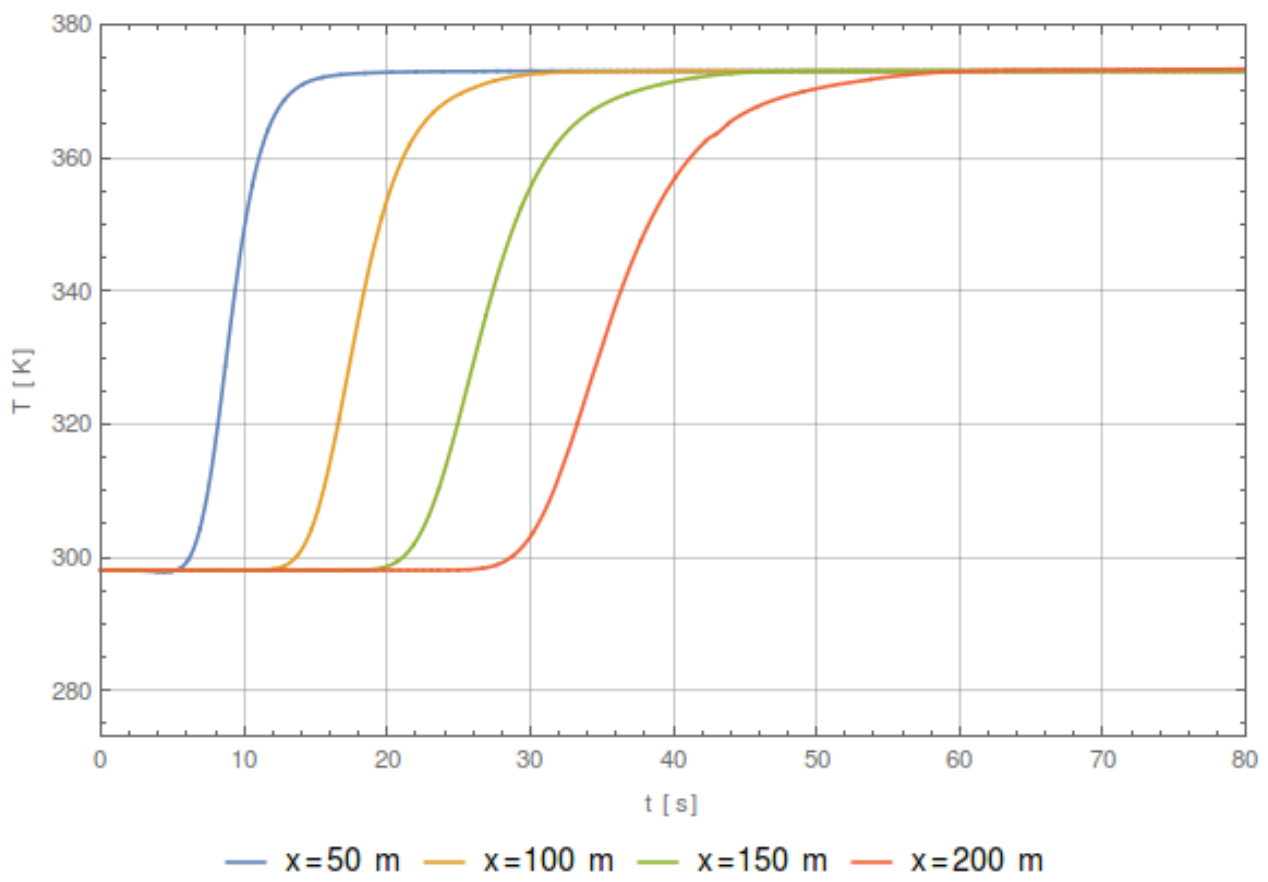

Figura D.46: Evolução temporal da temperatura média do fluido. $D_{n}=10$ ", $U=5 \mathrm{~m} / \mathrm{s}, R e=$ $4,38 \times 10^{6}, N u=1,32 \times 10^{4}, h_{i}=3,52 \times 10^{4} \mathrm{~W} / \mathrm{m}^{2} \mathrm{~K}, \mathrm{Gr}=5,03 \times 10^{1}, h_{e}=$ $5,33 \mathrm{~W} / \mathrm{m}^{2} \mathrm{~K}$. 


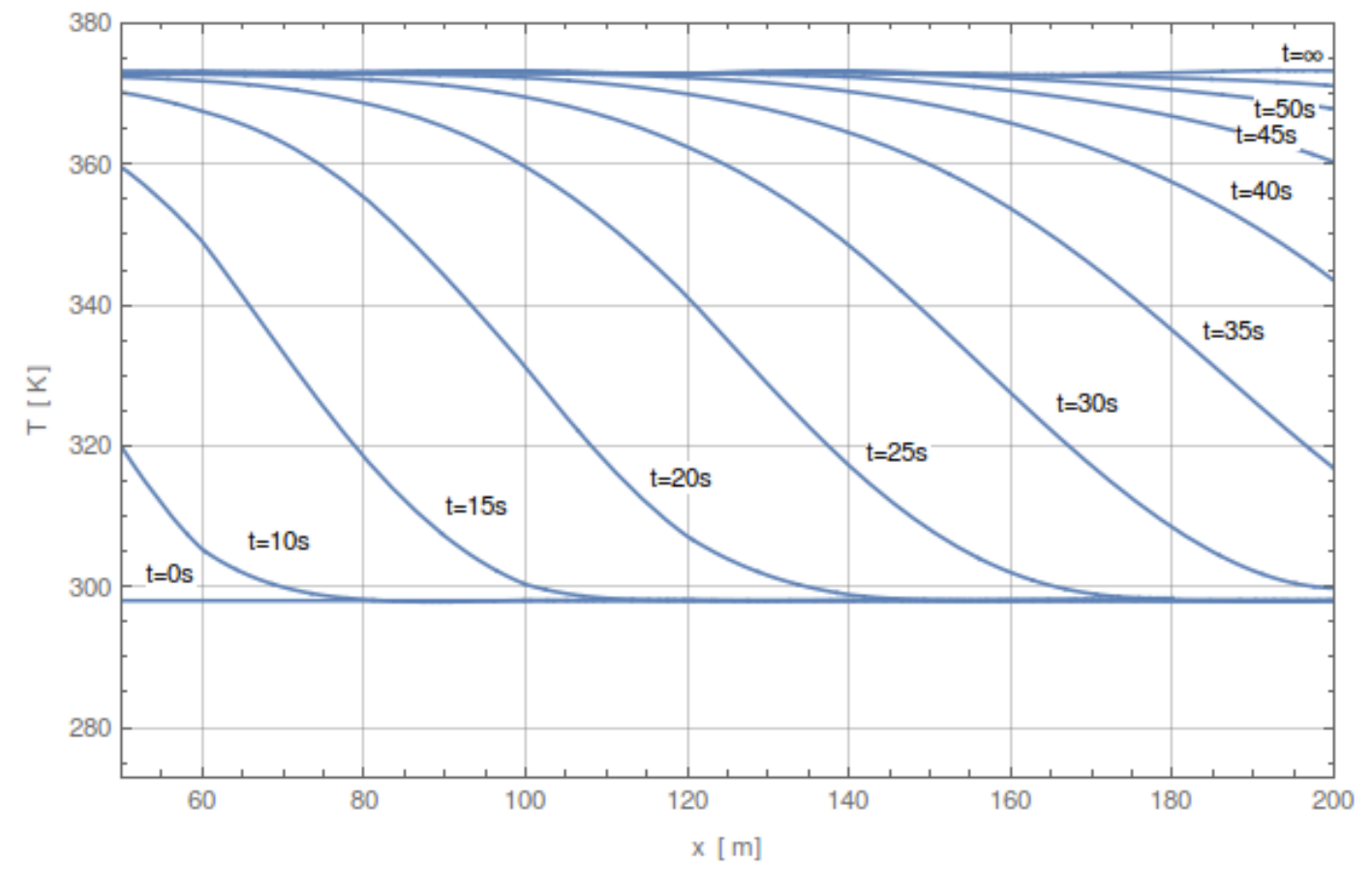

Figura D.47: Perfil da temperatura média do tubo. $D_{n}=10^{\prime \prime}, U=5 \mathrm{~m} / \mathrm{s}, R e=4,38 \times 10^{6}$, $N u=1,32 \times 10^{4}, h_{i}=3,52 \times 10^{4} \mathrm{~W} / \mathrm{m}^{2} \mathrm{~K}, \mathrm{Gr}=5,03 \times 10^{1}, h_{e}=5,33 \mathrm{~W} / \mathrm{m}^{2} \mathrm{~K}$.

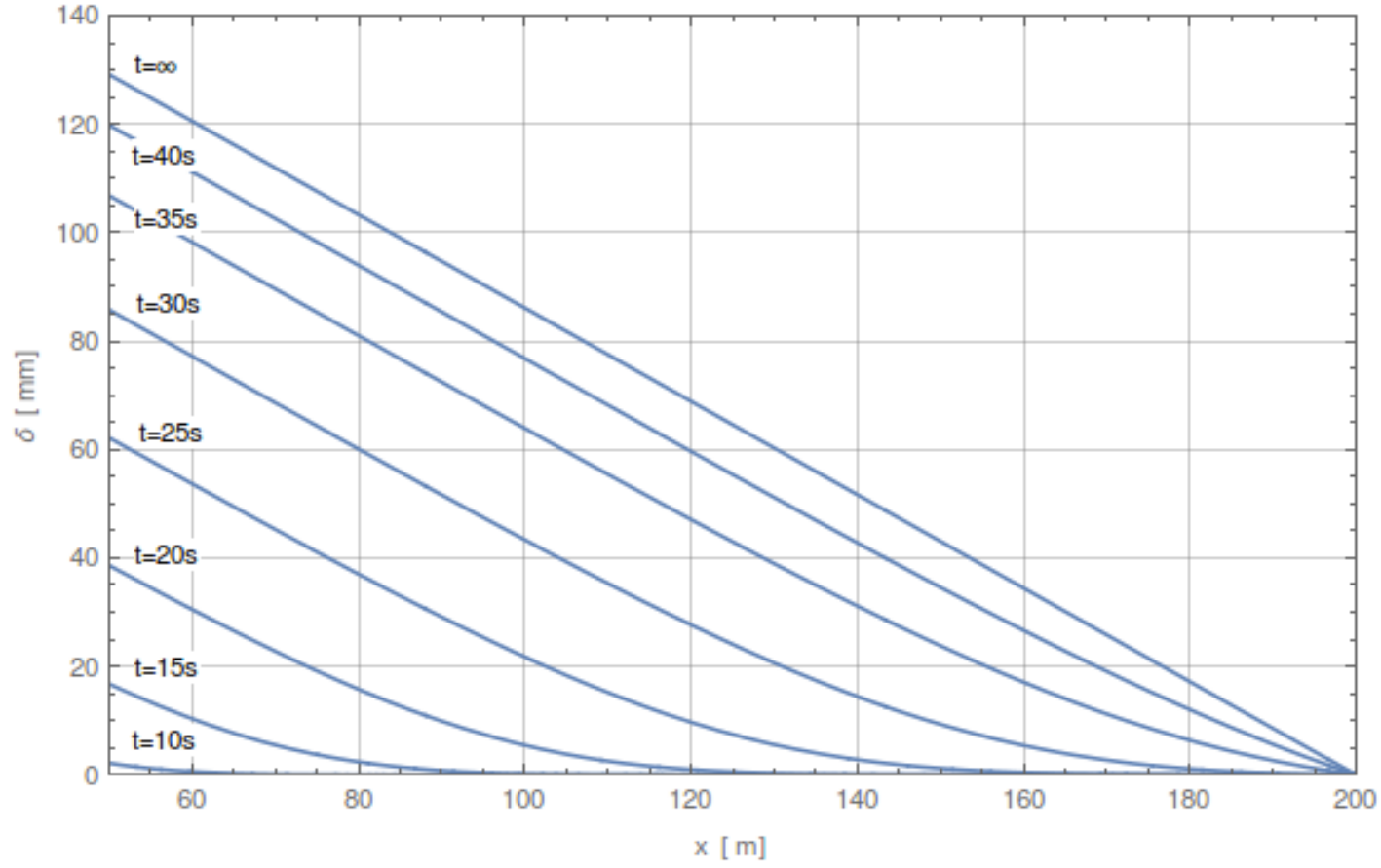

Figura D.48: Perfil da dilatação linear do tubo. $D_{n}=10$ ", $U=5 \mathrm{~m} / \mathrm{s}, R e=4,38 \times 10^{6}$, $N u=1,32 \times 10^{4}, h_{i}=3,52 \times 10^{4} \mathrm{~W} / \mathrm{m}^{2} \mathrm{~K}, \mathrm{Gr}=5,03 \times 10^{1}, h_{e}=5,33 \mathrm{~W} / \mathrm{m}^{2} \mathrm{~K}$. 


\section{Referências Bibliográficas}

ARPACI, V. S.; LARSEN, P. S. Convection Heat Transfer. Englewood Cliffs: Prentice-Hall, 1984.

ASME B31.3. ASME B31.3-2010: PROCESS PIPE. New York, 2010.

ASME B36.10. ASME B36.10-1996: WELDED and SEAMLESS WROUGHT STEEL PIPE. New York, 1996.

BEJAN, A. Convection Heat Transfer. 2 ed. ed. New York: J. Wiley, 1995.

BHOWMIK, H.; TOU, K. W. Study of transient forced convection heat transfer from discrete heat sources in a fc-72 cooled vertical channel. International Journal of Thermal Sciences, v. 44, p. 499-505, 2004.

BILIR, S..; ATEŞ, A. Transient conjugated heat transfer in thick walled pipes with convective boundary conditions. International Journal of Heat and Mass Transfer, v. 46, p. 2701-2709, 2003.

BOKAIAN, A. Thermal expansion of pipe-in-pipe systems. Marine Structures, v. 17, p. 475-500, 2004.

BOUMAZA, M.; OMARA, A. Numerical investigation of transport phenomena properties on transient heat transfer in a vertical pipe flow. Journal of King Saud University - Engineering Sciences, 2013.

ECKERT, E. R. G. Heat and Mass Transfer. 2 ed. ed. New: McGraw-Hill, 1959.

ESCOBEDO, J. J.; NIECKELE, A.; AZEVEDO, L. F. Transient thermal analysis in subsea pipelines. In: INTERNATIONAL CONGRESS OF MECHANICAL ENGINEERING, 18., 2005. Ouro Preto - MG: ABCM, 2005.

ESPINOSA PAREDES, G. et al. TEMLOPI/V.2: a computer program for estimation of fully transient temperatures in geothermal wells during circulation and shut-in. Computers \&f Geosciences, v. 27, p. 327-344, 2001.

FORGHIERI, R.; PAPA, G. Transient heat transfer through a thin-walled circular pipe. Nuclear Engineering and Design, v. 23, p. 147-154, 1972.

FORTUNA, A. de O. Técnicas Computacionais para Dinâmica dos Fluidos: Conceitos Básicos e Aplicações. São Paulo: Edusp, 2000.

HADIOUCHE, A.; MANSOURI, K. Application of integral transform technique of the transient flow heat transfer in the ducts. International Journal of Thermal Sciences, v. 49, p. 10-22, 2010. 
HASTAOGLU, M. A.; NEGIZ, A.; HEIDEMANN, R. A. Three-dimensional transient heat transfer from a buried pipe - part iii - comprehensive model. Chemical Engineering Science, v. 50, n. 16, p. 2545-2555, 1995.

INCROPERA, F. P.; DE WITT, D. P. Fundamentos de Transferência de Calor e de Massa. 5 ed. ed. Rio de Janeiro: LTC, 2003.

INTERGRAPH ${ }^{\circledR}$. Caesar II V. 6.1. 2015. Disponível em: < http://www.coade.com/ products/caesarii $>$.

JACKSON, J. D.; BÜYÜKALACA, O.; HE, S. Heat transfer in a pipe under conditions of transient turbulent flow. International Journal of Heat and Fluid Flow, v. 20, p. 115-127, 1998.

JIJI, L. M. Heat Conduction. 3 ed. ed. Berlin: Springer, 2009.

KAWAMURA, H. Experimental and analytical study of transient heat transfer for turbulent flow in a circular tube. International Journal of Heat and Mass Transfer, v. 20, p. 443-450, 1976.

KAYS, W. M.; CRAWFORD, M. E. Convective Heat and Mass Transfer. 3 ed. ed. New York: McGraw-Hill, 1993.

KELLOGG. Design of Piping Systems. 2 ed. ed. New York, London, Sydney: John Wiley \& Sons, Inc, 1955.

LEE, K.; YAN, W. Transient conjugated mixed convection inside ducts with convection from the ambient. International Journal of Heat and Mass Transfer, v. 39, p. 1203-1211, 1996.

LEE, S. Transient convective heat transfer to water near the critical region in a vertical tube. International Communications in Heat and Mass Transfer, v. 33, p. 610-617, 2006.

LIN, T. F.; KUO, J. Transient conjugated heat transfer in fully developed laminar pipe flows. International Journal of Heat and Mass Transfer, v. 31, n. 5, p. 1093-1102, 1988.

LITTLETON, C. T. Industrial Piping. 1 ed. ed. New York: McGraw-Hill, 1951.

LUNA, N.; MÉNDEZ, F.; MAR, E. Transient analysis of the conjugated heat transfer in circular ducts with a power-law fluid. Journal of Non-Newtonian Fluid Mechanics, v. 111, p. 69-85, 2003.

NAYYAR, M. L. Piping Handbook. 7 ed. ed. New York: McGraw-Hill, 2000.

NEGIZ, A.; HASTAOGLU, M. A.; HEIDEMANN, R. A. Threes-dimensional transient heat transfer from a buried pipe - i. laminar flow. Chemical Engineering Science, v. 48, n. 20, p. 3507-3517, 1993.

NELLIS, G.; KLEIN, S. A. Heat Transfer. Cambridge: Cambridge University Press, 2009.

POPE, S. B. Turbulent Flows. Cambridge: Cambridge University Press, 2000. 
POTTER, M. C.; WIGGERT, D. C.; HONDZO, M. Mechanics of Fluids. 2 ed. ed. Upper Saddle River: Prentice-Hall, 1997.

SCHLICHTING, H. et al. Boundary Layer Theory With 22 Tables. 8 ed. ed. Berlin: Springer, 2003.

SHIH, T.-M. et al. Literature survey of numerical heat transfer (2000-2009): Part i. An International Journal of Computation and Methodology, v. 57, n. 3-4, p. 159-296, 2010.

SILVA TELlES, P. C. Tubulações Industriais: Cálculo. 9 ed. ed. Rio de Janeiro: LTC, 1999.

SOFRONIOU, S.; KNAPP, R. Advanced Numerical Differential Equation Solving in Mathematica ${ }^{\circledR}$. United States: Wolfram Research, Inc, 2008.

TANDIROGLU, A. Effect of flow geometry parameters on transient heat transfer for turbulent flow in a circular tube with baffle inserts. International Journal of Heat and Mass Transfer, v. 49, p. 1559-1567, 2006.

VENUGOPAL, G.; BALAJI, S. C.; VENKATESHAN, S. P. A hybrid optimization technique for developing heat transfer correlations based on transient experiments. International Journal of Heat and Mass Transfer, v. 52, p. 1954-1964, 2008.

VICH, B.; ÖZIŞIK, M. N.; ULLRICH, D. F. Effects of axial conduction in laminar tube flow with convective boundaries. The Franklin Institute, v. 316, n. 2, p. 159-173, 1983.

WANG, C. Application of the maximum principle for differential equation in combination with the finite difference equations and error analysis. An International Journal of Computation and Methodology, v. 55, p. 56-72, 2009.

Wolfram Research. Mathematica V. 9.0. 2015. Disponível em: <http://www.wolfram. $\mathrm{com} /$ mathematica/>.

YAN, W.-M. Transient mixed convection heat transfer in vertical pipe flows. International Communications in Heat and Mass Transfer, v. 19, p. 89-101, 1992.

YAN, W. M.; TSAY, L. Y.; LIN, T. F. Transient conjugated heat transfer in laminar pipe flows. International Journal of Heat and Mass Transfer, v. 32, n. 4, p. 775-777, 1989.

ZARGARY, A.; BROCK, J. An integral equation describing conjugate transient heat transfer in fluid flow through insulated pipes. International Journal of Heat and Mass Transfer, v. 16, p. 1325-1328, 1973.

ZHENG, Z.; FLETCHER, D. F.; HAYNES, B. S. Transient laminar heat transfer simulations in periodic zigzag channels. International Journal of Heat and Mass Transfer, v. 71, p. 758-768, 2014. 